تأثثر مقرر إلكترونى مقترح على تعلم بعض مهارات كرة اليد لطلاب المرحلة الأولى من

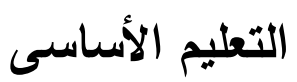

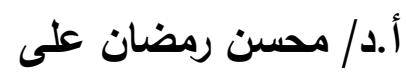

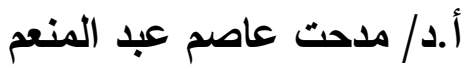

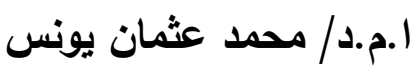

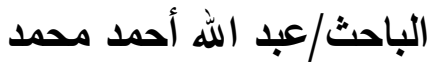

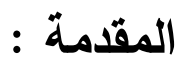

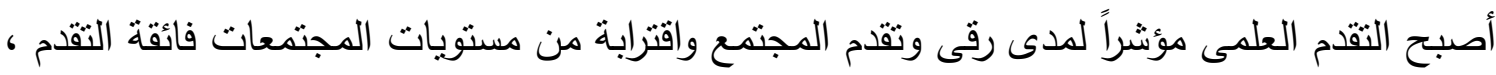

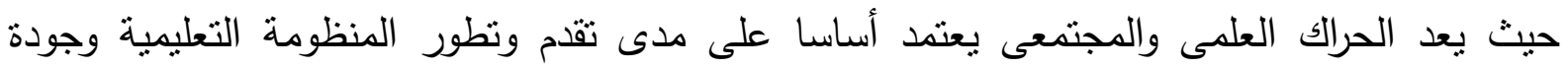

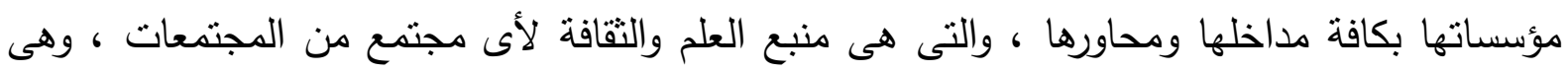

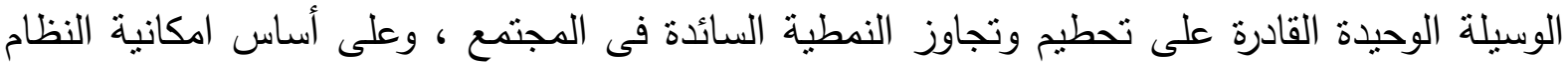

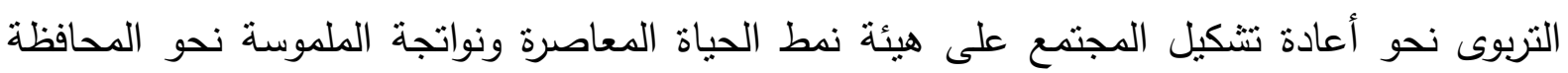

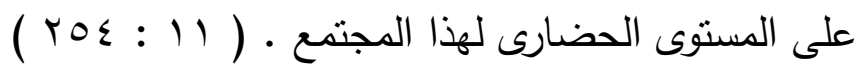
يتسم العصر الحالي الذي نعيثه الأن بالثورة العلدية والتكنولوجيا ، حيث تلتوالي تراكم الاكتثنافات

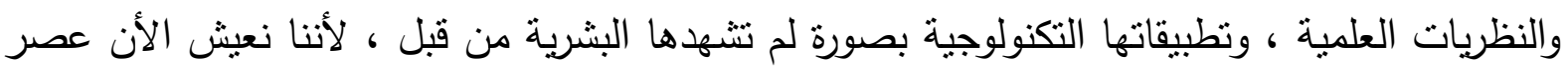

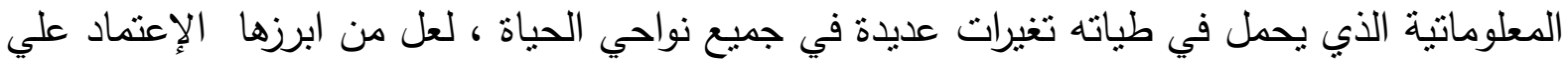

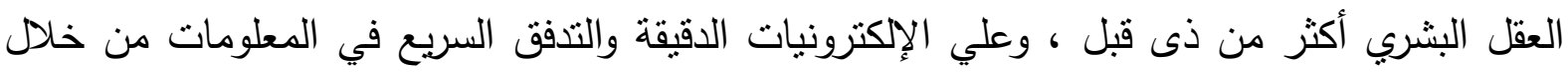

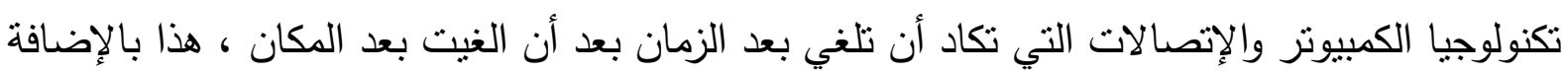

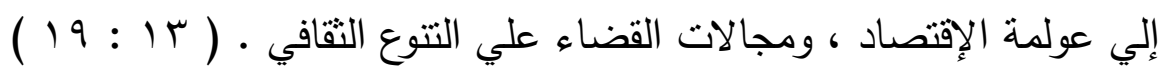

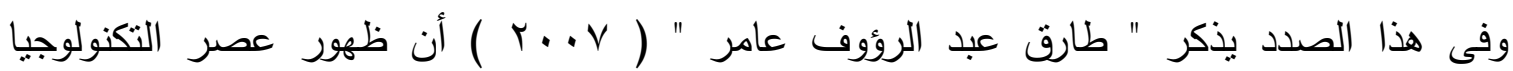

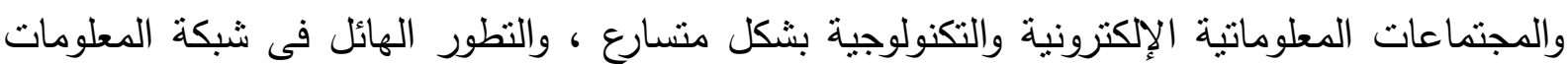

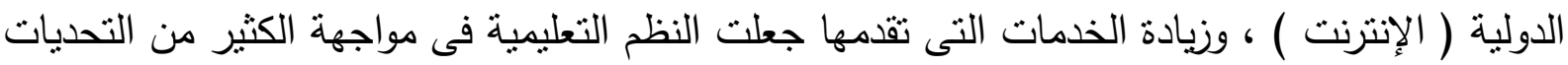

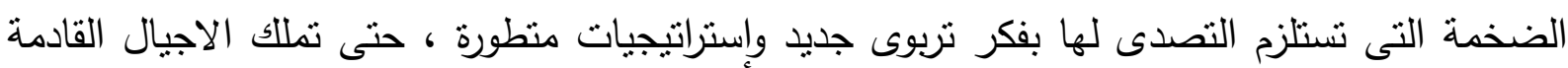
مهارات التعامل مع الدتغيرات التكنولوجية ( 9 : 10 ) ولقد أصبح التقام العلىى لأى مجتمع المعيار الرئيسى لددى رقى وتطور هذا الدجمع واقترابه من

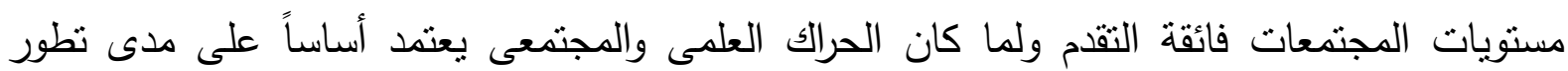
المنظومة النعليمية ، وجودة مؤسساته بكافة مدخلاتها والتى هى منبع العلم والفكر والثقافة ، لأى مجتمع الفي 
وهى الوسيلة الأساسية القادرة على تحطيم وتجاوز نمط التخلف السائد فى المتمع وعلى أساس إمكانية

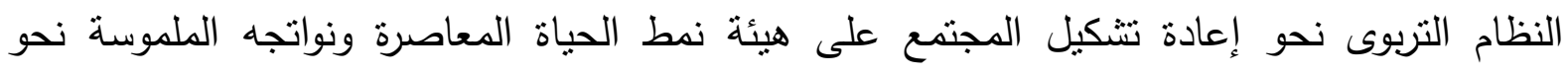

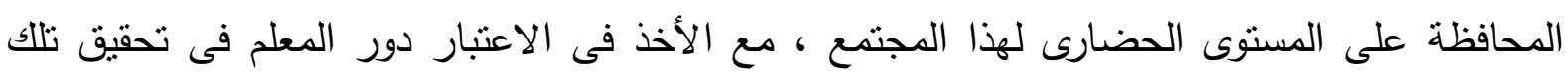
المنجزات والمكتسبات ـ (· (10 : (10)

يعد التعلم وسيلة لإعداد الأبناء وتحقيق أمال المجتمع وتطلعاته فى أبنائه حتى ينسنى لهم القيام

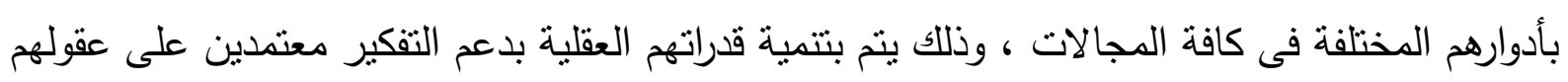

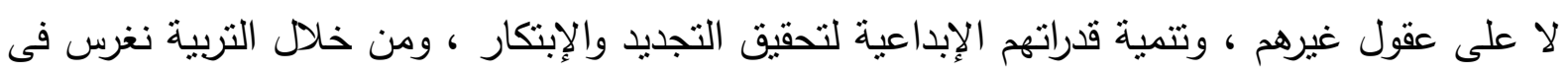
نفوس الأبناء القيم التى يرتضيها المجتمع كالتعاون والحب والإخاء والوحده وغيرها من القيم الإجتماعية

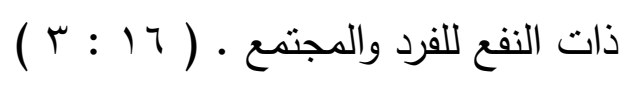

ونرى أن العصر الذى نعيشه يتسم الأن بالثورة العلمية والتكنولوجية ، كما أننا نعيش عصر

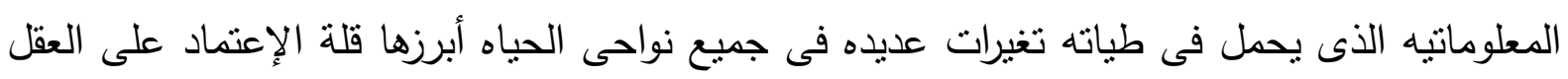

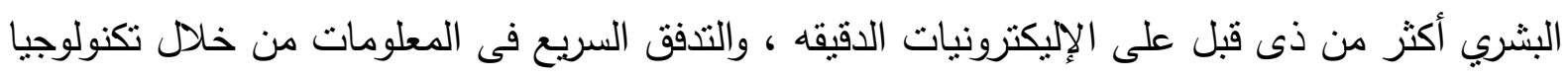

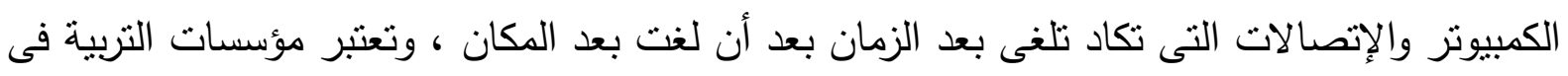

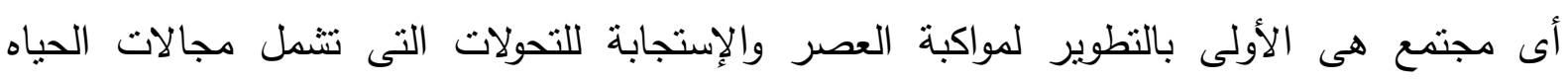

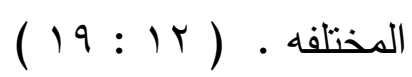
والتعليم الإككترونى هو التعليم الذى يهدف إلى إيجاد بيئة تفاعلية غنية بالتطبيقات المعتمدة على الكى

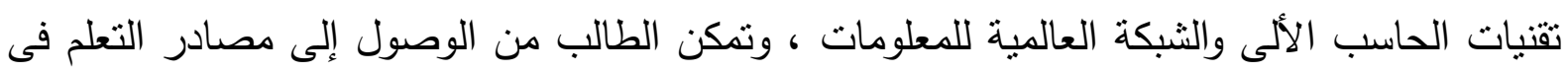

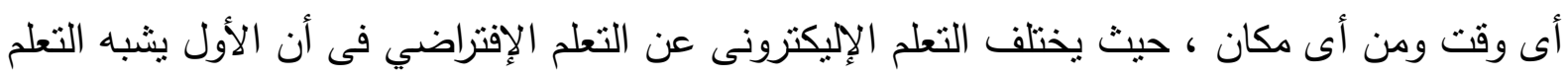

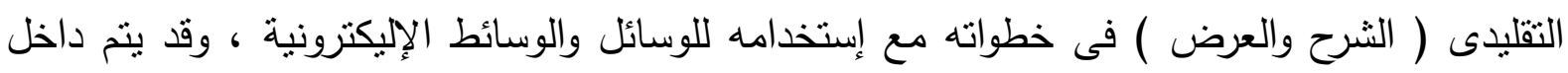

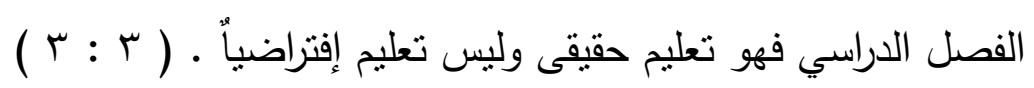

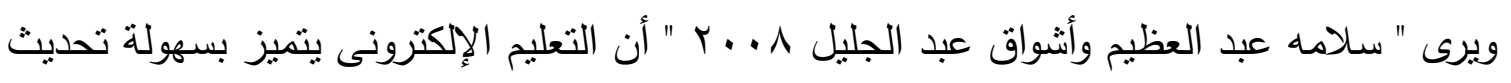

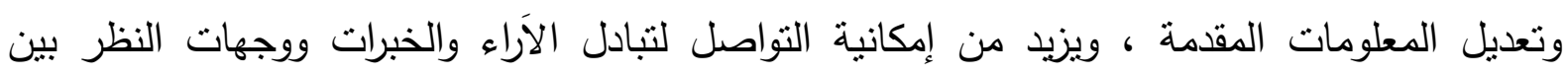

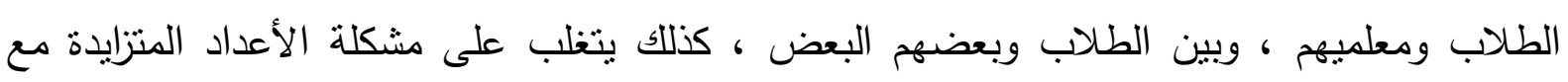

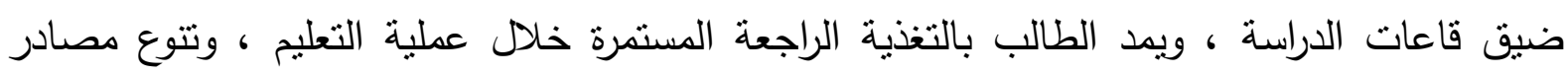

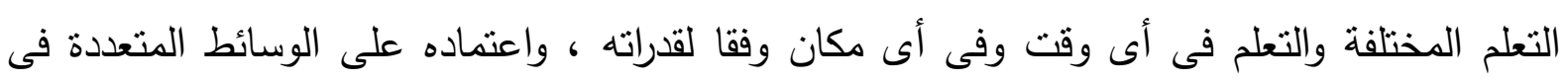

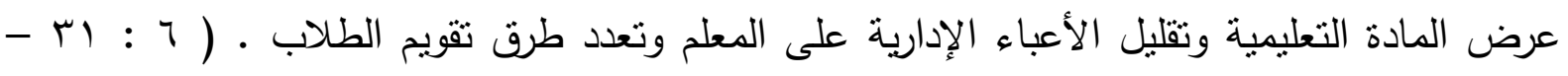
( r وقد ظهر الكتاب الإككتروني من مصطلح المكتبة الإلكترونية ، حيث بعتبر العنصر الرئيسي للمكتبة

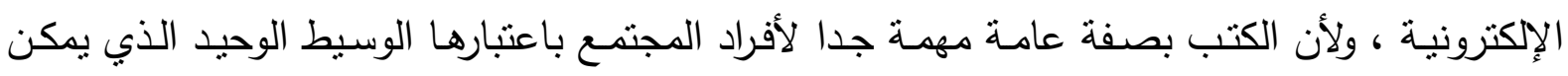


منتجوا المعرفة من توصيلها إلى الذين يحتاجونها ، ومن الثورة المتزايدة في مجال المعلومات التي

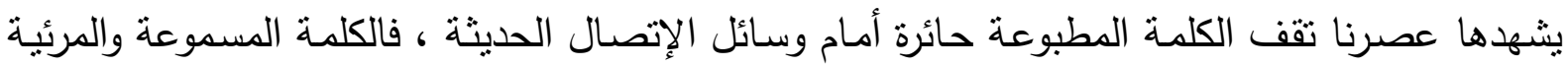

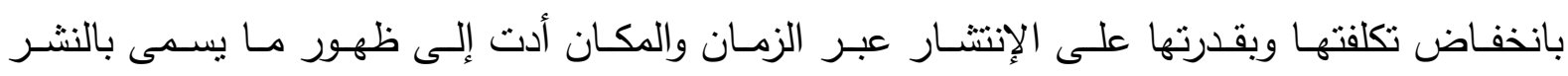

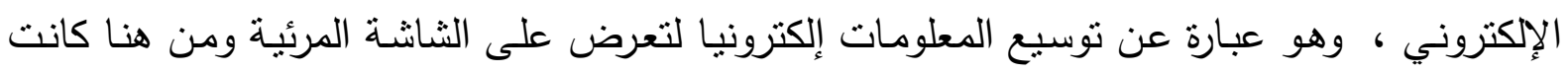

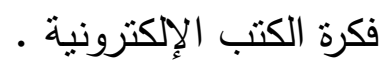

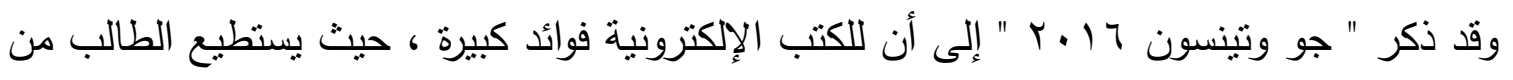

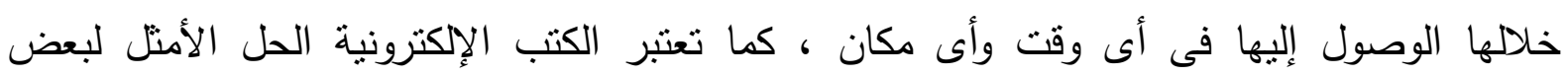

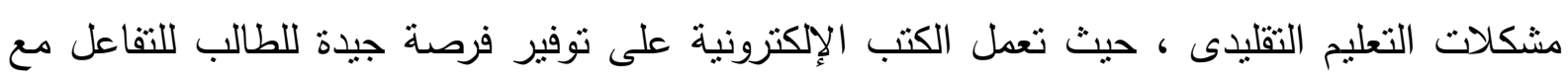

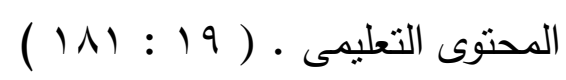
كما يعمل الكتاب الإلكترونى على تقديم معارف جديدة للمتعلم وذلك بدورة يساعدة على التعلم الذاتى

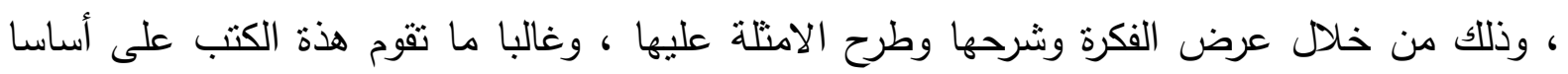

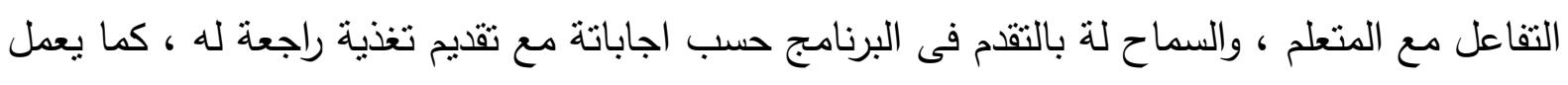

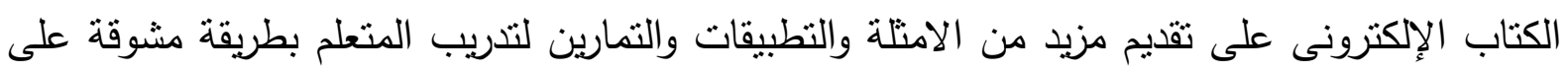

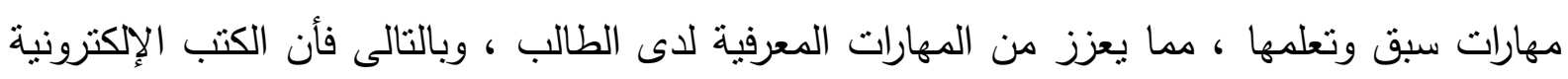

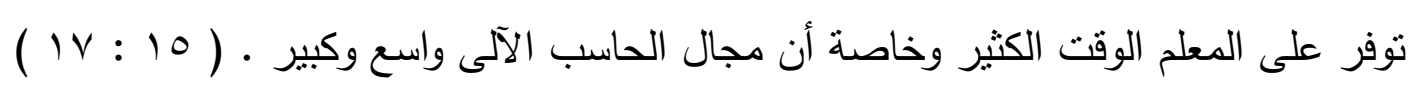

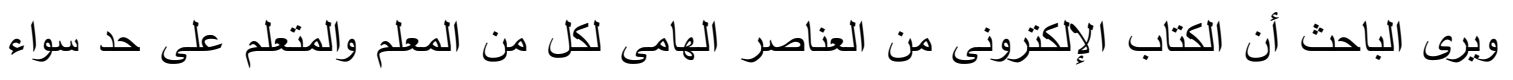
ومن العناصر الهامة والمفيدة فى العملية التعليمة والتى تساعد بشكل كبير على تحسئ لحسين عملية التعليم والتعلم ورفع مستوى وقدرات الطالب المهارية والمعرفية فى العملية التعليمية .

\section{مشكلة البحث : مثن}

تشهر الفترة الحالية محاولات جادة لتطوير التعليم فى جميع مراحلة ، وإحتلت العملية التعليمية مكاناً

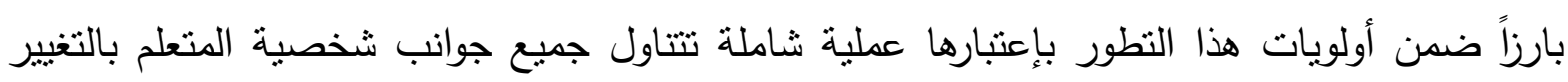

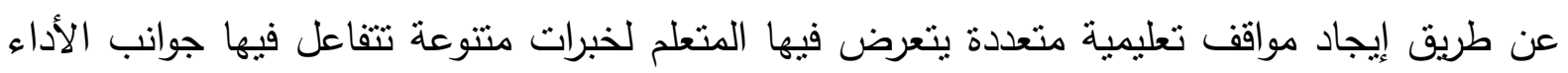
والإدراك والوجدان معاً بشكل متكامل . ونظرا لأن التتافس بين جميع الدول أصبح مرتكزا بشكل أساسى على القدرات ، والإمكانات العلمية

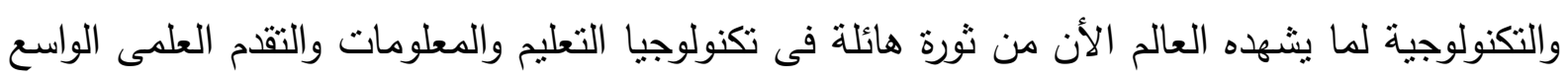

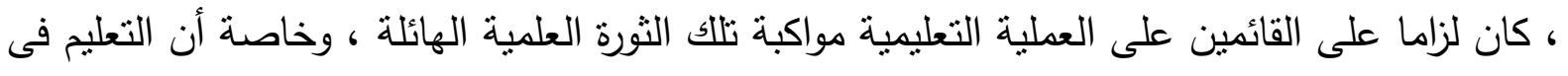

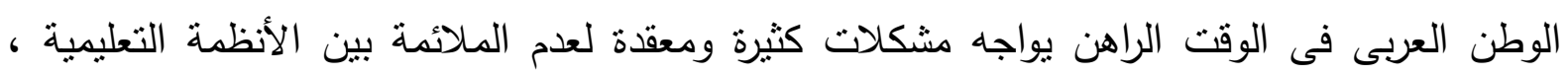

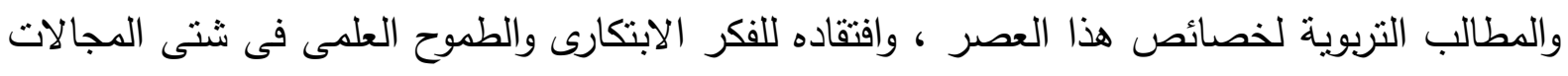

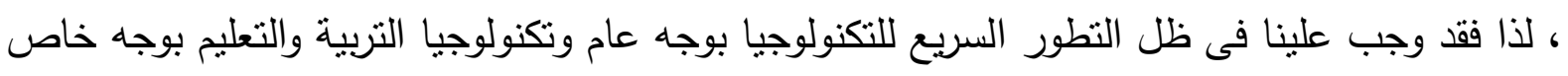


أن نعمل على رفع كفاءة وفاعلية العملية التعليمية والتربوية ، والارتقاء بها فى إطار التعليم العلىى القائم على الإبداع والابتكار، وذللك من خلال الوسائل العلمية المتطورة ، والمعارف والخبرات الإنسانية المتزايدة

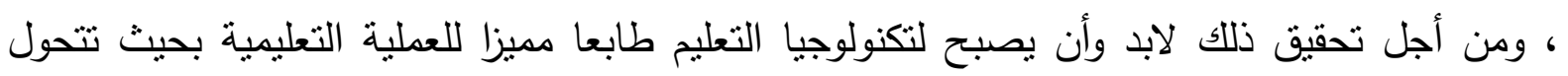

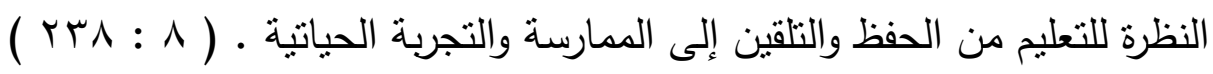

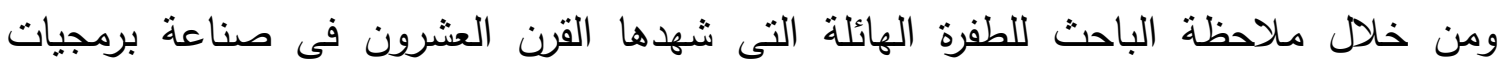
الكمبيوتر ، واتساع قاعدة المستخدمين لهذه الأجهزة ، والبرامج وتتوع النطبيقات المتاحة لكافة التهن

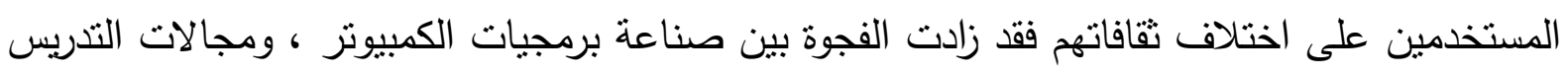
الدختلفة ، ولأن استخدام الطرق العلمية فى التدريس والتدريب لها إيجابياتها فى الارتقاء بمستوى الأداء

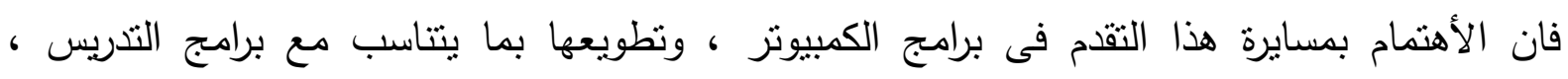

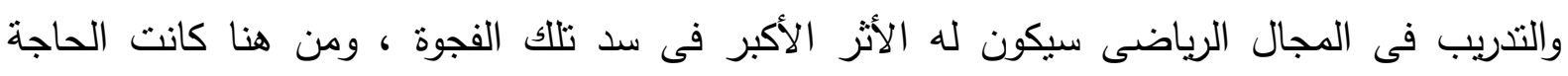

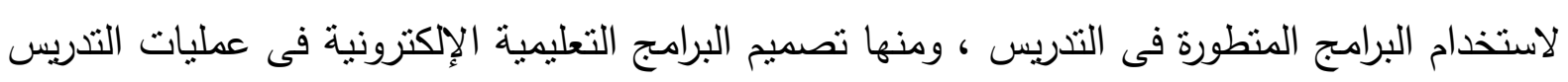

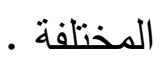

ومما سبق ومن خلاب عمل الباحث كمدرس تربية رياضية بأحد المعاهد الأزهريه ومن خلد خبرات الباحث كمدرس ، لاحظ أن تعليم وتدريب مهارات كرة اليد فى الددارس مازالت تعتد على الطى الطريقة

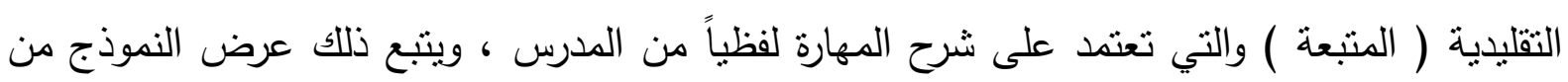

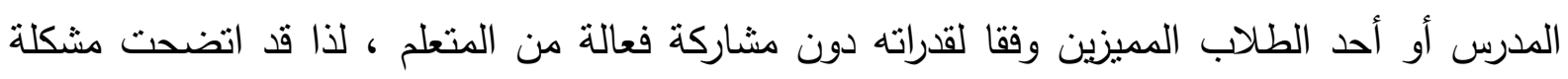

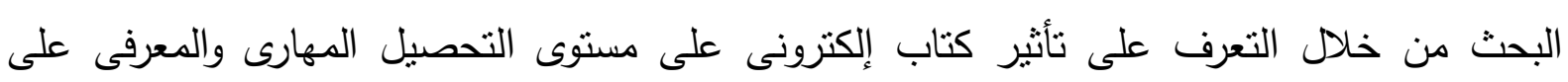

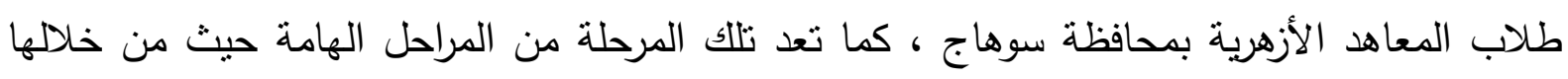

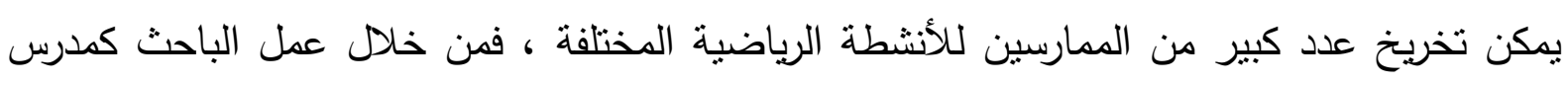

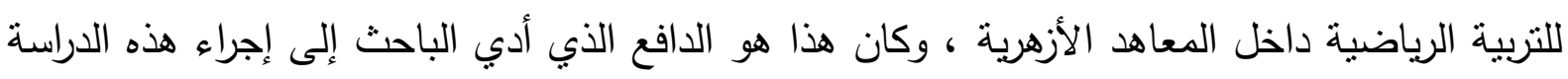

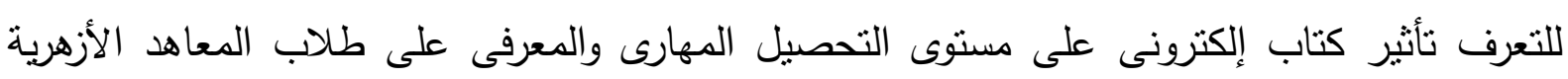

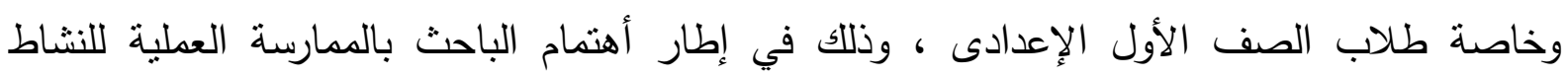

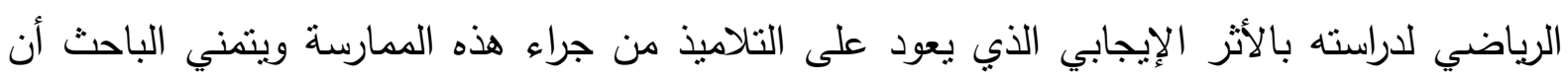
تكون هذه الدراسة بمثابة دفع للتقدم وتوسيع قاعدة الممارسة الرياضية في هذا لإئي المجال.

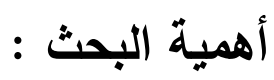

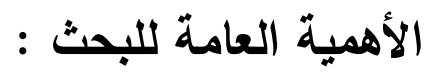

ا - تصميم كتاب إلكتروني يجعل تعلم المهارات المختلفة لكرة اليد تعلما ذات معنى لتلاميذ الصف الأول الإعدادي الأزهري. 
r- كما تعد هذه الدراسة محاولة علمية موجهة نحو معرفة تأثير استخدام كتاب إلكتروني على مستوى

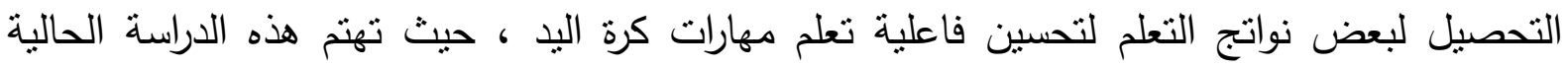

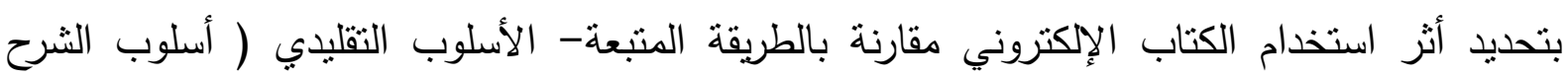
والعرض ) لتلاميذ الصف الأول الإعدادي بمعهد مجمع بدر الأزهري التابع لمركز المراغة بمحافظة الإنة سوهاج ، ومدى احتفاظهم بهذه المعارف والمعلومات. ب- ثنبى إستراتيجية تدريسية تعتمد على الكتاب الإلكتروني والتعرف على ألى أثرها لانتقال أثنر التعلم في تعلم مهارات كرة اليد المقررة على تلاميذ الصف الثالث الإعدادي بمعهد مجمع بدر الازهرى التابع لمركز المراغة بمحافظة سوهاج ، ومدى احتفاظهم بهذه المعارف والمعلومات.

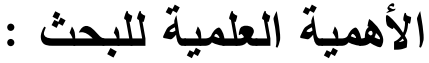

1- القاء الضوء على المقرر الإلكترونى من منظور الروئية المعاصرة لبرامج ومؤسسات التعليم ما قبل الجامعى لإعداد الكفاءات التى نواكب التغيرات السريعة والمتلاحقة فى تكنولوجيا التعليم والتعليم

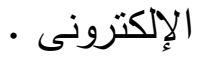
r- الدور الهام الذى يقوم به الدقرر الإكترونى فى التخلص العديد من المشكلات التى تواجه العملية التعليمية ، والتخلص من عيوب الطريقة التقليدية فى تعليم العديد من المهارات الحركية المختلفة عن لإنى طريق المقرر الإلكترونى. الأهمية التطبيقية للبحث : الإنكرونى

1- نوظيف الكتاب الإلكتروني كإستراتيجية مقترحة للتظلب على انخفاض مستوى التحصيل المعرفى التهي

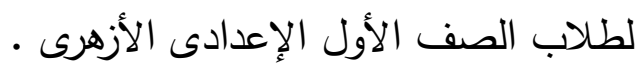
r- تتفيذ مبدأ التعلم الذاتى من خلال استخدام الكتاب الإلكترونى ومشاهدة الأنشطة المختلفة عبر

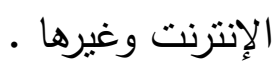

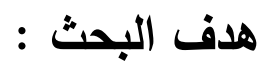
يهدف البحث الحالى فى التعرف على فاعلية كتاب إلكترونى فى كرة اليد لطلاب الصف الأولى في

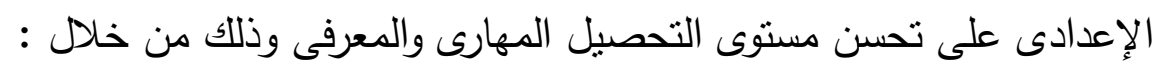

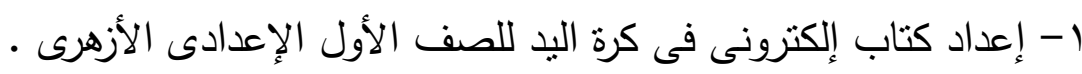

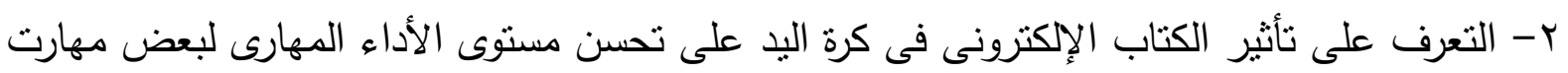

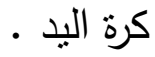
ז- التعرف على تأثثر الكتاب الإلكترونى فى كرة اليد على تحسن مستوى التحصيل المعرفى فى كرة اليد 
1- توجد فروق دالة إحصائياً بين منوسط درجات القياس القبلي ، والبعدي للمجموعة الضابطة فى القي

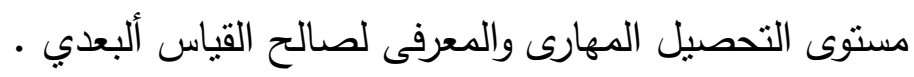

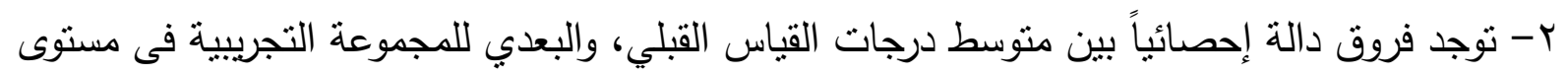

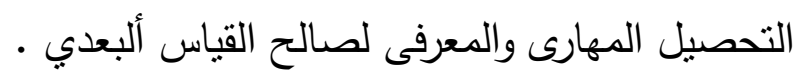

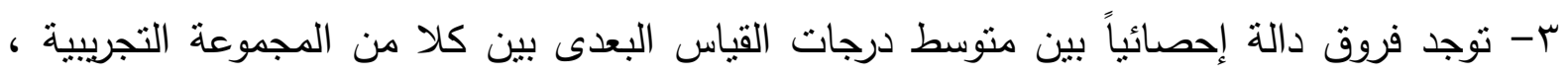

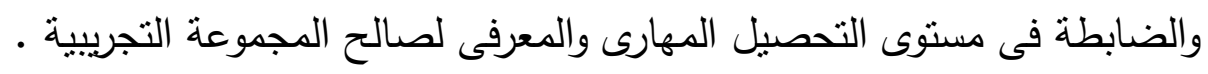

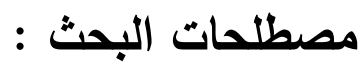

1 - التدريس : نثاط إنسانى مقصود يتضمن عناصر وأبعاد محددة وطرائق وأساليب ونماذج ومداخل ومهارات ومواقف يتم من خلالها إعطاء المعلومات وطرح الأسئلة وتقويم النتائج التعليمية

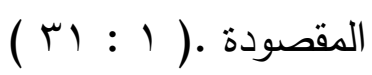
ץ- التعليم الإكترونى : عملية تقديم محتوى تعليميى إلكترونى عبر الوسائط المتعددة على الكمبيوتر

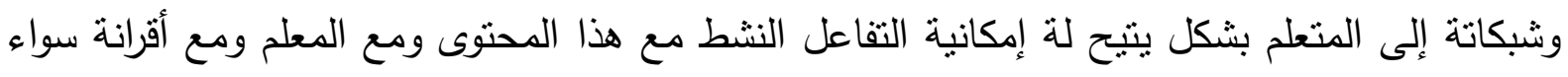

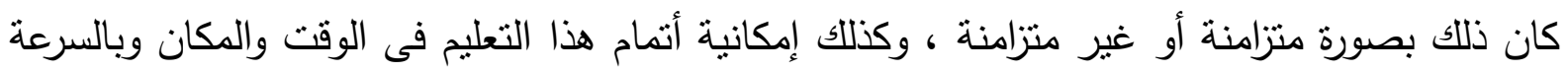

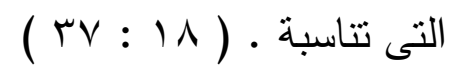
أو هى منظومة تعليمية لتقديم البرامج التعليمية للمتعلمين فى أى وقت وأى مكان بإستخدام تقنيات

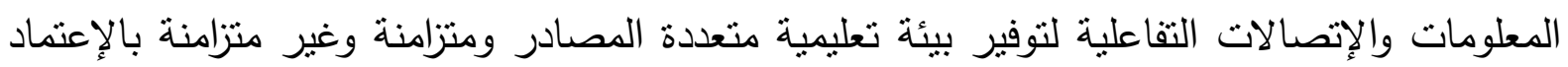

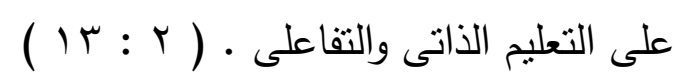
r- الكتاب الإكتروني: هو برنامج يعتمد على النصوص ، بلى بالإضافة إلى مجموعة والمثيرات والصورة

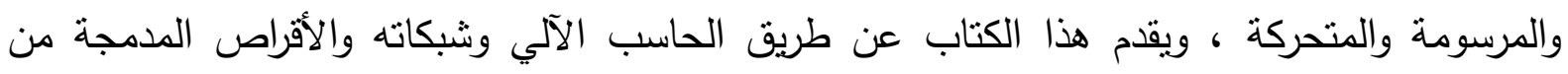

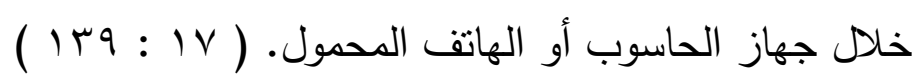



الاراسات المرجعية :

الاراسات المرجعية العربية :

\begin{tabular}{|c|c|c|c|c|c|c|c|}
\hline أهم النتائج & العينة & المنهج & هدف البحث & عنوان البحث & السنة & اسم الباحث & p \\
\hline 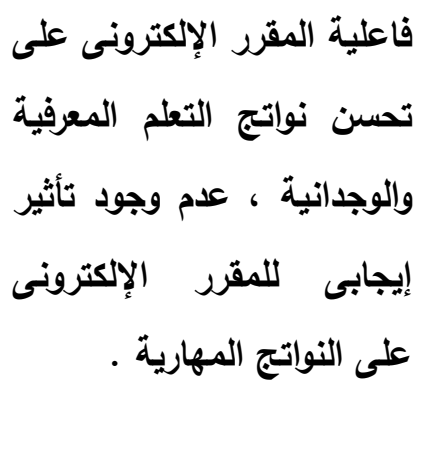 & 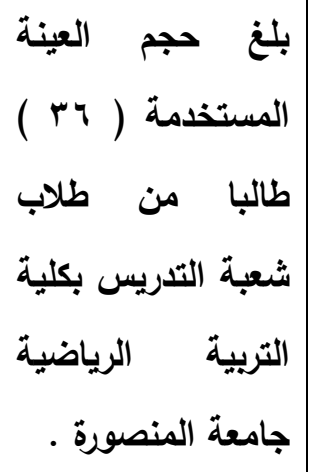 & 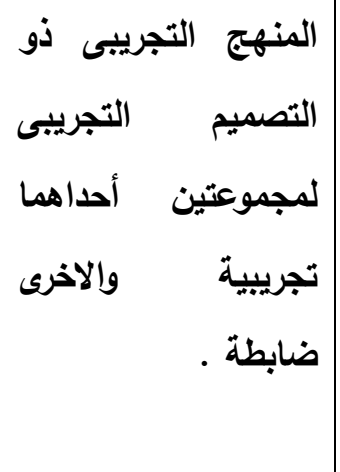 & 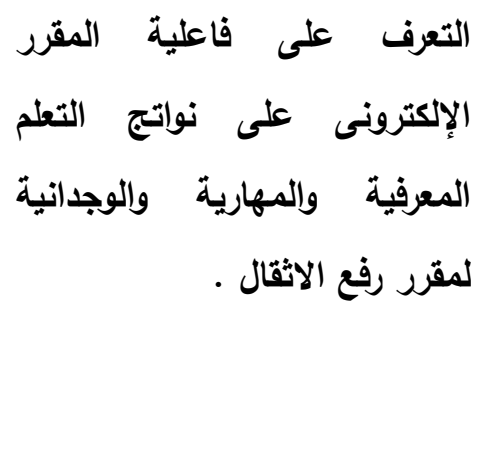 & 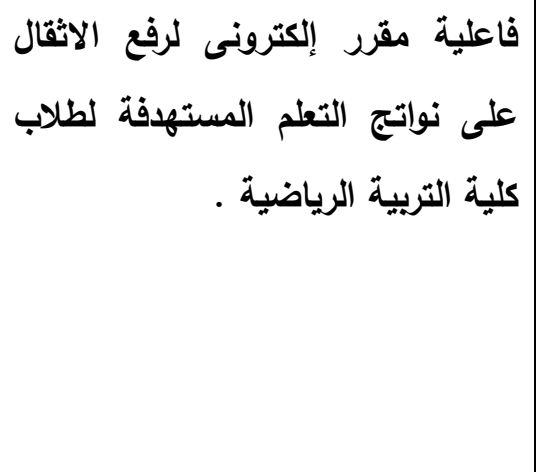 & $r .10$ & $\begin{array}{c}\text { محمد حسن محمد } \\
\text { حسن }\end{array}$ & 1 \\
\hline 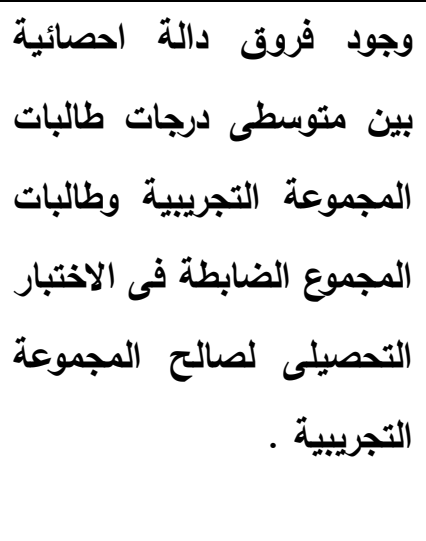 & 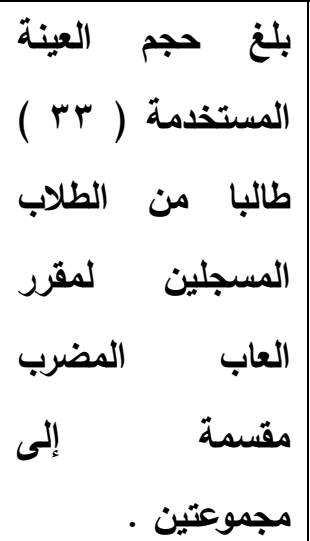 & 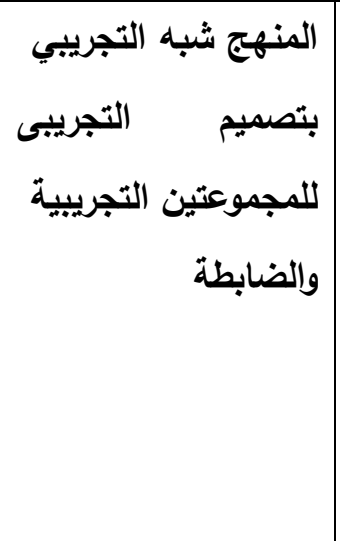 & 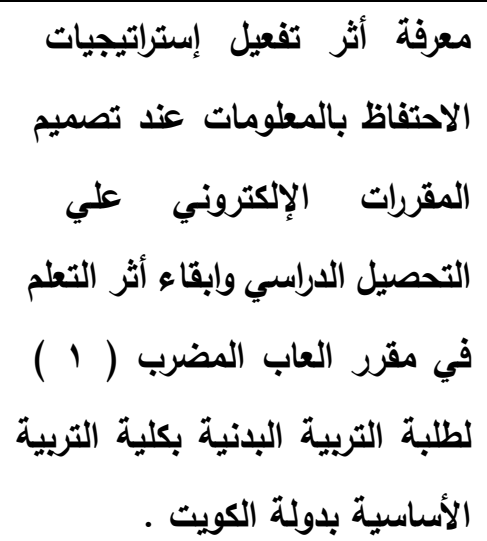 & 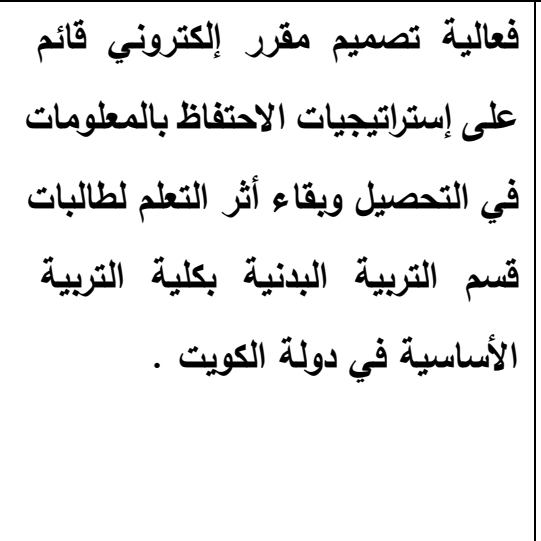 & $r+10$ & حسين صالح جوهر & $r$ \\
\hline
\end{tabular}




\begin{tabular}{|c|c|c|c|c|c|c|c|}
\hline أهم النتائَج & العينة & المنهج & هدف البحث & عنوان البحث & السنة & اسم الباحث & p \\
\hline 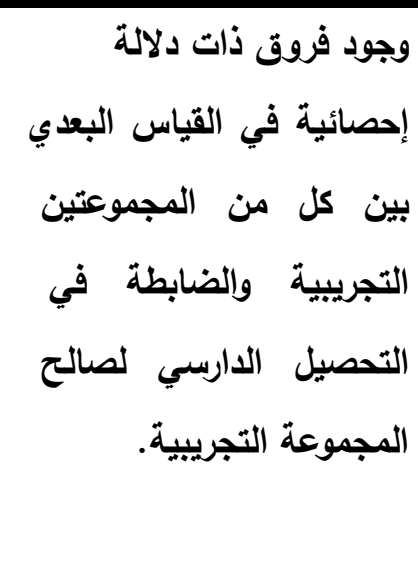 & 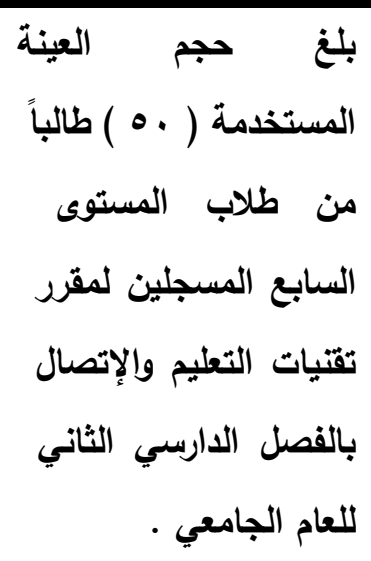 & 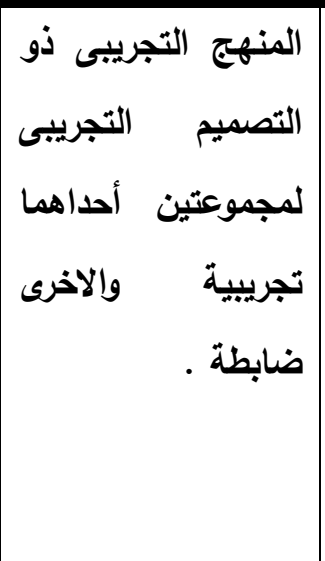 & 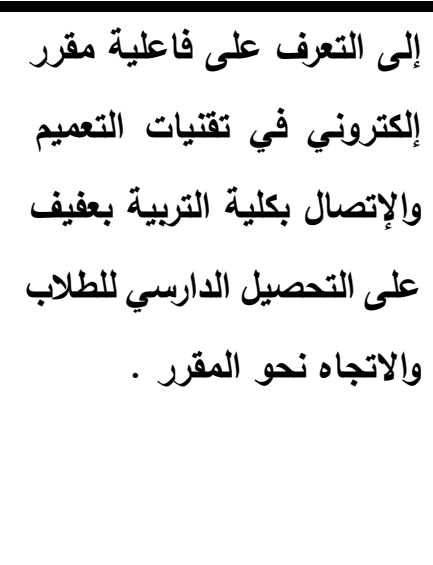 & فاعلية تصور مقترح لمقرر إلكتروني & $r .17$ & $\begin{array}{c}\text { شاهيناز عبدالرحمن } \\
\text { عثمان } \\
\text { ( v ) }\end{array}$ & $r$ \\
\hline 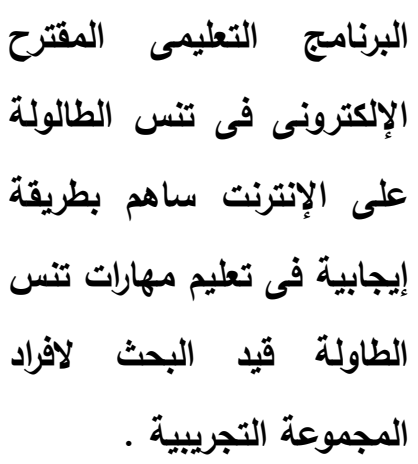 & 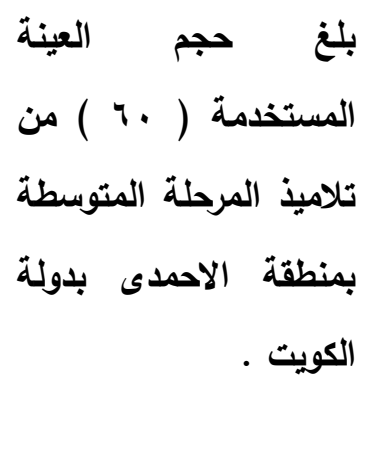 & |لتصنيم & 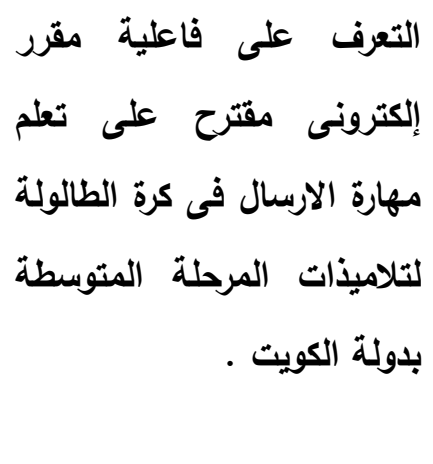 & 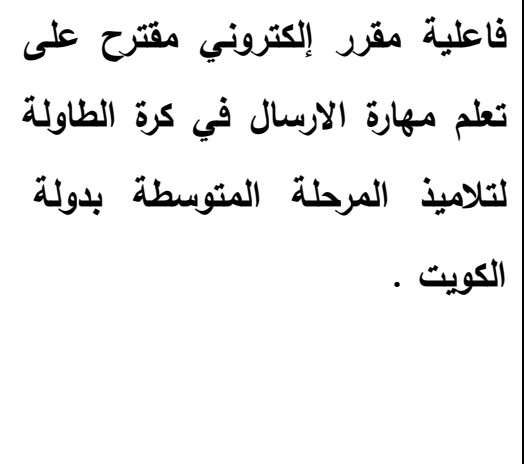 & $r .19$ & حسين صالح عبد اللة & $\varepsilon$ \\
\hline
\end{tabular}


ثانيا : الدراسات المرجعية الاجنبية :

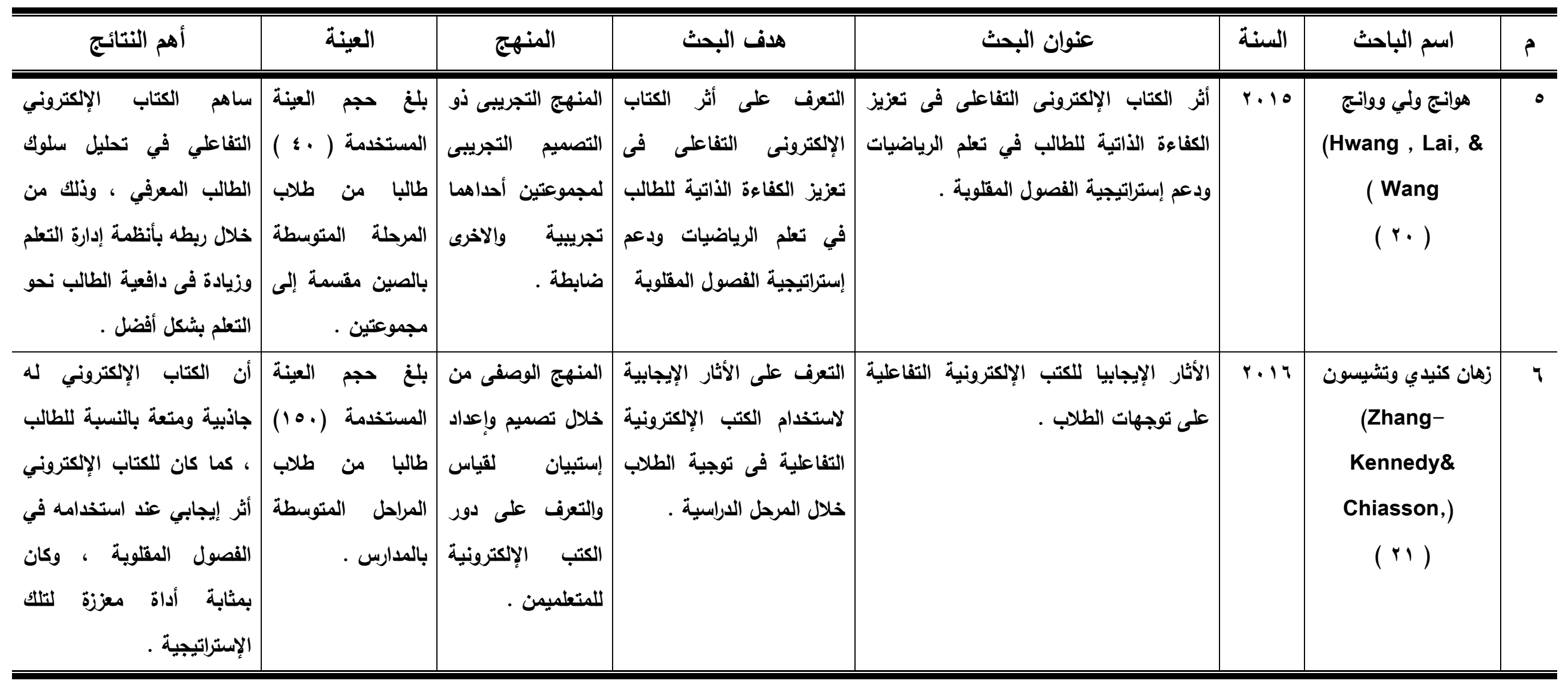


تحقيقا لأهداف البحث وفروضة استخدم الباحث المنهج التجريبيى باستخدام التصميم التجريبيى للجموعتين أحداهما تجريبية والاخرى ضابطة وبتطبيق القياسات القبلية والقياسات

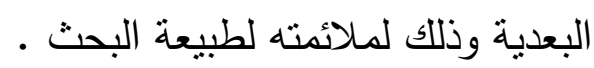

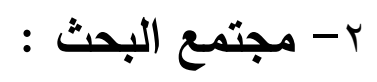

يتمثل مجتمع البحث فى طلاب الصف الاول الإعدادى بمعهد مجمع بدر الأزهرى التابع

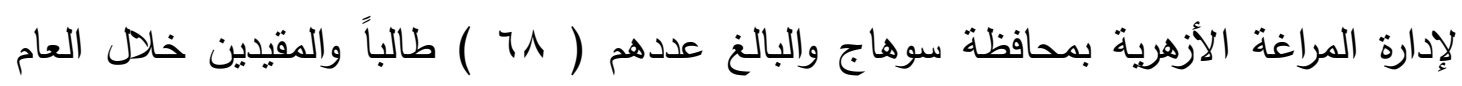

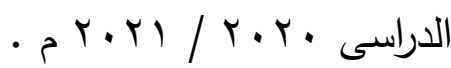

$$
\begin{aligned}
& \text { r- عينة البحث : }
\end{aligned}
$$

تم أختيار عينة البحث بالطريقة العمدية من مجتمع البحث من طلاب الصف الأول مجمع

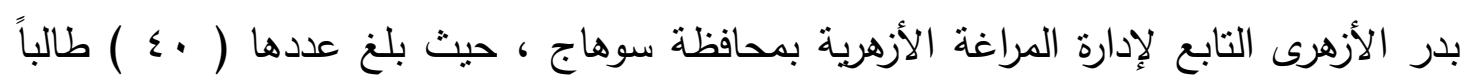

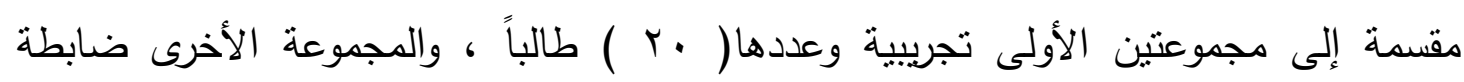

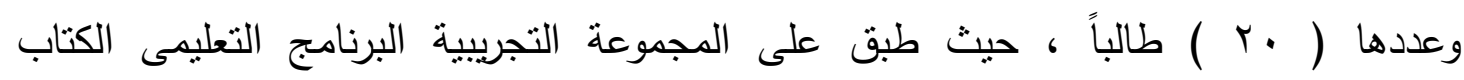
الإلكترونى فى كرة اليد والمعدة من قبل الباحث ، و وعلى المجموعة الضابطة طريقة الثرح

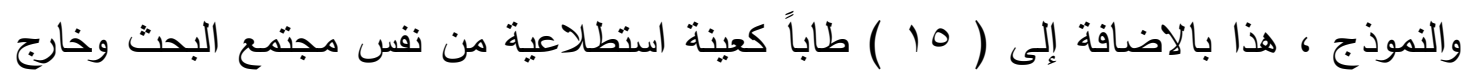

عينة البحث الأساسية .

$$
\text { جدول (r) (r) ( ) ( ) }
$$

\begin{tabular}{|c|c|c|c|c|c|c|c|c|c|c|c|}
\hline \multicolumn{4}{|c|}{ عينة البحث الأساسية } & \multirow{2}{*}{\multicolumn{2}{|c|}{ الاستطلاعية }} & \multirow{2}{*}{\multicolumn{2}{|c|}{ عينة البحث }} & \multirow{2}{*}{\multicolumn{2}{|c|}{ البحثة من عينة }} & \multirow{2}{*}{\multicolumn{2}{|c|}{ مجتمع البحث }} \\
\hline الضابطة & المجم & يموعة & & & & & & & & & \\
\hline النسبة & 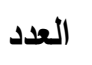 & النسبة & 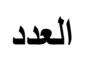 & النسبة & العدد العد & النسبة & 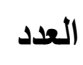 & النسبة & 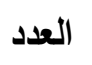 & النسبة & العدد العد \\
\hline$\%$ \% q, ४ & $r$. & $\% \curlyvee q, \varepsilon)$ & $r$. & $\%$ \%Y,. & 10 & 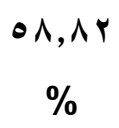 & $\varepsilon$. & $\begin{array}{c}\wedge \cdot, \wedge \wedge \\
\%\end{array}$ & 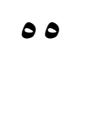 & $\% 1 \ldots$ & 11 \\
\hline
\end{tabular}

توصيف الاحصائى لعينة البحث

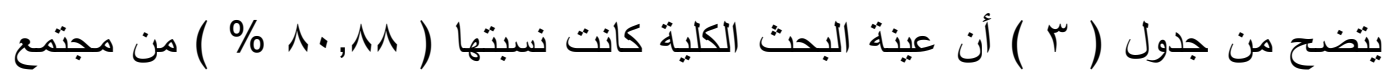

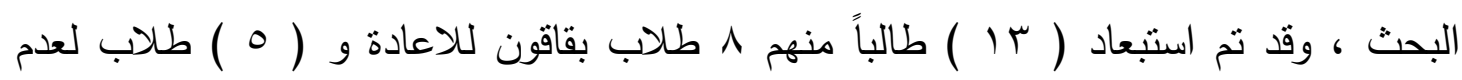
التزامهم أثناء اجراء القياسات ، وكانت نسبتهم ( r 19, (1\% ) ) ، كم تم اختيار ( 10 ( 1 ) طالباً كعينة 


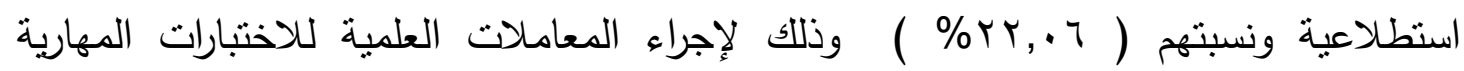
والمعرفية المستخدمة فى البحث.

\section{؛ - أسباب اختيار عينة البحث :}

تم اختبار عينة البحث بناء على الأسباب الآتية : - سهولة الحصول على عينة البحث . - جميع أفراد العينة يخضعون لخطة دراسية واحدة . - توافر عدد كافٍ من الطلاب لنطبيق البرنامج عليهم .

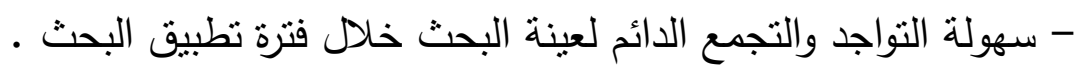
- جميع الطلاب فى مرحلة سنية متقاربة .

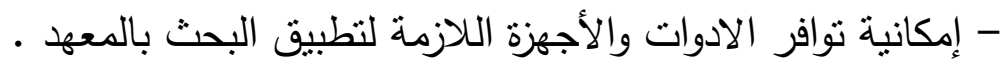

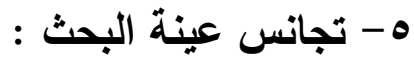

وقد قام الباحث بايجاد التجانس بين مجموعتى البحث فى بعض المتغيرات التى لها علاقة بنتائج البحث وهى بعض معدلات النمو ( السن - الطول - الوزن ) ، والقدرات البدنية لعينة البحث المختارة وجدول ( o ) يوضح تجانس عينة البحث فى معدلات النمو والقدرات البدنية .

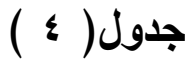

التوصيف الإحصائى لعينة البحث واعتدالية العينة في معدلات النمو

$\varepsilon \cdot=\dot{0}$

\begin{tabular}{|c|c|c|c|c|c|c|c|c|c|c|}
\hline التقلطح & الالتواء & المدى & قيمة & |قل قيمة & |المعيارى & الوسبط & |الحسابى & وحدة & المتغير & م \\
\hline$\cdot, 7 r-$ & $1, V r$ & $r, \ldots$ & $1 r, \ldots$ & 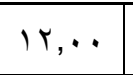 &. $.9 V$ & ${ }_{1}, \ldots$ & Ir,r. & سنة & السن & \multirow{3}{*}{ 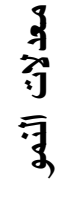 } \\
\hline$\cdot, 0 \mathrm{~V}-$ & • & $q, \ldots$ & $\| r v, \ldots$ & $\mid r \varepsilon,$. & 1, 1, & . & $1 \% 0, \wedge 0$ & سم & الطول & \\
\hline$\cdot, 7 \vee-$ & •, & $19, \ldots$ & $r 9,79$ & $r_{4, v .}$ & $r, \wedge r$ & $r v, \ldots$ & $\Gamma_{\Lambda}, \Gamma_{\Lambda}$ & ث كجم & الوزن & \\
\hline
\end{tabular}

يوضح جدول (ء) المتوسط الحسابى والوسيط والإنحراف المعيارى وأقل وأكبر قيمة والمدى والالتواء والتفلطح للمتغيرات الأساسية ( معدلات النمو - القدرات البدنية )

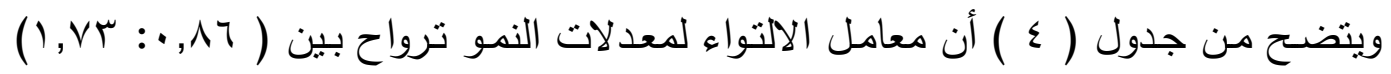

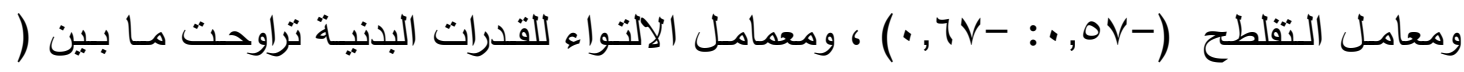

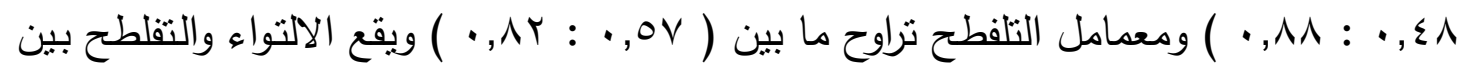

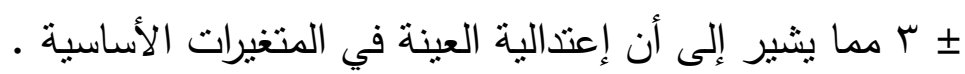




\section{تجانس مجموعتى البحث ودلالة الفروق في القياس القبلى:}

جدول (0)

تجانس مجموعتي البحث ودلالة الفروق بينهما في القياس القبلى للمتغيرات الأساسية ن

\begin{tabular}{|c|c|c|c|c|c|c|c|c|c|c|}
\hline \multicolumn{2}{|c|}{ التجانس } & \multicolumn{2}{|c|}{ دلالة الفروق } & \multicolumn{2}{|c|}{ التجريبية } & \multicolumn{2}{|c|}{ الضابطة } & \multirow{2}{*}{ وحدة القياس } & \multirow{2}{*}{ المتغير } & \multirow{2}{*}{ م } \\
\hline sig & ف & sig & $ت$ & $\varepsilon$ & م & $\varepsilon$ & م & & & \\
\hline$\cdot, 0 \mathrm{~V}$ & 1,11 & $r, \ldots$ & $\cdot, r$. & $1, \pi$ & $M, \Sigma$. & $1,1 \mathrm{~V}$ & $M, r$. & سنة & السن & 9 \\
\hline •,$Y T$ & $1, \vee \wedge$ & $\cdot, V_{1}$ & $\cdot, r$. & $r, 01$ & $1 \mu_{0, v .}$ & r ז & $1 \pi 4, \ldots$ & سم & الطول & $\overline{7}$ \\
\hline .19 & $\cdot, 97$ & • & $\cdot, .0$ & $r, 11$ & r & r,97 & r^, $\varepsilon$. & ث كجم & الوزن & \\
\hline
\end{tabular}

ت، ف دال عند

يوضـح جدول(0) المتوسط الحسـابى (م) والإنحـراف المعيـارى (ع) لكل مـن المجموعـة

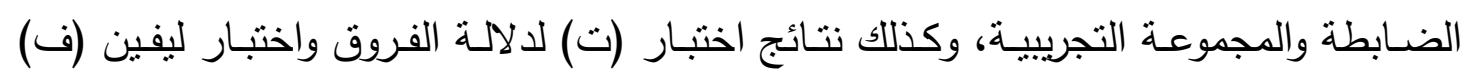
للتجانس بين المجموعتين ومستوى الدلالة (sig) لكل منهما .

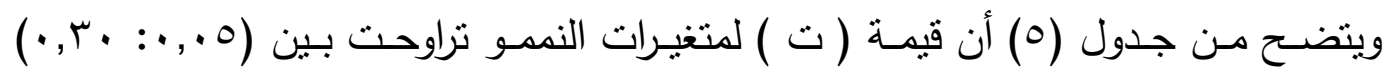

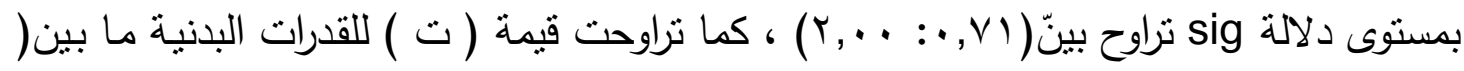

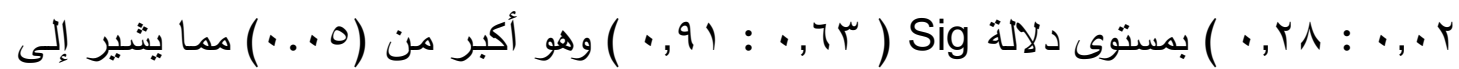

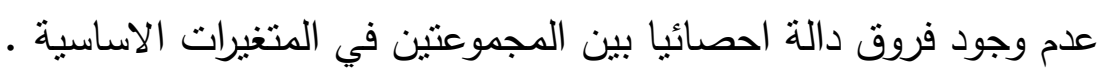

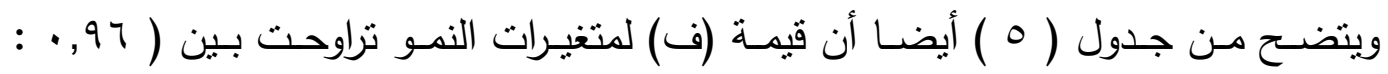

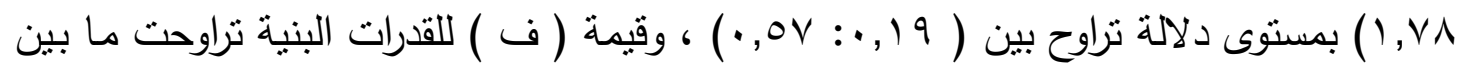

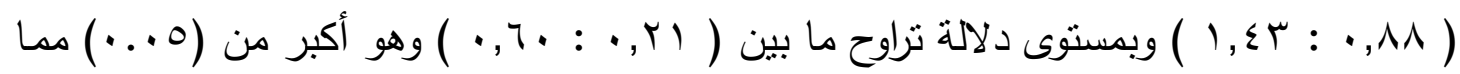

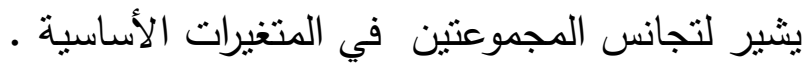
كذلك قام الباحث بإيجاد التوصيف الإحصائى لعينة البحث واعتدالية العينة في الاختبار المعرفى ومستوياته وكذللك كما هو موضح بالجدول التالى : 


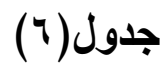

التوصيف الإحصائى لعينة البحث واعتدالية العينة في الاختبار المعرفى ومستوياته

$\varepsilon=r \dot{0}+10$

يوضح جدول (T) المتوسط الحسابى والوسيط والإنحراف المعيارى وأقل وأكبر قيمة والمدى

\begin{tabular}{|c|c|c|c|c|c|c|c|c|c|c|}
\hline التقلطح & الالتواء & الدىى & قيمة & |قل قيمة & المعيارى & الوسيط & الحسابى & ولقياس & المتغير & s \\
\hline , $7 r-$ & $\cdot, r v$ & $0, .$. & $1 \cdot, \cdot$. & $7, \cdots$ & r, iv & $\wedge, \cdot \cdot$ & ᄉ, & درجة & |الحفظ والتنكر & \\
\hline $1, r \vee-$ & $\cdot, \varepsilon 1$ & $0, \cdots$ & $1 \cdot, \ldots$ & $7, \cdots$ & $r, \cdot q$ & $\Lambda, \cdot \cdot$ & $\Lambda, Y \Lambda$ & درجة & الفهم والاستيعاب & , \\
\hline$\cdot, \wedge \varepsilon-$ & • & $\varepsilon,$. & $9, \ldots$ & $7, \cdot \cdot$ & 1,97 & $v, \cdot \cdot$ & $V, \pi r$ & درجة & التطبيق & $r$ \\
\hline$. V \leqslant-$ & $1,1 \mathrm{~V}$ & $1 \varepsilon,$. & $r q, \ldots$ & $1 \wedge, \cdots$ & $T, Y Y$ & $r r, .$. & $r \varepsilon, I T$ & درجة & الاختبار المعرفى ككل & \\
\hline
\end{tabular}

والالتواء والتقلطح للاختبار المعرفى.

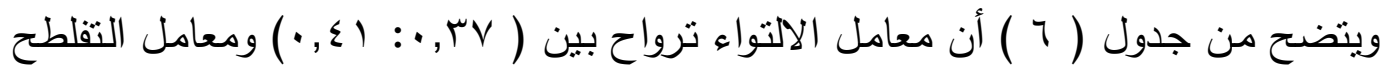

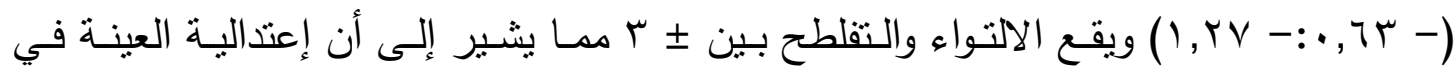

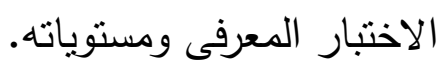

كذلك قد عمد الباحث إلى إيجاد التجانس بين مجموعتى البحث التجريبية والضابطة بين القياسين القبلى والبعد للمتغيرات المعرفية وكانت كالاتى :

$$
\text { جدول (v) }
$$

تجانس مجموعتي البحث

ودلالة الفروق بينهما في القياس القبلى للاختبار المعرفي ومستوياته

$\varepsilon \cdot=_{r} \dot{u}=1$

\begin{tabular}{|c|c|c|c|c|c|c|c|c|c|c|}
\hline \multicolumn{2}{|c|}{ التجانس } & \multicolumn{2}{|c|}{ دلالة الفروق } & \multicolumn{2}{|c|}{ التجريبية } & \multicolumn{2}{|c|}{ الضابطة } & \multirow{2}{*}{ وحلقاس } & \multirow{2}{*}{ المتغير } & \multirow{2}{*}{ م } \\
\hline sig & ف & sig & 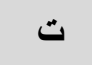 & $\varepsilon$ & b & $\varepsilon$ & م & & & \\
\hline$\because v$. & $\cdot, Y \wedge$ & $1, .9$ & $r, T)$ & $1, r v$ & $\Lambda, \Gamma$. & - 94 & 1, ז & درجة & الحفظ والتنكر & 1 \\
\hline-9. & $\ldots v$ & $\cdot, 71$ & $r, \leqslant 0$ & $1, \varepsilon V$ & $\Lambda, \cdot 7$ & $1,7 V$ & 1.0. & درجة & الفهم والاستيعاب & $r$ \\
\hline..$\wedge 1$ & גז. & $\cdot, \nabla \mu$ & $r, I V$ & 1,79 & 8.79 & 1,19 & V.00 & درجة & التطبيق & $r$ \\
\hline
\end{tabular}




\begin{tabular}{l|l|l|l|l|l|l|l|l|l|l}
\hline \& & \& \\
\hline
\end{tabular}

يوضـح جدول(V) المتوسط الحسـابى (م) والإنحراف المعيـارى (ع) لكل مـن المجموعـة

الضـابطة والمجموعـة التجريبية، وكذلك نتائج اختبار (ت) للالالة الفروق واختبـار ليفين (ف) للتجانس بين المجموعتين ومستوى الدلالة (sig) لكل منهما

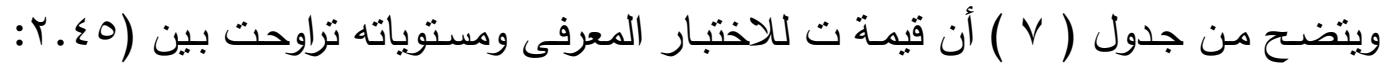

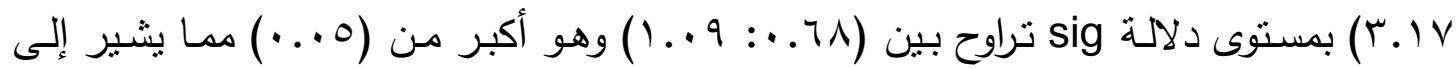
عدم وجود فروق دالة احصائيا بين المجموعتين في الاختبار المعرفى ومستوياته

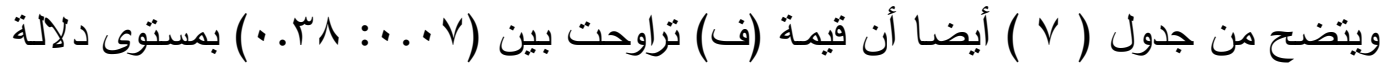
تراوح بين ( • . •. • . . •) وهو أكبر من (0 . . ) مما يشير لتجانس المجموعتين في الاختبار المعرفى ومستوباته

كذلك قد عمد الباحث إلى إيجاد التوصيف الإحصائى لعينة البحث فى المتغيرات المهارية قيد البحث وكذلك كما هو موضتح بالجدول التالى : جدول (^)

التوصيف الإحصائى لعينة البحث واعثدالية العينة للمتغيرات المهارية $\varepsilon \cdot=\dot{0}$

\begin{tabular}{|c|c|c|c|c|c|c|c|c|c|c|}
\hline التقلطح & الالتواء & المدى المد & قيمة & |قل قيمة & الانحراف & الوسيط & |الحستوسط & وحدة & المتغير & م \\
\hline., $11-$ & זיד, & $r, \ldots$ & $0, \ldots$ & $r, \ldots$ & מ & $\varepsilon, \ldots$ & $\varepsilon, 70$ & درجة & مسك واستلام الكرة & 1 \\
\hline$\cdot, Y_{1}-$ & $\cdot, \times 1$ & $r, .$. & $0, \ldots$ & $r, \ldots$ & $1, r V$ & $\varepsilon, \ldots$ & $\varepsilon, r V$ & درجة & تتطيط الكرة & r \\
\hline$\cdot, I V-$ & $\cdot, 79$ & $\varepsilon, \ldots$ & $0, \ldots$ & $r, \ldots$ & $\cdot, 97$ & $\varepsilon, \ldots$ & $\varepsilon, 79$ & درجة & التمرير الكرياجى & $r$ \\
\hline$\cdot, r q-$ & $\cdot$, OV & $\varepsilon, \cdot$ & $0, \ldots$ & $r, \ldots$ & $\cdot, \wedge т$ & $r, .$. & $r, q \vee$ & درجة & التمريرة الصدرية & $\varepsilon$ \\
\hline $.0 \leqslant-$ & $\cdot, \wedge \varepsilon$ & $\varepsilon, \cdots$ & $0, \cdots$ & $r, 0 \ldots$ & 1, 1, & $\varepsilon, \ldots$ & $\varepsilon, \vee q$ & درجة & التصويب الكرياجى & ○ \\
\hline$\cdot, \mathrm{V} \mathrm{H}_{-}$ & $\cdot, 91$ & $r, .$. & $0, \ldots$ & $r, \ldots$ & $r, 10$ & $r, .$. & $r, 9 q$ & درجة & المهارات الدفاعية & 9 \\
\hline., $01-$ & $\cdot, \wedge)$ & $r, . \cdot$ & $0, \cdots$ & $r, .$. & 1,79 & $r, .$. & $\Gamma, \wedge \vee$ & درجة & الخداع & v \\
\hline
\end{tabular}




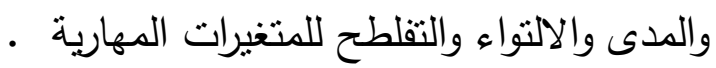

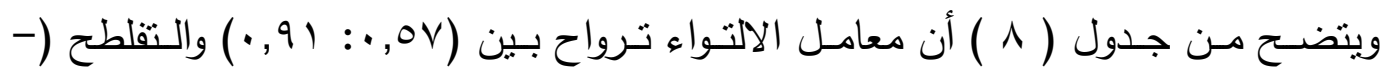

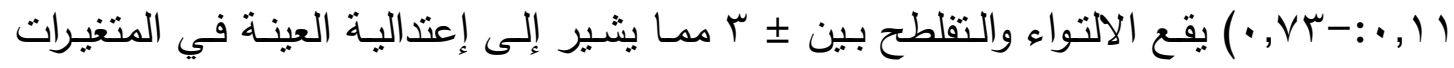

المهارية .

\section{جدول(9)}

تجانس مجموعتي البحث ودلالة الفروق بينهما في القياس القبلى للمتغيرات المهارية ن ن,

\begin{tabular}{|c|c|c|c|c|c|c|c|c|c|c|}
\hline \multicolumn{2}{|c|}{ التجانس } & \multicolumn{2}{|c|}{ دلالة الفروق } & \multicolumn{2}{|c|}{ التجريبية } & \multicolumn{2}{|c|}{ الضابطة } & \multirow{2}{*}{ وحداس } & \multirow{2}{*}{ المتغير } & \multirow{2}{*}{ p } \\
\hline sig & ف & sig & $ت$ & $\varepsilon$ & م & $\varepsilon$ & 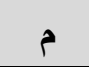 & & & \\
\hline$\cdot . \leqslant V$ &. .10 & 1.7. & 1,11 & $1.7 r$ & $\varepsilon, \uparrow \wedge$ & $1 . v \varepsilon$ & $\varepsilon, T Y$ & درجة & مسك واستتلام الكرة & 1 \\
\hline $.0 Y$ & $.7 \mathrm{~V}$ & 1.7 & $r, \cdot V$ & $1.7 \varepsilon$ & $\varepsilon, Y V$ & l.Ar & $\varepsilon, Y V$ & درجة & تنطيط الكرة & r \\
\hline$\cdot, r q$ & $\cdot, \mathrm{VV}$ & $\cdot, 70$ & דוr & I, N & $\varepsilon, V_{0}$ & $r, r_{T}$ & $\varepsilon, 7$ & درجة & التمرير الكرياجى & $r$ \\
\hline$\cdot, 71$ & $\cdot, \wedge$. & $\cdot, 9 \leqslant$ & $r, 1 \varepsilon$ & $1, r q$ & $r, 9 \wedge$ & $r, 7$. & r,97 & درجة & التمريرة الصدرية & $\varepsilon$ \\
\hline דוז, & $1,1 \leq$ & $\cdot, \mu_{\Lambda}$ & 1,91 & $r, I V$ & $V, V V$ & $1, r \wedge$ & $\varepsilon, \lambda)$ & درجة & التصويب الكرياجى & 0 \\
\hline.$r \Lambda$ & $1 . r 9$ &.$r V$ & Y,OV & $1 . v$. & $r, 91$ & 1.70 & $\varepsilon, \cdots$ & درجة & المهارات الدفاعية & 7 \\
\hline$\cdot, \leqslant 9$ & $\cdot, 9 \leqslant$ & 1,17 & $r, 91$ & $1, \varepsilon 1$ & $r, q 1$ & דו & r,人т & درجة & الخداع & v \\
\hline
\end{tabular}

ت، ف دال عند

يوضـح جدول (9) المتوسط الحسـي (م) والإنحراف المعيارى (ع) لكل مـن المجموعـة

الضـابطة والمجموعـة التجريبية، وكذللك نتائج اختبار (ت) لدلالـة الفروق واختبار ليفين (ف) للتجانس بين المجموعتين ومستوى الدلالة (sig) لكل منهما

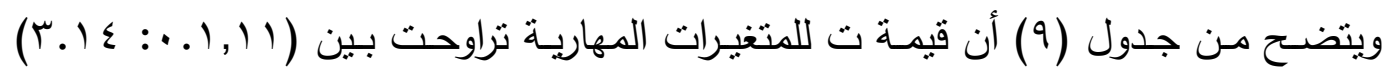

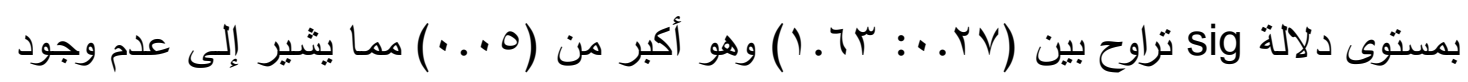
فروق دالة إحصائيا بين المجموعتين في المتغيرات المهارية.

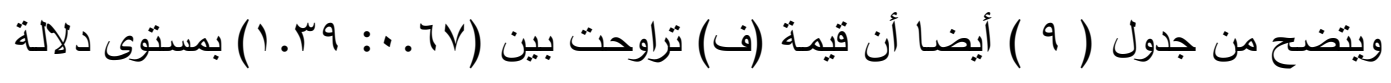

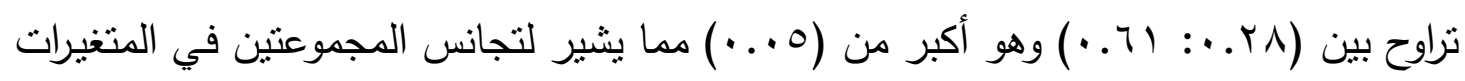
المهارية. 
جدول (1.)

التوصيف الإحصائى لمجتمع البحث فى متغيرات القدرات البذنية

\begin{tabular}{|c|c|c|c|c|c|c|c|c|c|}
\hline \multirow{2}{*}{\multicolumn{2}{|c|}{ معامل الإلتواء }} & \multicolumn{6}{|c|}{ التكافو } & \multirow{3}{*}{ المتغيرات } & \multirow{3}{*}{ r } \\
\hline & & \multirow{2}{*}{ الجدولية } & \multirow{2}{*}{ المحتسبة } & \multicolumn{2}{|c|}{ المجموعة التجريبية } & \multicolumn{2}{|c|}{ المجموعة التجريبية } & & \\
\hline التجريبية & الضابطة & & & $\varepsilon^{-+}$ & سَ & $\varepsilon^{-+}$ & سَ & & \\
\hline$\cdot, \mathrm{VV}$ & $\cdot, V Y$ & \multirow{7}{*}{$1, \vee \vee \wedge$} & $\varepsilon, 1 \vee \varepsilon$ & $\cdot, T$ & $\varepsilon, 79$ & $\cdot, \mathrm{VV}$ & $\varepsilon, 00$ & السرعة الانتقالية ( ث ) & 1 \\
\hline$\cdot, \vee \vee q$ & $\cdot, \wedge$ & & $\varepsilon, T M r$ & $1, \cdot 9$ & $\Lambda, \leqslant 0$ & $\cdot, \lambda r$ & $\wedge, \perp \vee$ & السرعة الحركية ( عدد ) & r \\
\hline$\cdot, \wedge T$ & $\cdot, 79$ & & $r, q \leqslant 1$ & $\cdot, 94$ & $v, 07$ & $\cdot, 1, r_{1}$ & $v, 79$ & القوة المميزة بالسرعة ( متر ) & r \\
\hline$\cdot, V \varepsilon$ & $\cdot, \vee \vee T$ & & בוזיר ר & $1,1 \mathrm{~V}$ & $1 \cdot, \leqslant V$ & $1, \varepsilon r$ & $1 \cdot, 79$ & الرشاقة ( عدد ) & $\varepsilon$ \\
\hline$\cdot, 91$ & $\cdot, \lambda r$ & & $7, \leqslant \vee r$ & דיז, & $11, r V$ & $\cdot, \wedge 7$ & $11, \leqslant 1$ & المرونة ( سم ) & 0 \\
\hline$\cdot, \vee \wedge$ & $\cdot, 9 r$ & & $0, V) \leqslant$ & T & $r \wedge, 11$ & $\cdot, \wedge 9$ & $Y V, q V$ & التوافق ( ث ) & 7 \\
\hline$\cdot, 7 \wedge$ & $\cdot, \wedge \wedge$ & & $\leq, 7 \leq 0$ & $\cdot, 9 \Lambda$ & $\wedge, 19$ & $1,1 \leq$ & $\Lambda, Y_{1}$ & الاقة ( درجة ) & V \\
\hline
\end{tabular}

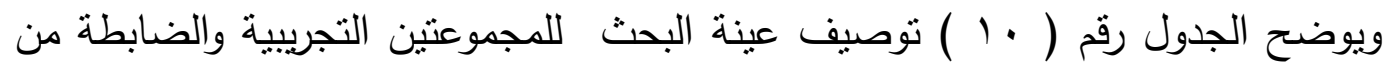

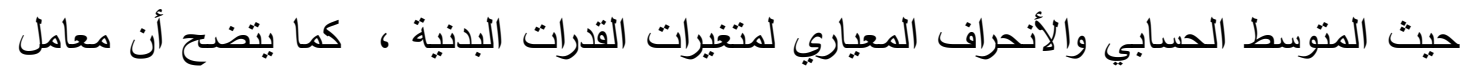

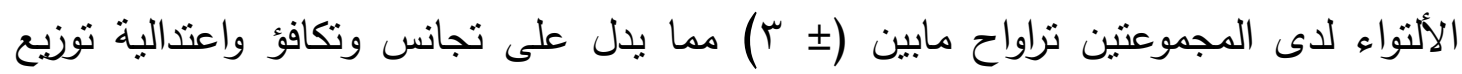
عينتي البحث فى المتغيرات البدنية قيد البحث ـ 1- وسائل وأدوات جمع البيانات :

قام الباحث بـالإطلاع على المراجع والدراسـات السـابقة بغرض الاستفادة منها فى كيفيـة

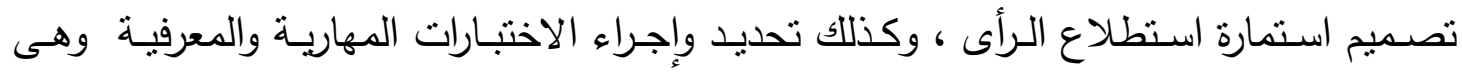

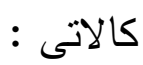
أ- الأجهزة والأدوات المستخدمة فى البحث : اعتمد الباحث فى جمع البيانات والمعلومات الخاصة بالبحث على عدد من الأدوات والتىى

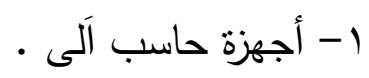

r- اقراص ممغنطة عليها المجتوى التعليمى ( الكتاب الإلكترونى ) r- جهاز رستاميتز لقياس الطول لاقرب سنيمتر • ع - ميزان طبر لقباس الوزن لاقرب جرام • 
0- عدد من الكرات اليد تتناسب مع عينة البحث .

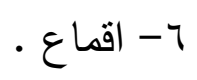

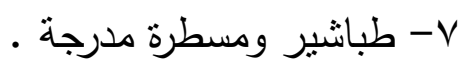

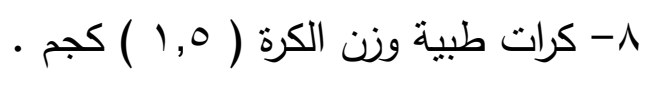

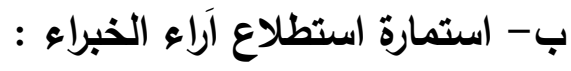

$$
\text { حيث تم استخدام هذة الاستمارة لتحديد الآتى : }
$$

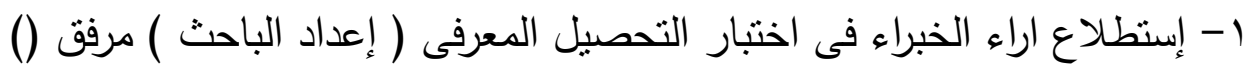

r- إسنطلاع رأى الخبراء فى صلاحية ومناسبة استخدام الكتاب الإكترونى المعد من قبل الباحث لههارات كرة اليد المختارة قبد البحث ، وذللك من خلال عرض اسطوانة C.D عليها

الكتاب الإلكترونى المعد من قبل الباحث وما يحتوية من مهارات كرة اليد المختارة مرفق () .

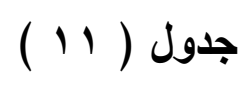

\begin{tabular}{|c|c|c|c|c|c|}
\hline \multicolumn{2}{|c|}{ النسبة المئوية للاَراء } & \multicolumn{2}{|c|}{ راَى الخبير } & \multirow[b]{2}{*}{ 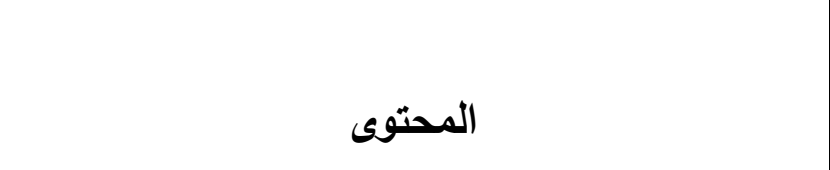 } & \multirow[b]{2}{*}{ p } \\
\hline 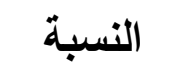 & 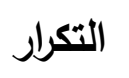 & غير مناسب & 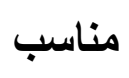 & & \\
\hline$\% 1 \ldots$ & $\checkmark$ & - & $\checkmark$ & وضوح الهدف العام من الكتاب الإككترونى . & 1 \\
\hline$\% 1 \ldots$ & $\checkmark$ & - & $\checkmark$ & وضوح الاهداف المعرفية والمهارية والوجدانية للكتاب & r \\
\hline$\% \wedge 0, \vee 1$ & 7 & 1 & 7 & الرئيسية ) وضوح مقدة وعرض الكتاب ( الافتتاحية - القائمة & r \\
\hline$\% \wedge 0, \vee>$ & 7 & 1 & 7 & المختارة بوضوح وعرض مراحل الاداء لجميع مهارات كرة اليد & $\varepsilon$ \\
\hline$\% \wedge 0, \vee>$ & 7 & 1 & 7 & 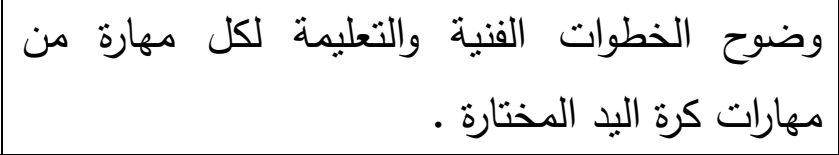 & $\bullet$ \\
\hline$\% 1 \ldots$ & $v$ & - & $\checkmark$ & 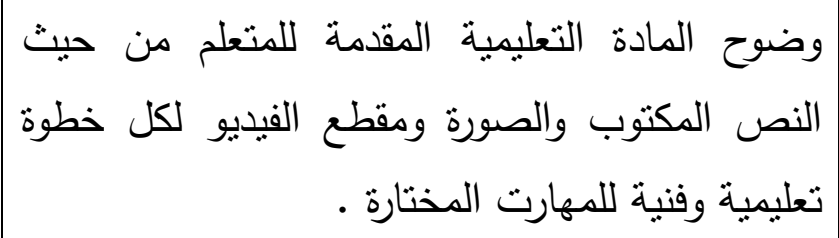 & 9 \\
\hline$\% \wedge 0, \vee 1$ & 7 & 1 & 7 & مناسبة حجم الخطوط والوانها وانساقها مع البرنامج & 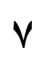 \\
\hline
\end{tabular}

استجابة الخبراء فى استطلاع أرائهم نحو البرنامج التعليمى

$V=ن$ 


\begin{tabular}{|c|c|c|c|c|c|}
\hline & & & & | المستخدم • & \\
\hline$\% 1 \ldots$ & V & - & V & 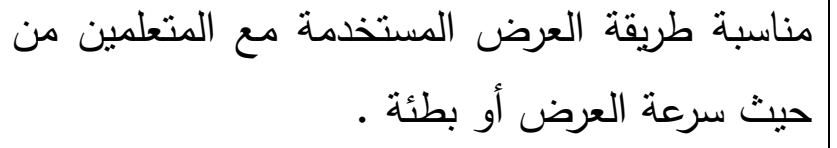 & $\Lambda$ \\
\hline$\% 1 \ldots$ & V & - & V & 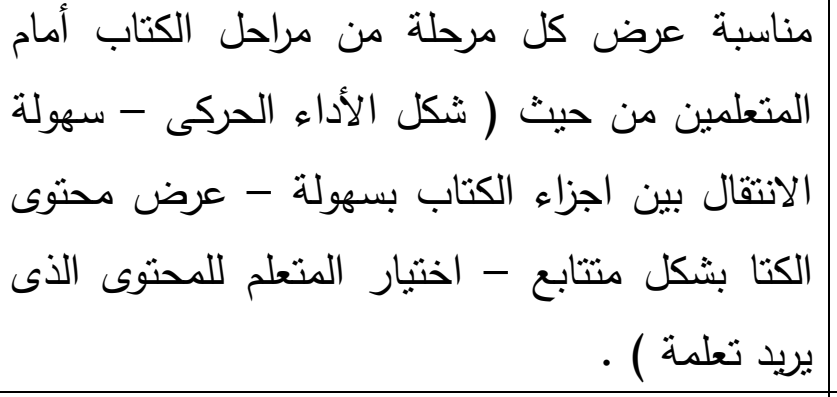 & 9 \\
\hline$\% \wedge \bullet, \vee \backslash$ & 7 & 1 & 7 & مهارات كرة اليد جميع الفديوهات والصور المستخدمة فى تعليم & 1. \\
\hline$\% \wedge 0, \vee_{1}$ & 7 & 1 & 7 & |وضوح ومناسبة أساليب التقويم المستخدمة فى الكتاب & 11 \\
\hline
\end{tabular}

يضح من جدول ( 11 ) أن نسبة موافقة الخبراء على الكتاب الإلكترونى المقترح والمعد من

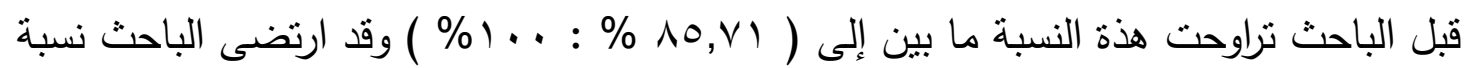
موافق ( . ^ \% ) مما يدل على قوة هذا الكتاب الإلكترونى وتأثيرها الواضح فى العملية التعليمة.

ج- استمارة تسجيل البيانات ( تصميم الباحث ) : قام الباحث بتصميم استمارة لتسجيل البيانات الخاصة بقياسات الدراسة وقد احتوت على ثلاثة أجزاء رئيسية كما يلى : 1- الجزء الأول : وهو خاص بتسجيل البيانات بهدف استخدامها فى إجراء التجانس والتكافو لعينة البحث الأساسية ( قبل إجراء التجربة الأساسية ) وتضمنت ثلاك الاستمارة البيانات الاتية : - بيانات تعريفية ومنها ( اسم الطالب - تصنيف المجموعة تجريبية وضابطة ) . - بيانات خاصة بمتغيرات النمو ( السن - الطول - الوزن ) والقدرات البدنية وبالقياسات الموضوعية الخاصة بالدراسة ( التحصيل المعرفى - الأداء المهارى ) . ץ- الجزء الثانى : وهو خاص بتسجيل البيانات بهذف استخدامها فى إجراء المعاملات العلمية للاختبار والمقاييس المستخدمة ، أى للتأكد مما يلى : - المعاملات العلمية للاختبار التحصيلى ( الصدق والثبات ) . - المعاملات العلمية لاختبار الأداء المهارى . 
r- الجزء الثالث : وهو خاص بتسجيل البيانات بعد الانتهاء من التجربة الأساسية بهدف التعرف على تأثثر استخدام الكتاب الإلكترونى المقترحة على مستوى التحصيل المعرفى والأداء المهارى لعينة البحث المختارة .

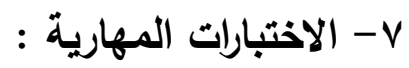

اقتصرت الدراسة النى قام بها الباحث على بعض مهارات كرة اليد المقررة على طلاب الصف

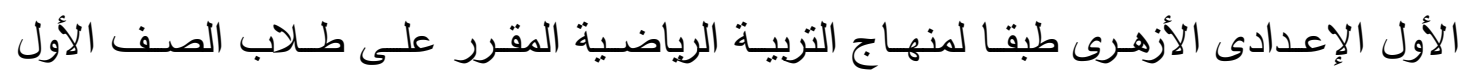

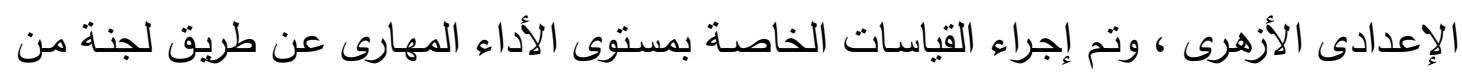

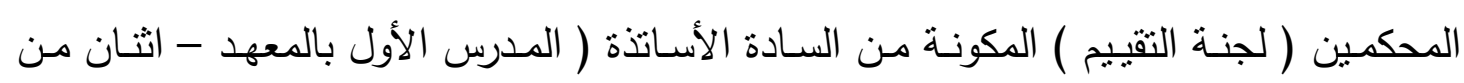

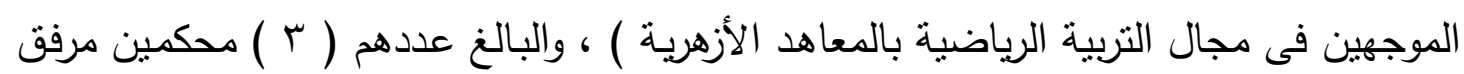

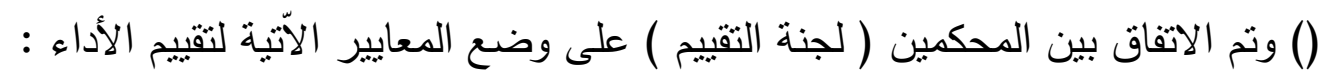

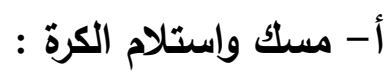

نم إجراء القياسات الخاصة بمستوى الأداء المهارى بناء على المعايير الاتية :

- شكل جسم اللاعب بوجة عام أثناء استلام الكرة الممرة إلية . - شكل اليدين عند استلام الكرة . - شكل وضع القدمين أثناء استلام الكرة . - وضع الرأس والنظر أثناء عملية الاستلام . - انسيابية الأداء للاعب أثناء الاستلام .

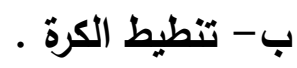
نم إجراء القياسات الخاصة بمستوى الأداء المهارى بناء على المعايير الاتية : - شكل جسم اللاعب بوجة عام أثناء أداءمهارة تتطيط الكرة. - شكل اليد التى تقوم يتتطيط الكرة . - شكل وحركة اليدين مع القدمين أثناء الادء . - وضع الرأس واتجاة النظر - انسيابية أداء اللاعب أثناء اداء المهارة . ج- التمريز الكرباجى • 
تم إجراء القياسات الخاصة بمستوى الأداء المهارى بناء على المعايير الاتية : - شكل جسم اللاعب بوجة عام أثناء أداء المهارة . - شكل اليد الممرة للكرة أثناء أداء التمرير . - توافق حركة الجذع والقدمين واليد الممرة للكرة عند أداء التمرير • - شكل الرأس واتجاة النظر عند أداء التمريرلاعب المستلم .

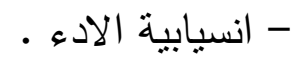

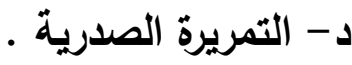

تم إجراء القياسات الخاصة بمستوى الأداء المهارى بناء على المعايير الاتية : - شكل جسم اللاعب بوجة عام أثناء أداء المهارة . - شكل اليد الممرة للكرة أثناء أداء التمرير - توافق الجذع والقدمين واليد الممرة للكرة عند أداء التمرير - شكل الرأس واتجاة النظر عند أداء التمرير للاعب المستلم .

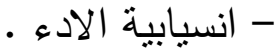

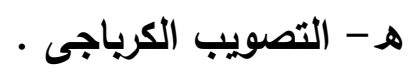

تم إجراء القياسات الخاصة بمستوى الأداء المهارى بناء على المعايير الاتية : - شكل جسم اللاعب بوجة عام أثناء أداء المهارة . - شكل اليد أثناء أداء الوقب لأداء التصويب . - شكل الجزع والقدمين واليد المصوبة عند أداء التصويب . - شكل الرأس واتجاة النظر للاعب المصوب على المرمى .

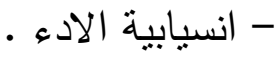

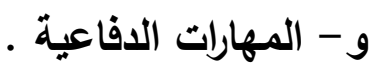

تم إجراء القياسات الخاصة بمستوى الأداء المهارى بناء على المعايير الاتية : - شكل جسم اللاعب وتحركاتة لأداء الدفاع • 
- اتخاذ اليدين الوضع المناسب أثناء أداء الدفاع • - شكل الجذع وتحركات القدمين عند أداء التحركات الدفاعية . - تحركات القدمين أثناء أداء الدفاع - شكل الرأس واتجاة النظر على اللاعب الحامل للكرة .

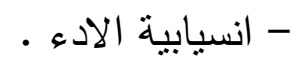

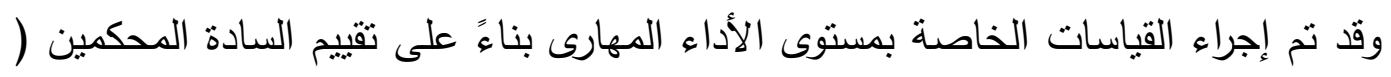

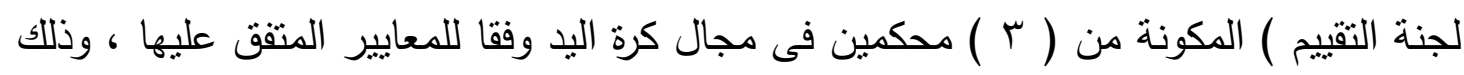

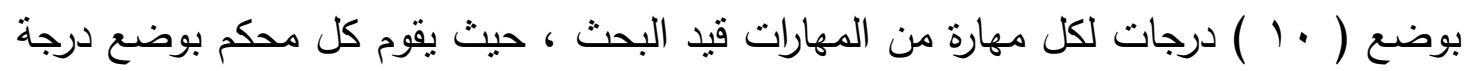

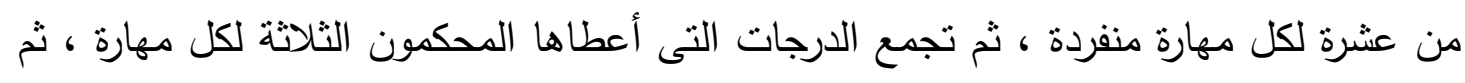
تحسب درجة الطالب فى كل مهارة من خلال حساب متوسط الدرجات التى اعطاها الدحكمون

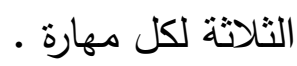

\section{1 - شروط اختيار الخبير :}

قام الباحث باختيار الخبراء البالغ عددهم ( r ا ) خبير الموضح بالمرفق رقم ( 1 ) وقد نم اختبار الخبرا وفقا للشروط الآتية : أ- أن يكون عضو هيئة تدريس بكلية التربية الرياضية بإحدى الأقسام الآتية :

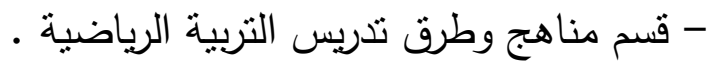

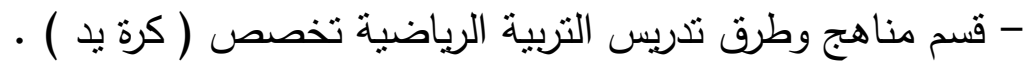
- قسم التدريب الرياضى تخصص مس ( كرة يد ) .

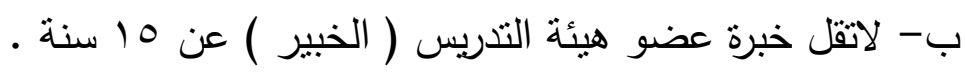

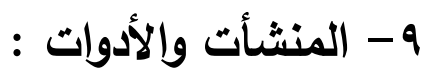

تم العصول على موافقة المعهد على استخدم الملعب والأداوت الموجودة بالمعهد من ملعب ،

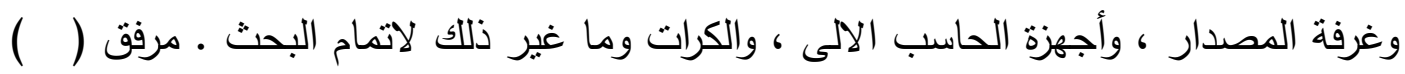

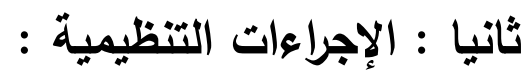

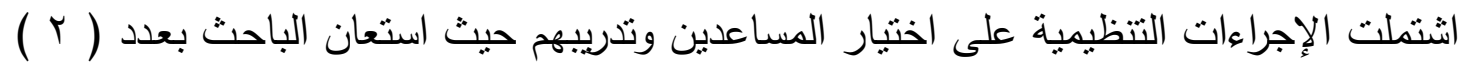
المدرسين من الزملاء فى العمل ، وذلك للمساعدة فى إجراء قياسات البحث ، وعقد الباحث عدة

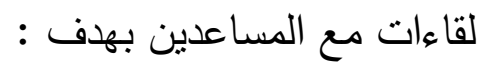
- شرح الهدف من البحث وتحديد القياسات المطلوبة . 
- التعرف على الأجهزة والأدوات وطريق استخدامها . - تحديد وترتيب القياسات والاختبارات .

\section{- اختبار مستوى التحصيل المعرفى : إعداد الباحث )}

قام الباحث بتصميم اختبار التحصيل المعرفى بهدف التعرف على قدر المعلومات والمعارف المرتبطة بالمهارات التدريسية الموجودة لدى طلبة عينة الدراسة الأساسية ( ن= • ؛ ) للمجموعة

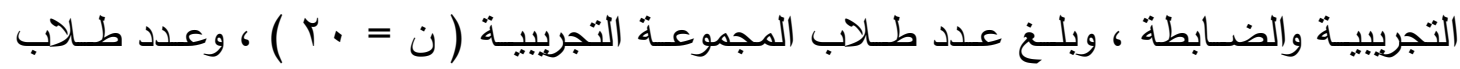
المجموعة الضابطة ( ن = • ب ) وذلك فى المهارات المختارة قبد البحث . - خطوات بناء الاختبار المعرفى :

قام الباحث بإعداد اختباراً معرفيا فى مهارات كرة اليد وقد تضمن هذا الاختبار ( تاريخ كرة اليد - مهارات كرة البد - قانون كرة اليد ) بعد الاسترشاد بخطوات بناء الاختبار المعرفى في الإطار النظرى وذلك كالآتي : - الني

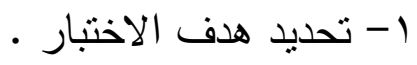

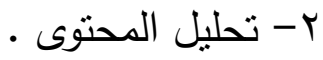

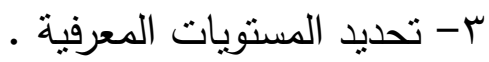
ع- تحديد المحاور الأساسية للاختبار • 0- ت ت تحديد وصياغة الفقرات .

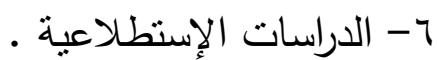

V- المعاملات العلمية للاختبار ( الصدق والثبات- معامل السهولة والصعوبة ومعامل التمييز )

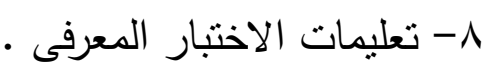
9- تحديد الوزن النسبى لأسئلة الاختبار •

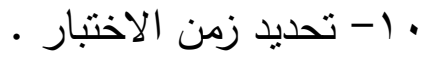
· - 11 - 11 - مفتاح تصحيح الاختبار

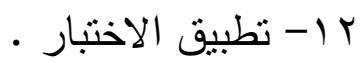


وفيما يلى توضيح لكل خطوة من خطوات تصميم الاختبار المعرفى : 1 - تحديد الهذف من الاختبار :

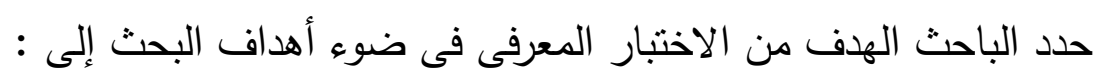

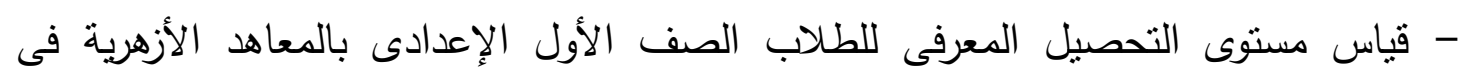

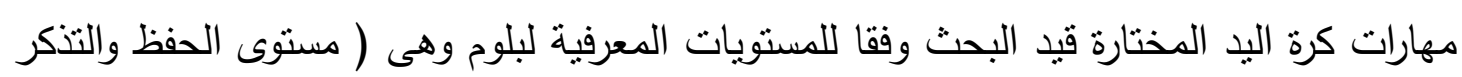
- مستوى الفهم والاستيعاب - مستوى التطبيق - ومستوى التحليل - ومستوى التركيب ) . - قياس الفرق بين تحصيل الطلاب فى المجموعة التجريبية ( التعليم باستخدام الكتاب الإلكترونى المعد من قبل الباحث ) وطلاب المجموعة الضابطة ( التعليم باستخدام الثرح

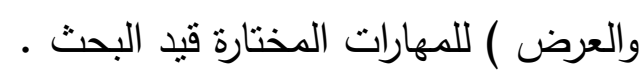

- قياس مستوى التحصيل المعرفى للمهارات المختارة قيد البحث لمنهاج كرة اليد من الناحية

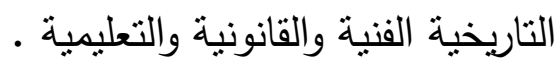

- التوصل إلى مدى فاعلية الكتاب الإلكترونى المعد من قبل الباحث فى التحصيل المعرفى . r- تحليل المحتوى :

تم تحليل المحتوى والدفاهيم فى منهاج كرة اليد المقرر على طلاب الصف الأول الإعدادى

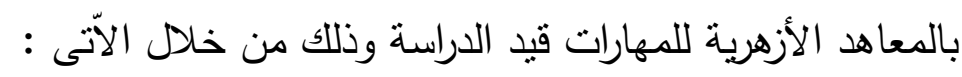

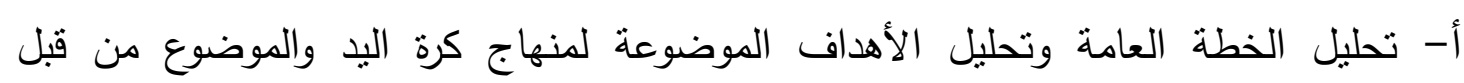
المتخصصين فى التعليم الأزهرى . ب- تحليل المراجع والكتب العلمية والأجنبية المتخصصة فئ مجال الاختبارات المعرفية وفى

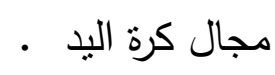
ج- تحليل الدراسات والبحوث العربية والاجنبية فى مجال الاختبارات المعرفية . r- تحليل المستويات المعرفية : بعد تحديد الإطار المعرفى الخاص بمهارات كرة اليد ، ومن خله القراءات النظرية فى المراجع والبحوث العلمية العربية والاجنبية التى تتاولت الجانب المعرفى ، وقام الباحث بتحديد المستويات المعرفية التى سوف يدور حولها الاختبار وهى منتثلة فى الأتى :

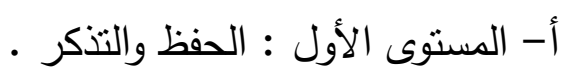

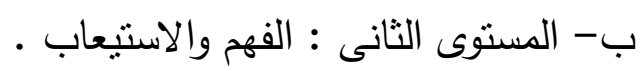

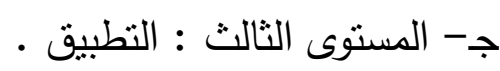


د- المستوى الرابع : مستوى التحليل .

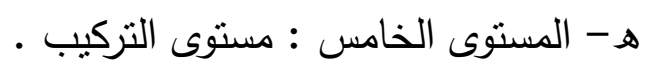

ز - المستوى السادس : مستوى التقويم •

وتم عرض تلك المحاور على عدد من الخبراء فى مجال المناهج وطرق التنريس وعددهم (

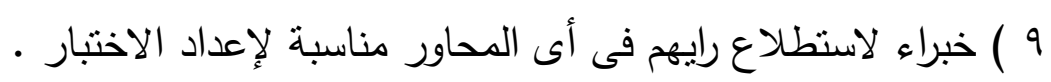

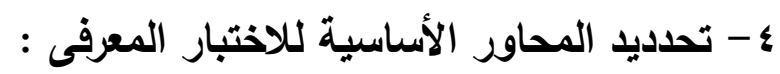

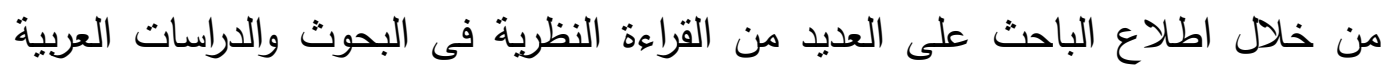

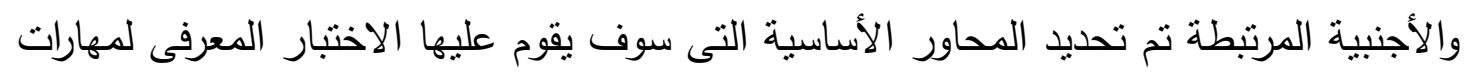

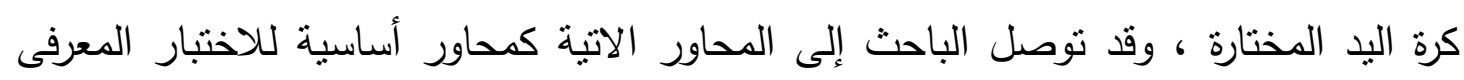

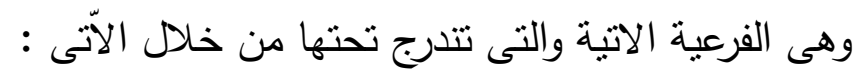
أ- الحفظ والتذكر : ويتضمن هذا المحور النقاط الآتية :

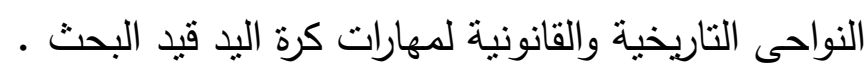
ب- الفهم والاستيعاب : ويتضمن هذا المحور النقاط الآتية :

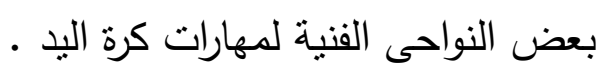
ج- التطبيق : ويتضمن هذا المحور النقاط الآتية :

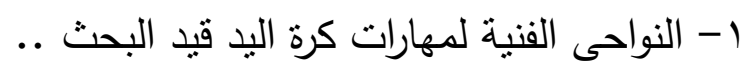

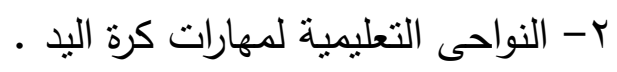

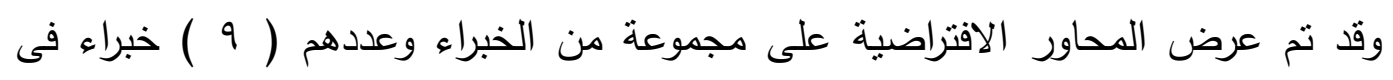

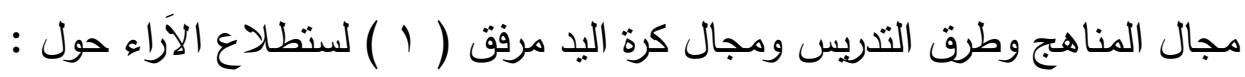
1- مدى كفاية المحاور •

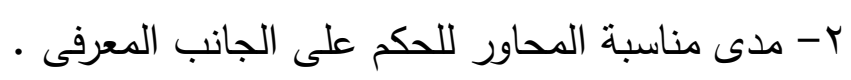

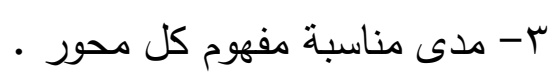

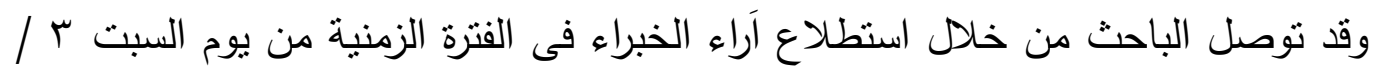

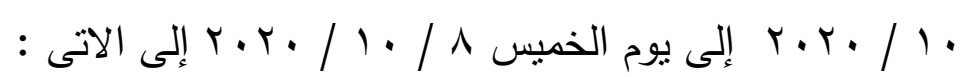

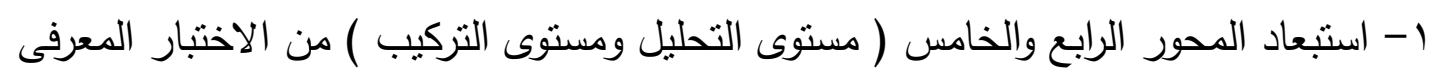

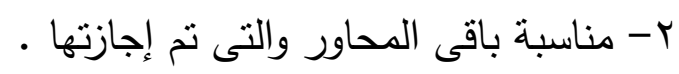

وبذلك توصل الباحث إلى أن الاختبار المعرفى مكون من ( r ) محاور أساسية وهذة المحاور هى كالآتى : توصلئ 
مسنوى الحفظ والتنكر - مستوى الفهم والاستيعاب - مستوى التطبيق ، والجدول الثالى يوضح ذلك :

\section{جدول (r I I)}

استجابة الخبراء على المستويات المقترحة للاختبار

\begin{tabular}{|c|c|c|c|c|c|}
\hline \multicolumn{2}{|c|}{ غير مناسب } & \multicolumn{2}{|c|}{ مناسب } & \multirow{2}{*}{ المستوى } & \multirow{2}{*}{ b } \\
\hline النسبة & العدد & النسبة & العدد & & \\
\hline$\%$. & · & $\% 1 \ldots$ & 9 & الحفظ والتذكر & المستوى الأول \\
\hline$\%$. & . & $\% 1 \ldots$ & 9 & الفهم والاستيعاب & المستوى الثاني \\
\hline$\% 11,11$ & 1 & $\% \wedge \wedge, \wedge ৭$ & $\wedge$ & التطبيق & المستوى الثالث \\
\hline$\% \vee \vee, \vee \wedge$ & V & $\% r r, r, r$ & r & التحليل & المستوى الرابع \\
\hline$\% \wedge \wedge, \wedge 9$ & $\wedge$ & $\% 11,11$ & 1 & التركيب & الخامستوى \\
\hline
\end{tabular}

يوضـح جدول(0) آراء الخبراء في المستويات المختلفة للاختبار ويتضـح من جدول (9) أن

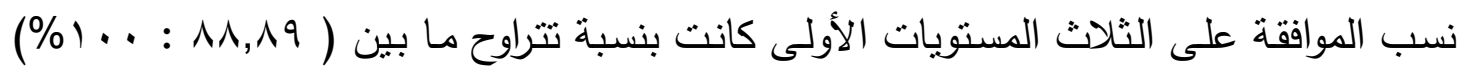
وهى أكبر من أقل نسبة معنوية ( مقبولة) والتي تم استخراجها من اختبار معنوية النسب والتي

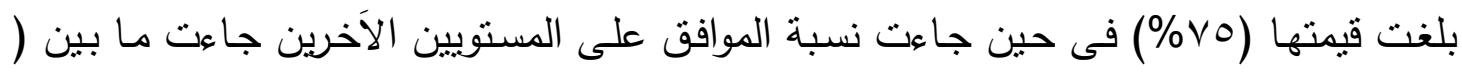

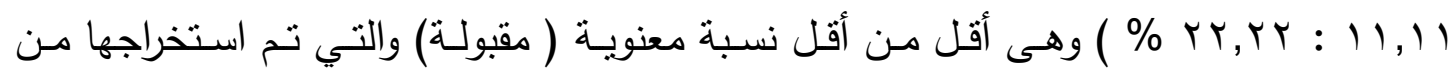
اختبار معنوية النسب والتي بلغت قيمتها (\%0\%) للك تم استبعداهما وعليه تقبل المستويات الثلاثة الأولى وتستبعد باقى المستويات . ه - تحديد وصياغة مفردات الاختبار : لصياغة العبارات اختار الباحث نوعان من الأسئلة وهى : أ- الإجابة بوضع صح أو خطأ : وقد اختار الباحث هذا النوع من الأسئلة لما يتوفر فيه من

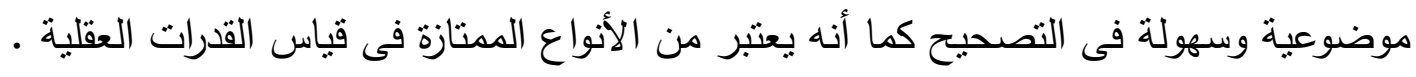
ب- الاختيار من متعدد : وقد اختار الباحث هذا النوع من الاسئلة لما يتوفر فيه من موضوعية

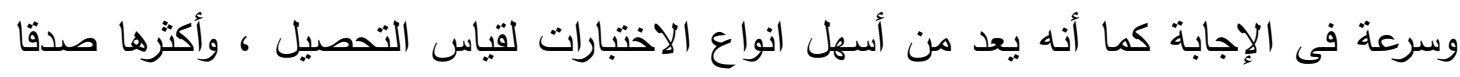

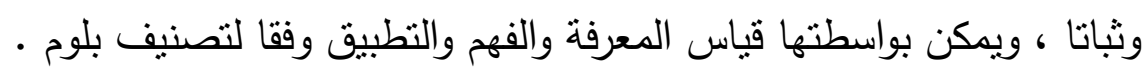




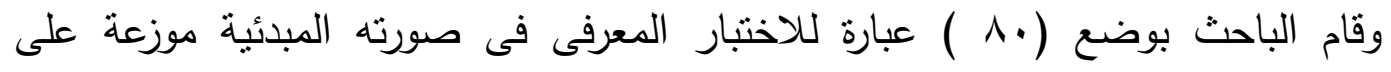

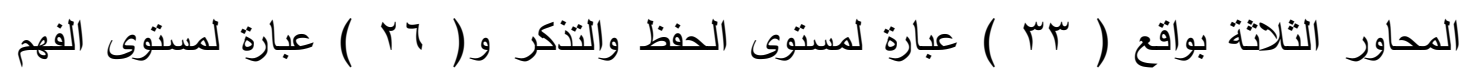
والاستيعاب و ( Y ) عبارة لمستوى التطبيق وتم عرض العبارات على مجموعة من الخبراء عددهم ( 9 ) خبراء فى مجال كرة اليد ومجال طرق التدريس للتأكد من صلاحية الاختبار

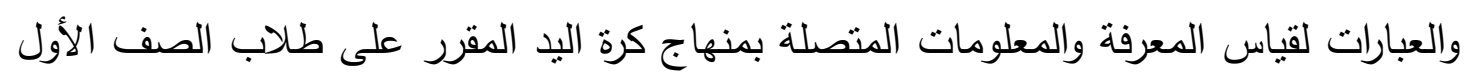

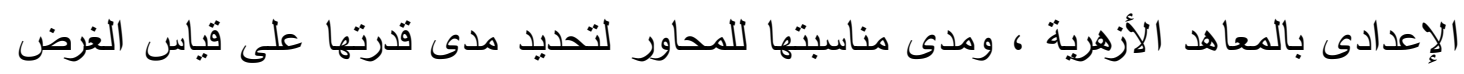

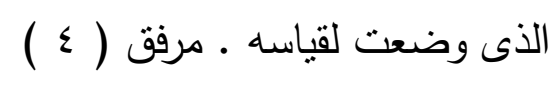

وقد قام الباحث بوضع عبارات الاختبار المعرفى فى صورتها المبدئية وتتكون من ( • ( ) )

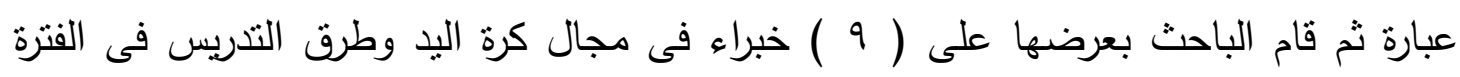

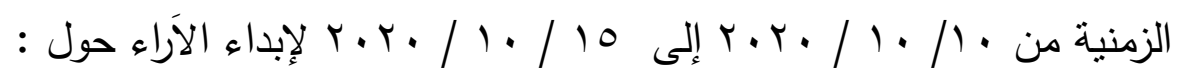

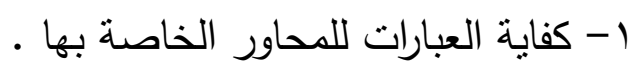
r- درجة مناسبة صياغة العبارات لعينة البحث . وقد نوصل الباحث إلى مناسبة أغلب عبارات الاختبار المعرفى من حيث طرق صياغتها

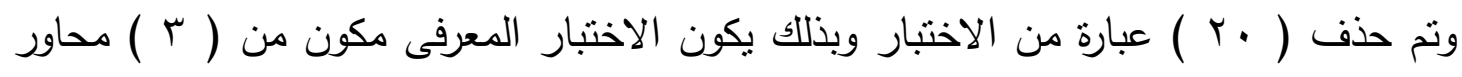

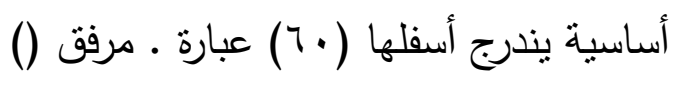

- الاراسة الاستطلاعية : الدراسة الاستطلاعية : ( إيجاد المعاملات العلمية للاختبار ) : :

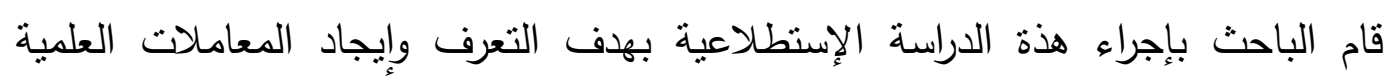

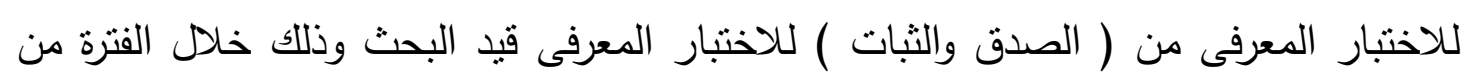

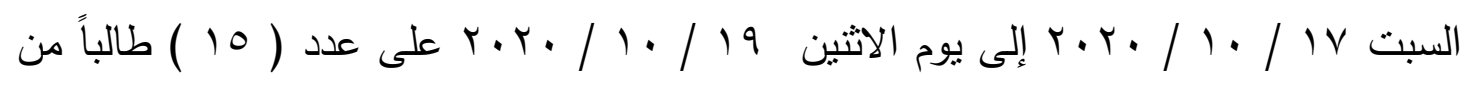
طلاب الصف الأول الإعدادى بمجمع بدر الأزهرى والتابع لإدارة المراغة الأزهرية بمحافظة الإنة

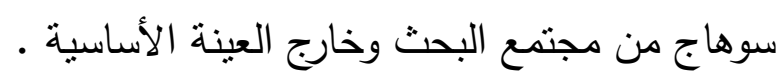

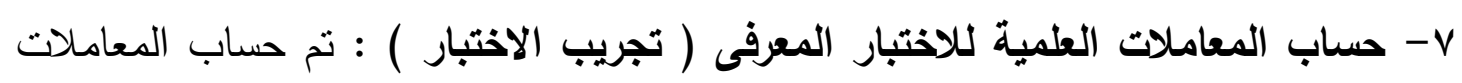

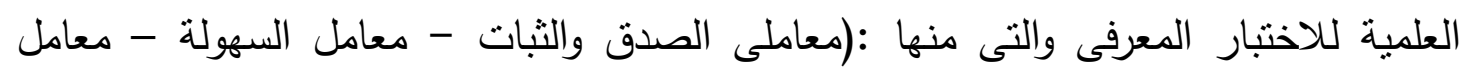

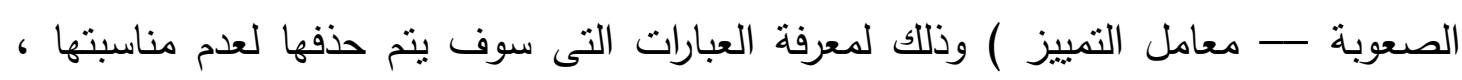

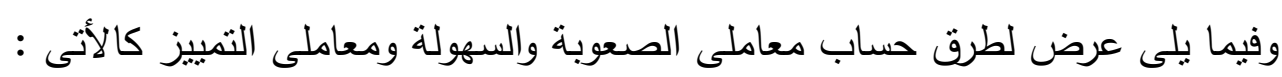
أولا: الصدق : الصى عرض 
قام الباحث بحسـاب كل مـن الصدق المنطقى بـالعرض على السـادة الخبراء ثم صـدق الاتساق الداخلى بحساب معامل الارتباط بين الأسئلة ومجموع المستوى الذى تقع بـه والأسئلة ومجموع الاختبار ككل والمستويات وإجمالى الاختبار •

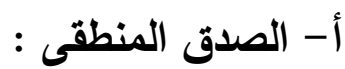

حيث تم عرض الاستمارة على عدد ( 9 ) من الخبراء فى مجال كرة اليد وطرق التدريس بكلية التربية الرياضية للبنين - جامعة حلوان مرفق ( 1 ) ، وقد أثنار الخبراء على أن الاختبار صادق ويقيس الجوانب المختلفة التى وضع من أجلها ، ويتضح ذلك من الجدول رقم ( 14 ) مع استبعاد العبارات أو الأسئلة التى لم يوافق عليها الخبراء، وكانت النتائج كالاتى :

$$
\text { جدول (T) }
$$

استجابة الخبراء على أسئلة الاختبار المعرفى (1)

\begin{tabular}{|c|c|c|c|c|c|c|c|}
\hline نسبة الاتفاق & رقم السؤال & نسبة الاتفاق & رقم السؤال & نسبة الاتفاق & رقم السؤال & نسبة الاتفاق & رقم السؤال \\
\hline$\% \wedge \wedge, \wedge q$ & 91 & $\% \vee \vee, \vee \wedge$ & $\leqslant 1$ & 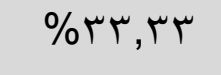 & YI & \multicolumn{2}{|c|}{ المستوى الأول : الحفظ والتذكر } \\
\hline$\% \wedge \wedge, \wedge q$ & $7 r$ & $\% \wedge \wedge, \wedge q$ & $\varepsilon r$ & $\% \vee \vee, \vee \wedge$ & $r Y$ & $\% \vee \vee, \vee \wedge$ & 1 \\
\hline$\% \leq \varepsilon, \varepsilon \leq$ & Tr & $\% \leq \varepsilon, \varepsilon \varepsilon$ & $\varepsilon r$ & $\% \vee \wedge \% \vee \vee$ & $r r$ & $\% \vee \vee, \vee \wedge$ & r \\
\hline$\% \vee \vee, \vee \wedge$ & $7 \varepsilon$ & $\% \wedge \wedge, \wedge q$ & $\leqslant \varepsilon$ & $\% \leq \varepsilon, \leqslant \leq$ & $r \varepsilon$ & $\% \vee \vee, \vee \wedge$ & $\mu$ \\
\hline$\% \vee \vee, \vee \wedge$ & 70 & $\% \wedge \wedge, \wedge q$ & $\leq 0$ & $\% \wedge \wedge, \wedge q$ & ro & $\% \leq \leqslant, \leqslant \leqslant$ & $\varepsilon$ \\
\hline$\% \wedge \wedge, \wedge q$ & 79 & $\% 1 \ldots$ & $\leqslant 7$ & $\% \vee \vee, \vee \wedge$ & Y & $\% \wedge \wedge, \wedge q$ & 0 \\
\hline$\% 1 \ldots$ & $7 V$ & $\% 1 \ldots$ & $\leqslant V$ & $\% \leq \leq, \leq \leq$ & YV & $\% \wedge ৭ \% \wedge \wedge$ & 9 \\
\hline$\% 1 \ldots$ & 71 & $\% \wedge \wedge, \wedge \uparrow$ & $\leqslant \wedge$ & $\% 1 \ldots$ & YA & $\% 1 \ldots$ & v \\
\hline$\% 00,07$ & 79 & $\% \leq \varepsilon, \leqslant \varepsilon$ & $\leqslant 9$ & $\% 1 \ldots$ & rq & $\% 1 \ldots$ & $\Lambda$ \\
\hline$\% \vee \vee, \vee \wedge$ & $V \cdot$ & $\% \vee \vee, \vee \wedge$ & o. & $\% \leq \leq, \leq \leq$ & $\mu$ & سז, & 9 \\
\hline$\% \wedge \wedge, \wedge q$ & VI & سז,rr\% & 01 & $\% 1 \ldots$ & r & $\% 00,07$ & 1. \\
\hline$\% \wedge \wedge, \wedge q$ & Vr & $\% \wedge \wedge, \wedge q$ & or & $\% \wedge \wedge, \wedge q$ & rr & $\% 1 \ldots$ & 11 \\
\hline$\% 1 \ldots$ & VY & $\% \wedge \wedge, \wedge q$ & or & $\% \wedge \wedge, \wedge q$ & 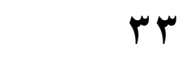 & $\% \wedge \wedge, \wedge q$ & ir \\
\hline$\% \leq \varepsilon, \varepsilon \leq$ & $V \leq$ & $\% 1 \ldots$ & $0 \leq$ & لفهم والاستيعاب & المستوى الثان & $\% \wedge \wedge, \wedge q$ & ir \\
\hline$\% \vee \vee, \vee \wedge$ & Vo & \%r,r & 00 & $\% \wedge \wedge, \wedge ৭$ & r & $\% \wedge \wedge, \wedge ৭$ & $1 \varepsilon$ \\
\hline$\% \vee \vee, \vee \wedge$ & V & $\% \wedge \wedge, \wedge q$ & 07 & $\% 1 \ldots$ & ro & \%rr,r & 10 \\
\hline$\% 00,07$ & $V V$ & $\% \vee \vee, \vee \wedge$ & ov & $\% \leq \varepsilon, \varepsilon \leq$ & rq & $\% \leq \varepsilon, \leq \varepsilon$ & 17 \\
\hline
\end{tabular}




\begin{tabular}{|c|c|c|c|c|c|c|c|}
\hline$\% \wedge \wedge, \wedge ৭$ & $\vee \wedge$ & $\% \wedge \wedge, \wedge q$ & $\Delta \wedge$ & $\% \wedge \wedge, \wedge ৭$ & rv & $\% \wedge \wedge, \wedge q$ & iv \\
\hline$\% 1 \ldots$ & $\vee q$ & $\% 1 \ldots$ & 09 & $\% \wedge \wedge, \wedge q$ & $\mu \wedge$ & $\% 1 \ldots$ & 11 \\
\hline$\% 1 \ldots$ & $\Lambda$. & \multicolumn{2}{|c|}{ المستوى الثالث : التطبيق } & $\% \leq \varepsilon, \leq \leq$ & rq & $\% 1 \ldots$ & 19 \\
\hline -------- & ------- & $\% 1$. & 7. & $\% 1 \ldots$ & $\varepsilon$. & $\% \leq \varepsilon, \leq \leq$ & $r$ \\
\hline
\end{tabular}

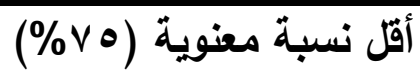

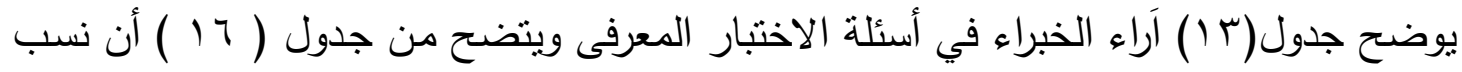

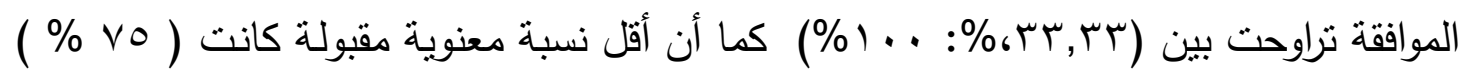

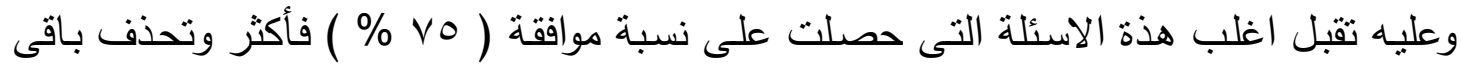

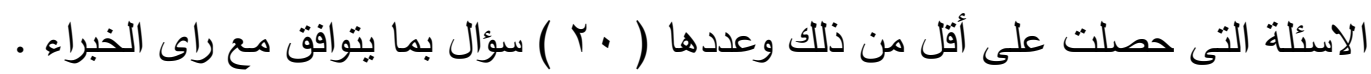

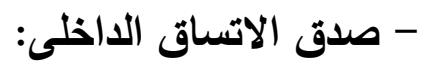
بعد حساب الصدق المنطقي عن طريق العرض على الخبراء سيتم حساب صدق الاتساق الداخلي قام الباحث بحساب صدق الاتساق الداخلى من خلال تطبيق الاختبار على عينة استطلاعية من طلاب الصف الأول الإعدادى بمعهة بدر الأزهرى والبالغ عددها ( 10 (1) ) طالباً

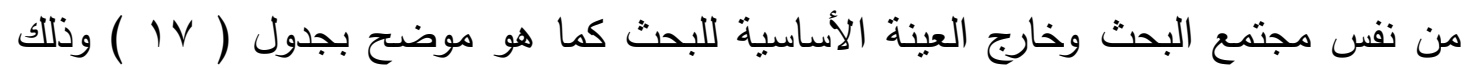

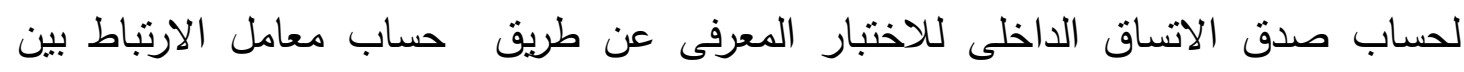

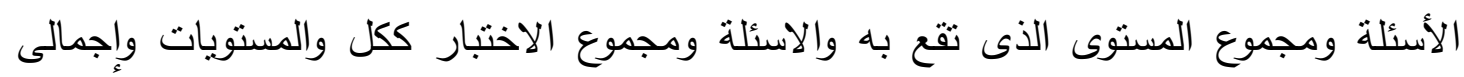

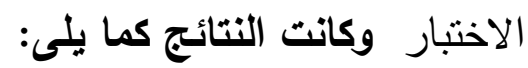

\section{جدول (ع أ)

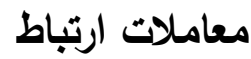

أسئلة الاختبار بمجموع المستوى المنتمية اليه ومجموع الاختبار ككل

ن $10=$

\begin{tabular}{|c|c|c|c|c|c|c|c|c|c|c|c|}
\hline ر & لم & السؤال & ¿ر & لم & السؤال & ر & لم & السؤال & ر & لم & السؤل \\
\hline$\cdot, \leqslant 9$ & $\cdot, \leqslant V$ & $\varepsilon 7$ & $\cdot, V V$ & $\cdot \cdot, V T$ & ו ו &., 07 & $\cdot, 71$ & 17 & \multicolumn{3}{|c|}{ الحفظ والتذكر } \\
\hline$\cdot, \leqslant \leqslant$ & •, & $\varepsilon V$ & .,or & $\cdot, \leqslant 9$ & Tr &., 07 & $\cdot, 0 \leqslant$ & IV & $\cdot, 7$. & $\cdot, \varepsilon V$ & 1 \\
\hline$\cdot, 0 \mathrm{~V}$ & $\cdot, \leqslant 9$ & $\varepsilon \wedge$ & $\cdot, \leqslant 1$ & $\cdot, r V$ & س & $\cdot, \Sigma T$ & $\cdot, \Sigma$ & 11 & $\cdot$, Or & $\cdot, 79$ & $r$ \\
\hline., 79 & $\cdot, \vee \vee \leqslant$ & $\leqslant 9$ &., 09 &., 70 & TE & $\cdot, \wedge 7$ & $\cdot, \lambda r$ & 19 & $\cdot, \leqslant V$ & • & $r$ \\
\hline$\cdot, 7 \mathrm{~V}$ & $\cdot, 7 \leq$ & 0. & $\cdot, \varepsilon$ & • & ro &., 01 & $\cdot, 7$ & $r$. & $\cdot, \varepsilon \leqslant$ & $\cdot, \Sigma V$ & $\varepsilon$ \\
\hline$\cdot, 7 \mathrm{~V}$ & $\cdot, V \cdot$ & 01 & $\cdot, 7$ & $\cdot, 7 V$ & דr & $\cdot, V \leq$ & $\cdot, V Y$ & YI & $\cdot, \vee \vee q$ & $\cdot, \wedge$. & 0 \\
\hline., 09 & $\cdot, 71$ & or & $\cdot, \sum \wedge$ &., 00 & rv &., 79 & $\cdot, V \cdot$ & rr & $\cdot, 0$ & $\cdot, \varepsilon \leqslant$ & 7 \\
\hline
\end{tabular}




\begin{tabular}{|c|c|c|c|c|c|c|c|c|c|c|c|}
\hline$\cdot, \leqslant V$ & $\cdot, \leqslant 9$ & or & ., & $\cdot, \leq r$ & r人 &., 7 . &., $0 Y$ & rT & $\cdot, \pi r$ &., 0 & V \\
\hline., 01 & $\cdot, 79$ & $0 \leqslant$ & $\cdot, 7 \leq$ &., $0 \mathrm{~V}$ & rq & \multicolumn{3}{|c|}{ الفهم والاستيعاب } &., 01 & $\cdot, \leqslant \wedge$ & $\Lambda$ \\
\hline$\cdot, 71$ & $\cdot, 79$ & 00 &., 09 & $\cdot, 77$ & $\varepsilon$. &., 09 & $\cdot, 0 \leqslant$ & $r \varepsilon$ & $\cdot, 77$ & $\cdot, V \vee$ & 9 \\
\hline$\cdot, V V$ & $\cdot, \wedge 1$ & 07 & $\cdot, 71$ & $\cdot, 7 \wedge$ & $\leqslant 1$ & $\cdot, r q$ &., 0 & ro & $\cdot, \sum \wedge$ &., $0 Y$ & 1. \\
\hline$\cdot, 79$ & $\cdot, \vee \vee 7$ & OV & $\cdot, 79$ & $\cdot, V_{1}$ & $\varepsilon r$ &., 01 & ת & rT &., 01 & سד, . & 11 \\
\hline$\cdot, 70$ & $\cdot, \vee \wedge$ & 01 & $\cdot, 0 \leqslant$ &., 09 & $\varepsilon r$ & $\cdot, \leqslant V$ & $\cdot, \sum \wedge$ & TV &., 00 & $\cdot, \leqslant 9$ & IT \\
\hline., 01 & $\cdot, \leqslant 7$ & 09 & \multicolumn{3}{|c|}{ مستوى التطبيق } &., 79 & $\cdot, \vee q$ & $r \wedge$ & $\cdot, \Sigma V$ & $\cdot$, or & 14 \\
\hline$\cdot, 7 \leqslant$ & $\cdot, 09$ & 7. & $\cdot, 77$ & $\cdot, 71$ & $\varepsilon \varepsilon$ & $\cdot, \leqslant 9$ & $\cdot, r q$ & rq & מד, • & $\cdot, \Sigma \varepsilon$ & $1 \leq$ \\
\hline--- & ---- & ------ & $\cdot, V_{1}$ & $\cdot, V V$ & $\leqslant 0$ &., 0 & $\cdot, 7$. & $r$. & $\cdot, V \varepsilon$ & $\cdot, V_{1}$ & 10 \\
\hline
\end{tabular}

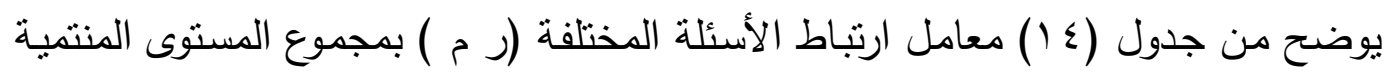

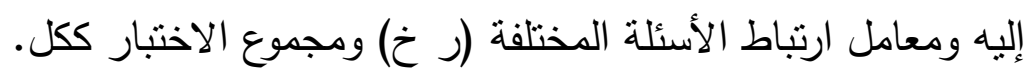

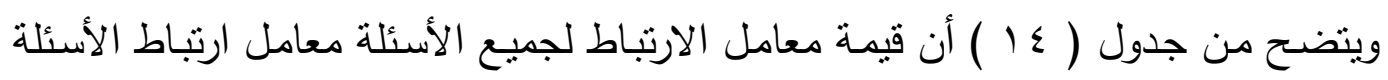

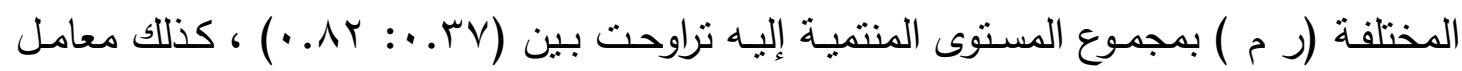

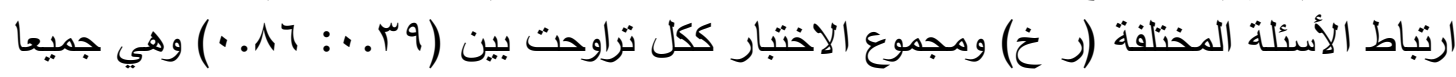

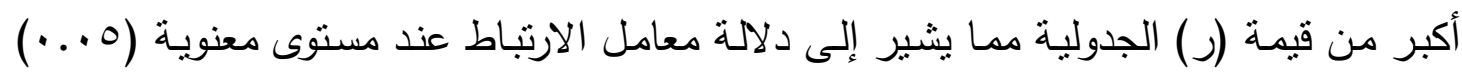
ويشير إلى صدق انساق وانتماء هذه الأسئلة لمستوياتها وللاختبار ككل. جدول (10)

معاملات ارتباط مستويات الاختبار ومجموع الاختبار ككل

$10=\dot{0}$

\begin{tabular}{|c|c|c|}
\hline النسبة & المستوى & 5 \\
\hline$\cdot . \wedge \vee$ & الحفظ والتذكر & المستوى الأول \\
\hline. .19 & الفهم والاستيعاب & المستوى الثاني \\
\hline.$\wedge \varepsilon$ & التطبيق & المستوى الثالث \\
\hline
\end{tabular}

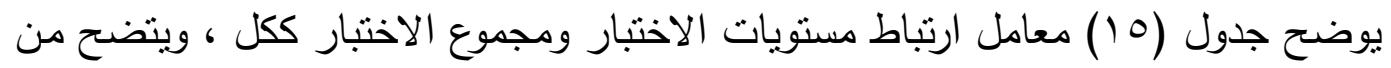

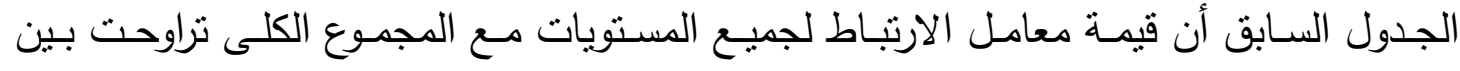

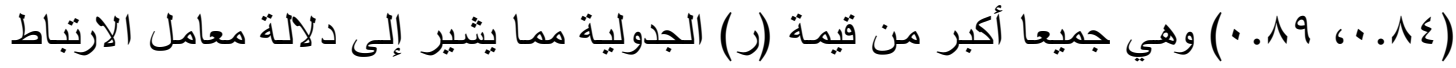
عند مستوى معنوية (0. . ·) ويثير إلى صدق اتساق وانتماء هذه المستويات للاختبار ككل. 
قام الباحث قام بحساب معامل ثبات الاختبار بطريقة إعادة تطبيق الاختبار وذلك بحساب ثبات القائمة باستخدام طريقتى الفا كرونباخ والتجزئة النصفية.

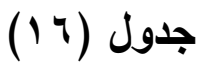
قيم معاملات ألفا كرونباخ والتجزئة النصفية لمستويات الاختبار والاختبار ككل $10=\dot{0}$

\begin{tabular}{|c|c|c|c|}
\hline التجزئة النصفية & كرونباخ الفا & المستوى & r \\
\hline.$\wedge \mathrm{V}$ &..$\wedge \wedge$ & الحفظ والتذكر & المستوى الأول \\
\hline .119 &.$\wedge 1$ & الفهم والاستيعاب & المستوى الثاني \\
\hline.$\wedge V$ & $\because 9$. & التطبيق & المستوى الثالث \\
\hline$\cdot .9$. &. $.9 r$ & الاختبار ككل & الاختبار ككل \\
\hline
\end{tabular}

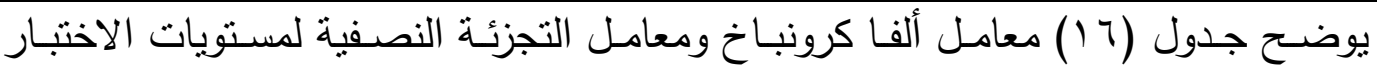

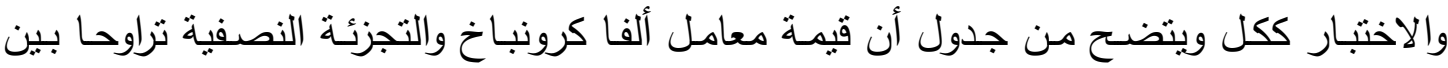

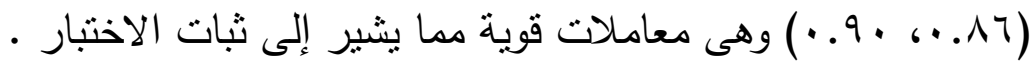

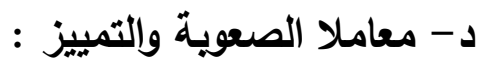

أ- معاملا السهولة والصعوية : Difficulty and Easiness Index

قام الباحث يإيجاد معاملى السهولة والصعوبة للاراسة الاستطلاعية على عينة من الطلاب

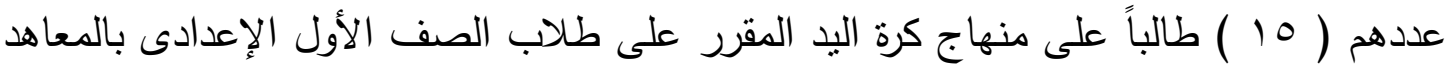

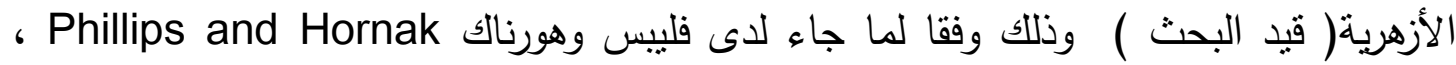
وذلك طبقا للمعادلة التالية ، وذلك طبقا للمعادلة التالية : عدد الأفراد الذين أجابوا إجابة صحيحة على كل مفردة

$$
\text { أ- معامل السهولة = }
$$

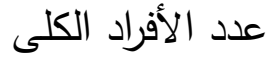

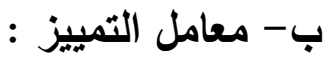

قام الباحث بحساب معامل التمييز وذلك للتمييز بين أفراد العينة فى المستوى المعرفى وذلك

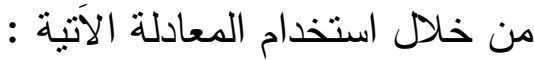
عدد الإجابات الصحيحة فى الهجوعة العليا - عدد الإجابات الصحيحة فى السفلى 


\section{جدول (IV)}

معاملات الصعوية والتميز لأسئلة الاختبار المعرفى (IV

$10=\dot{0}$

\begin{tabular}{|c|c|c|c|c|c|c|c|c|c|c|c|}
\hline التمييز & الصعوي. & السؤال & التمييز & الصعوي & السؤال & التمييز & الصعوي & السؤال & التمييز & الصعوية & السؤال \\
\hline$\cdot, 09$ & $\cdot, 0 \leq$ & $\leqslant 7$ &., 07 & $\cdot, 07$ & I & $\cdot, \leqslant \wedge$ & $\cdot, 00$ & 17 & \multicolumn{3}{|c|}{ الحفظ والتنكر } \\
\hline$\cdot, 7 \varepsilon$ & $\cdot, \leqslant 9$ & $\varepsilon V$ &., 09 & $\cdot, 01$ & rr & $\cdot, \leq 7$ & $\cdot, \Sigma \Lambda$ & IV & $\cdot, T V$ & $\cdot, r q$ & 1 \\
\hline$\cdot, \leqslant \vee$ & $\cdot, \varepsilon \Gamma$ & $\varepsilon \wedge$ & $\cdot, 0 \wedge$ & $\cdot, \leqslant V$ & Tr & •, Tr & $\cdot, 07$ & 11 & .,$\varepsilon r$ & $\cdot, \varepsilon \leqslant$ & $r$ \\
\hline$\cdot, 0 \leqslant$ & $\cdot, \leqslant V$ & $\leqslant 9$ & $\cdot, \leqslant V$ & $\cdot, \leqslant \wedge$ & rs & $\cdot, 7 \wedge$ & $\cdot, 7 \leq$ & 19 & $\cdot, 7 V$ & $\cdot, \Sigma \vee$ & r \\
\hline$\cdot, \leqslant 9$ & $\cdot, 71$ & 0. & $\cdot, 77$ & $\cdot, \leqslant \Lambda$ & ro & $\cdot, 7 \wedge$ & $\cdot, 7$ & $r$. &., 00 &., 01 & $\varepsilon$ \\
\hline$\cdot, 7$ & $\cdot$, or & 01 & $\cdot, 01$ & $\cdot, \leqslant \Lambda$ & דץ & $\cdot, 7$ &., 07 & YI & $\cdot, \leqslant \wedge$ & $\cdot, \leqslant V$ & 0 \\
\hline$\cdot, 7 \leqslant$ & $\cdot, 0$ & or & $\cdot, 0$ & $\cdot, 0$ & rv & $\cdot, 09$ & $\cdot, \leqslant 9$ & rt & $\cdot, \leqslant \wedge$ & $\cdot, \varepsilon$. & 7 \\
\hline$\cdot, 7 V$ & $\cdot, 0$ & or & $\cdot, 0 \wedge$ & $\cdot, 01$ & r &., 70 & $\cdot, 0 \wedge$ & r & י & $\cdot, o r$ & V \\
\hline$\cdot, 0 Y$ & $\cdot, 07$ & $0 \leq$ & $\cdot, 07$ & $\cdot$, or & rq & \multicolumn{3}{|c|}{ الفهم والاستيعاب } & $\cdot, 7 \pi$ & $\cdot, \leqslant\rceil$ & $\wedge$ \\
\hline$\cdot, 0$ & $\cdot, 0 \leq$ & 00 & $\cdot, 77$ & $\cdot, 71$ & $\varepsilon$ & $\cdot, 0 \wedge$ & $\cdot, \leqslant \wedge$ & $r \varepsilon$ & $\cdot, \leqslant \vee$ & $\cdot, \Sigma \Gamma$ & 9 \\
\hline$\cdot, 0 \mathrm{~V}$ & $\cdot$, or & 07 & $\cdot, 7$ & $\cdot, 09$ & $\varepsilon 1$ & $\cdot, \leq 9$ & • & ro & $\cdot, 7$. & $\cdot, \leqslant 9$ & 1. \\
\hline . & $\cdot, \mathrm{OV}$ & ov & $\cdot, 71$ & $\cdot, 09$ & $\sum r$ & $\therefore, \leqslant 9$ & $\cdot, 09$ & ru & $\cdot, 09$ & $\cdot, o r$ & 11 \\
\hline$\cdot, 07$ & $\cdot, \Sigma V$ & $0 \wedge$ & $\cdot, \leqslant \wedge$ & $\cdot, 7$ & $\varepsilon r$ & $\cdot, 77$ & $\cdot, 7 \varepsilon$ & rV & $\cdot, 0 \leqslant$ & $\cdot, 0$ & Ir \\
\hline$\cdot, \leqslant 9$ & $\cdot, \leq 9$ & 09 & \multicolumn{3}{|c|}{ مستوى التطبيق } & $\cdot, 7$ & $\cdot, \leqslant \vee$ & rᄉ & $\cdot, \leq 9$ & $\cdot, 7$ & 14 \\
\hline$\cdot, 77$ & $\cdot, 01$ & 7. & $\cdot, 04$ & $\cdot, 7 \leq$ & $\varepsilon \varepsilon$ & $\cdot, 7 r$ & $\cdot, \Sigma V$ & rq & $\cdot, 00$ & $\cdot, \leq 7$ & $1 \varepsilon$ \\
\hline--- & ---- & ----- & $\cdot, 0 \mathrm{~V}$ & $\cdot, 0 \leqslant$ & $\leq 0$ &., 70 & $\cdot$, Or & $r$. & $\cdot, 0 \mathrm{~V}$ & $\cdot$, or & 10 \\
\hline
\end{tabular}

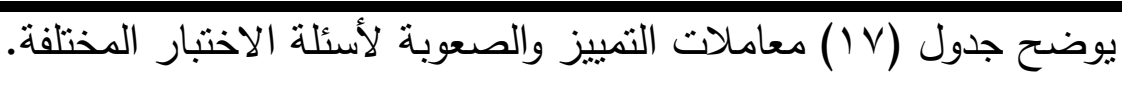

ويتضح من جدول ( V ) أن قيمة معامل التمييز للاختبار المعرفى تراوحت بين ( rع . ،

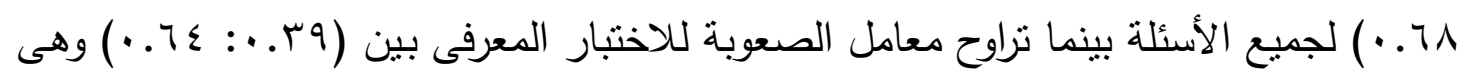

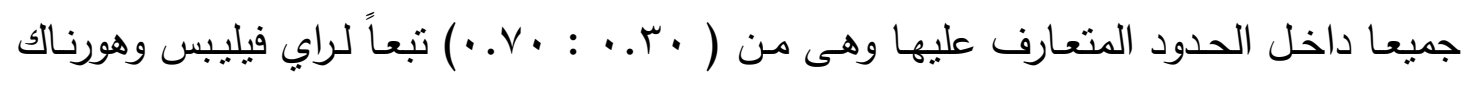
وعليه فان الاختبار يمتاز بقدرته على التمييز وكذللك يمتاز بمعامل (Philips \& Hornak)

صعوبة مقبول.

وبذلك أصبح عدد عبارات الاخنبار المعرفى ( 7 ) سؤلا موزعة على المحاور كالآتى : ا- مستوى الحفظ والتذكر : ( س ) عبارة . 


$$
\begin{aligned}
& \text { r- مستوى الفهم والاستيعاب : ( ) عبارة . }
\end{aligned}
$$

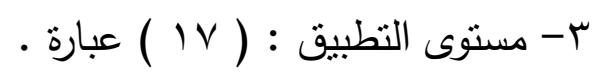

كما أسفرت نتيجة تطبيق الاختبار على ملائمة الاختبار لمستوى الطلاب من حيث المستوى

\section{9- تعليمات الاختبار :}

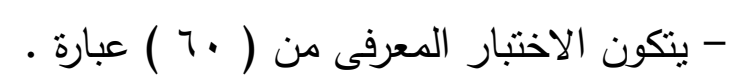
- يطبق الاختبار على طلاب الصف الأول الإعداد بمعهد بدر الأزهرى التابع لإدارة المراغة

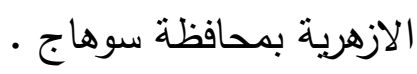

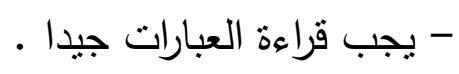

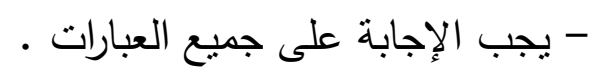
- وضع أكثر من علامة على سؤال واحد يلغى درجة هذا السؤال .

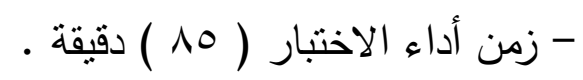

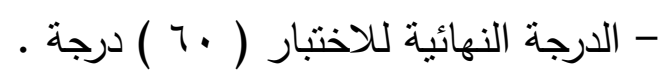

\section{ـ 1 - تحديد الوزن النسبى للاختبار :}

بعد تحليل المهارت الموضوعة داخل الكتاب الإلكترونى المختارة فى كرة اليد قيد البحث

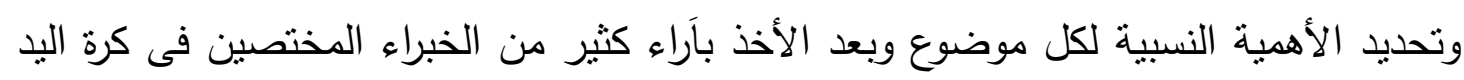
وطرق التدريس وبعد تطبيق الاختبار على عينة استطلاعية نتج التوزيع التالى لأسئلة الاختبار

$$
\text { المعرفى وهو الوارد فى الجداول الآتية : }
$$

\begin{tabular}{|c|c|c|c|c|c|}
\hline النسبة & التطبيق & النسبة & الفهم والاستيعاب & النسبة & حفظ وتذكر \\
\hline$\%$ rA, r & iv & سז, سז \% & $r$. & \% rی,rr & r \\
\hline
\end{tabular}

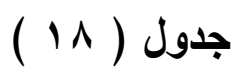

يوضح توزيع عدد الأسئلة فى كل محور من المحاور الرئيسية الثلاث

يوضح جدول ( 11 ) عدد الأسئلة فى كل مستوى من المستويات المعرفية للاختبار حيث

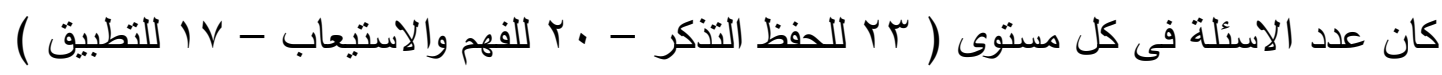




\section{1 - تحديد زمن الاختبار :}

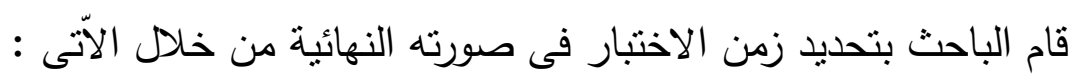

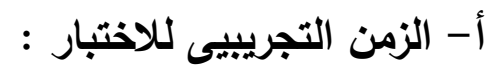

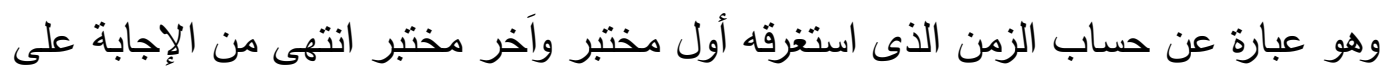

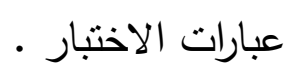

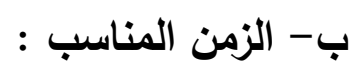

تم حساب الزمن المناسب للاختبار من خلال جمع الزمن الذى استغرقه أول مختبر من

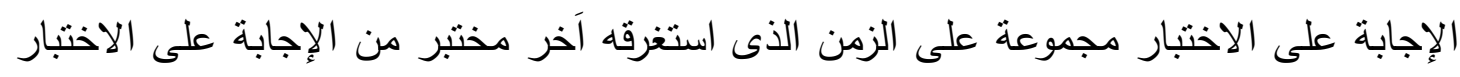

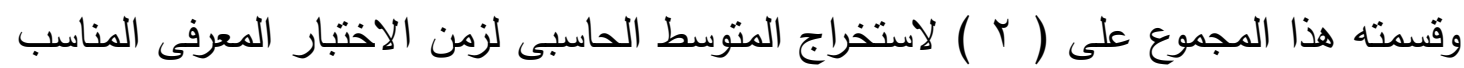
وذللك كما هو موضح فى الجدول التالى :

\begin{tabular}{|c|c|c|c|c|}
\hline \multirow[t]{2}{*}{ الزمن المناسب } & \multirow[t]{2}{*}{ المجموع } & \multicolumn{2}{|c|}{ الزمن التجريبيى للاختبار } & \multirow[t]{2}{*}{ زمن الاختبار } \\
\hline & & اجابة اخر مختبر & اجابة اول مختبر & \\
\hline 10 دقيقة & r / V دقيقة r r & ه و دقيقة & ^ 1 دقيقة & زمن الاختبار \\
\hline
\end{tabular}

\section{جدول (19 (19)}

زمن تطبيق الاختبار المعرفى فى صورتة النهائية

يتضح من جدول ( 19 ) أن المتوسط الحسابى لزمن الإجابة على أسئلة الاختبار المعرفى فى

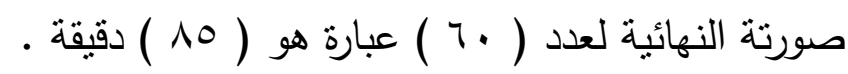

$$
\text { : } 11
$$

قام الباحث بالاطلاع على المراجع العربية والأجنبية والدراسات السابقة العربية والأجنبية واستطلاع آراء الخبراء للتعرف على الإجابة النموذجية الخاصة بكل سؤال من أسئلة الاختبار

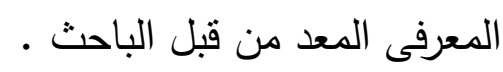

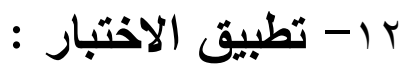

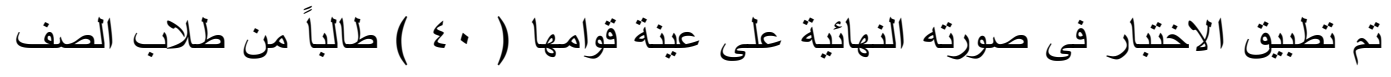

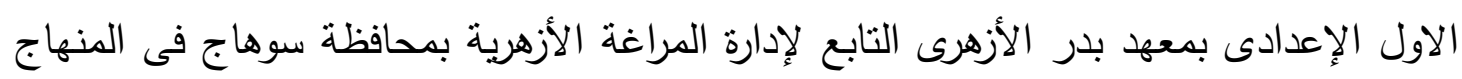

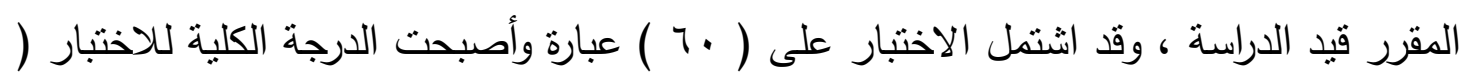


• 7 ) درجة بمعدل درجة واحدة لكل سؤال ، وبذللك يحتوى الاختبار على ثلاث محاور ودرجاتهم كالآتى :

$$
\begin{aligned}
& \text { - مستوى الحفظ والتذكر ودرجتة ( r ) درجة . } \\
& \text { - مستوى الفهم والاستعاب ودرجتة ( • r ) درجة . } \\
& \text { - مستوى التطبيق ودرجتة ( V ) درجة . }
\end{aligned}
$$

وقد تم تطبيق الاختبار المعرفى فى صورته النهائية على عينة البحث المختارة خلال الفترة

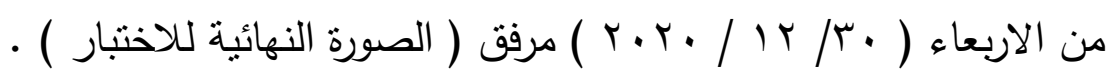

\section{- إعداد ويناء وحدات الكتاب الإلكترونى التعليمى :}

يهدف البحث الحالى فى التعرف على فاعلية كتاب إلكترونى فى كرة اليد لطلاب الصف

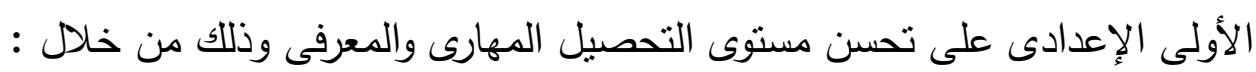
1- إعداد كتاب إلكترونى فى كرة اليد للصف الأول الإعدادى الأزهرى .

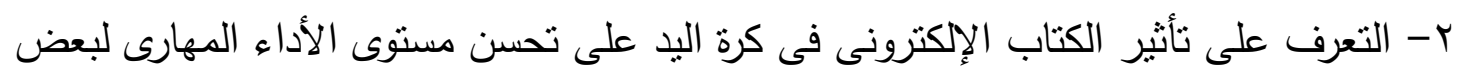
مهارت كرة اليد .

r- التعرف على ثأثثر الكتاب الإكترونى فى كرة اليد على تحسن مستوى التحصيل المعرفى فى حلى كرة اليد.

\section{- هدف وحدات الكتاب الإلكترونى :}

يهدف استخدام الكتاب الإككترونى إلى تحسين مستوى الأداء المهارى ومستوى التحصيل المعرفى فى بعض مهارات كرة اليد المقرة على طلاب الصف الأول الإعدادى بالمعاهد الأزهرية .

وقد اعتمد الباحث فى بناء وإعداد الكتاب الإلكترونى على المصادر النالية :

- البحوث والدراسات السابقة .

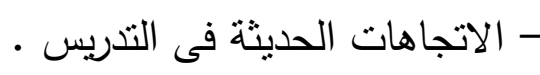

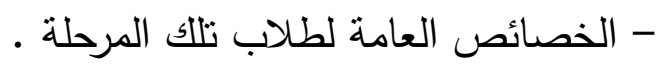

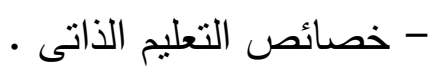


- خطوات بناء الكتاب الإلكترونى عن طريقة الحاسب الآلى . وفيما يلى شرح لأهداف وأغراض البرنامج التعليمى المقترح :

\section{- أسس وضع الكتاب الإلكترونى :}

ثم مراجعة الأسس التالية عند وضع وتصميم الكتاب الإلكترونى لمهارات كرة اليد المقرر على طلاب الصف الأول الإعدادى بالمعاهد الأزهرية باعنبار أن هذه الأسس تعتبر الأنسر معايير

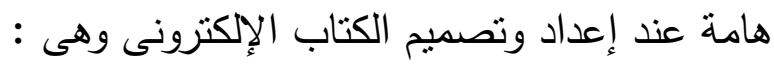

1 - أن يتتاسب محتوى الكتاب الإلكترونى مع أهدافة ومع الهتمع الذى وضع من أجله . r- أن يراعى الكتاب الإلكترونى خصائص النمو للمرحلة السنية قيد البحث . r- أن يكون الكتاب الإكترونى فى مستوى قدرات العينة المختارة . ـ- أن يراعى الكتاب الإلكترونى الفروق الفردية بين الطلاب أثناء الأداء والتطبيق . 0- أن يحقق الكتاب الإكترونى الثعور بالتشويق والاثارة . צ- أن براعى الكتاب الإلكترونى مبدأ التدرج من السهل إلى الصعب . V- أن تتحدى محتويات الكتاب الإكترونى قدرات الطلاب بما يسمح باستتارة دوافعهم لتحقيق التربق

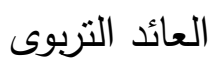
1- إناحة الفرصة للاشتراك والممارسة لكل الطلاب فى وقت واحد . 9- مراعاة اشباع حاجات الطلاب من الحركة والنشاط . • 1 - أن يراعى محتوى الكتاب الإلكترونى الثكل الصحيح للأده من خطوات فنية وتعليمية . - الإمكانات اللأزمة لتنفيذ وتطبيق المهارات المختارة داخل الكتاب الإكترونى : 1 - ملعب مخطط ومحدد لكرة اليد . r- عدد من كور اليد بما يتتاسب وعدد الطلاب ( التجريبية والضابطة ) .

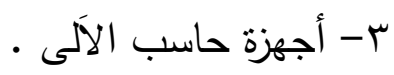


ع - الأدوات المتاحة من اقماع وصولجانات واطواق لاستخدامها فى التعليم • 0- أسطوانات ممغنطة عليها الكتاب الإلكترونى المعد من قبل الباحث .

- إجراءات تحليد محتوى الكتاب الإلكترونى :

1- التعرف على منهاج كرة اليد المقرر على طلاب الصف الأول الإعدادى بالمعاهد الأزهرية

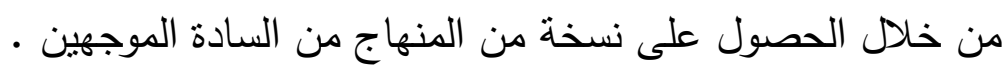
ץ- تحديد واختيار مهارات كرة اليد التى سوف ينم إعداد الكتاب الإلكترونى بها . r- تحديد وكتابة الجز النظرى عن تاريخ كرة اليد ، ومهارات كرة اليد من حيث ( الخطوات الفنية - الخطوات التعليمية ) ، وقانون كرة اليد .

ع - تجهيز عدد من الصور الثابتة والمتحركة للخطوات الفنية والتعليمية والقانون لكل مهارة . 0- مقاطع فيديو لكل خطوة فنية وتعليمية لكل مهارة من المهارات المختارة . مرحلة تصميم الكتاب الإلكترونى : وقد روعى عند تصميم الكتاب الإلكترونى الخطوات الآتية :

1- الاستفادة الكاملة من مساحة الثاشة للحاسب الآلى عن طريق تتظيمها بشكل جيد .

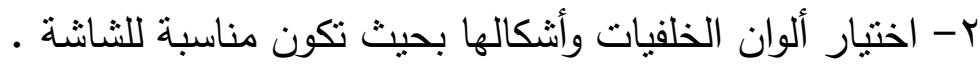
r- عرض النص المكتوب ببساطة وخط واضح وطريقة مشوقة ومتتاسقة . ع - استخدام المؤثرات الصوتية والبصرية بأسلوب فعال لتدعيم عملية التعليم • ه- استخدام الصور الثابتة والمتحركة ومقاطع الفيديو والنص المكتوب لعرض كل مهارة من

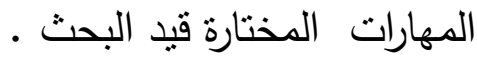
צ- إككانية الطالب فى التجول والإبحار داخل الوحدات بسهولة ويسر • - إعداد مكونات الكتاب الإلكترونى وإنتاجها : ا- قام البحث بالإطلاع على العديد من المراجع البحوث العلمية المتخصصة فى مجال كرة اليد

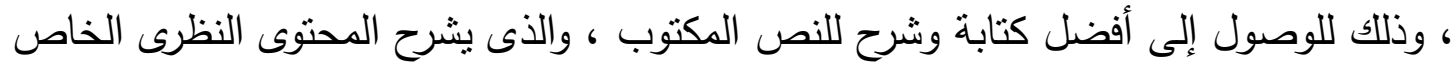


بكل خطوة فنية ، أو تعليمية للمهارات قيد البحث ، وقد تم كتابة تلك النصوص عن طريق برنامج وورد 2010 بكل فئس

r- تحديد عنوان الكتاب وهو ( كتاب إلكترونى لتعليم مهارات كرة اليد ) ، ويهذف هذا الكتاب إلى تعليم طلاب المجموعة التجريبية لمهارات كرة اليد وتحسن مستوى التحصيل المعرفى . ז- يجب تحديد الافكار الفرعية للكتاب الإلكترونى وهو تعليم مهارة التمرير ومسك واستلام الكرة

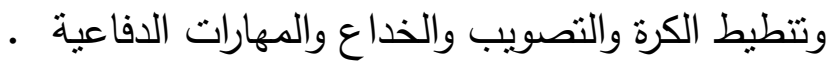
r- نم إعداد الصور الثابتة والمتحركة الخاصة بكل خطوة فنية أو تعليمية لكل مهارة عن طريق تحديد الصور ووضعها على برنامج Photo Shop والذى عن طريقه نم اقتصاص الصور

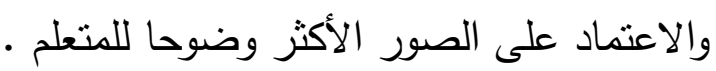
r- تم تجهيز مقاطع الفيديو مجمعة لكل مهارة بها الخطوات الفنية والتعليمية وتم وضع هذه

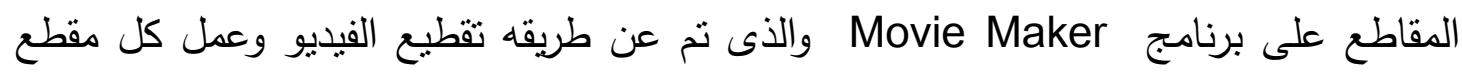
منفردا لكل خطوة فنية أو خطوة تعليمية .

ـ- تم تسجيل الصوت الخاص بكل مهارة بصوت الباحث والتعليق على كل مهارة من حيث الخطوات الفنية والتعليمية وذلك عن طريق برنامج Movie Maker ثم إضافة كل صوت للمقطع التابع له وذللك نفس البرنامج • ه- تم إدماج كل هذة الوحدات والخطوات السابقة مع بعضها من صور ثابتة ومتحركة ومقاطع الفيديو والنص المكتوب وقد تم اللجؤ إلى أحد المختصين فى مجال الحاسب الألى لإخراج

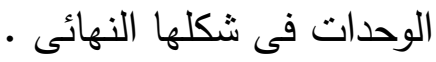

צ- كتابة السيناريو للكتاب : لقد اشتمل السيناريو على وصف للمهارت المراد تعلمها والموجودة داخل الكتاب الإككترونى من نص مكتوب وصور وفيديوهات ، كذلك تحديد الاطارات أو الطريقة

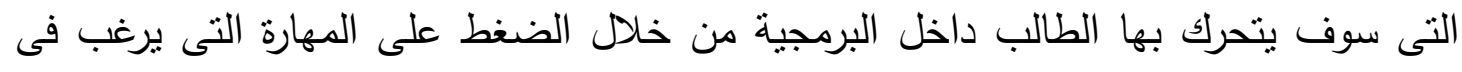
تعلمها فيتم نقلة إلى تلك المهارة ، كذلك اشتخدام عدد من الازار فى البرمجية للتنقل من خلالالها

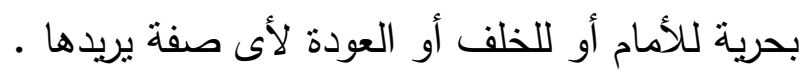

V - برمجة السيناريو التعليمى للكتاب الإكترونى : وقد لجا الباحث إلى احد انظمة تصيمم

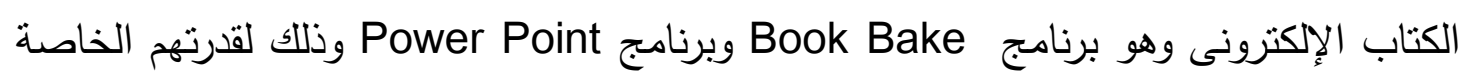


على اضافة النص المكتوب والصور الثابتة والمتحركة واضافة مقاطع الفيديو ، بحيث تكون متاحة بسهولة للمتعلم بمجرد فتح الكتاب واختيار الجزء المراد تعلمة .

\section{- تقويم الكتاب الإكترونى : - ت}

وقد استخدم الباحث نوعين من النقويم وهما :

أ- التقويم الداخلى ( تقويم الخبراء ) :

بعد الانتهاء من إعداد الكتاب الإلكترونى لمهارات كرة اليد المختارة قيد البحث فى صورتها

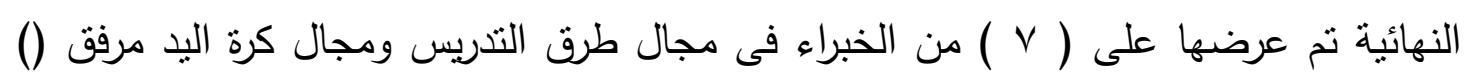

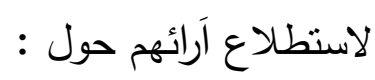

1- مدى مناسبة الأهداف الموضوعة للوحدات .

r- مدى مناسبة أسلوب عرض المحتوى على الطلاب .

r- مدى صلاحية الكتاب الإكترونى فى العملية التعليمية .

وقد تم ذلك من خلال تصميم استمارة استطلاع للرائ تم توزيعها على الخبراء مع الكتاب

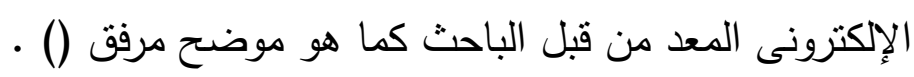

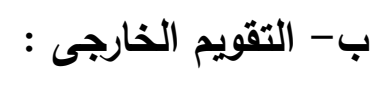

بعد الاتتهاء من إعداد الكتاب الإكترونى باستخدام الحاسب الآلى فى صورته النهاية قام

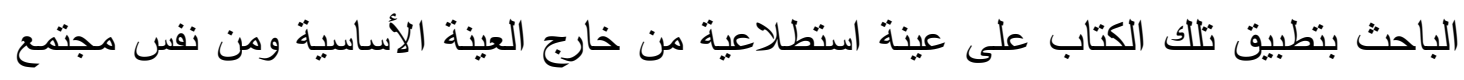

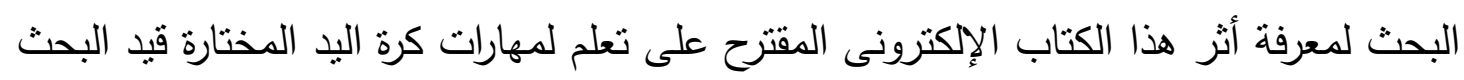

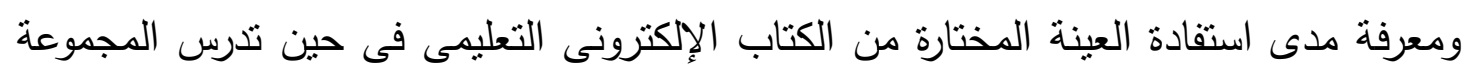

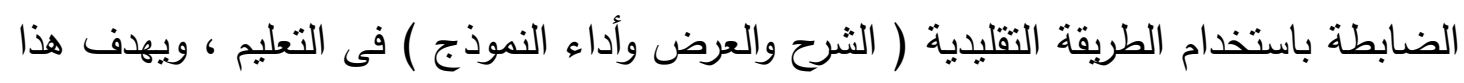
النوع من التقويم إلى : باسنى الطعابن

1- تقنين بعض الموضوعات الموجودة فى الكتاب الإلكترونى سواء كان ذلك بسبب نقص فى محتوى بعض الموضوعات أو زيادة فيها . r- التعرف على الصعوبات التى قد تواجة الباحث أثناء التطبيق الفعلى للبحث . 
r- التأكد من صلاحية الأجهزة والأداوات المستخدمة فى البحث من حاسب آلى وأجهزة العرض

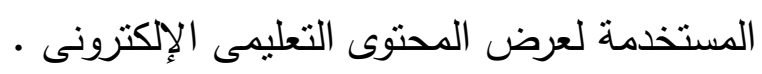
ع - النأكد من صلاحية المكان وتوافر عوامل الامن والسلامة أثناء التطبيق الفعلى للبحث . ه- التعرف على ملاحظات الطلاب عن الكتاب الإكترونى ومدى مناسبة هذا الكتاب لقدرات

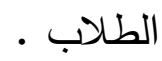

7- التعرف على أكثر الصعوبات التى قد نواجة الباحث أثثاء تطبيق الكتاب الإلكترونى على

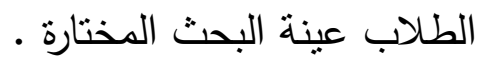

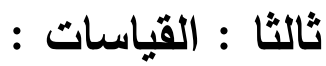

\section{أ- القياسات القبلية عن طريق درجات التكافؤ :}

تم إجراء القياسات القبلية بهدف التعرف على مستوى الطلاب فى المجموعنين التجريبية والضابطة قبل البدء فى تنفيذ البرنامج ( التجربة الأساسية ) تم إجراء القياسات القبلية لاختبار

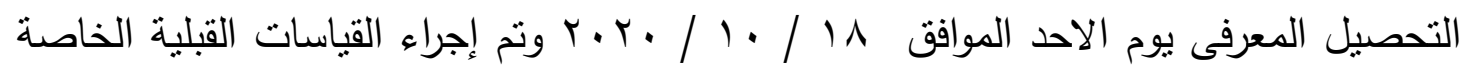

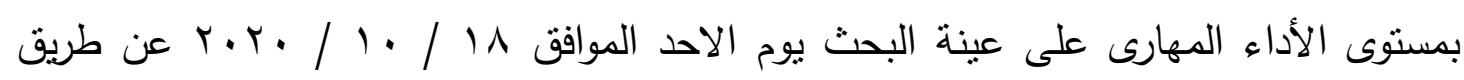

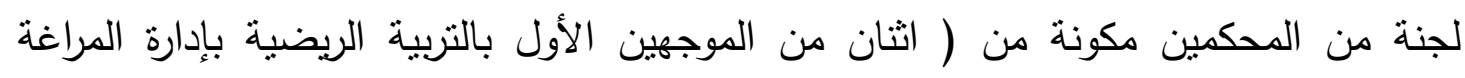

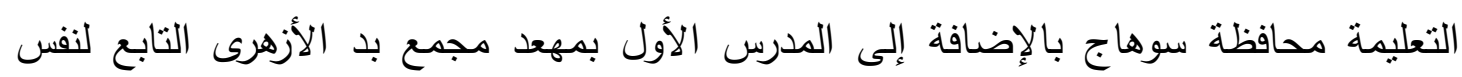

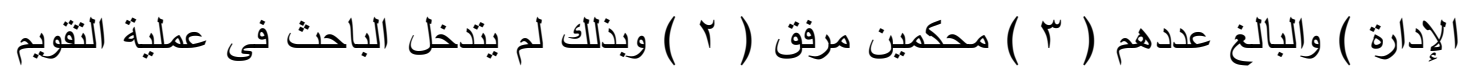

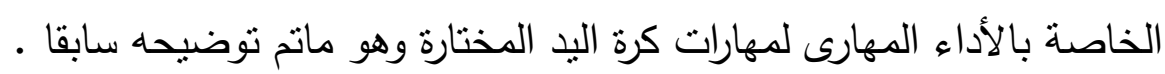

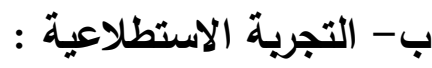

قام الباحث بإجراء الدراسة الاستطلاعية على عينة استطلاعية من نفس مجتمع البحث

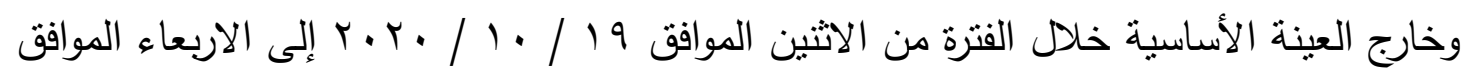

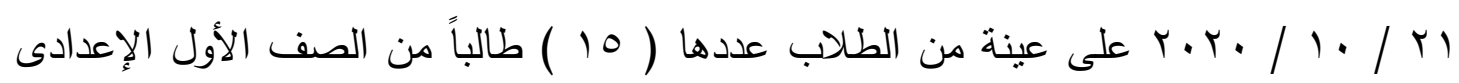

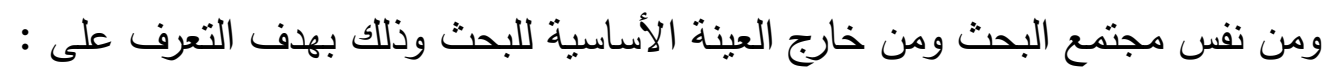
1- دقة وكفاية المساعدين وتفهم المواصفات القياسية للاختبار قيد البحث . r- صلاحية الأدوات والأجهزة والمنشات النى يجرى بها أو عليها تعليم مهارات كرة اليد . r- ترتيب تطبيق القياسات والاختبارات . 
ع - تتظيم وتتسيق سير العمل والوقوف على كيفية تتفيذ البرنامج التعليميى . 0- اكتثاف الصعوبات التى قد تواجه الباحث أثناء التطبيق والمساعدين . هذا وقد أسفرت الدراسة الاستطلاعية السابقة عن تحقيق أهدافها واستطاع الباحث الخروج

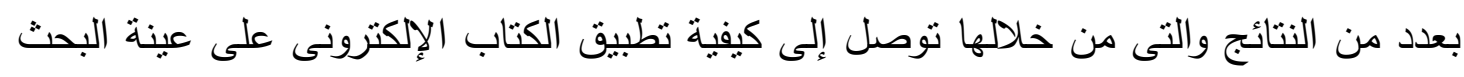

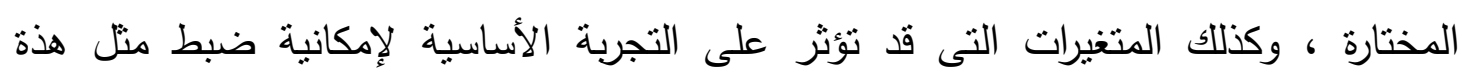

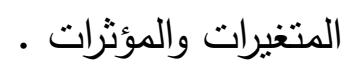

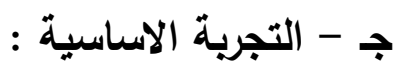

وقد قام الباحث بتتفيذ التجربة الأساسية على عينة البحث الأساسية وذلك حسب التوزيع

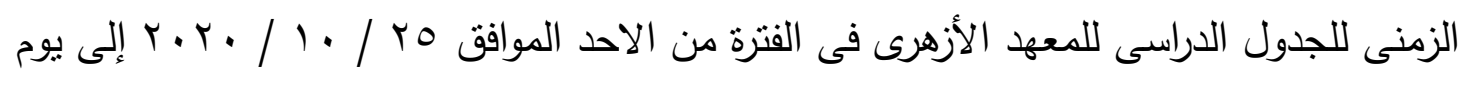

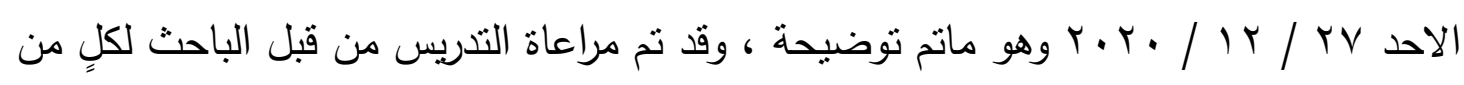

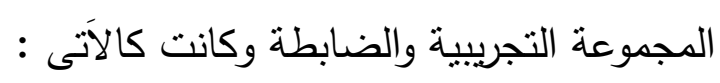

\section{1 - التدريس للمجموعة الضابطة :}

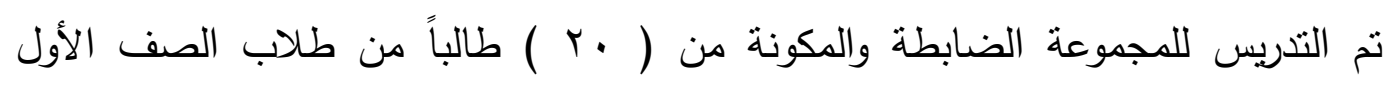

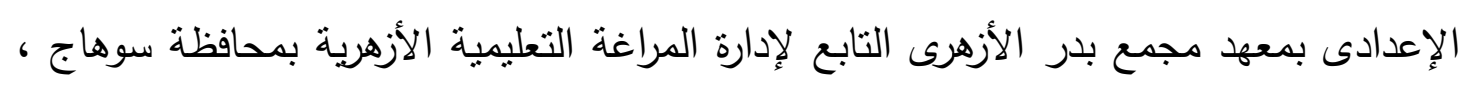

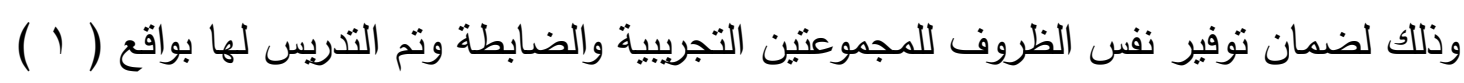

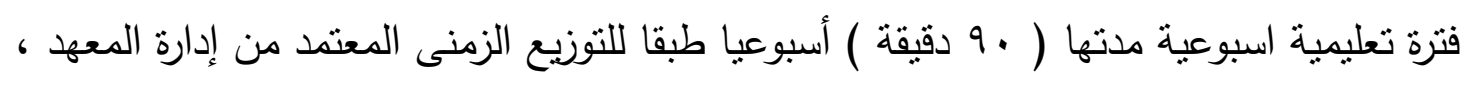

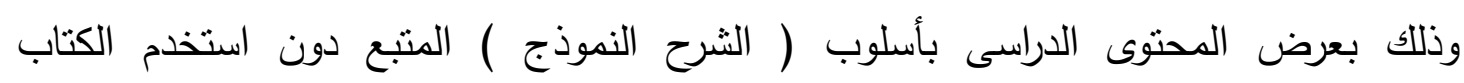

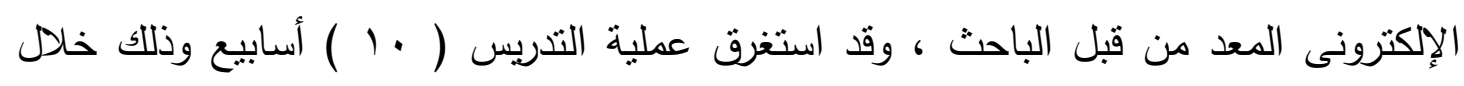

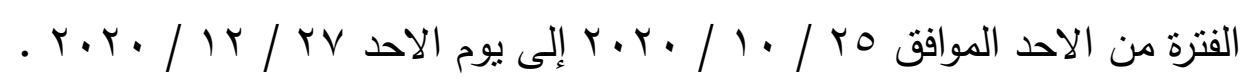

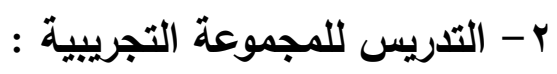

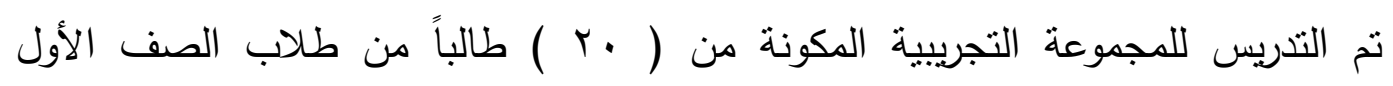

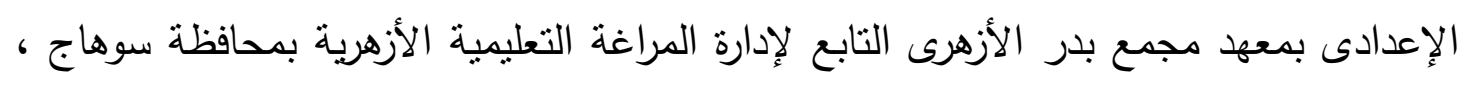

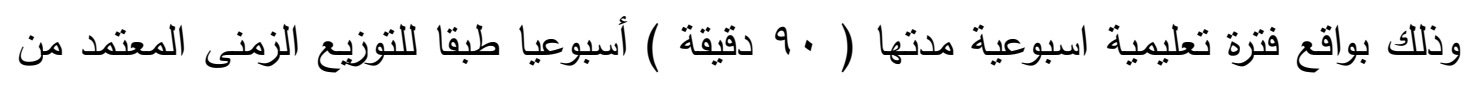

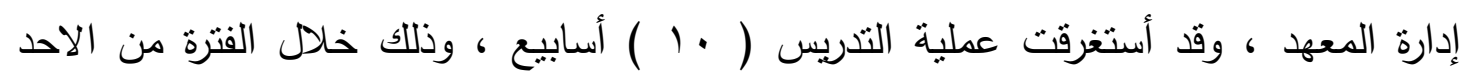

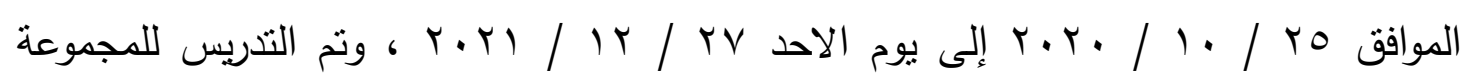

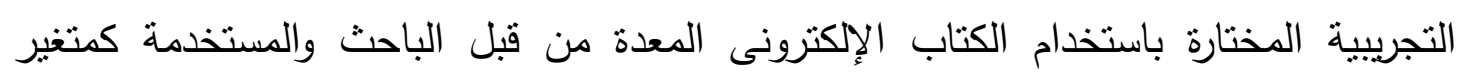

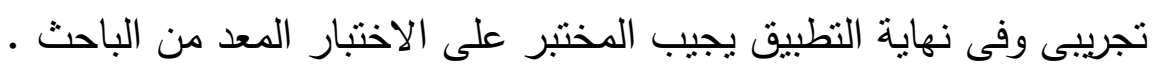


قام الباحث بأداء القياسات البعدية الخاصة بمستوى الأداء المهارى فقد عن طريق تشكيل

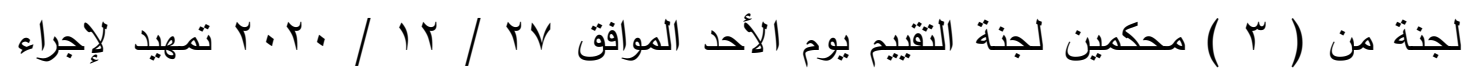
القياسات البعدية حيث تكونت هذة اللجنة من اثثان من الموجهين الأول بالتربية الرياضية بإدارة

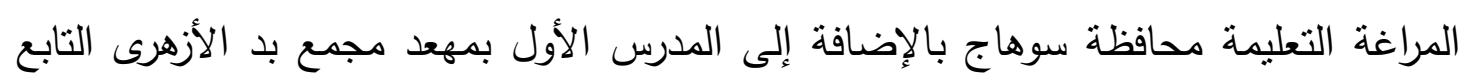

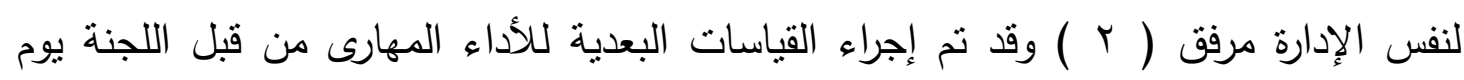

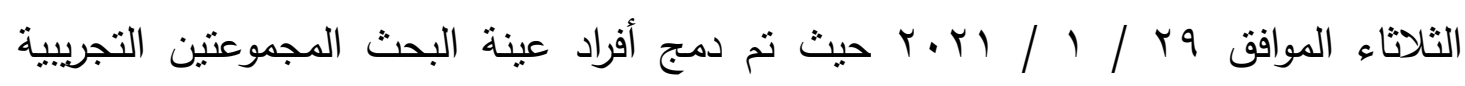
والضابطة معا وعددهم ( •؛ ) طالباً قبل إجراء القياسات وتم توزيعهم عشوائيا على لجنة المحكمين لإجراء التقييم ( القياسات البعدية ) على أن يقوم الباحث بتوزيع استمارات على اللجنة

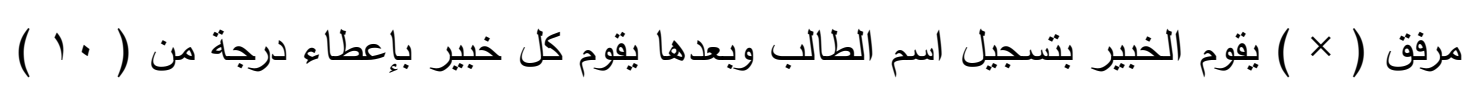
لكل طالب على كل مهارة يوديها ثم يقوم الباحث بتجميع هذة الاستمارات وتجميع درجات الثلاث

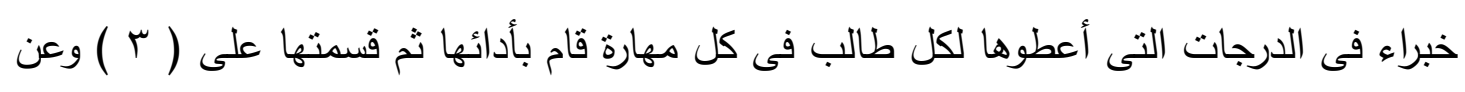
طريقها يتم استخراج متوسط درجات كل طالب فى كل مهارة من المهارات قيد البحث . كما قام الباحث بإجراء القياسات البعدية للاختبار المعرفى قيد البحث من خلال توزيع عينة البحث التجريبية والضابطة فى قاعتين دراسيتنين ، وتوزيع الطلاب عشوئيا على نلك القاعينين

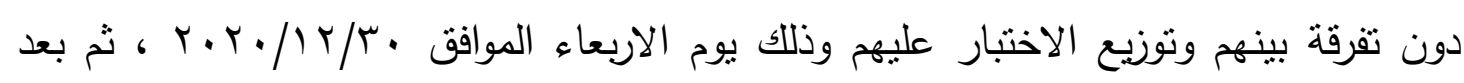
مرور الوقت المحدد للاختبار وزمنة ( 10 دقبقة ) قام الباحث بتجميع الاختبار تمريدا لإجراء

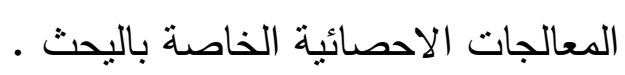

$$
\text { درجة الخبير الاول + الثانى + الثالث }
$$

درجة الطالب فى المهارة الاولى = 


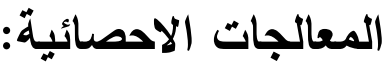

تم جمـع جميع البيانات وتتظيمها وجدولتها تمهيدا لمعالجتها إحصـائيا وقد استخدم الباحث الأساليب الإحصائية التالية لمعالجة البيانات: التوصيف الإحصائي (المتوسط الحسابي، الوسيط، الانحراف المعيارى، أقل وأكبر قيمة، المدى،

الالتواء، التفلطح)

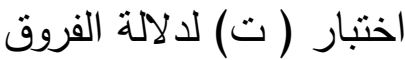

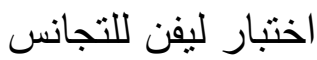

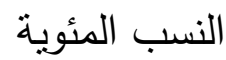

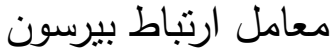
معامل ألفا كرونباخ

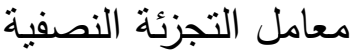

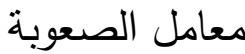
معامل التمييز

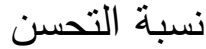
وذللك باستخدام حزمة البرامج الإحصائية SPSS. وبرنامج ميكروسوفت أكسل 
أولا: عرض النتائج

الفـروق بـين القياسـين القبليـين للمجمـوعتين التجريبيـة والضـابطة فى مسـتوى

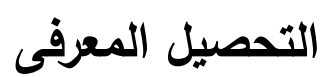

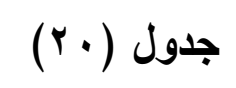

دلالة الفروق بين متوسط القياسين

القبليين للمجموعتين التجريبية والضابطة في الاختبار المعرفي دئين

$\varepsilon=\dot{u}$

\begin{tabular}{|c|c|c|c|c|c|c|c|c|c|c|}
\hline \multirow{2}{*}{ sig } & \multirow{2}{*}{ ت } & \multicolumn{2}{|c|}{ الفروق } & \multicolumn{2}{|c|}{ التجريبية } & \multicolumn{2}{|c|}{ الضابطة } & \multirow{2}{*}{ | وحدة القياس | } & \multirow{2}{*}{ المتغير } & \multirow{2}{*}{ م } \\
\hline & & $\varepsilon$ & b & $\varepsilon$ & r & $\varepsilon$ & b & & & \\
\hline$\ldots$ & $1 \%, 74$ &. .44 & $\overline{., \ldots}$ & $1, \vee \wedge \wedge 9$ & $\begin{array}{l}, T \ldots \\
\end{array}$ & .,9r. & $\overline{v, Y \ldots}$ & درجة & الحفظ والتنكر & 1 \\
\hline$\cdots$ & $\mid r, \Sigma 1$ & $\ldots 1 \mathrm{~V}$ & $\cdot, r_{.}$ & $1,77 \varepsilon$ & $v, 70$. & $1, \vee \curlyvee q$ & $\checkmark, \wedge \circ$ & درجة & الفهم والاستيعاب & $r$ \\
\hline$\ldots$ & M,Tr &.$\mu r$ & $\cdot, \leqslant 0$ & $1, V \vee r$ & v, vo. & 1,049 & $v, r \ldots$ & درجة & التطبيق & $r$ \\
\hline$\ldots$ & $\varepsilon \leqslant, 79$ & r &., 70 & $\cdot, 9 \wedge \mathrm{V}$ & rr... & $1, \mathrm{VA \Lambda}$ & rr,O.. & درجة & الاختبار المعرفى ككل & $\varepsilon$ \\
\hline
\end{tabular}

يتضـح مـن جدول ( · r ) أنـه لا توجد فروق دالـة إحصـائياً بين متوسط قيساس درجات

المجموعتين ( التجريبيـة / الضـابطة ) في اختبار التحصيل المعرفى بين القياسين القبلينين

للجموعتين التجريبية والضابطة ، مما يدل على تكافؤ مجموعتين الدراسة قبل تطبيق الاختبار

$$
\text { المقترح قيد البحث . - مبن }
$$

الفـروق بـين القياسـين القبليـين للمجمـوعتين التجريبيـة والضـابطة فى مسـتوى

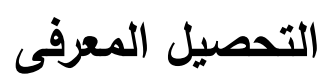

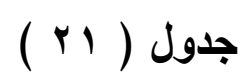

دلالة الفروق بين متوسط القياسيين

\begin{tabular}{|c|c|c|c|c|c|c|c|c|c|c|}
\hline \multirow{2}{*}{ sig } & \multirow{2}{*}{$ت$} & \multicolumn{2}{|c|}{ الفروق } & \multicolumn{2}{|c|}{ المجموعة التجريبية } & \multicolumn{2}{|c|}{ المجموعة الضابطة } & \multirow{2}{*}{ ولقدة } & \multirow{2}{*}{ المتغير } & \multirow{2}{*}{ r } \\
\hline & & $\varepsilon$ & p & $\varepsilon$ & p & $\varepsilon$ & p & & & \\
\hline
\end{tabular}

القبليين للمجموعتين التجريبية والضابطة في الاختبارات المهارية

$\varepsilon=\dot{0}$ 


\begin{tabular}{|c|c|c|c|c|c|c|c|c|c|c|}
\hline$\cdots$ & $\varepsilon, r T \varepsilon$ & $\cdot, \wedge \backslash 1$ & $\cdot, \wedge 0$. & $\cdot, 70 \mathrm{~V}$ & $r, v \ldots$ & $\cdot, 01$ & $\varepsilon, 00$. & درجة & مسك واستتلام الكرة & 1 \\
\hline$\cdots$ & 0,7ז4 & $\cdot, \Sigma \vee \wedge$ & $\cdot, 7 \ldots$ & 9 & r,vo. & $\cdot, \Lambda \mid r$ & s.ro. & درجة & تنطيط الكرة & r \\
\hline$\cdots$ & $\varepsilon, 79 r$ & $\cdot, 1 \leqslant V$ & $1,0 \ldots$ & $\cdot, v \leq 0$ & $\varepsilon, 10$ & $\cdot, Y Y O$ & $\varepsilon, \ldots$ & درجة & التمرير الكرياجى & $r$ \\
\hline$\cdots$ & $\varepsilon$, rד & $\cdot, 10 \leqslant$ & $1, r o$. & $\cdot, \vee \backslash \wedge$ & $\varepsilon, 1 \ldots$ & $\cdot, \wedge 01$ & $\varepsilon, r O$. & درجة & التمريرة الصدرية & $\varepsilon$ \\
\hline$\cdots$ & 9,709 & $\cdot, 119$ & $1,0$. & $\cdot, T V T$ & $\varepsilon, r \ldots$ & $\cdot, V \leqslant 0$ & $\varepsilon, r_{O}$ & درجة & التصويب الكرياجى & 0 \\
\hline$\cdots$ & $V, 0 \leqslant V$ & • & $1,1 \ldots$ & $\cdot, 091$ & $\varepsilon, \varepsilon \cdots$ & $\cdot, \wedge \circ \mathrm{V}$ & $\varepsilon, r o$. & درجة & المهاراة الدفاعية & 7 \\
\hline$\cdots$ & $0,07 \varepsilon$ & דזח, &., 10 & $\cdot, 7 \leq 1$ & $r, q \ldots$ & $\cdot, \leqslant \vee q$ & $\varepsilon, .0$ & درجة & الخداع & v \\
\hline
\end{tabular}

ت دال عند sig

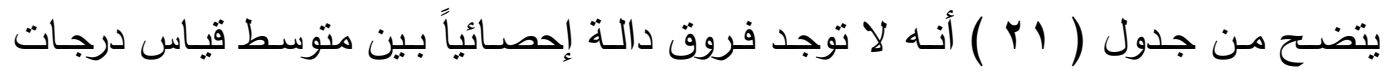

المجموعتين ( التجريبية / الضابطة ) في الاختبارات المهارية بين القياسين القبليين للمجموعتين

التجربيية والضـابطة ، مما يدل على تكافؤ مجموعتين الدراسـة قبل تطبيق الاختبار المقترح قيد

البحث

$$
\text { جدول (Yr) }
$$

دلالة الفروق بين متوسط القياسين

القبلي والبعدي للمجموعة الضابطة في الاختبار المعرفي

$r \cdot=\dot{v}$

\begin{tabular}{|c|c|c|c|c|c|c|c|c|c|c|}
\hline \multirow{2}{*}{ sig } & \multirow{2}{*}{ ت } & \multicolumn{2}{|c|}{ الفروق } & \multicolumn{2}{|c|}{ القياس البعدى } & \multicolumn{2}{|c|}{ القياس القبلى } & \multirow{2}{*}{ وحدة القياس } & \multirow{2}{*}{ المتغير } & \multirow{2}{*}{ b } \\
\hline & & $\varepsilon$ & r & $\varepsilon$ & r & $\varepsilon$ & r & & & \\
\hline$\cdots$ & IT,IV & $.7 \varepsilon$ & $\varepsilon, \varepsilon \ldots$ & $1, r \circ V$ & $M, \ldots$ & $\cdot, 94$. & $\vee, 7 \ldots$ & درجة & الحفظ والتذكر & 1 \\
\hline$\cdots$ & $I Y, V A$ & 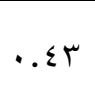 & $r, q \ldots$ & $1,0 \wedge 0$ & $\begin{array}{c}1 \cdot, \times 0 \\
.\end{array}$ & $1, \vee \vee q$ & $\vee, \wedge \circ$. & درجة & الفهم والاس & $r$ \\
\hline$\cdots$ & $\mid \leq, 71$ &.$V V$ & $r, \wedge \circ$. & $1, r 71$ & $\begin{array}{c}1 ., 10 \\
.\end{array}$ & 1,049 & $\vee, \Gamma \ldots$ & درجة & التطبيق & $\mu$ \\
\hline$\cdots$ & ع &. .09 & $1 \cdot, 10$ & $r, r q$ & $\begin{array}{c}r, q . \\
.\end{array}$ & $1, \vee \wedge \wedge$ & $r r, 0 \ldots$ & درجة & الاختبار المعرفى ككل & $\varepsilon$ \\
\hline
\end{tabular}

ت دال عند 
يوضـح جدول(r r) المتوسط الحسـابى والإنحراف المعيارى لكل مـن القياسين القبلى في والبعدى والفروق للمجموعة الضابطة في الاختبار المعرفى .

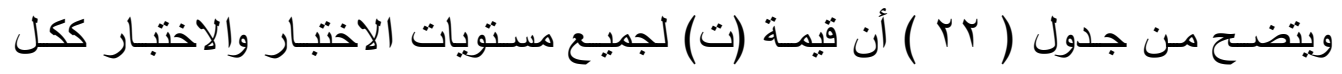

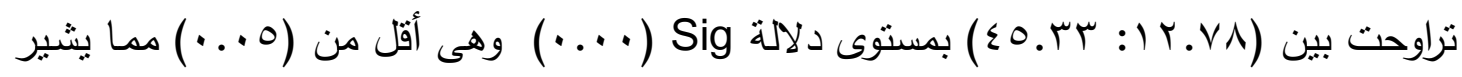
إلى وجود فروق دالة إحصائيا بين القباسين القبلى والبعدي لصالح القياس البعدى .

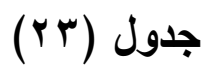
دلالة الفروق بين متوسط القياسين القبلي والبعدي للمجموعة الضابطة في الاختبارات المهارية $r_{\cdot}=\dot{u}$

\begin{tabular}{|c|c|c|c|c|c|c|c|c|c|c|}
\hline \multirow{2}{*}{ sig } & \multirow{2}{*}{ ت } & \multicolumn{2}{|c|}{ الفروق } & \multicolumn{2}{|c|}{ القياس البعدى } & \multicolumn{2}{|c|}{ القياس القبلى } & \multirow{2}{*}{ وحدة } & \multirow{2}{*}{ المتغير } & \multirow{2}{*}{ p } \\
\hline & & $\varepsilon$ & r & $\varepsilon$ & r & $\varepsilon$ & r & & & \\
\hline$\cdots$ & V,rII & $\cdot, \wedge 0 \leqslant$ & 1,10 & $\cdot, 091$ & $7, \varepsilon \ldots$ &., 01 . & $\{, 00$. & درجة & مسك واستلام الكرة & 1 \\
\hline$\cdots \cdot$ & $9,1 \Gamma q$ & $\cdot, 707$ & $1,0 \ldots$ & $\cdot, 0 \wedge \mathrm{V}$ & $0,10$. & • & s.ro. & درجة & تنطيط الكرة & $r$ \\
\hline$\cdots \cdot$ & VTr, Y & $\cdot, r \leq V$ & $1,0 \ldots$ & $\cdot, 7.0$ & 0,00 . & $\cdot$, YYO & $\varepsilon, \ldots$ & درجة & التمرير الكرياجى & $r$ \\
\hline$\cdots$ & $1 \cdot, .04$ & $\cdot, \leqslant \wedge 9$ & $1, r o$. & $\cdot, T \cdot V$ & $0,0 \ldots$ & $\cdot, 101$ & $\varepsilon$, ro. & درجة & التمريرة الصدرية & $\varepsilon$ \\
\hline$\cdots \cdots$ & $9,1 \Gamma q$ & • TrV & $1,0$. & $\cdot, 0 . r$ & $0, \varepsilon \ldots$ & $\cdot, V \leqslant 0$ & $\varepsilon$, ro. & درجة & التصويب الكرباجى & 0 \\
\hline$\cdots$ & $1 \cdot, .04$ & $\cdot, 7 \wedge 1$ & $1,1 \ldots$ & $\cdot, 7 \times 1$ & 0, ro. & $\cdot$, , O V & $\varepsilon$, ro. & درجة & المهاراة الدفاعية & 7 \\
\hline$\cdots$ & $0,9 \leq$ & $\cdot, 0 \leqslant V$ & 1,10 & $\cdot, \varepsilon \wedge 9$ & $0,10$. & $\cdot, \varepsilon \vee q$ & $\varepsilon, \vee \ldots$ & درجة & الخداع & V \\
\hline
\end{tabular}
ت دال عند sig

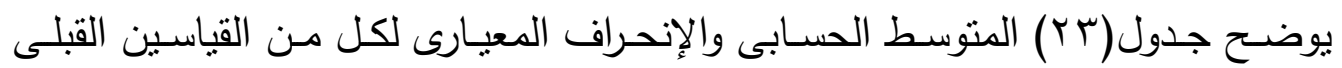
والبعدى والفروق للمجموعة الضابطة في الاختبارات المهارية .

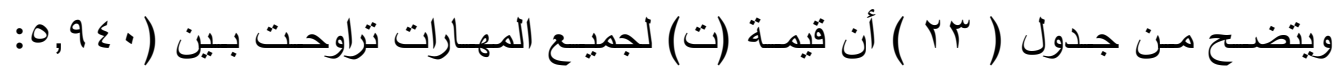

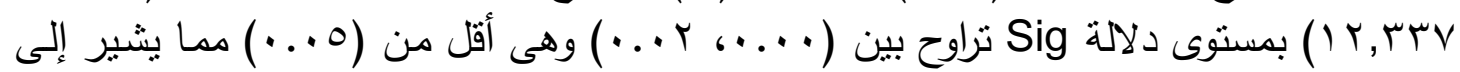

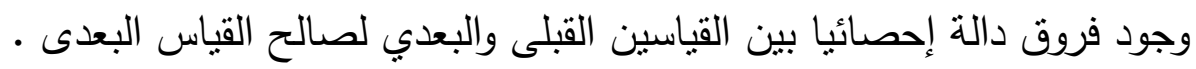




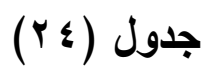

نسبة تحسن المجموعة الضابطة في الاختبار المعرفى (r

$r_{\cdot}=\dot{0}$

\begin{tabular}{|c|c|c|c|c|c|c|c|}
\hline \multirow{2}{*}{ نسبة التحسن } & \multicolumn{2}{|c|}{ القياس البعدى } & \multicolumn{2}{|c|}{ القياس القبلى } & \multirow{2}{*}{ القياس } & \multirow{2}{*}{ المتغير } & \\
\hline & $\varepsilon$ & 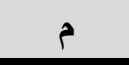 & $\varepsilon$ & 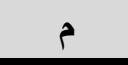 & & & \\
\hline$\% १ 9,1 \%$. & 1, rov & $K, \cdot$. & , ,9r. & $v, \tau \ldots$ & درجة & | الحفظ والتذكر & \\
\hline$\% \backslash\{, 0 \ldots$ & 1,010 & $1 .$, Vo. & $1, v<q$ & $\mathrm{v}, \wedge \mathrm{O}$. & درجة & |الفهر والاستيعاب & \\
\hline$\% 17,001$ & $1, r 71$ & $1 ., 10$. & 1,049 & $v, r \ldots$ & درجة & |التطبيق & 1 \\
\hline \%।V,rTr & $r, r q$ & $r r, q .$. & $1, Y \wedge \wedge$ & $r r, O .$. & درجة & |الاختبار المعرفى ككل & \\
\hline
\end{tabular}

يوضح جدول(؟ Y) المتوسط الحسابى والإنحراف المعيارى لكل من القياسين القبلى والبعدى ونسب التحسن للمجموعة الضابطة في الاختبار المعرفى .

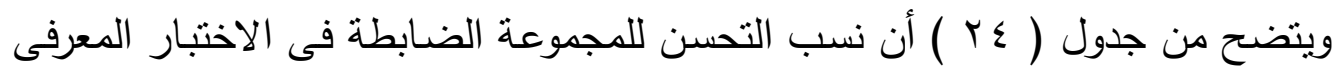

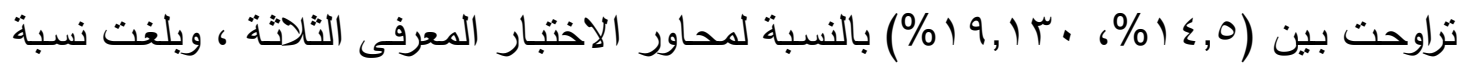

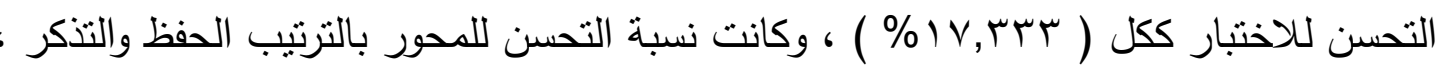

والتطبيق ثم الفهم والإنتيعاب.

\section{جلول (ro)}

نسبة تحسن المجموعة الضابطة في الاختبارات المهارية

$r_{\cdot}=\dot{0}$

\begin{tabular}{|c|c|c|c|c|c|c|c|}
\hline \multirow{2}{*}{ نسبة التحسن } & \multicolumn{2}{|c|}{ القياس البعدى } & \multicolumn{2}{|c|}{ القياس القبلى } & \multirow{2}{*}{ وحدة } & \multirow{2}{*}{ المتغير } & \multirow{2}{*}{ م } \\
\hline & $\varepsilon$ & b & $\varepsilon$ & b & & & \\
\hline$\% \backslash \wedge, 0 \ldots$ & $\cdot, 091$ & $7, \varepsilon \ldots$ &., 01 & $\varepsilon, 00$. & درجة & مسك واستلام الكرة & 1 \\
\hline$\% 10, \ldots$ &., $0 \wedge \mathrm{V}$ & 0,10 & ( & s.ro. & درجة & تنطيط الكرة & r \\
\hline$\% 10,0 \ldots$ & $\cdot, 7.0$ & 0,00 & $\cdot$, YYO & $\varepsilon, \ldots$ & درجة & التمرير الكرياجى & $r$ \\
\hline$\% \backslash r, 0 \ldots$ & $\cdot, T \cdot V$ & $0,0 \ldots$ & $\cdot, 101$ & $\varepsilon$, YO. & درجة & التمريرة الصدرية & $\varepsilon$ \\
\hline$\% 1 \cdot, 0 \ldots$ & $\cdot, 0 . r$ & $0, \varepsilon \ldots$ & $\cdot, V \leq 0$ & $\varepsilon$, ro. & درجة & التصويب الكرياجى & ○ \\
\hline$\% 11, \ldots$ & $\cdot, 7 \vee 1$ & $0, r 0$. & $\cdot, \mathrm{NOV}$ & $\varepsilon, Y_{O}$ & درجة & المهاراة الدفاعية & 7 \\
\hline$\% 11,0 \ldots$ & $\cdot, \leqslant \wedge 9$ & $0, \wedge 0$. & $\cdot, \leqslant \vee q$ & $\varepsilon, \vee \ldots$ & درجة & الخداع & $v$ \\
\hline
\end{tabular}




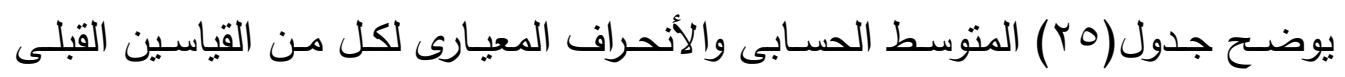

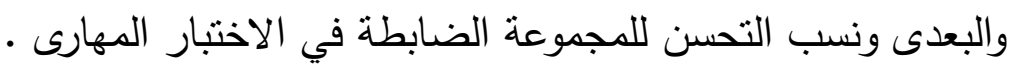

ويتضح من جدول ( o o ) ) والثكل ( 9 ) ) أن نسب التحسن للمجموعة الضابطة تراوحت

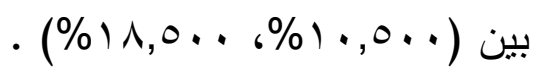

الفروق بين القياسين القبلى والبعدى للمجموعة التجريبية

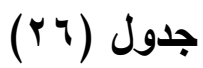

دلالة الفروق بين متوسط القياسين

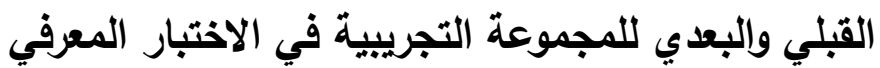

$r_{\cdot}=\dot{u}$

\begin{tabular}{|c|c|c|c|c|c|c|c|c|c|c|}
\hline \multirow{2}{*}{ sig } & \multirow{2}{*}{$ت$} & \multicolumn{2}{|c|}{ الفروق } & \multicolumn{2}{|c|}{ القياس البعدى } & \multicolumn{2}{|c|}{ القياس القبلى } & \multirow{2}{*}{ وحدة القياس } & \multirow{2}{*}{ المتغير } & \multirow{2}{*}{ b } \\
\hline & & $\varepsilon$ & 5 & $\varepsilon$ & b & $\varepsilon$ & 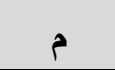 & & & \\
\hline$\cdots$ & Y..乏Ir- & $1, \cdot v \cdot$ & $\begin{array}{c}1 ., 10 \\
.\end{array}$ & 1,111 & IV, Vo. & $1, \vee \wedge 9$ & $\vee, \neg \ldots$ & درجة & |الحفظ والتذكر & 1 \\
\hline$\cdots$ & $r \leq .70 \leqslant-$ & $1, r r$. & $\wedge, \leqslant 0$. & ع عr, & $17,1 \ldots$ & $1,77 \leq$ & $v, 70$. & درجة & |الفهم والاستيعاب & $r$ \\
\hline$\cdots$ & 19.rTV- & 1,119 & $7, .0$ & $1,1.0$ & $M, \Lambda \ldots$ & $1, V \vee r$ & $\mathrm{~V}, \mathrm{VO}$. & درجة & |التطبيق & $r$ \\
\hline$\cdots$ & YT.V.0- & $\cdot, \wedge 9 \leq$ & $\begin{array}{c}r \leq, 70 \\
.\end{array}$ & ז & $\leqslant \vee .70$. & $\cdot, 9 \wedge \vee$ & rr... & درجة & |الاختبار المعرفى ككل & $\varepsilon$ \\
\hline
\end{tabular}

ت دال عند

يوضـح جدول(ب ب) المتوسط الحسـابى والإنحراف المعيارى لكل مـن القياسين القبلى

والبعدى والفروق للمجموعة التجريبية في الاختبار المعرفى •

ويتضـح من جدول ( Tr ) أن قيمـة (ت) لجميع مستويات الاختبـار والاختبار ككل

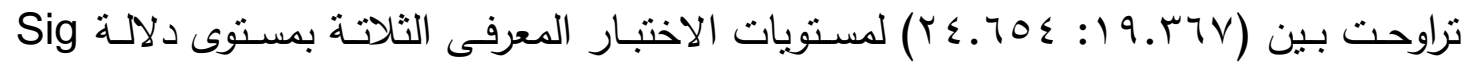

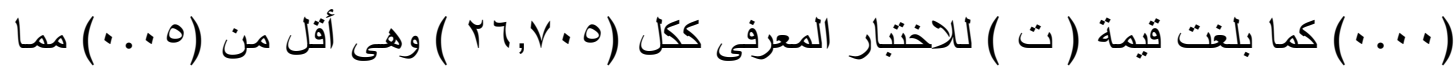

يشير الى وجود فروق دالة احصائيا بين القياسين القبلى والبعدي لصالح القياس البعدى .

$$
\text { جدول (rv) }
$$

دلالة الفروق بين متوسط القياسين

القبلي والبعدي للمجموعة التجريبية في الاختبارات المهارية

$r_{\cdot}=\dot{0}$ 


\begin{tabular}{|c|c|c|c|c|c|c|c|c|c|c|}
\hline \multirow{2}{*}{ sig } & \multirow{2}{*}{ ت } & \multicolumn{2}{|c|}{ الفروق } & \multicolumn{2}{|c|}{ القياس البعدى } & \multicolumn{2}{|c|}{ القياس القبلى } & \multirow{2}{*}{ وحدة القياس } & \multirow{2}{*}{ المتغير } & \multirow{2}{*}{ ? } \\
\hline & & $\varepsilon$ & r & $\varepsilon$ & r & $\varepsilon$ & م & & & \\
\hline$\cdots$ & $10, \cdot v 9$ & $\cdot, 7 \leq 1$ & $\varepsilon, \ldots$ & Tr & $\vee, \vee \ldots$ & $\cdot$, TOV & $r, v \ldots$ & درجة & مسك واستتلام الكرة & 1 \\
\hline$\ldots$ & $1 \varepsilon, T Y K$ & $\cdot, 07 \mathrm{~V}$ & $\varepsilon, 0 \ldots$ & $\cdot, \times 17$ & $\Lambda$, Yo. & 9 9 ד, • & r,vo. & درجة & تنطيط الكرة & r \\
\hline$\cdots \cdots$ & $1 \cdot, 977$ & $\cdot, 7) \leq$ & $r, 0 .$. & $\cdot, 7 \times 1$ & $v, 70$. & $\cdot, \mathrm{V} \leqslant 0$ & $\varepsilon, 10$. & | درجة & التمرير الكرياجى & $r$ \\
\hline$\cdots \cdots$ & $11, \varepsilon r T$ & ( & r, , . & $\cdot, 0.4$ & $\vee, \vee \ldots$ & • & $\varepsilon, 1 \ldots$ & |درجة & التمريرة الصدرية & $\varepsilon$ \\
\hline$\cdots$ & 9,097 & $\cdot, \Sigma \vee \vee$ & r, ro. & $\cdot, 7 \lambda 1$ & $v, 70$. & • & $\varepsilon, r \ldots$ & درجة & التصويب الكرياجى & 0 \\
\hline$\cdots$ & ᄉ, Т人ץ & $\cdot, 0 \wedge 9$ & r,ro. &., 7.0 & $\vee, \vee O$. & $\cdot, 091$ & $\varepsilon, \varepsilon \ldots$ & |درجة & المهاراة الدفاعية & 7 \\
\hline$\cdots$ & $|r, Y 0|$ & $\cdot, 70 \mathrm{~V}$ & $r, 70$. & $\cdot, 91 \mathrm{r}$ & $v, 00$. & $\cdot, 7 \leqslant 1$ & $\Gamma, q \ldots$ & درجة & الخداع & v \\
\hline
\end{tabular}

ت د دال عند

يوضـح جدول(YV) المتوسط الحسـابى والإنحراف المعيـارى لكل مـن القياسـين القبلى

والبعدى والفروق للمجموعة التجريبية في الاختبارات المهارية .

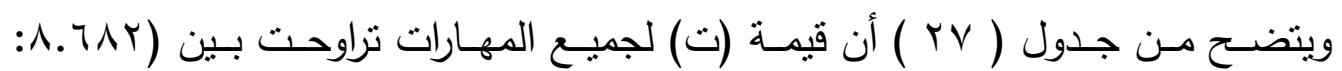

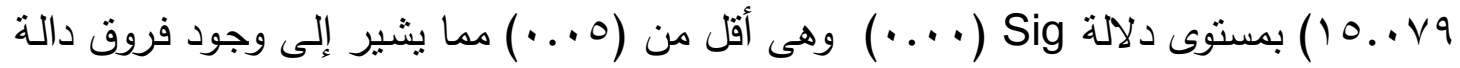

إحصائيا بين القياسين القبلى والبعدي لصالح القياس البعدي •

جدول (r^)

نسبة تحسن المجموعة التجريبية في الاختبار المعرفى

$r \cdot=\dot{v}$

\begin{tabular}{|c|c|c|c|c|c|c|c|}
\hline \multirow{2}{*}{ نسبة التحسن } & \multicolumn{2}{|c|}{ القياس البعدى } & \multicolumn{2}{|c|}{ القياس القبلى } & \multirow{2}{*}{ وحدة القياس } & \multirow{2}{*}{ المتغير } & \multirow{2}{*}{ r } \\
\hline & $\varepsilon$ & r & $\varepsilon$ & p & & & \\
\hline$\% \varepsilon \varepsilon, 1 r$. & 1,111 & iv, vo. & $1, \vee \wedge 9$ & $\vee, \uparrow \ldots$ & درجة & |الحفظ والتذكر & 1 \\
\hline$\% \leqslant r, r \circ$. & ع & $17,1 \ldots$ & $1,77 \varepsilon$ & $V, 70$. & درجة & |الفهم والاستيعاب & r \\
\hline$\%$ \%, 011 & $1,1.0$ & $\Lambda, \wedge \ldots$ & I,VVr & $v, v o$. & درجة & |التطبيق & $r$ \\
\hline$\% \leftleftarrows 1, \cdot \wedge r$ & r & $\leq V .70$. & $\cdot, 9 \wedge \vee$ & rt... & درجة & الاختبار المعرفى ككل & \{ \\
\hline
\end{tabular}


يوضح جدول(Y) المتوسط الحسابى والإنحراف المعيارى لكل من القياسين القبلى والبعدى ونسب التحسن للمجموعة التجريبية في الاختبار المعرفى •

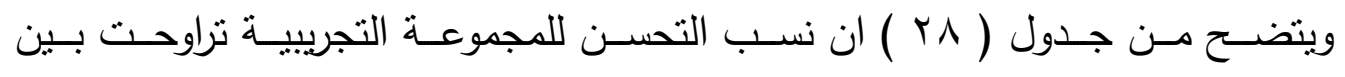

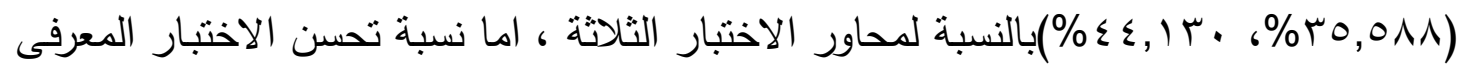

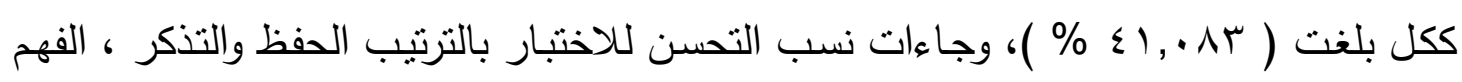

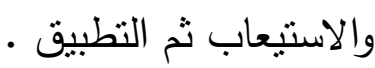

\section{جدول (ra)}

نسبة تحسن المجموعة التجريبية في الاختبارات المهارية

$r_{\cdot}=\dot{0}$

\begin{tabular}{|c|c|c|c|c|c|c|c|}
\hline \multirow{2}{*}{ نسبة التحسن } & \multicolumn{2}{|c|}{ القياس البعدى } & \multicolumn{2}{|c|}{ القياس القبلى } & \multirow{2}{*}{ وحدة } & \multirow{2}{*}{ المتغير } & \multirow{2}{*}{ م } \\
\hline & $\varepsilon$ & r & $\varepsilon$ & م & & & \\
\hline$\% \leq$ & . & $\vee, \vee \ldots$ & $\cdot, 70 \mathrm{~V}$ & $r, \nabla \ldots$ & درجة & مسك واستتلام الكرة & 1 \\
\hline$\% \leq 0$ & $\cdot, \times 17$ & $\Lambda$, Y०. & 9 & r,vo. & درجة & تنطيط الكرة & r \\
\hline$\%$ ro & $\cdot, 7 \times 1$ & $v, 70$. & $\cdot, \mathrm{V} \leqslant 0$ & $\varepsilon, 10$. & a & التمرير الكرياجى & $r$ \\
\hline ד ד \% & r & $\vee, \vee \cdots$ & $\cdot, \vee \backslash \wedge$ & $\varepsilon, 1 \ldots$ & ل درجة & التمريرة الصدرية & $\varepsilon$ \\
\hline$\% r r, 0$ & $\cdot, 7 \lambda 1$ & $V, 70$. & $\cdot, T V \mu$ & $\varepsilon, r \ldots$ & & التصويب الكرباجى & 0 \\
\hline$\%$ rr,o & $\cdot, 7.0$ & $\vee, \vee o$. &., 091 & $\varepsilon, \varepsilon \ldots$ & درجة & المهاراة الدفاعية & 9 \\
\hline$\%$ \% & $\cdot, 91 Y$ & $\vee, 00$. & $\cdot, T \leq 1$ & $r, q \ldots$ & درجة & الخداع & $v$ \\
\hline
\end{tabular}

يوضح جدول(Y9) المتوسط الحسابى والإنحراف المعيارى لكل من القياسين القبلى والبعدى ونسب التحسن للمجموعة التجريبية في الاختبار المعرفى .

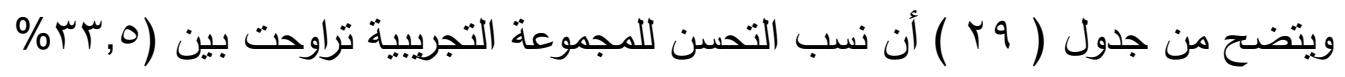

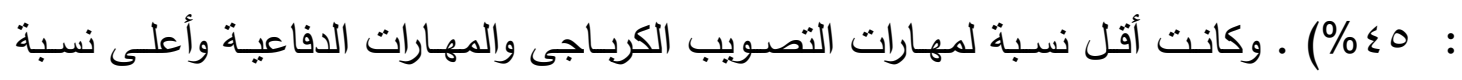

جاءت لمهارة تتطيط الكرة .

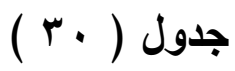

دلالة الفروق بين القياسين البعديين للمجموعتين ( التجريبية / الضابطة )

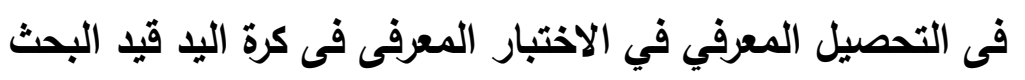


ن

\begin{tabular}{|c|c|c|c|c|c|c|c|c|c|c|}
\hline \multirow{2}{*}{ sig } & \multirow{2}{*}{$ت$} & \multicolumn{2}{|c|}{ الفروق } & \multicolumn{2}{|c|}{ المجموعة الضابطة } & \multicolumn{2}{|c|}{ المجموعة التجريبية } & \multirow{2}{*}{ وحدة } & \multirow{2}{*}{ المتغير } & \multirow{2}{*}{ r } \\
\hline & & $\varepsilon$ & م & $\varepsilon$ & م & $\varepsilon$ & م & & & \\
\hline$\cdots$ & $\varepsilon, \wedge) \leqslant$ & $\cdot, 701$ & 0, , 0. & 1, rov & $\mid r, \ldots$ & 1,111 & IV, vo. & درجة & | الحفظ والتذكر & 1 \\
\hline$\cdots$ & 5.970 &., $0 \wedge r$ & 0, ro. & 1,010 & $1 \cdot, v_{0}$ & ( & $17,1 \ldots$ & درجة & |القهم والاستيعاب & r \\
\hline$\cdots$ & $7,\{\vee 1$ & $\cdot, \wedge r$. & $r, 70$. & $1, r 71$ & $1 \cdot, 10$ & $1,1.0$ & $i r, \wedge \ldots$ & درجة & | التطبيق & $r$ \\
\hline$\cdots$ & $9.0 \mathrm{~V} \varepsilon$ & $1, r \leqslant V$ & $1 \leqslant, \vee_{0}$ & $r, r_{q}$ & $r r, q \ldots$ & r, & $\varepsilon \vee .70$. & درجة & |الاختبار المعرفى ككل & $\varepsilon$ \\
\hline
\end{tabular}

( )

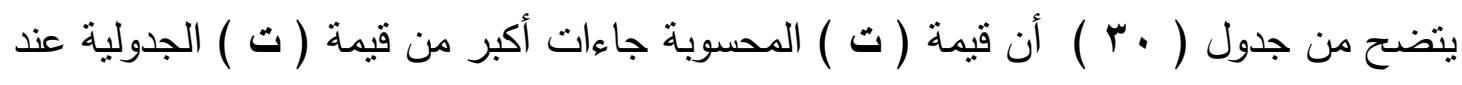
مسنوى دلالة ( ه.,. ) مما يدل على وجود فروق دالة احصائية بين القياسين ( البعديين )

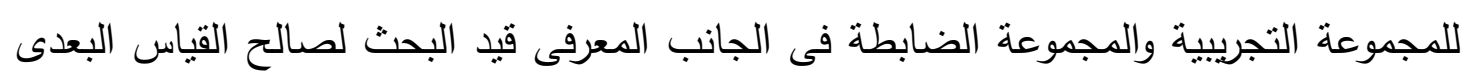

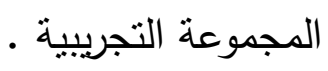

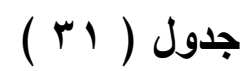

دلالة الفروق بين القياسين البعديين للمجموعتين ( التجريبية / الضابطة )

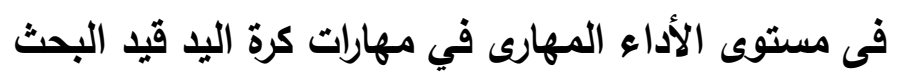

$\varepsilon \cdot=\dot{0}$

\begin{tabular}{|c|c|c|c|c|c|c|c|c|c|c|}
\hline \multirow[t]{2}{*}{ sig } & \multirow[t]{2}{*}{ ت } & \multicolumn{2}{|c|}{ الفروق } & \multicolumn{2}{|c|}{ المجموعة } & \multicolumn{2}{|c|}{ المجموعة } & \multirow{2}{*}{ وحدة } & \multirow[t]{2}{*}{ المتغير } & \multirow[t]{2}{*}{ p } \\
\hline & & $\varepsilon$ & م & $\varepsilon$ & م & $\varepsilon$ & p & & & \\
\hline$\cdots$ & $0, \Sigma Y r$ & $\cdot, \varepsilon V \Gamma$ & $1, r \ldots$ &., 091 & $\neg, \varepsilon \ldots$ & . & $\vee, v \ldots$ & درجة & مسك واستلام الكرة & 1 \\
\hline$\cdots$ & $0, \wedge 9 r$ & $\cdot, \leqslant 77$ & $r, \varepsilon \ldots$ & $\cdot, 0 \wedge \mathrm{V}$ & $0,10$. & $\cdot, \times 17$ & $\Lambda$, ro. & درجة & تتطيط الكرة & $r$ \\
\hline$\cdots$ & $\uparrow, \uparrow \vee \varepsilon$ & $\cdot, \leqslant \wedge 9$ & $r, 1 \ldots$ &., 7.0 & 0,00 & $\cdot, 7 \times 1$ & $v, 70$. & | درجة & التمرير الكرياجى & $r$ \\
\hline$\cdots$ & $\nearrow, \wedge \leq \vee$ & תTr, & $r, r \ldots$ & $\cdot, T \cdot V$ & $0,0 \ldots$ & $\cdot, 0 . r$ & $\vee, \vee \ldots$ & |درجة & التمريرة الصدرية & $\varepsilon$ \\
\hline
\end{tabular}




\begin{tabular}{|c|c|c|c|c|c|c|c|c|c|c|}
\hline$\cdots$ & $\varepsilon, q \wedge \vee$ & $\cdot .01 \mathrm{~V}$ & r, ro. & $\cdot, 0.4$ & $0, \varepsilon \ldots$ & ו ו & $v, 70$. & |درجة & التصويب الكرياجى & 0 \\
\hline$\cdots$ & $v, r \wedge v$ & $\cdot, 7 \leq 1$ & $r, \varepsilon \ldots$ & • & 0, . & $\cdot, 7.0$ & v, vo. & درجة & المهاراة الدفاعية & 7 \\
\hline$\cdots$ & $0,91 \mathrm{~V}$ &., 079 & $1, \vee \ldots$ & $\cdot, \sum \wedge १$ & $0,10$. & $\cdot, q 1 Y$ & $v, 00$. & درجة & الخداع & V \\
\hline
\end{tabular}

يتضح من جدول ( l l ) وجود فروق دالة إحصائياً بين متوسط درجات القياسين البعديين لدى للمجمـوعتين التجريبيـة والضـابطة في المتغيـرات المهاريـة قيـد البحـث لصـالح القيـاس البعـدي للمجموعة التجريبية . ثانيا: تقسير التتائج : بنـاء على مـا أظهرته وأسفرت عنـة النتائج الإحصـائية وفى حدود القياسـات التي تم إجراؤهـا، وفى الإطـار المحدد لعينـة البحث سـوف يـتم مناقثـة مدى تحقق الأهداف وصـدق الإق الفروض ومن واقع البيانات وفى ضوء المعالجات الإحصائية السابق عرض نتائجها وانطلاقا من فروض البحث توصل الباحث إلى مناقشة نتائجه على النحو التالى :

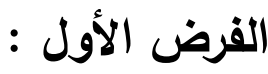

" توجد فروق دالة إحصائياً بين متوسط درجات القياس القبلي ، والبعدي للمجموعة الضابطة فى مستوى التحصيل المهارى والمعرفى لصالح القياس ألبعدي " . يتضـح مـن جدول (Yr) وجـود فـروق دالـة إحصـائيا بـين القياسـين القبلى والبعـى للمجموعـة الضـابطة في جميع مستويات الاختبـار المعرفى والاختبـار ككل فقد نراوحت نتيجة

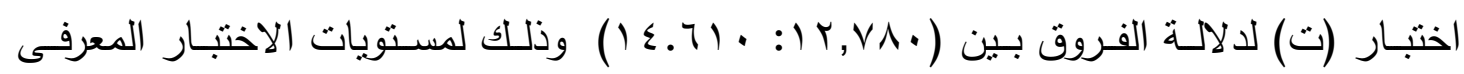
الثناثة ( الحفظ والتذكر - الفهم والاستيعاب - التطبيق ) وجات قيمـة ( ت ) للاختبار ككل (

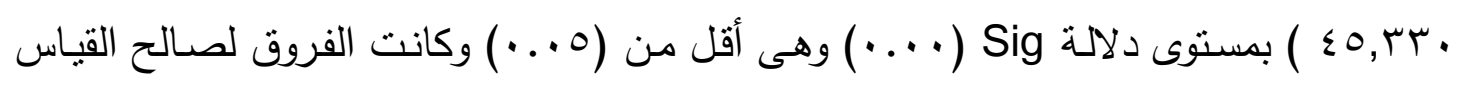
- البعدى بينمـا بتضـح من جدول (Tr) وجود فروق دالة إحصـائيا بين القياسين القبلى والبعدى للمجموعـة الضـابطة في جميـع الاختبـارات المهاريـة حيـث تراوحت نتيجـة اختبـار (ت) لدلالـة

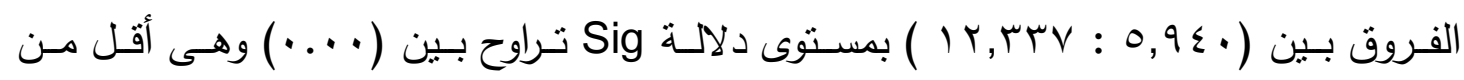
(0. . . ) وكانت الفروق لصالح القياس البعدى . 
كذللك يتضح من جدول (؟ Y) أن القياس البعدى للمجموعة الضابطة في جميع مسنويات

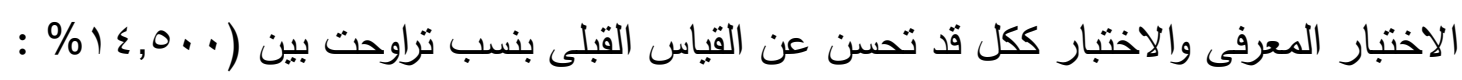
. (\%) $9,1 \%$.

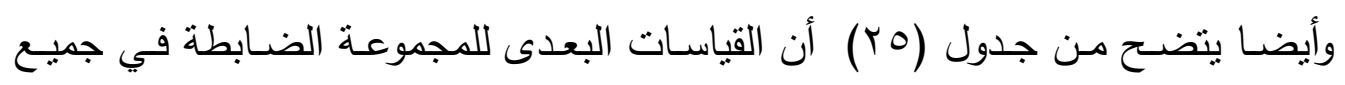

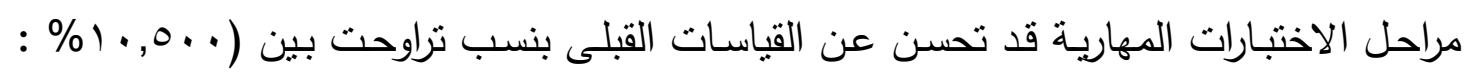
. $(\%) \wedge, 0 \ldots$

وتتبير تلك النتائج إلى أن البرنامج التعليمى المتبع بأسلوب ( الثرح والعرض ) في

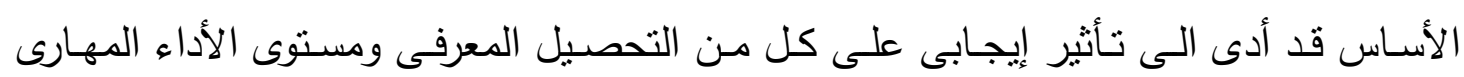
• للمتعلمين الاستين

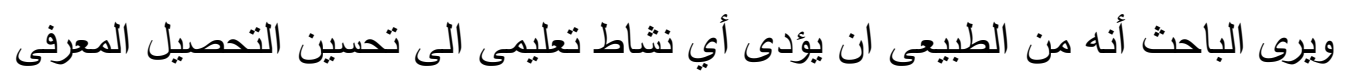

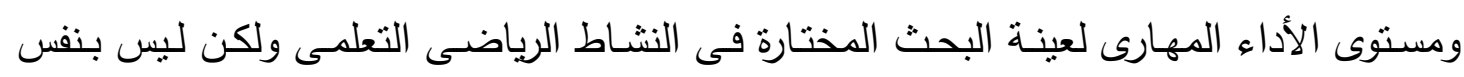
فعالية البرامج الأكثر تخصصية كالبرنامج المقترح والمعد من قبل الباحث ل ويعزو الباحث هذه النتيجة إلى أن التعلم ( بأسلوب الثرح والعرض ) المتبعة يقدم المزيد

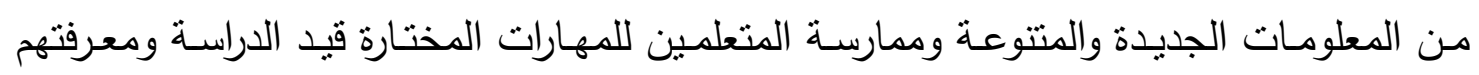

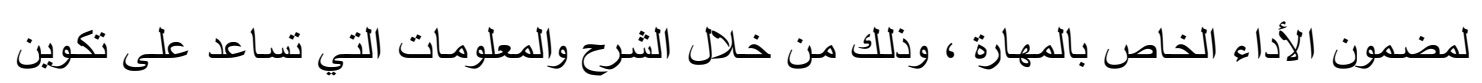
الصور الواضحة لتلك المهارات. كما يعزو الباحث سبب ذلك التقدم لدي المجموعة الضـابطة إلى جدوى ( أسلوب الثـرح

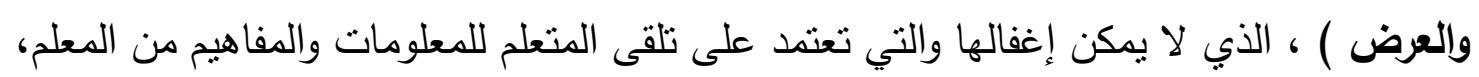
حيث قيام المتعلم بشرح المهارة وعرض نموذج لها والتندج في عملية تقديم التغذية الراجعة خلال

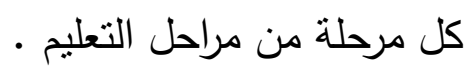

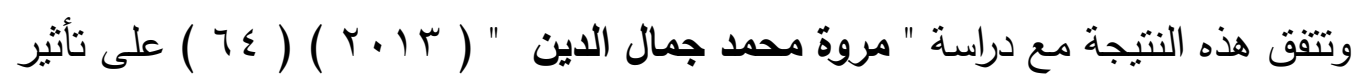
الثرح والعرض فى تحسن المجموعة الضابطة في كل من التحصيل المعرفى ومستوى الأداء .

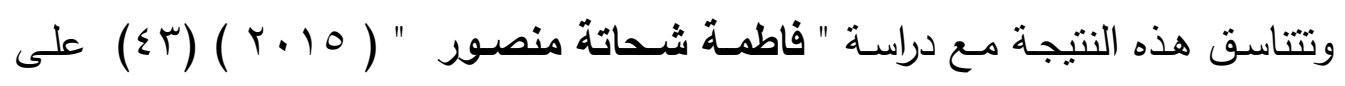
التأثنر الواضح لأسلوب الثرح والعرض في تحسن مستوى التحصيل المهارى لسباحة الزحف على البطن للمجموعة الضابطة. 
وبذاللك يتحقق الفرض الأول والذي يقرر " وجود فروق دالة إحصائياً بين متوسط درجات القياس القبلي والبعدي للمجموعة الضـابطة في مستوي كلاً من التحصيل المعرفي، والأداء المهارى " لصالح القياس البعدي.

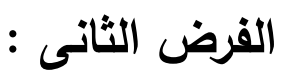

" توجد فروق دالة إحصائياً بين متوسط درجات القياس القبلي ، والبعدي للمجموعة

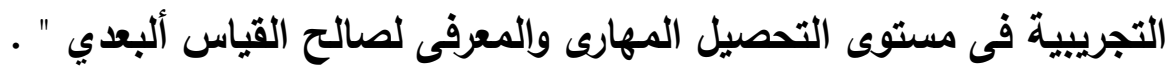

يتضـح مـن جدول (Tr) وجـود فروق دالـة إحصـائيا بـين القياسـين القبلى والبعدى

للمجموعة التجريبية في جميع مستويات الاختبار المعرفى والاختبار ككل فقد تراوحت نتيجة

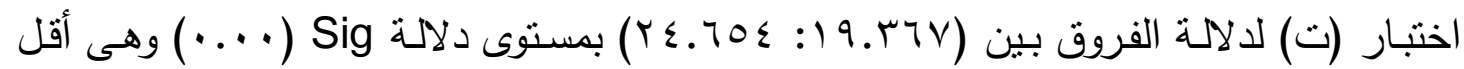
من (0.. •) وكانت الفروق لصالح القياس البعدى .

بينما يتضـح من جدول (YV) وجود فروق دالة إحصـائيا بين القياسين القبلى والبعدى

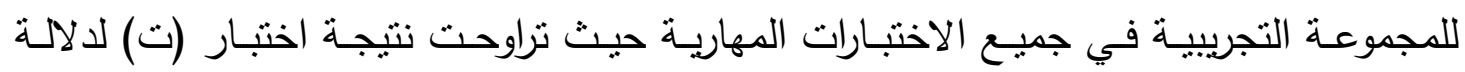

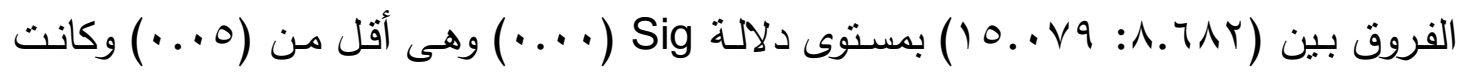

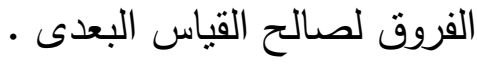

كذللك يتضح من جدول (Y^) أن القياس البعدى للمجموعة التجريبية في جميع مستويات

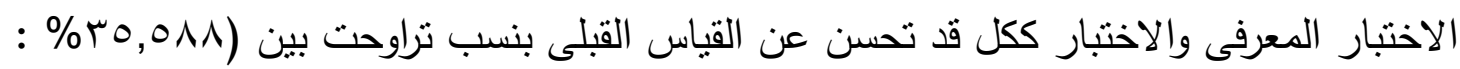

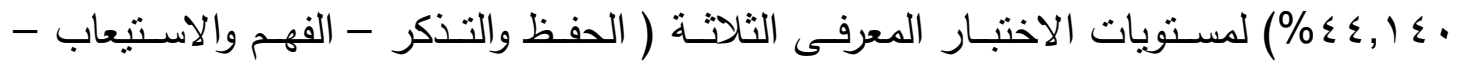
التطبيق ) وكانت نسبة تحست الاختبار ككل ( rی ., וء \% ) .

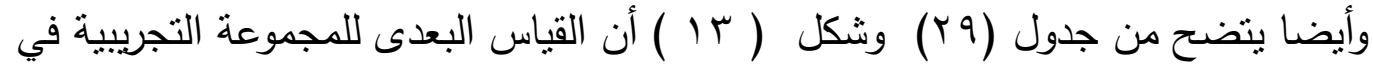

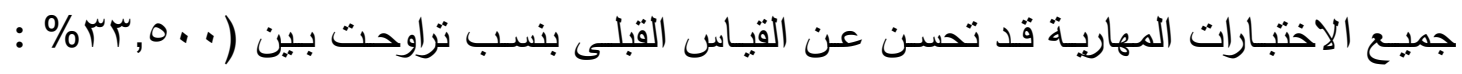
$\cdot(\% \leq 0, \ldots$

ويرى الباحث أن تفوق القياس البعدى للمجموع التجريبية عن القياس القبلى فى استخدام المقرر الإككترونى والمعد من قبل الباحث والذى ساهم فى استخدام العديد من مساعدات التعليم والوسائل التعليمية ، والتى قد لاتتوافر لدى العديد من المتعلمين من الوسائل السمعية والبصرية

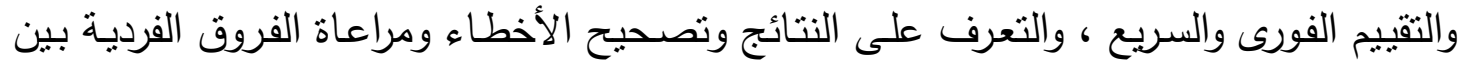

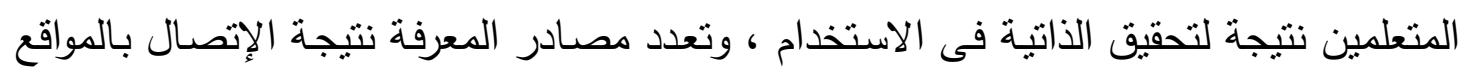
المختلفة على الثبكة العالمية للمعلومات ، وأن الطالب يتعلم ويخطى فئ في جو من الأد الخصوصية 
، كما أنه يمكنه ترك المراحل التى يراها سهلة أو غير مناسبة ، وتوسيع نطاق التعليم وتوسيع

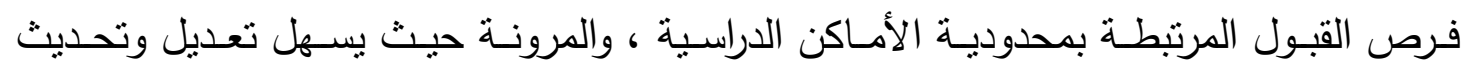

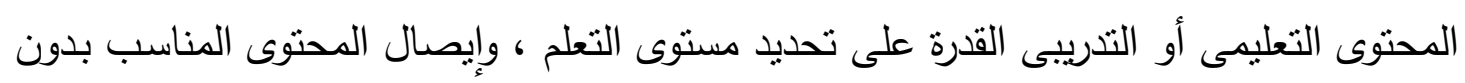

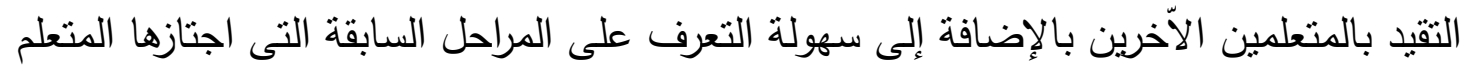

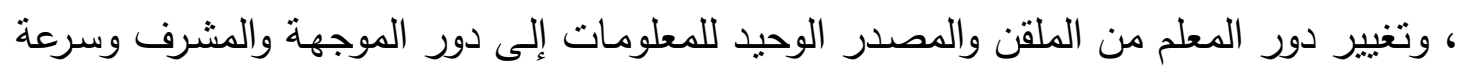

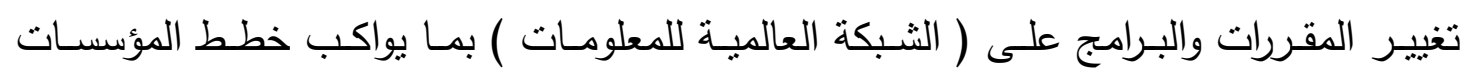

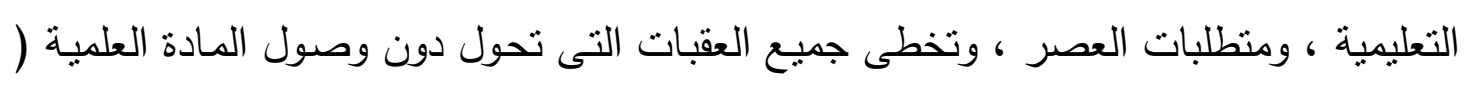

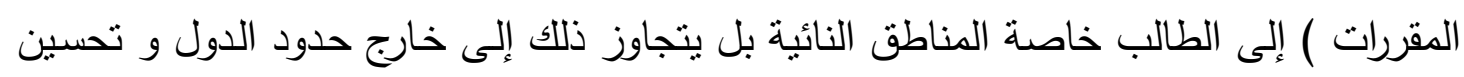
وإثراء محتوى العملية التعليمية وتتمية القدرات الفكرية .

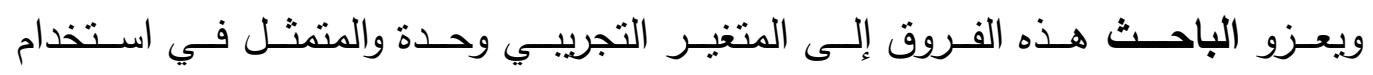

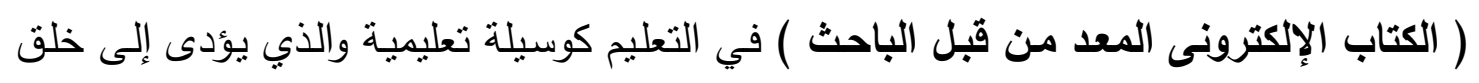

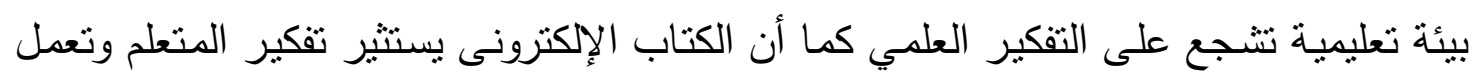

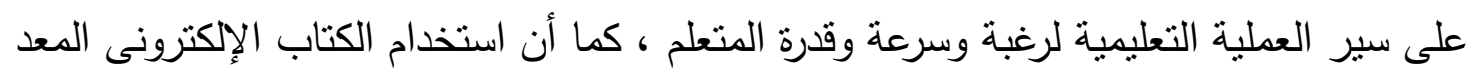

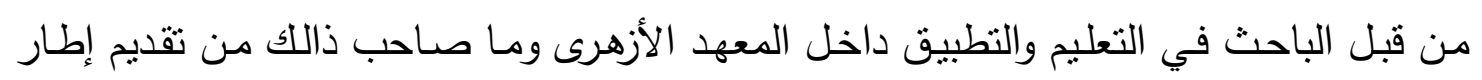
نظري وبيان عملي وتوفير التغذية الراجعة للأداء الصحيح قد ساعد على تفهم المتعلمين للمهارات

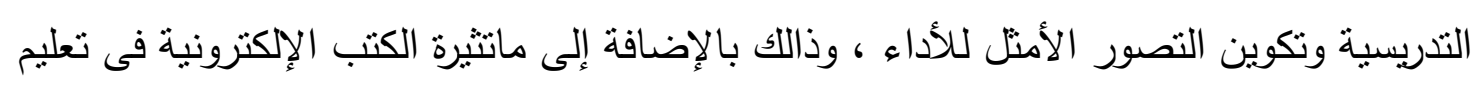

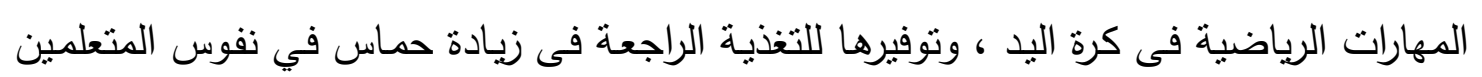
مما انعكس على أدائهم بسرعة وإتقان للمهارات التدريسية المختارة قبد البحث.

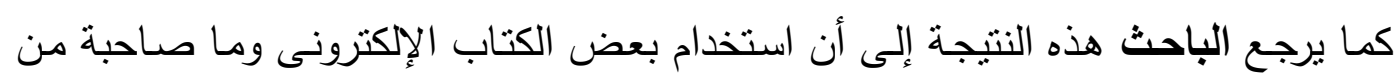

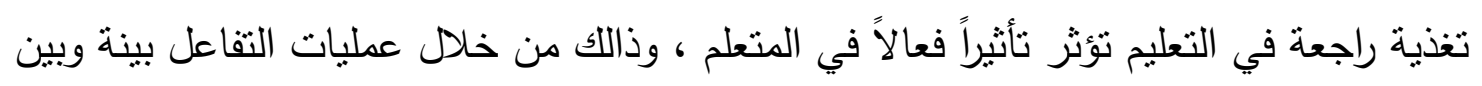

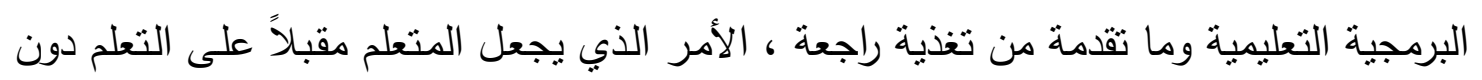

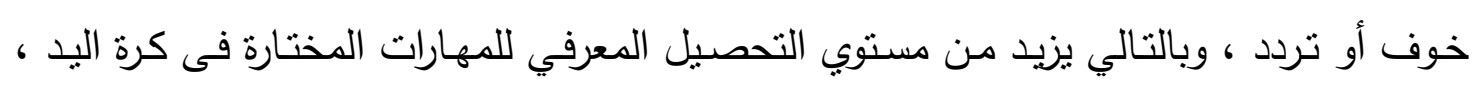

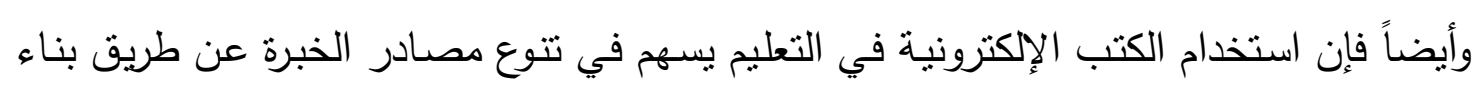

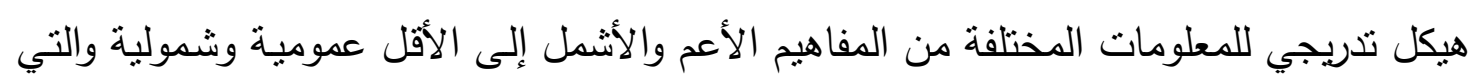

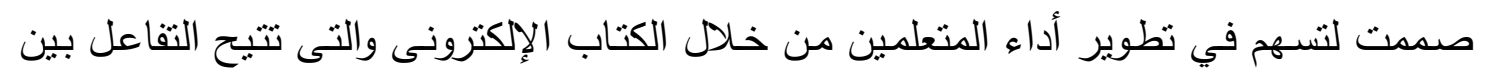

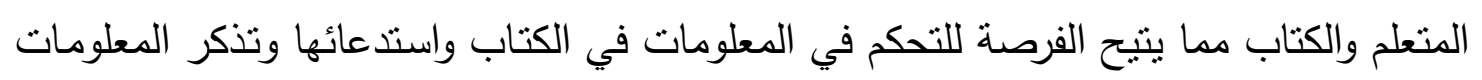
والحقائق والقوانين ، وكذلك إدراك الفرد للمعلومات التي تعرض عليه وليه واستخدام المواد والأفكار

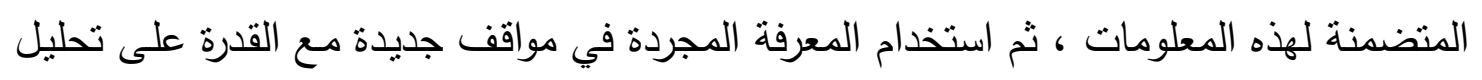


الدحتوي وتجزئته إلى العناصر التي تتكون منها إلي جانب القدرة على ربط عناصر أو أجزاء المعرفة لتكون شيء له معنى لم يكن موجوداً من قبل.

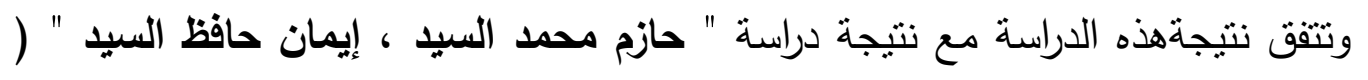

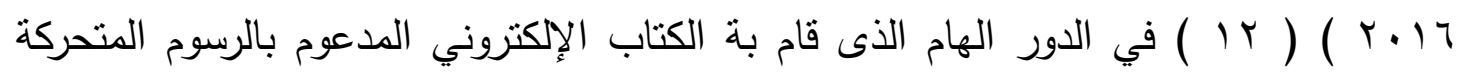

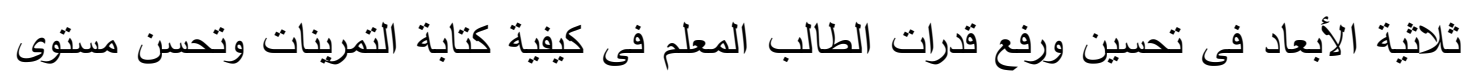

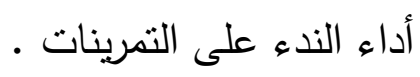

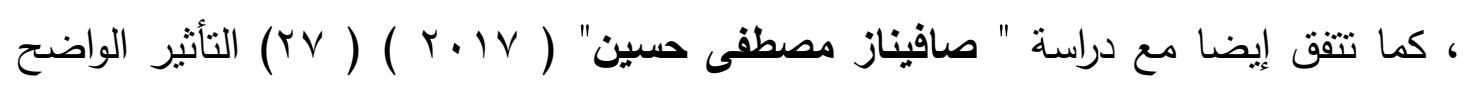
للكتاب الإكترونى فى تحسن مستوى التحصيل المهارى للمجموعة التجريبية عن الضابطة فى

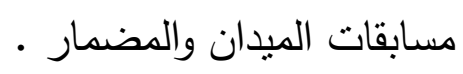

وبذالك يتحقق الفرض الثانى والذي يقرر " وجود فروق دالة إحصائياً بين متوسط درجات القياس القبلي والبعدي للمجموعة التجريبية في مستوي كلاً من التحصيل المعرفي، والأداء المهارى " لصالح القياس البعدي. الفرض الثالث : - | (الث

" توجد فروق دالة إحصائياً بين متوسط درجات القياس البعدى بين كلا من المجموعة ، التجريبية ، والضابطة فى مستوى التحصيل المهارى والمعرفى لصالح المجموعة التجريبية " . يتضح من جدول (•r) وجود فروق دالة إحصائيا بين المجموعة الضابطة والمجموعة

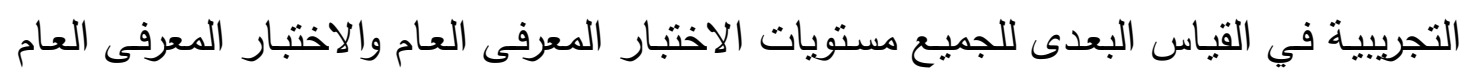

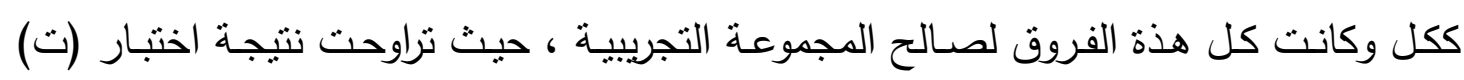

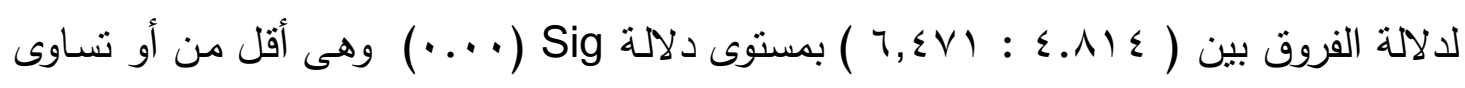

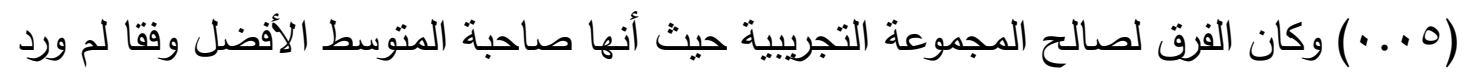

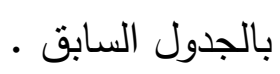

كمـا ينضـح مـن جدولي (اب) وجود فروق دالـة إحصـائيا بين المجموعـة الضـابطة والمجموعة التجريبية في القياس البعدى لجميع الاختبارات المهارية لصالح المجموعة التجريبية

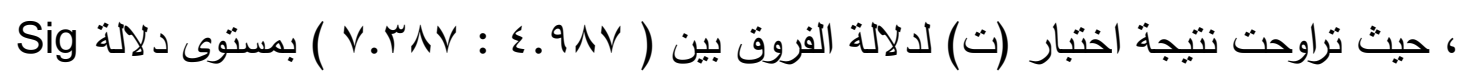

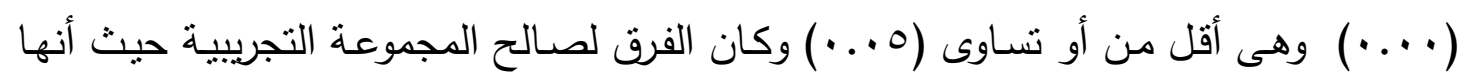


صاحبة المنوسط الأفضل وفقا لم يتضح أيضا من شكل (0r) . ويعلل الباحـث هذه الفروق الإحصـائية بـين المجموعتين التجريبيـة والضـابطة ولصـالح

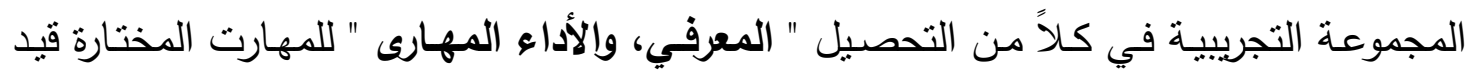
الدراسة أن الكتاب الإلكترونى المعد من قبل الباحث والتي خضعت لها المجموعة التجريبية تهنم

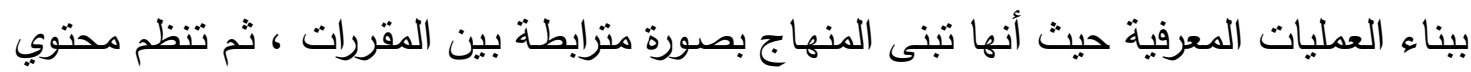

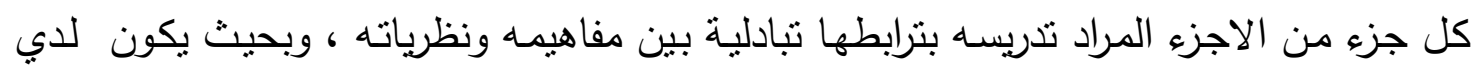

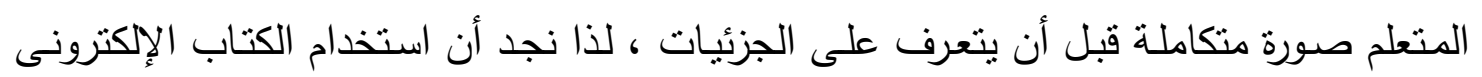

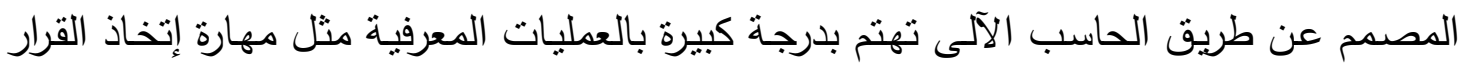
والتفكير وأن التعليم يقاس بقدرة الطالب على التعرف على أبعاد الموقف والترابطات بين أجزاؤه.

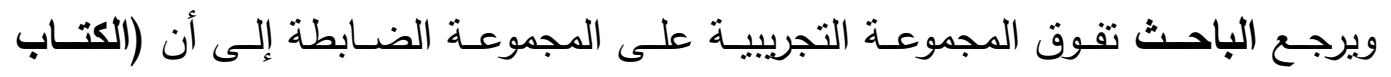

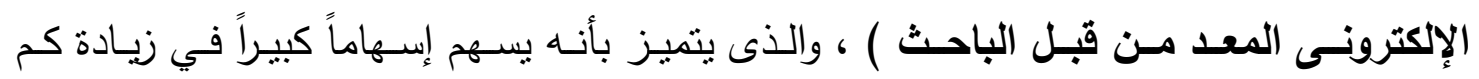

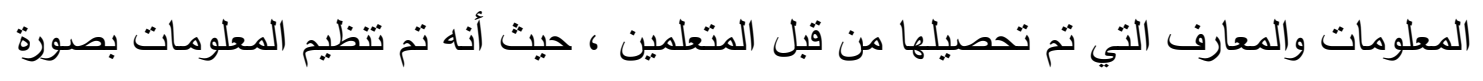

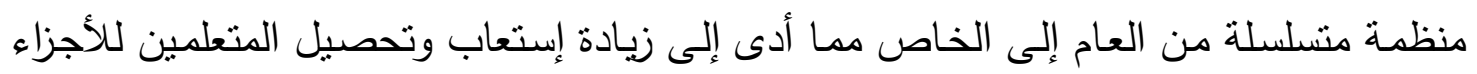
المقرر تدريسها في كل محاضرة. ويعزو الباحث التقدم في مستوي الأداء المهارى للمهارات المختارة للمجموعة التجريبية إلى لى الكي

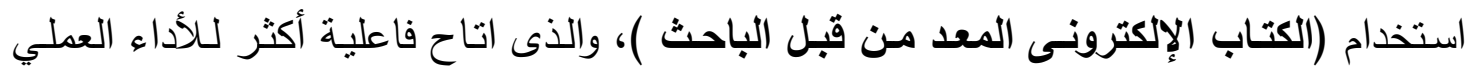

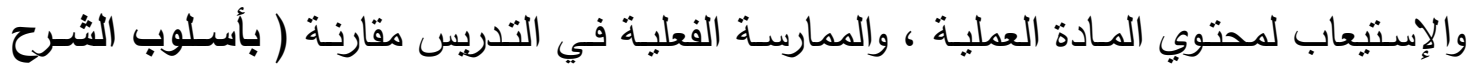

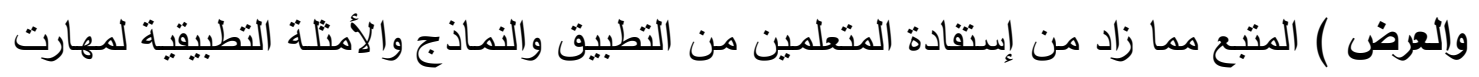
كرة اليد المقررة قيد الدراسة ، وكذلك استخدام (الكتاب اللإلكترونسى ) في عملية التعليم وأيضاً

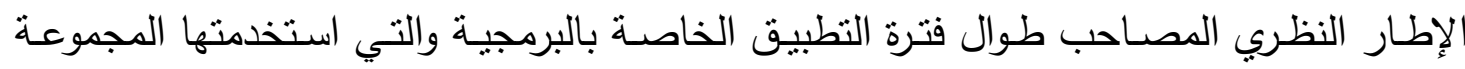

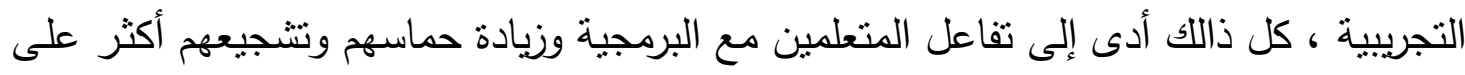

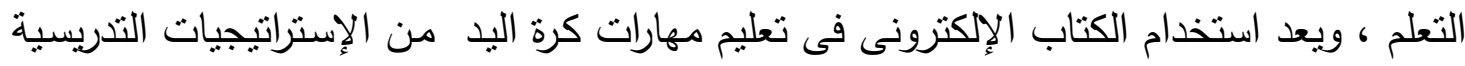

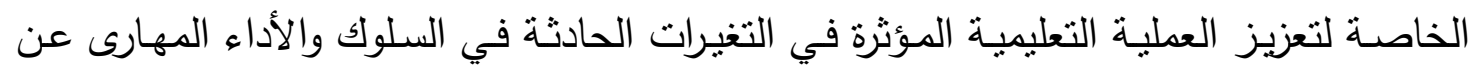

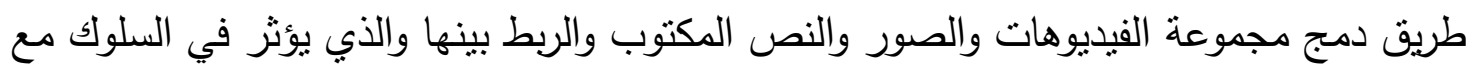
إعادة التذعيم بتكرار عرض البرمجية .

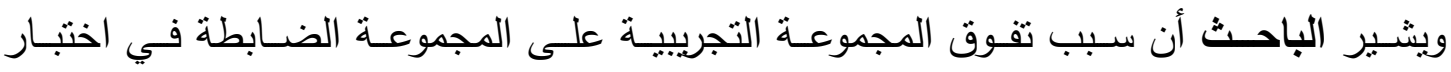

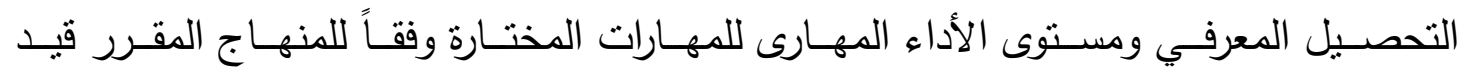

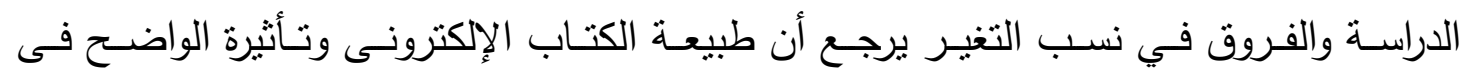

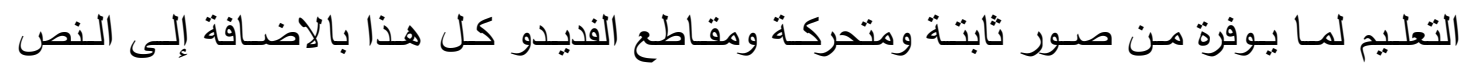




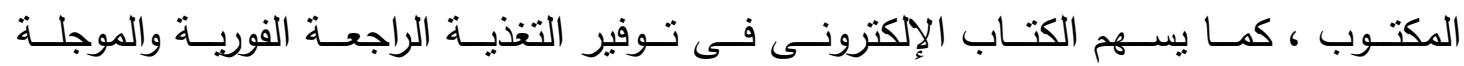
للمتعلمين التى ساعدة في عمليات التذكر والإحتفاظ بالتعلم لمدي طويل.

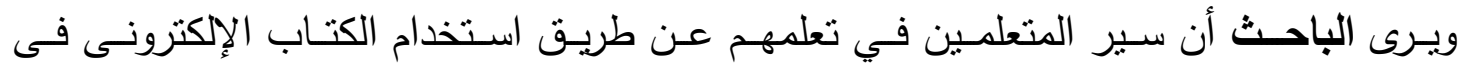

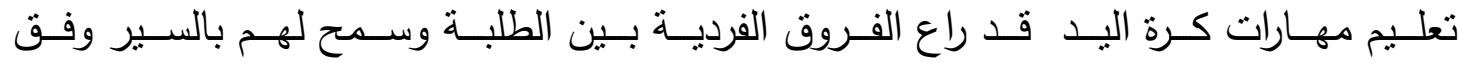

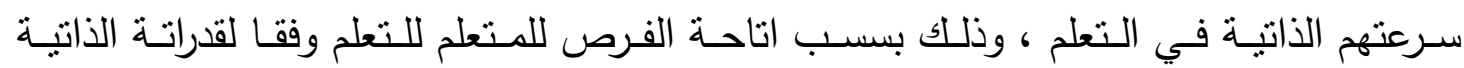

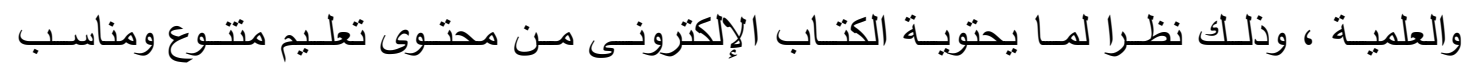
لمختلف المراحل العمرية .

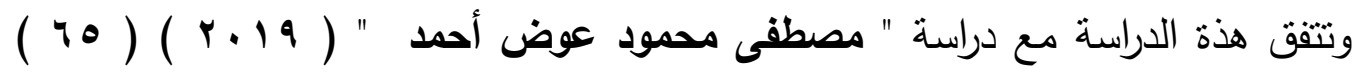

والتى أكدت على وجود فروق دالة احصائية بين القياسين البعديين للمجموعتين التجريبية والضابطة لصالح المجموعة التجريبية مما يدل على التأثير القوى للمقرر الإلكترونى فى مستوى لئى التحصيل والمعرفى وتحسن المستوى الوجدانى .

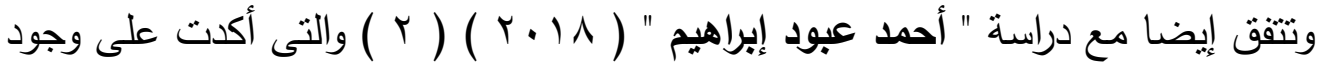
فروق دالة احصائية بين القياسين البعديين للمجموعتين التجريبية والضابطة لصالح المجموعة التجريبية مما يدل على التأثير القوى للمقرر الإلكترونى فى مستوى التحصيل المهارى والمعرفى

كما اتققت إيضا مع دراسة " توم هارى وويرد Tom Harry and Ward

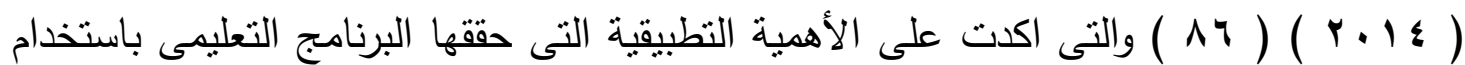
تكنولوجيا التعليم الإكترونى فى تحسن مستوى طلاب المجموعة التجريبية فى المستوى المهارى • وبذلك تتحقق صحة الفرض الثالث والتي تتص على أنه " توجد فروق دالة إحصائياً بين متوسط درجات القياس البعدى بين كلا من المجموعة التجريبية ، والضابطة فى مستوى التحصيل المهارى والمعرفى لصالح المجموعة التجريبية " 
فى ضوء المعالجة الإحصائية ونتائج البحث التى تم التوصل إليها الباحث ، وفي ضوء

العينة المختارة والمنهج المستخدم تمكن الباحث الوصول إلى الإستتناجات التالية:

1- نوجد فروق دالة إحصائية بين متوسط درجات القياس القبلي والبعدي للمجموعة الضابطة (أسلوب الثرح والعرض) فى مستوى " التحصيل المعرفى ومستوى الأداء المهارى" لتعلم مهارات كرة اليد المختارة لصالح القياس البعدي.

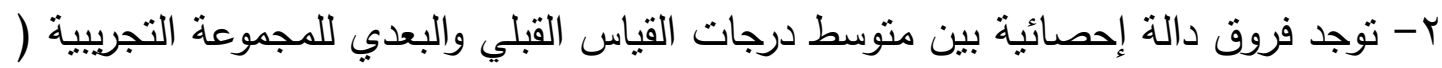

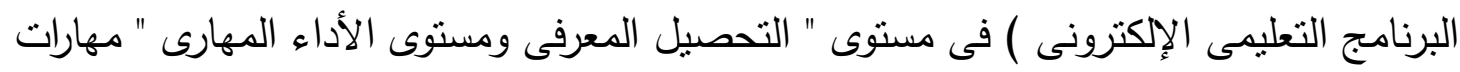
كرة اليد المختارة لصالح القياس البعدي. r- توجد فروق دالة إحصائية بين متوسط درجات القياسات البعدية للمجموعنين الضابطة والتجريبية فى مستوى " التحصيل المعرفى ومستوى الأداء المهارى " لتعلم مهارات كرة اليد المختارة لصالح المجموعة التجريبية. ؟ - نوجد فروق دالة احصائية بين نسب تحسن كل من المجموعة التجريبية والضابط فى مستوى

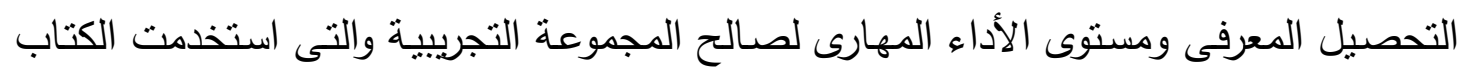
الإلكترونى فى تعلم مهارات كرة اليد المختارة . 0- برنامج الكتاب الإلكترونى والمطبق على المجموعة التجريبية كان أكثر فاعلية من الأسلوب التقليدى فى التعليم " الثـرح والعرض " حيث كـان لـة تأثير إيجابى على مستوى التحصيل المهارى والمعرفى لمهارات كرة اليد المختارة .

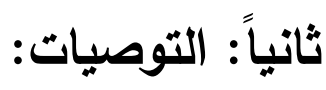

في ضـوء مـا أسفرت عنـه نتائج البحث إعتمـاداً على البيانات ، والمعلومـات التي أمكن التوصل إليها يمكن الإستفادة منها في مجال طرق تدريس التربية الرياضية ، ومن خلال هذه الدراسة يتقام الباحث بالتوصيات التالية:

1- تطبيق البرنامج التعليمى الإلكترونى باستخدام الكتاب الإلكترونى لتعلم مهارات كرة اليد على

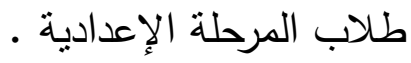


r- العمل على أن تتضمن برامج إعداد معلم التربية الرياضية قبل الخدمة وأثنائها على كيفية

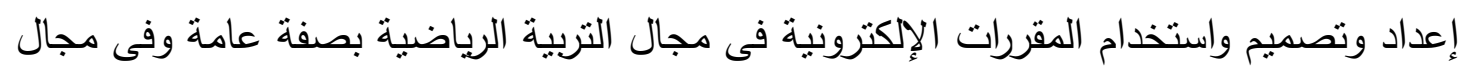

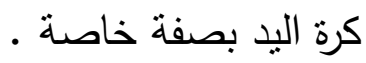

r- تطبيق البرنامج التعليمى الكتاب الإلكترونى فى تعلم مهارات اخرى فى كرة اليد وانشطة

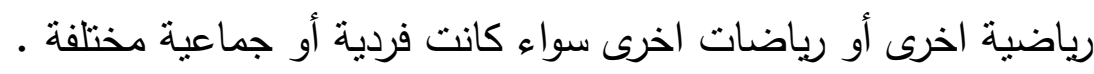
ع - تطبيق البرنامج التعليمى الكتاب الإلكترونى على مراحل دراسية اخرى مختلفة حتى تساعد على تتمية وتطوير المتغيرات البننية والمعرفية والمهارية . 0- إجراء دراسات مشابهة باستخدام الكتاب الإلكترونى لانشطة رياضية متتوعة ومختلفة .

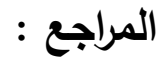

1- أحمد ماهر أنور، على : التدريس في التربية الرياضية بين النظرية والتطبيق ، طا ، دار الفكر العربي ،

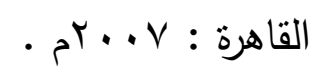

محمد عبد المجيا

: تكنولوجيا المعلومات ووسائطها الإكترونية ، مكتبة النهضة المصرية ، القاهرة :

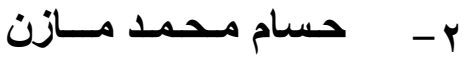
$\cdot$. $r \cdot 1$

فاعلية استخدام مقرر إليكتروني لمنهاج كرة السلة للمرحلة الإعدادية على نواتج التعلم

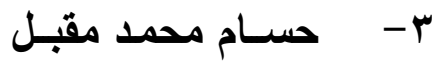

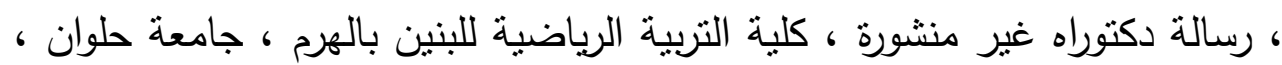

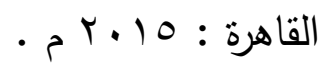

: فعالية تصميم مقرر إلكتروني قائم على استراتيجيات الاحتفاظ بالمعلومات في

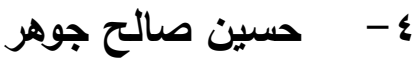

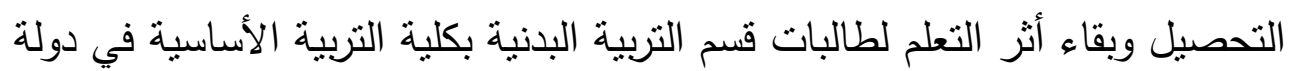

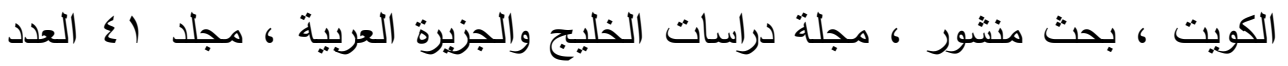

$$
\text { • } 10: 10 \mathrm{~V}
$$

: فاعلية مقرر إلكتروني مقترح على تعلم مهارة الارسال في كرة الطاولة لتلاميذ المرحلة ه- حسين صالح عبد اللة المتوسطة بدولة الكويت ـ مجلة علوم الرياضة وتطبيقات التربية البدنية ، جامعة

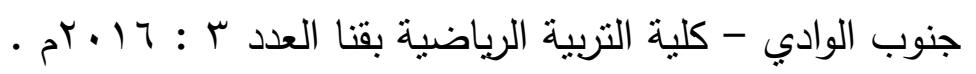

: الجودة في التعليم الإكتروني ( مفاهيم ونظرية وخبرات علمية ) ، الإسكندرية دار

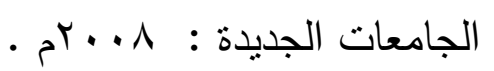

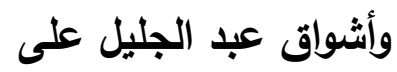

: فاعلية تصور مقترح لمقرر إلكتروني في تقنيات التعليم على التحصيل الدراسي والاتجاه نحو المقرر ، بحث منشور المجلة التربوية الدولية المتخصصة ، مجلد اعليه

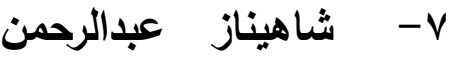

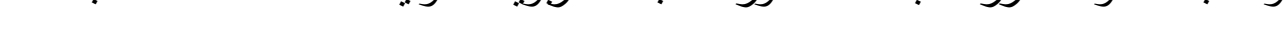




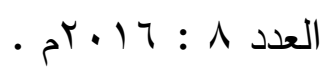

: تأثير الوسائط الفائقة على تعليم بعض مهارات الريشة الطائرة لطلاب كلية التربية - - - مسلاح بريسم صـالح الرياضية بجامعة ميسان ، رسالة ماجستير ، كلية التربية الرياضية للبنين بالهرم ،

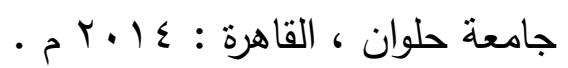

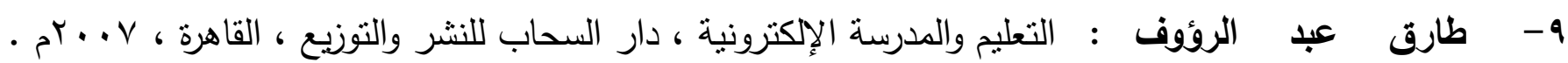
عامر • 1 - عبد الله بن إسحاق ، وسائل الاتصال التعليمية ، مطبعة بهادر، مكة المكرمة، الطبعة الرابعة : ^ . . بم. إحسان بن محمد عثمان

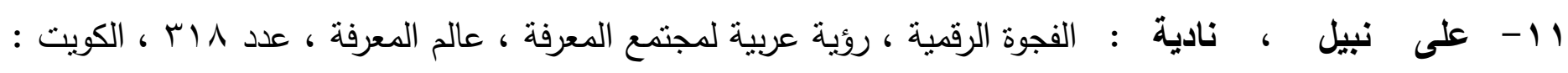
- + . 9 حجازي

r ا - ماجد مصطفى إسماعيل : تأثير استخدام تكنولوجيا الوسائط المتعدة على مستوى أداء بعض المهارات في كرة القدم ، مجلة علمية محكمة ، كلية الداب ، جامعة المنوفية ، مركز الخدمة ، إبراهيم المتولي أحمد

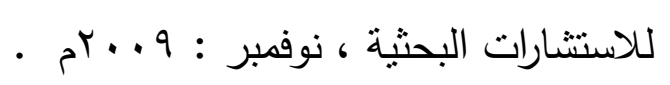

: تكنولوجيا التعليم والوسائل التعليمية ، طب ، دار ومكتبة الإسراء للطبع والنشر

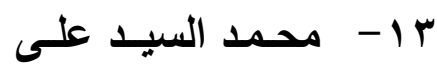

$$
\text { والتوزيع ، طنطا : } 9 \text {. . ب م. }
$$

: فاعلية مقرر إلكترونى لرفع الاتقال على نواتج التعلم المستهدفة لطلاب كلية التربية

\& 1 - محمد حسن محمد حسن الرياضية ، بحث منشور ، مجلة بحوث التربية الرياضية ، كلية التربية الرياضية

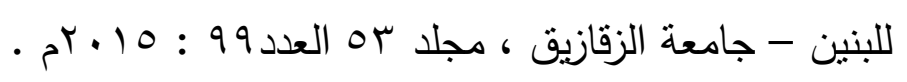

ه - - محمد علي محمد أحمد : أثز الكتاب الإلكتروني المفترح لمقرر الأحياء بالصف الثانوي على التحصيل الدراسي للطلاب بولاية جنوب دارفور : دراسة تحليلية تطبيقية .مجلة جيل العلوم الإنسانية

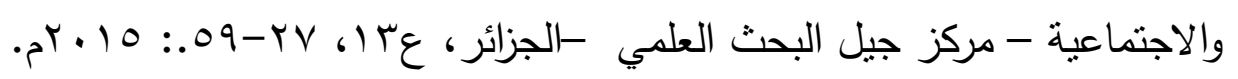

جا - منـه الله حسن نعمان : أثز التفاعل بين أنماط بناء الفيلم التسجيلي التعليمي وتوقيت المناقشة الجماعية في هرحري التحصيل وبقاء أثز التعلم، رسالة ماجستير، كلية التربية ، جامعة حلوان: ب ا ـ بـم. سلام IV - يوسف جابر محمد : تأثير برمجية تعليمية باستخدام الوسائط الفائقة على تعلم بعض مسابقات العاب القوى لتلاميذ المرحلة الابتدائية بمحافظة شمال سيناء ، رسالة ماجستير غير منشورة محمد ، كلية التربية الرياضية ، جامعة بنها : ع ا • بام .

ثانيا : المراجع الاجنبية :

18 Dabbagh, $\mathbf{N}$
: Pedagogical models for E-Learning: A theory-based design framework. International journal of technology in teaching 
and learning, 1(1), 25-44:2005.

19 James Cawlnia \& : The impact of the use of Electronic Modules in educational to Kevin Gigallo teach some of the offensive Skills to Epee in Fencing Journal of Physical Education Studies and Research Vol. 52 No. $1818: 2018$.

20 Korhonen, A., Naps, : Requirements and design strategies for open source interactive T., Boisvert, C computer science eBooks Teaching and permanent learning. Paper presented at the 53-72: 2013.

21 Tom Harry \& Ward : Communication and Relationship with Hearing Impaired Children, Jopered: The Journal of Physical Education Education, Recreation and Dance, 77(6): 34- 40. from http://search. ebsco host. com/login. aspx. Professional Development Collection : 2014 . 


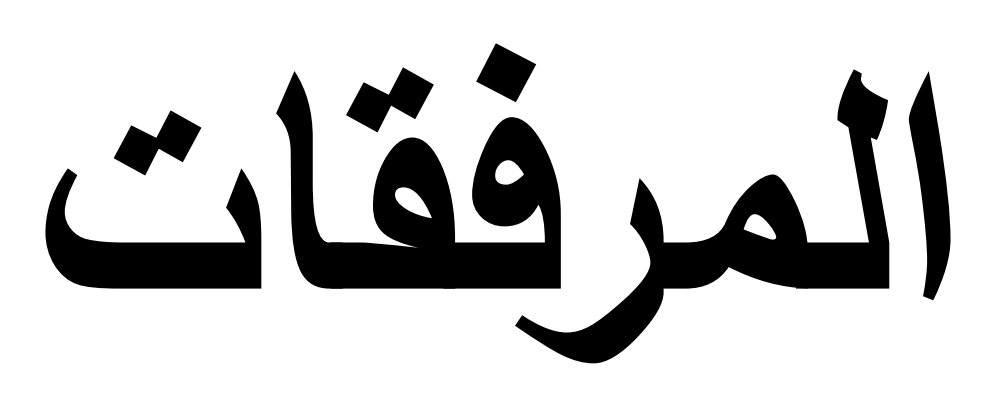




$$
\text { مرفــق ( ) }
$$

أسمـــاء الســادة الخبــراء 


\begin{tabular}{|c|c|c|}
\hline وظلفت & ــم الخبيبـــــر & م \\
\hline 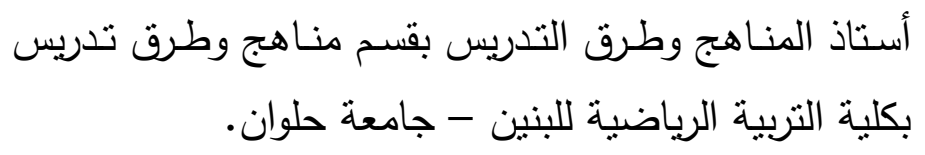 & أ.د// أحمد ماهر أنور حسن & -1 \\
\hline أسـتاذ طـرق التـدربس بقسـم منـاهج وطـرق تـدريس التربيـة & أ.د//عادل فوزى جمال & $-r$ \\
\hline 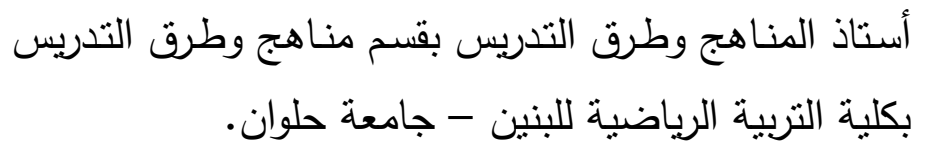 & أ.د/ جمال الدين عبد العاطى الشافعى & $-r$ \\
\hline 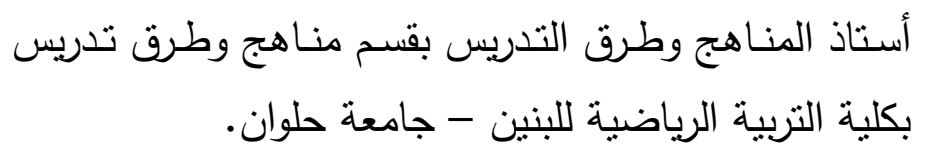 & أ.د// محمد عاطف الابحر & $-\varepsilon$ \\
\hline 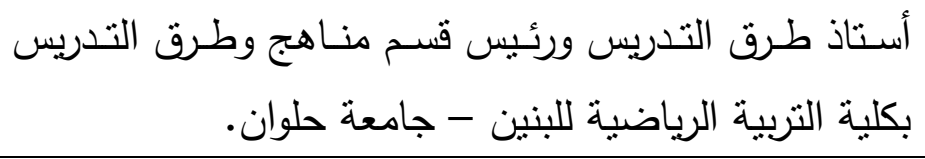 & أ.د/ مصطقى محمد أحمد الجبالى & -0 \\
\hline أسـتاذ طـرق التـدريس بقسـم منـاهج وطـرق تـدريس التربيـة & أ.د/ نبيل محمد محمد حسن & -7 \\
\hline 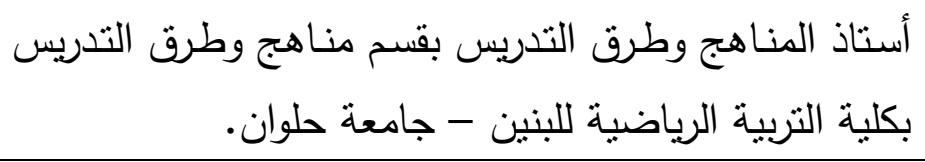 & أ.دد/ أحمد عبد العزيز معارك & $-V$ \\
\hline أســاذ أصــول التربيـة بقــم منـاهج وطـرق تـدريس التربــة & أ.د/ محسن رمضان على & $-\Lambda$ \\
\hline أســاذ طـرق التـريس بقسـم منـاهج وطـرق تـدريس التربــة & أ.د/ مدحث عاصم سيد & -9 \\
\hline أســاذ أصــول التربيـة بقسـم منـاهج وطـرق تـدريس التربيـة & أ.د/ محمد حامد عبد الخالق البلتاجى & -1. \\
\hline أســاذ طـرق التـربس بقسـم منــاهج وطـرق تـدريس التربيـة & أ.د/ عابر محمد سيد & -11 \\
\hline أسيـاذ طـرق التـدريس بقسـم منــاهج وطـرق تـدريس التربيـة & أ.د/ أحمد الوزير & $1 Y$ \\
\hline
\end{tabular}

أسماء السادة الخبراء الذين تم استطلاع رأيهم من أعضاء هيئة التذريس 


$$
\text { مرفــق (r) }
$$

\section{أسماء السادة المحكمين ( لجنة التقييم ) من}

الموجهين والمدرسين بالمعهذ 


$$
\text { بيانات بأسماء السادة المحكمين ( لجنة التقييم ) }
$$

من أعضاء هيئة التدريس بمنطقة المراغة الأزهرية بمحافظة سوهاج

\begin{tabular}{|c|c|c|}
\hline 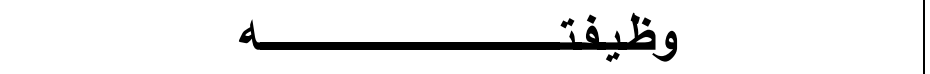 & اســـــــــم المحكم & b \\
\hline موجه أول عام بمنطقة المراغة الأزهرية بمحافظة سوهاج • & خالد محمد نبيل محمود & -1 \\
\hline موجه أول عام بمنطقة المراغة الأزهرية بمحافظة سوهاج. & أحمد على أحمد & $-r$ \\
\hline |مدرس أول تربية رياضية بمعهد مجمع بدر الأزهرى التابع & شريف إبراهيم محمد & $-r$ \\
\hline
\end{tabular}

أسماء السادة المحكمين ( لجنة التقييم ) من أعضاء هيئة التدريس بمنطقة المراغة الازهرية بمحافظة سوهاج 


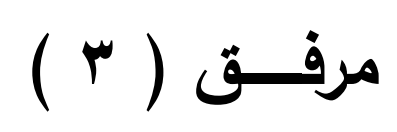

نموذج لبعض اجزاء الكتاب الإكترونى المعد من

الباحث لمهارت كرة اليد لطلاب المعاهد الأزهرية 

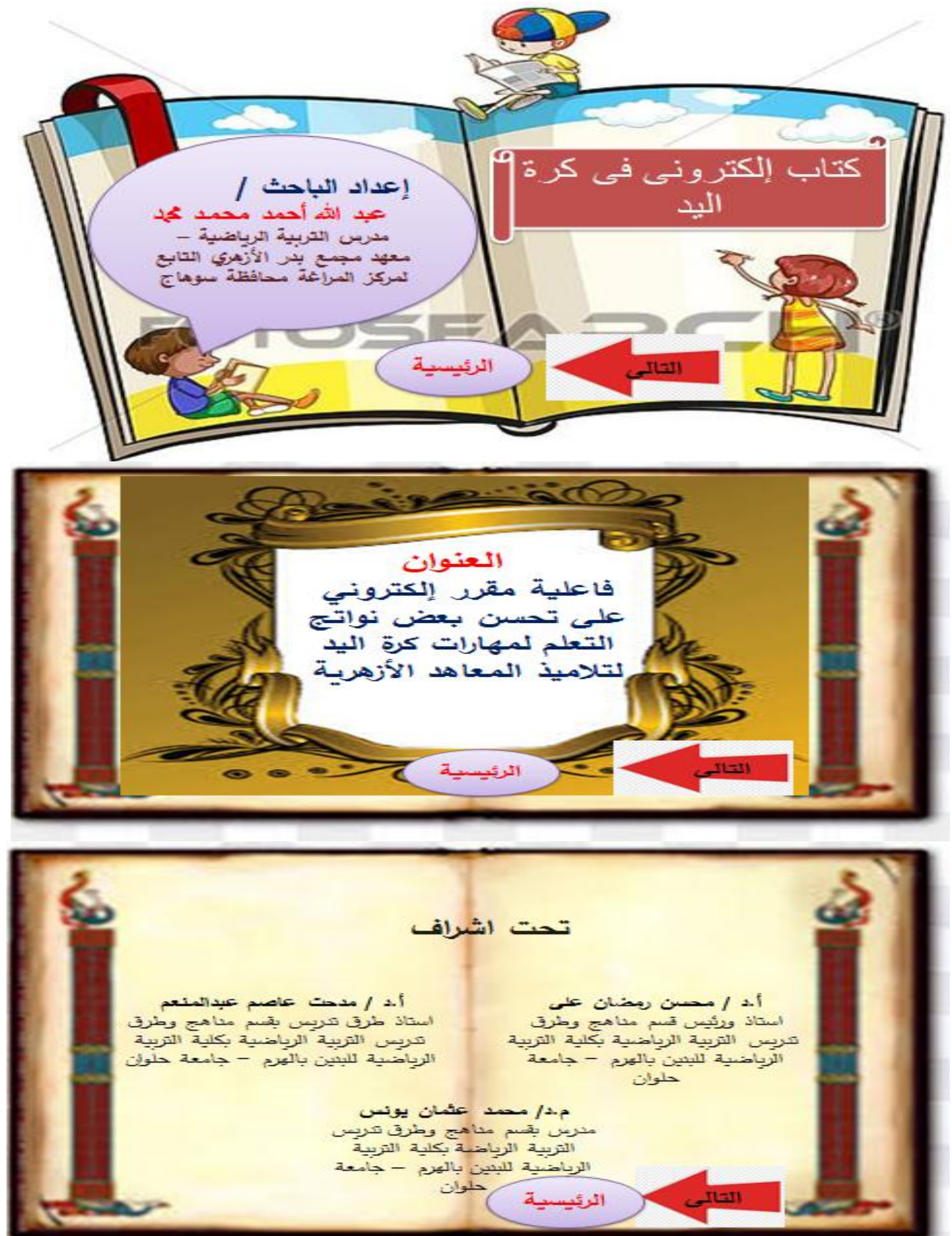


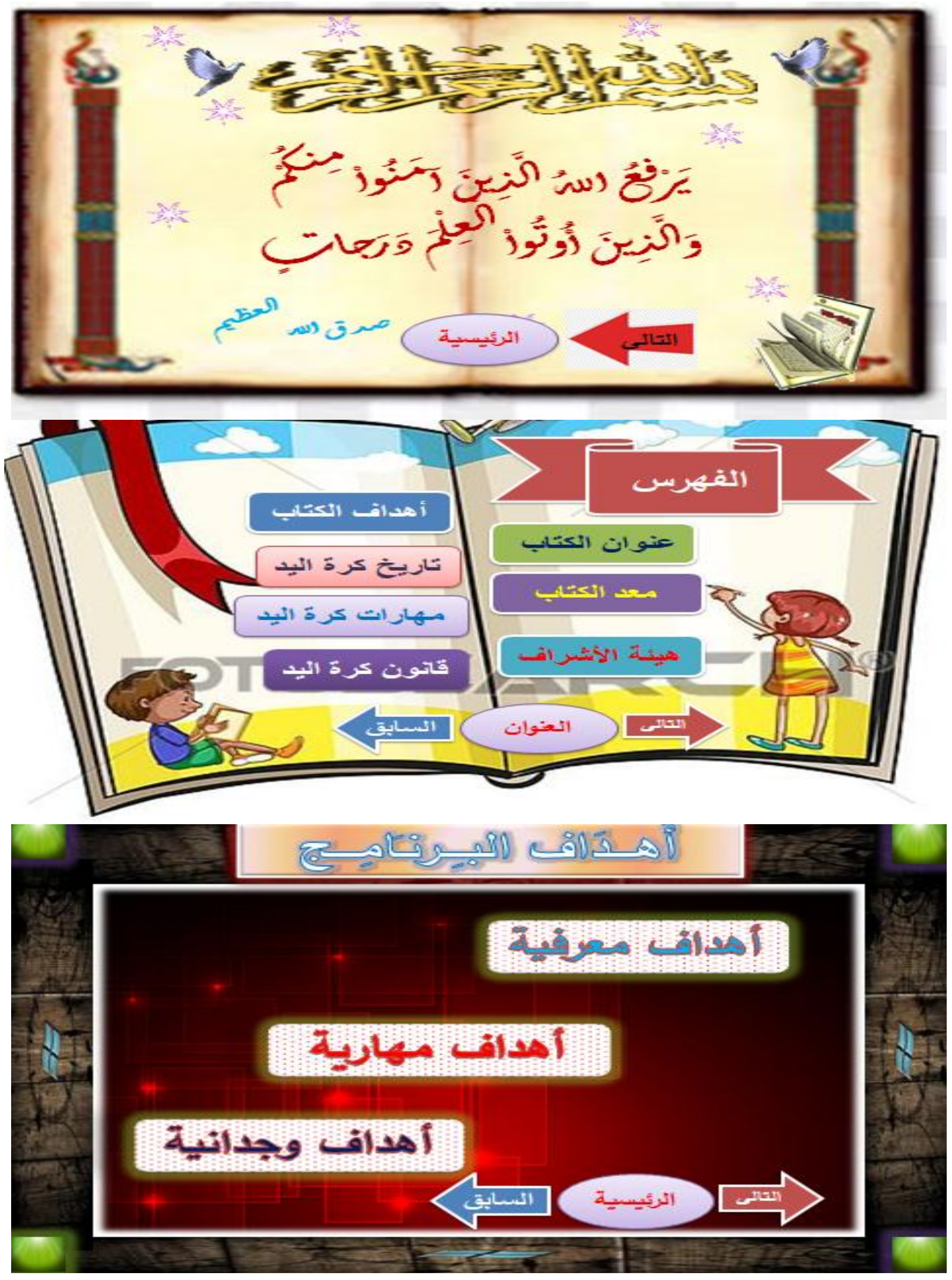




\section{- đั.}

3 - أن يفـرق المـتعلم

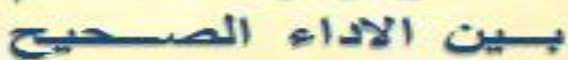
والخـاطى لمهـارت كيرة اليث 4

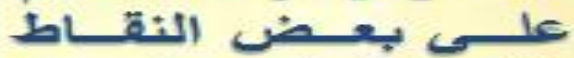
القانونية الحثاصنة بكرة اليث.
1

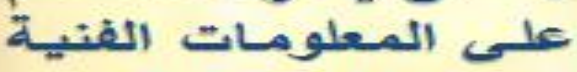
عن مهارات كرة اليث. 2 - 2

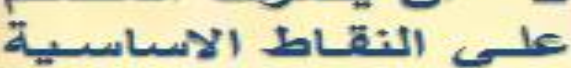

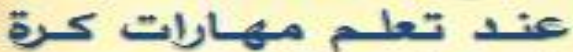
اليث المختخلفة.
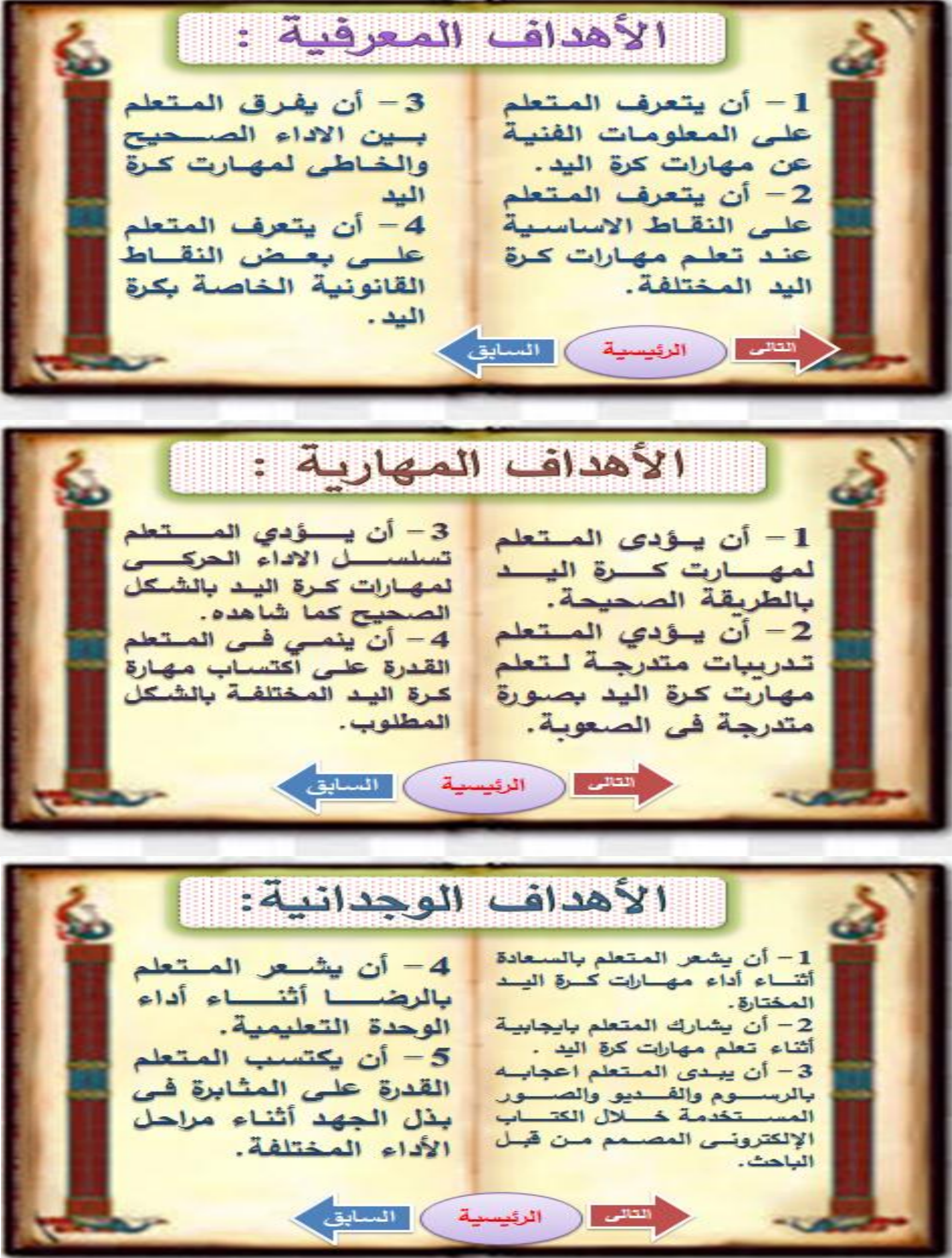

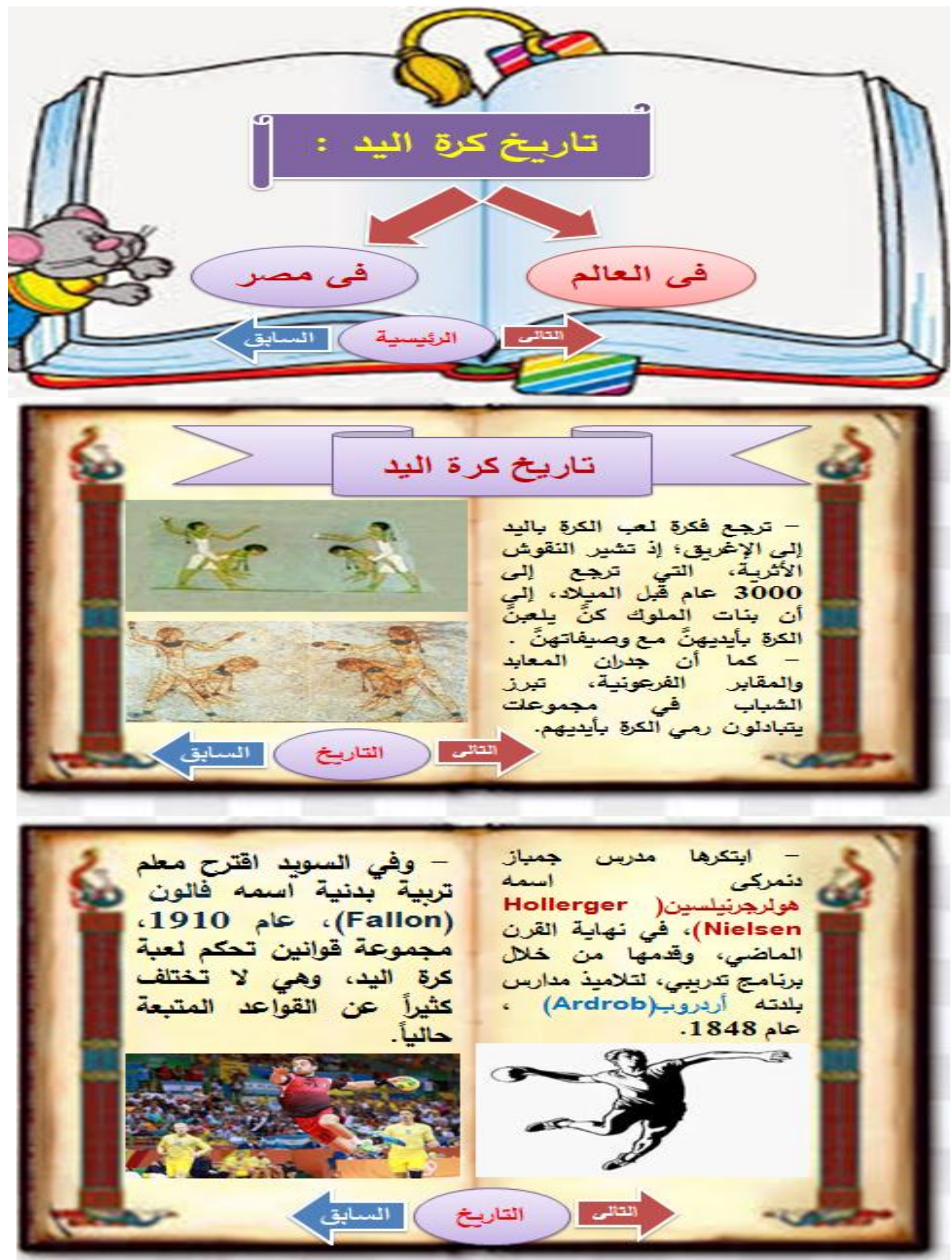

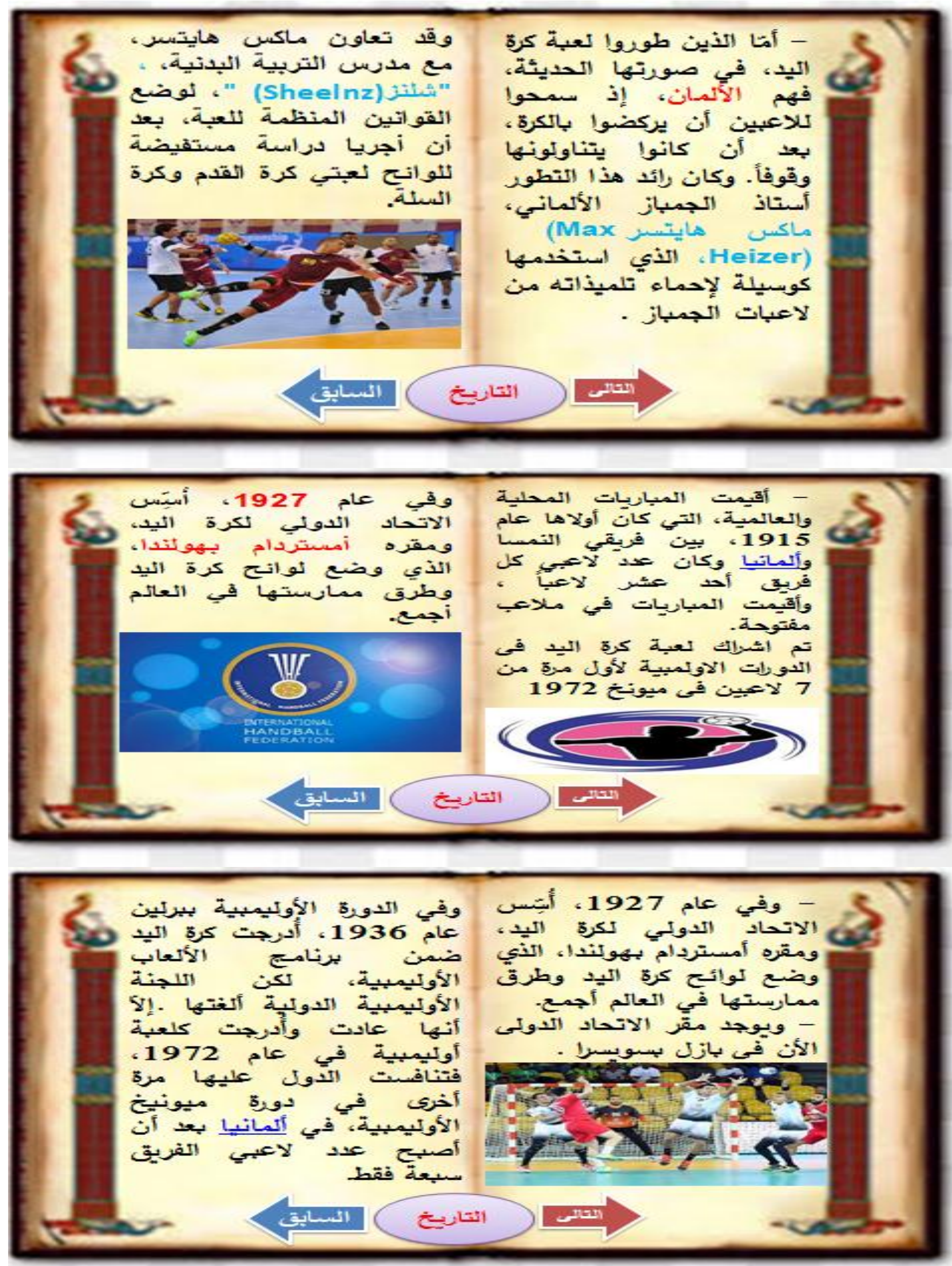


$$
\text { كرة اليث في مصر }
$$

ويرجح المضل الكييز في نهي

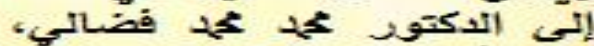

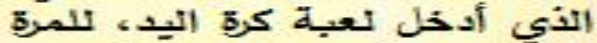

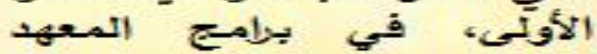

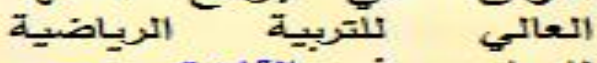

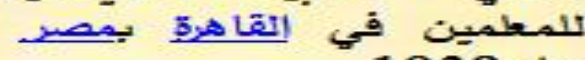
- عام 1938

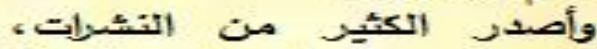

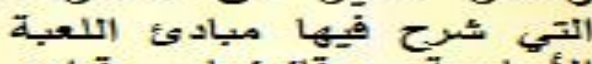

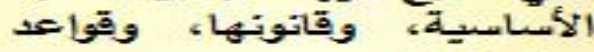
مصاربستها.

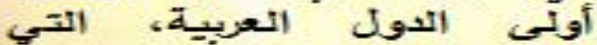

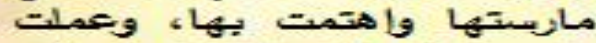
على تطويرها وانتئسارها في في كاقة الثول المعربية.
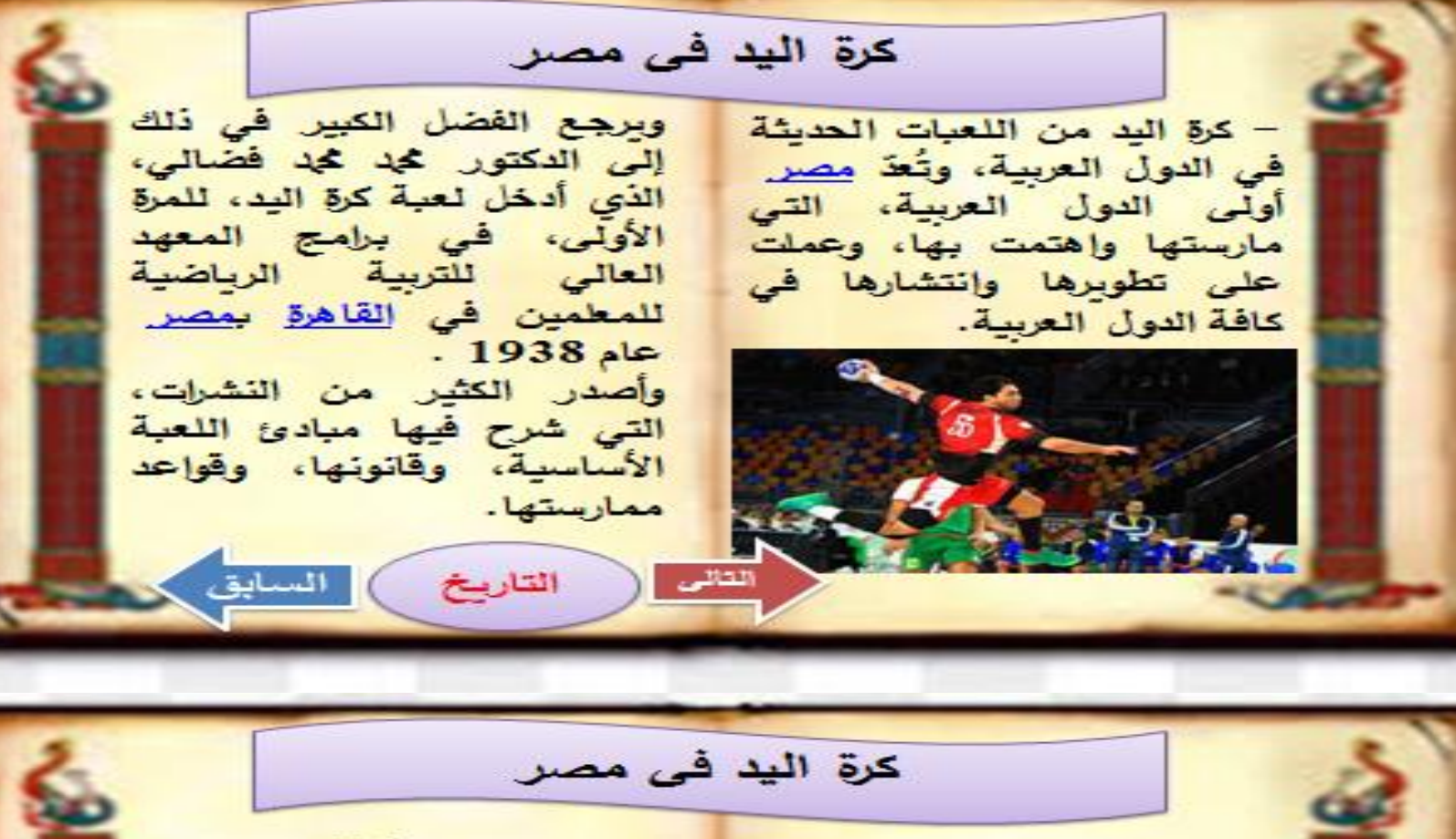

كرة اليث فه مصر

وصدرت موافقة الاتحاث الثوني لكرة اليد، على قيود

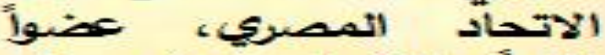
دائماً بالاتحاد الثدفي عام 1960 فازت مص مصر بيطونة كاسن التعايم للشبلب عام 1993

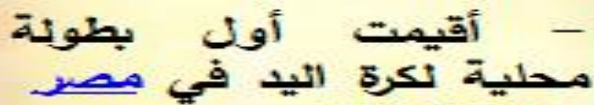
عام 1957. - وبكتي في في التعام نفسه

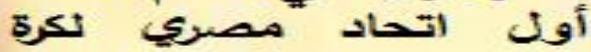

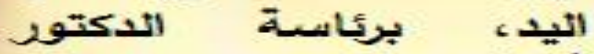
- فضماتحي

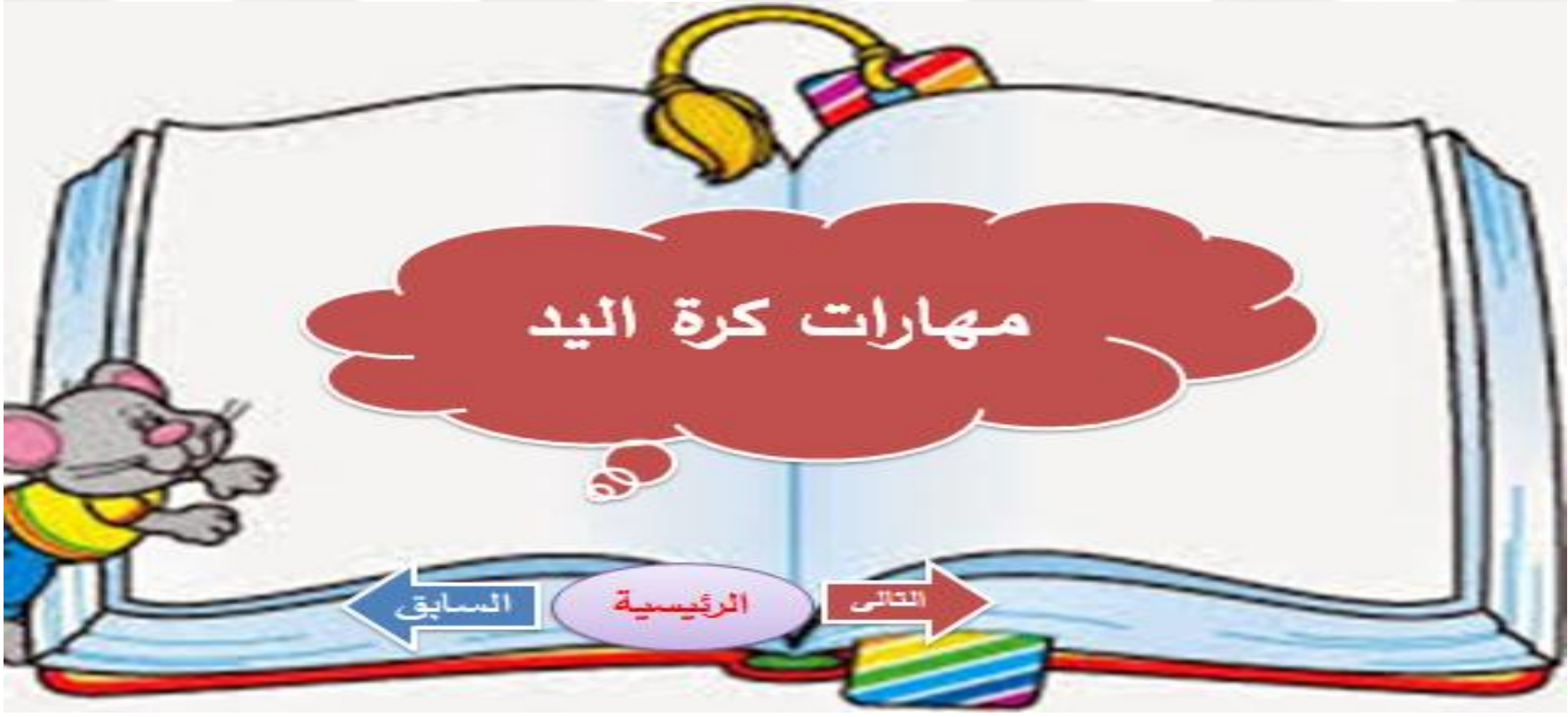




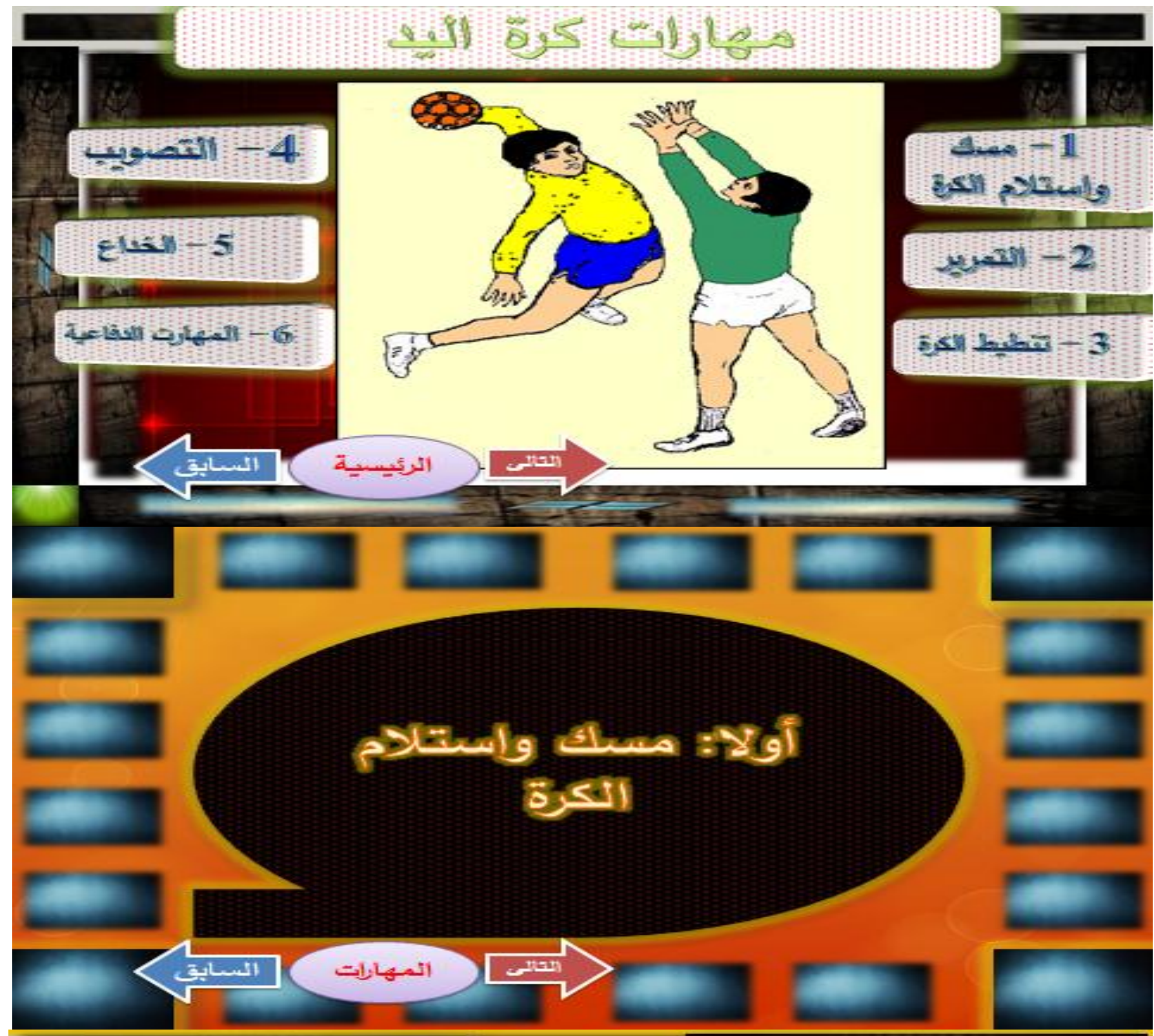

تlat

ㅊำเป็)

-1)

드는

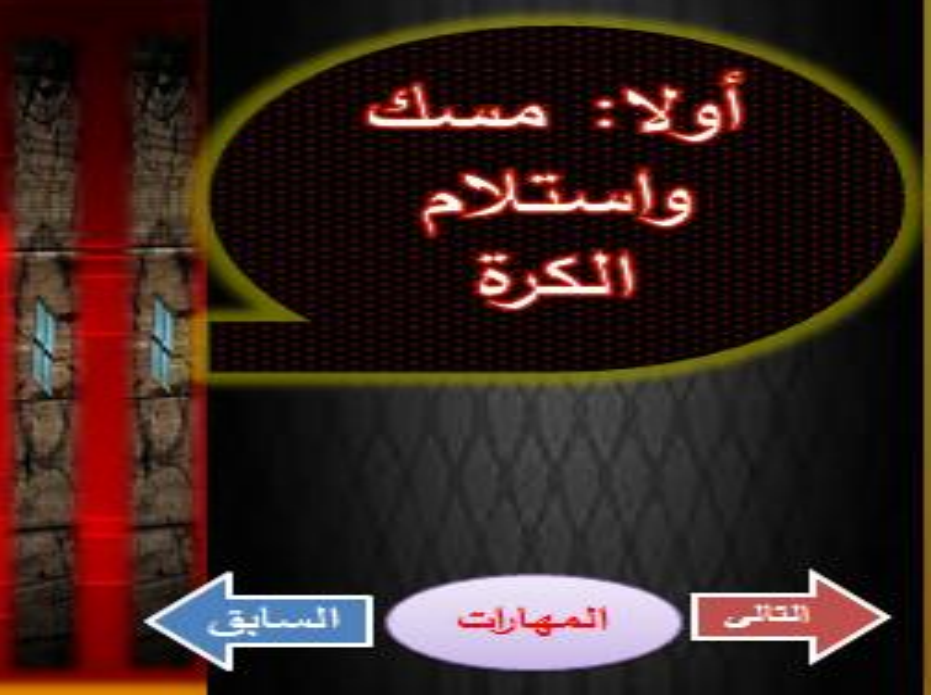



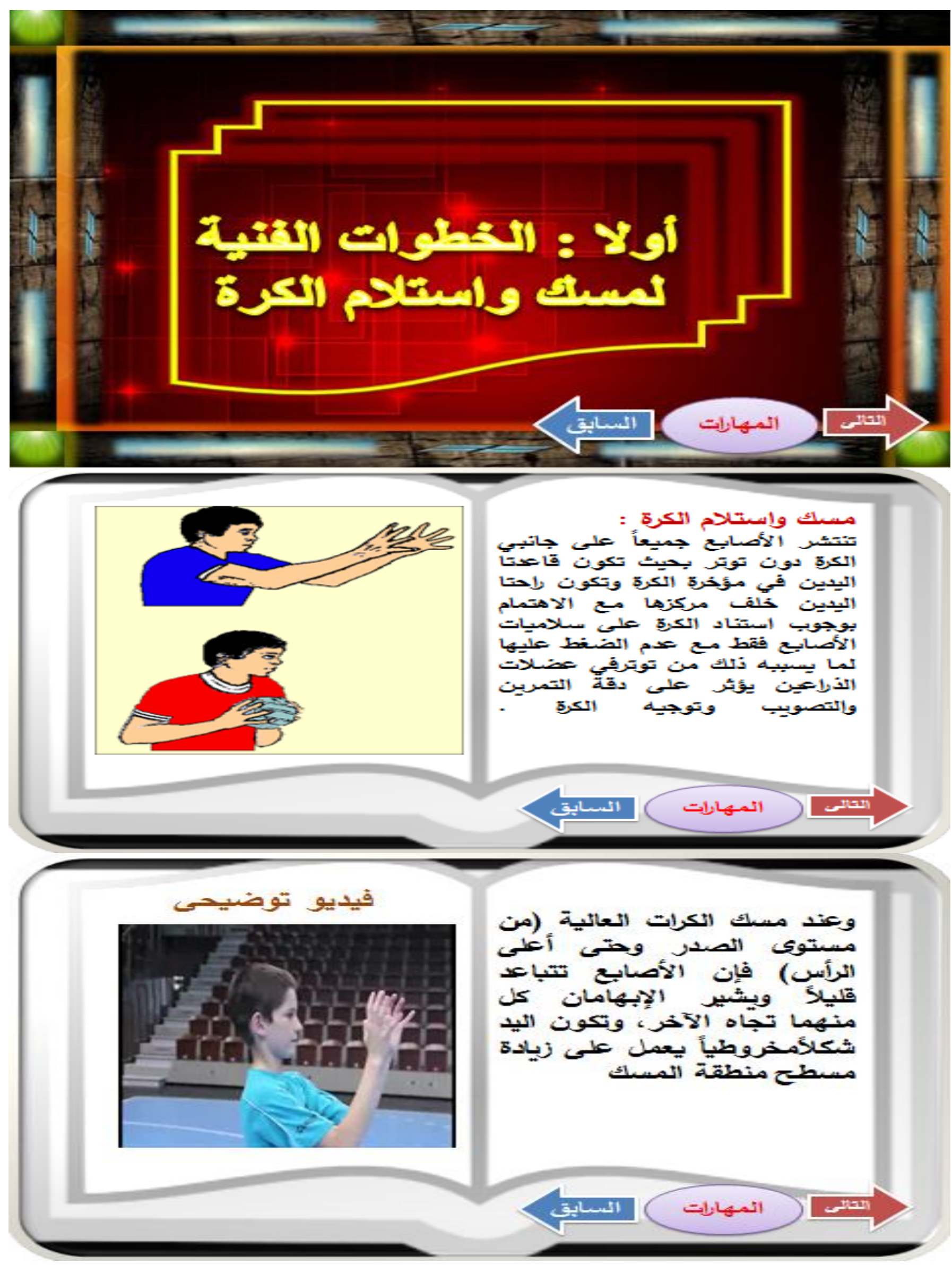

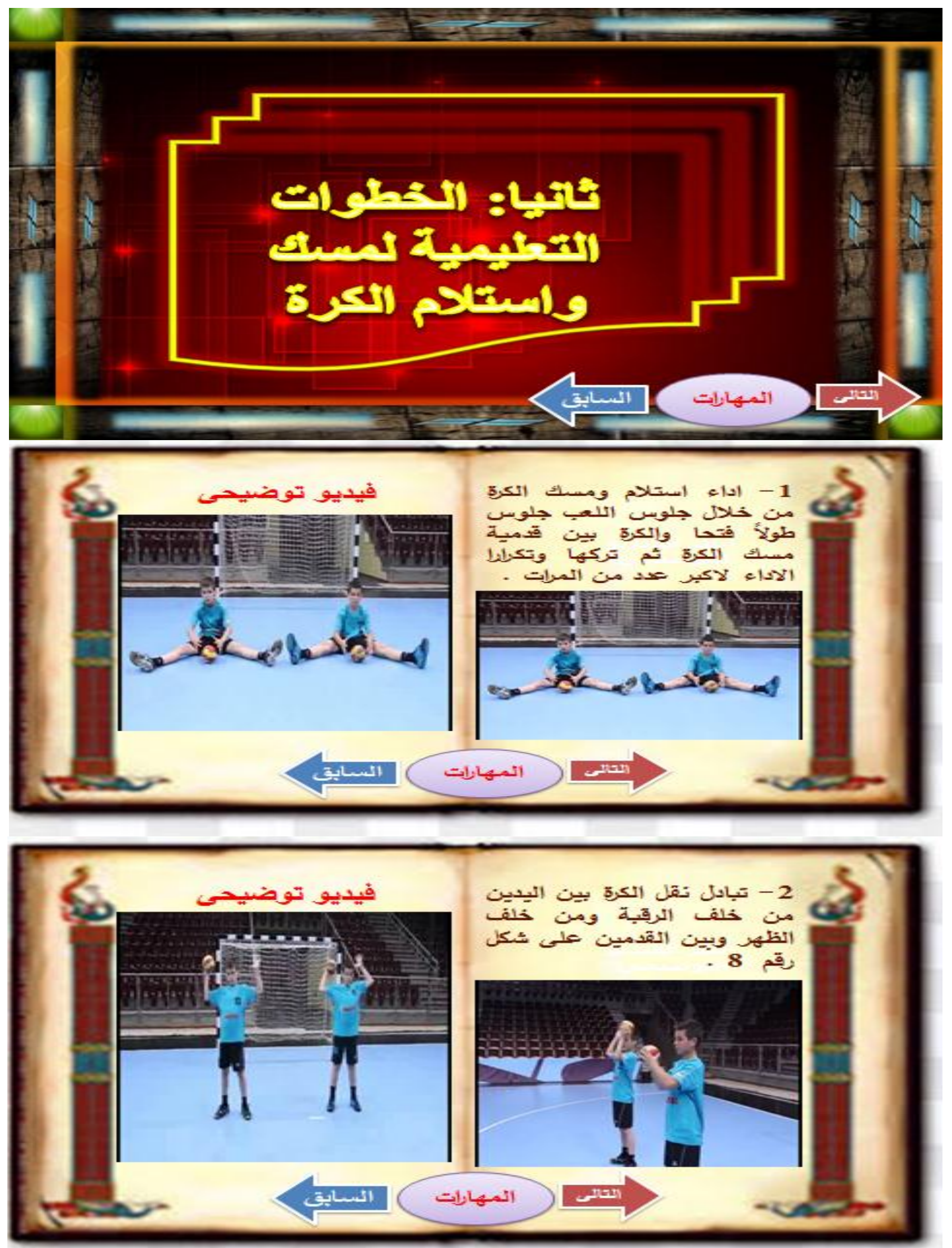

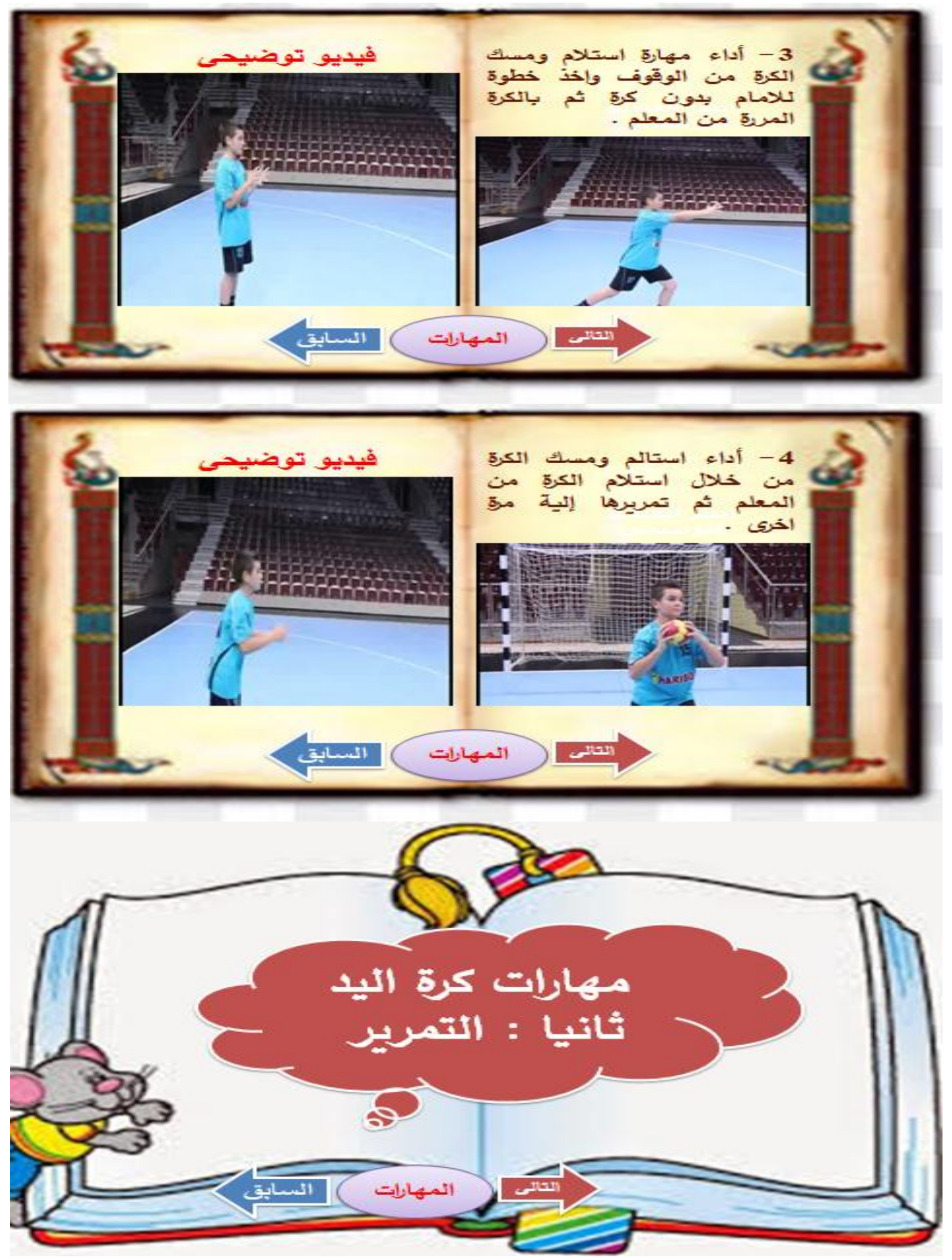

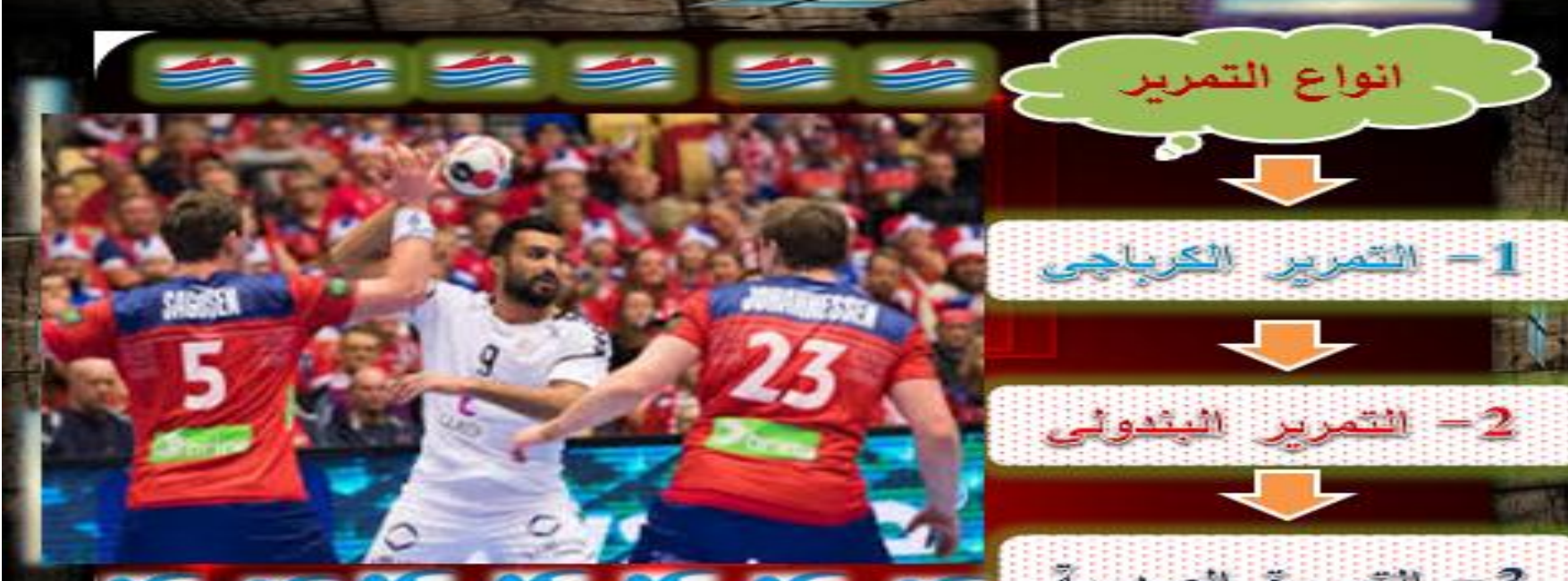

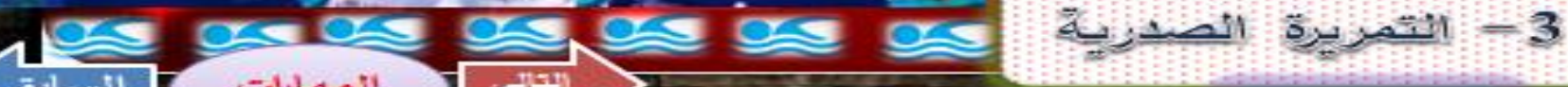

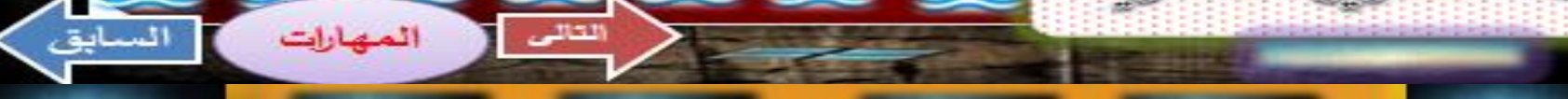

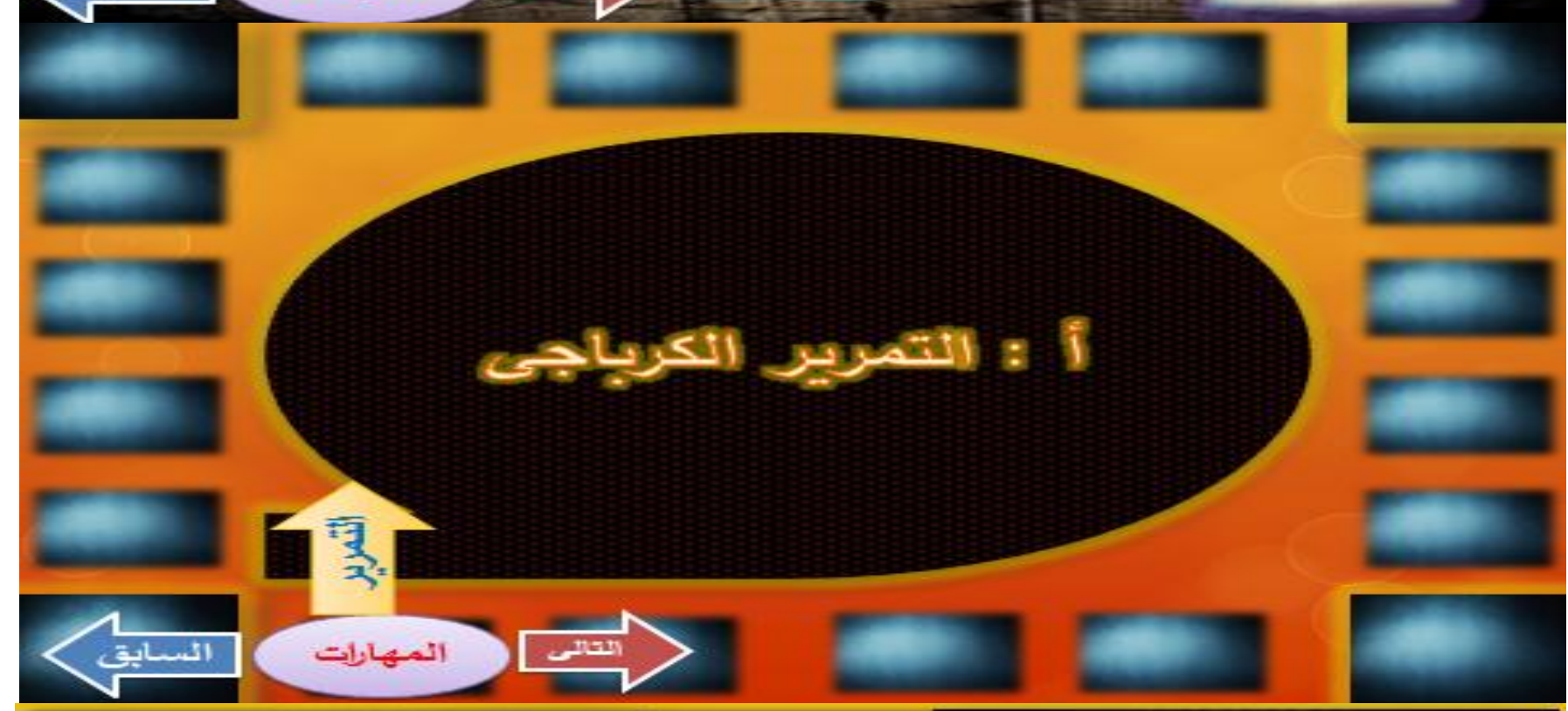

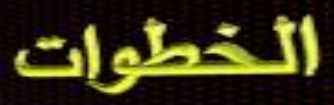

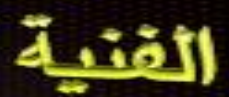

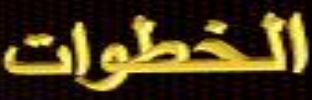

dinabivi

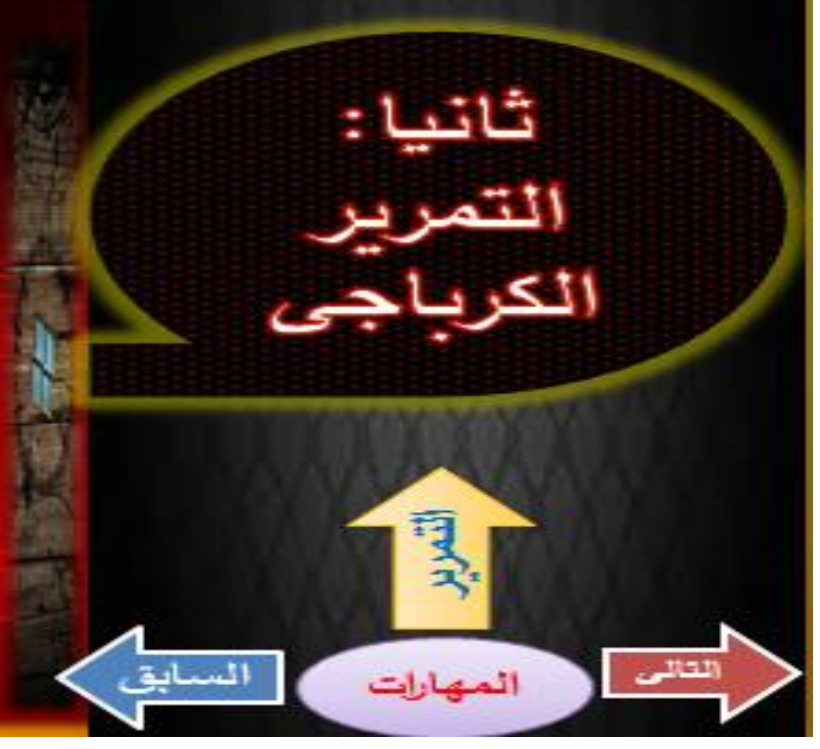




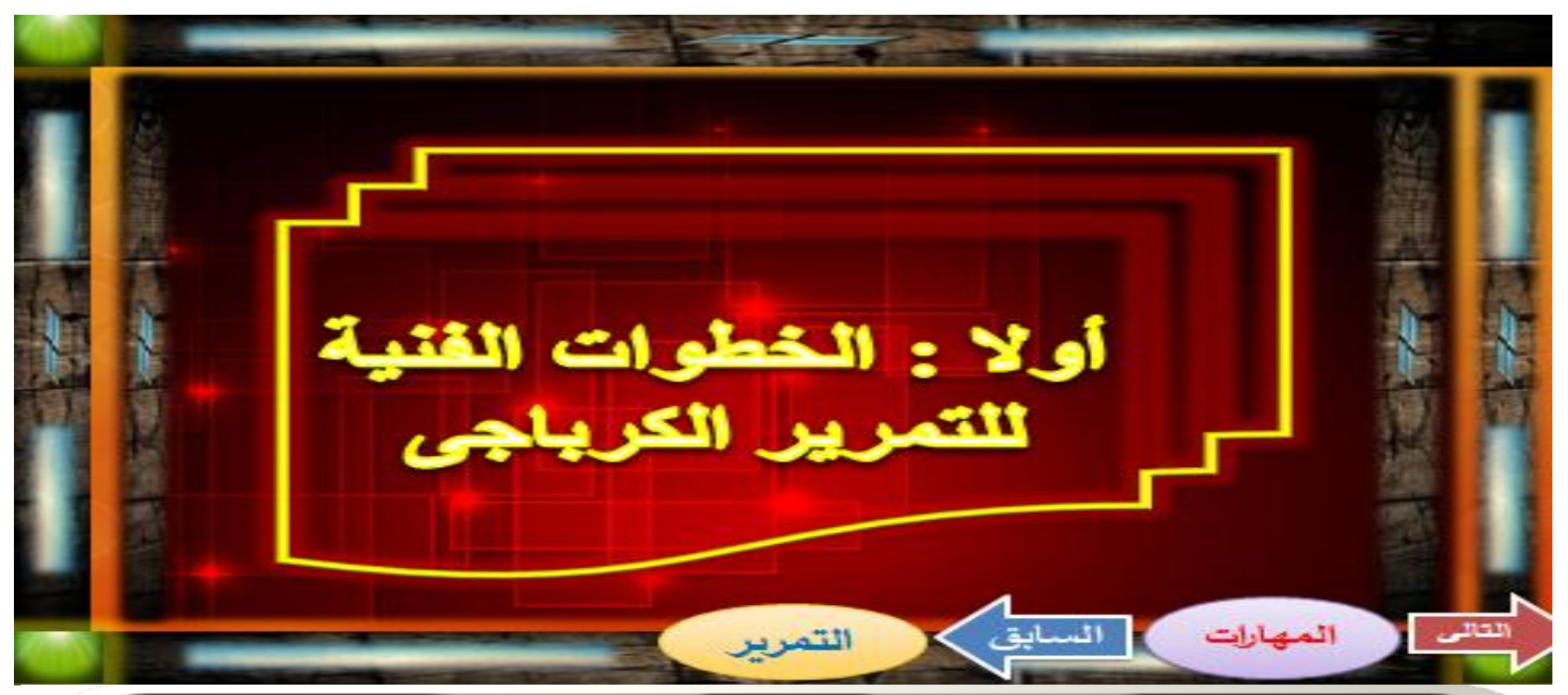

2

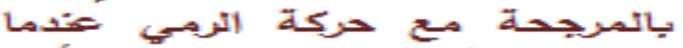

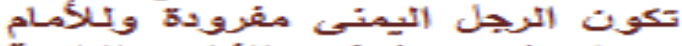

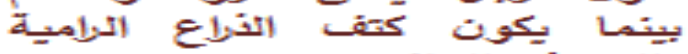

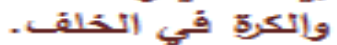

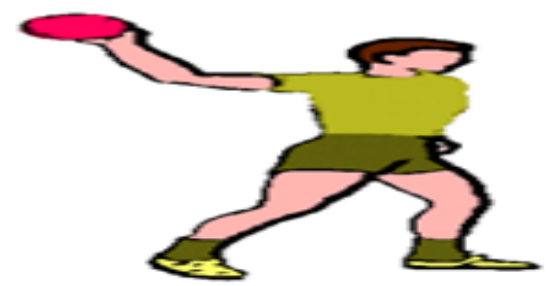

$$
\text { أو }
$$

1

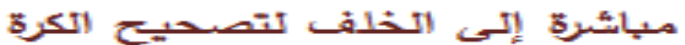
في بث واحدة (آيث آلرامبية) بعد تأمينها باتيث آلحرة إلهى مستوى

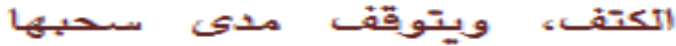

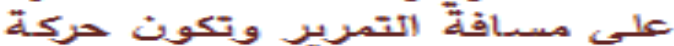

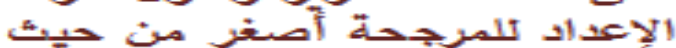

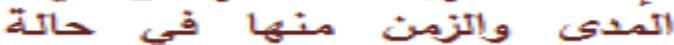

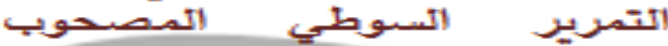

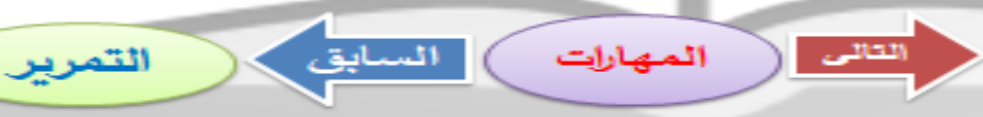
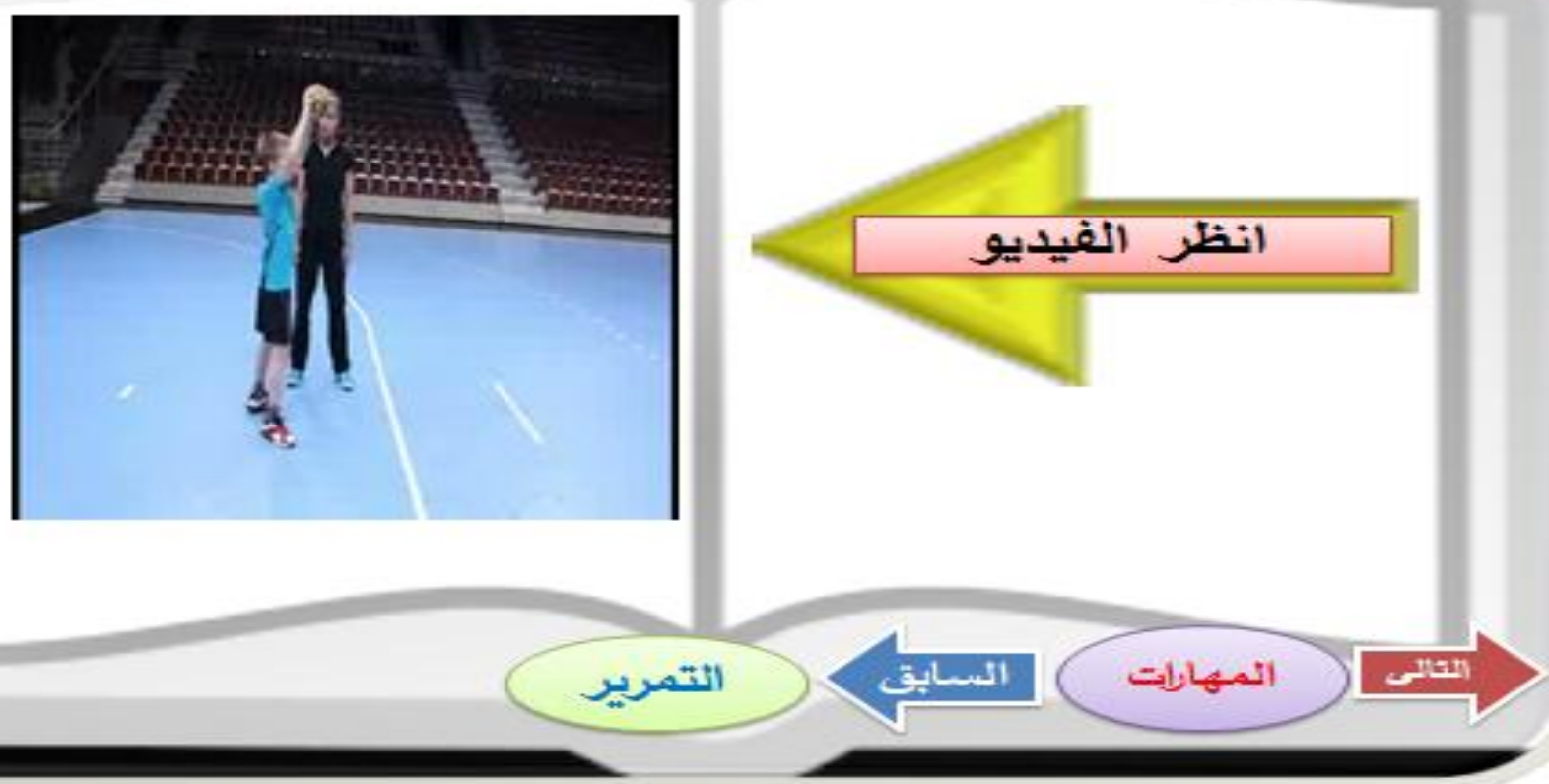
4 -4 تستمر الحركة يتقدم التقدم

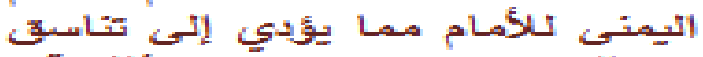

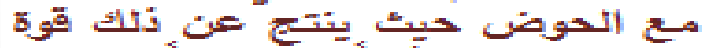

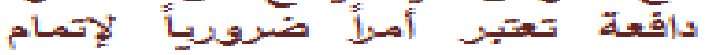

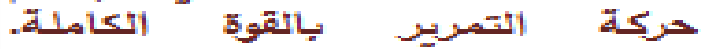
قري

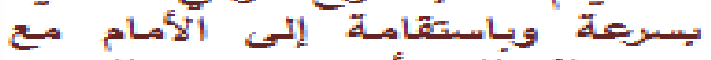

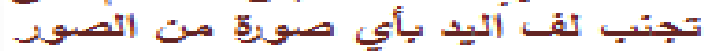

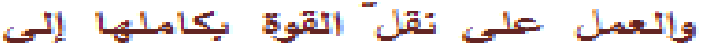
الكرة.

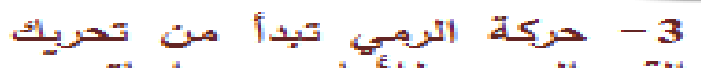

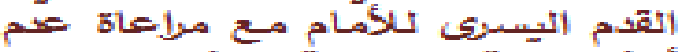

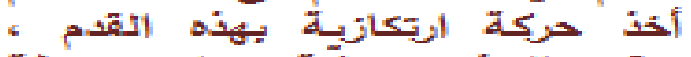

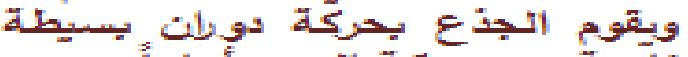
تاتجية عث حركية الجزي أماماً.

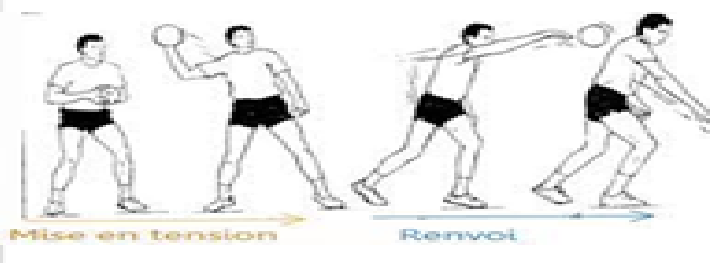

\section{التمريز}
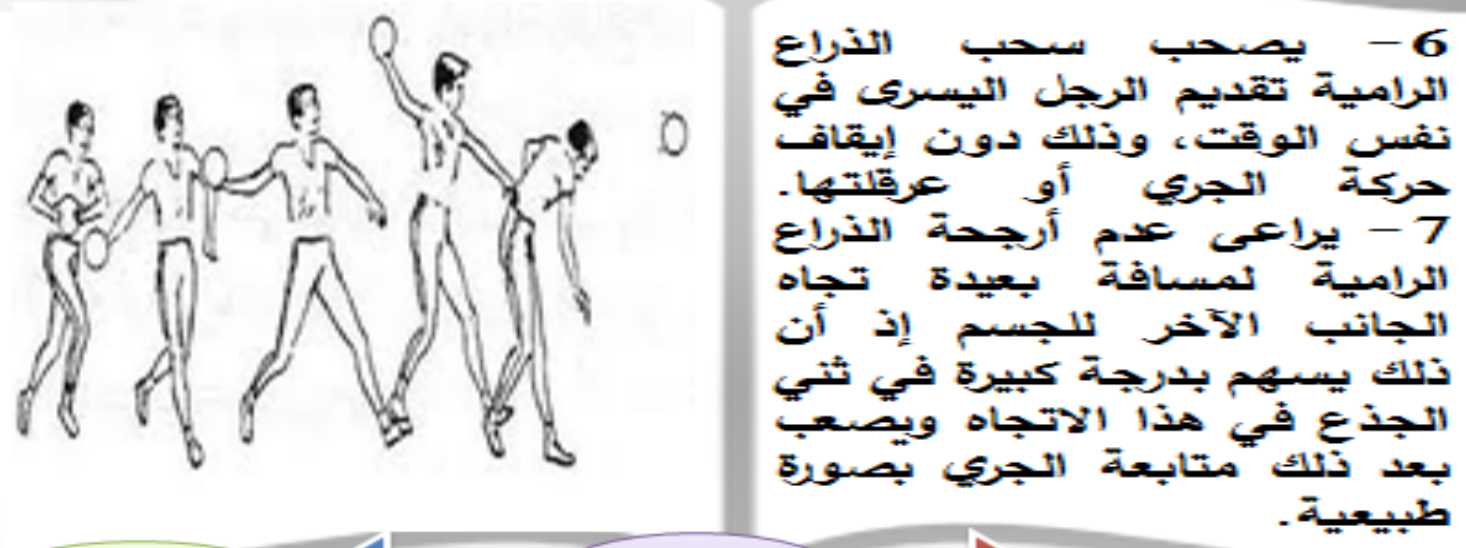

التمربير

$\int<$ intil المـهبالات

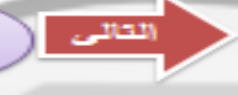
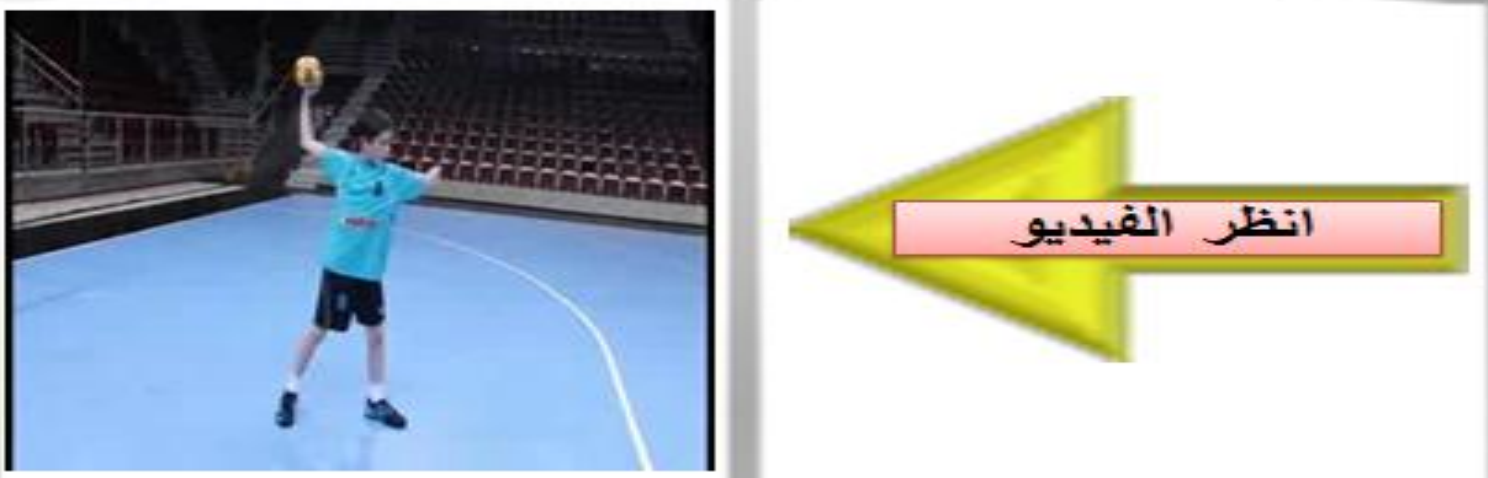

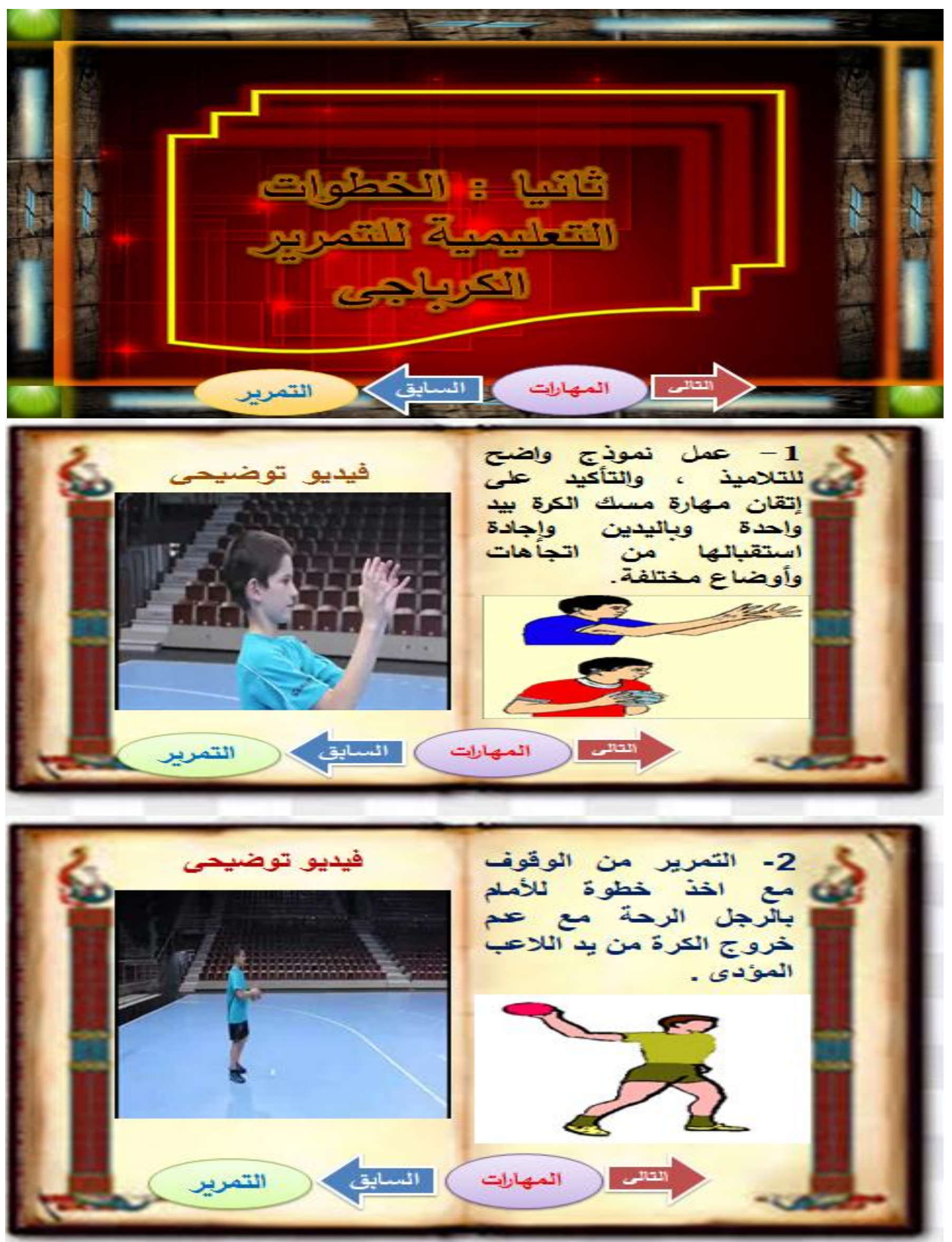

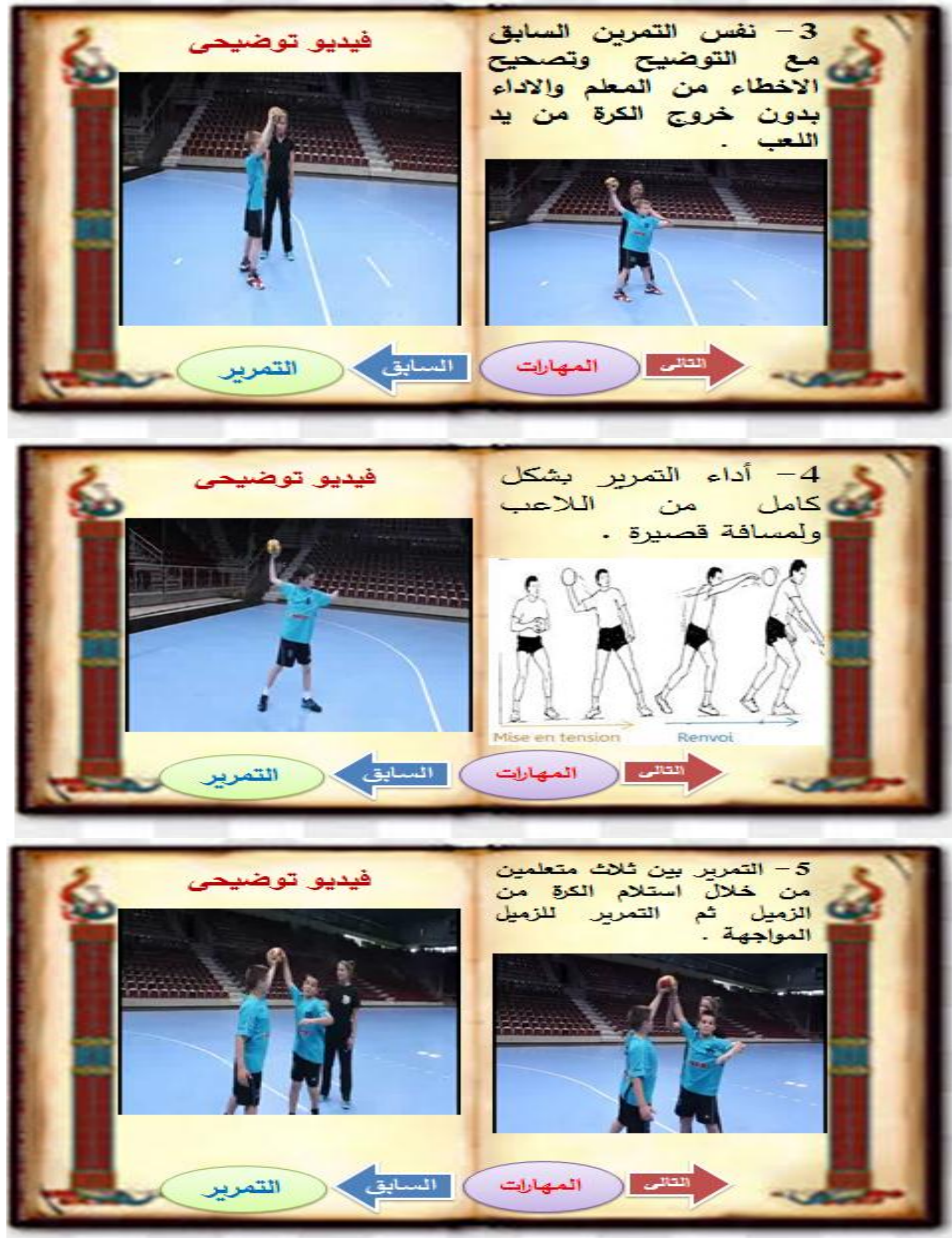

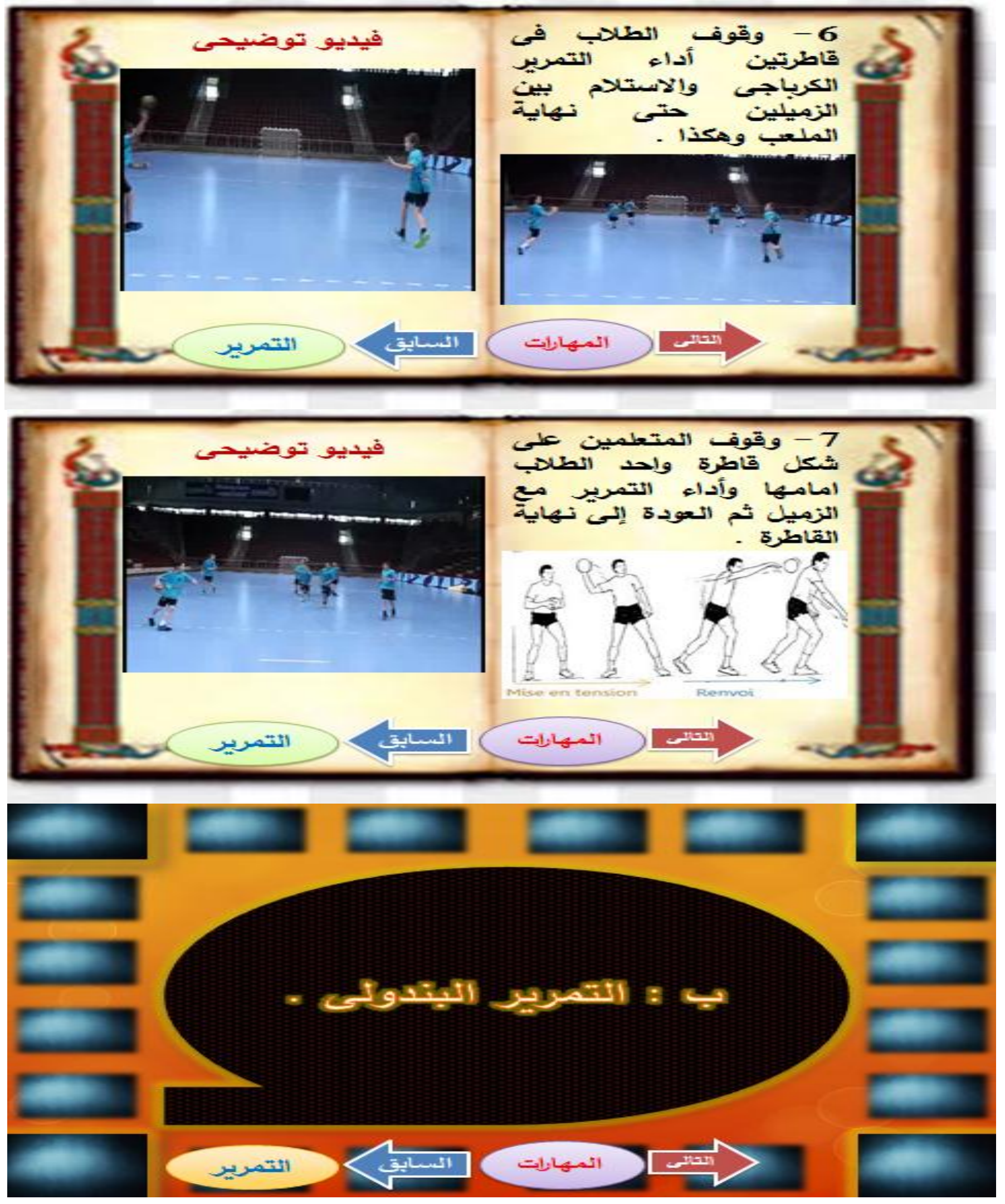


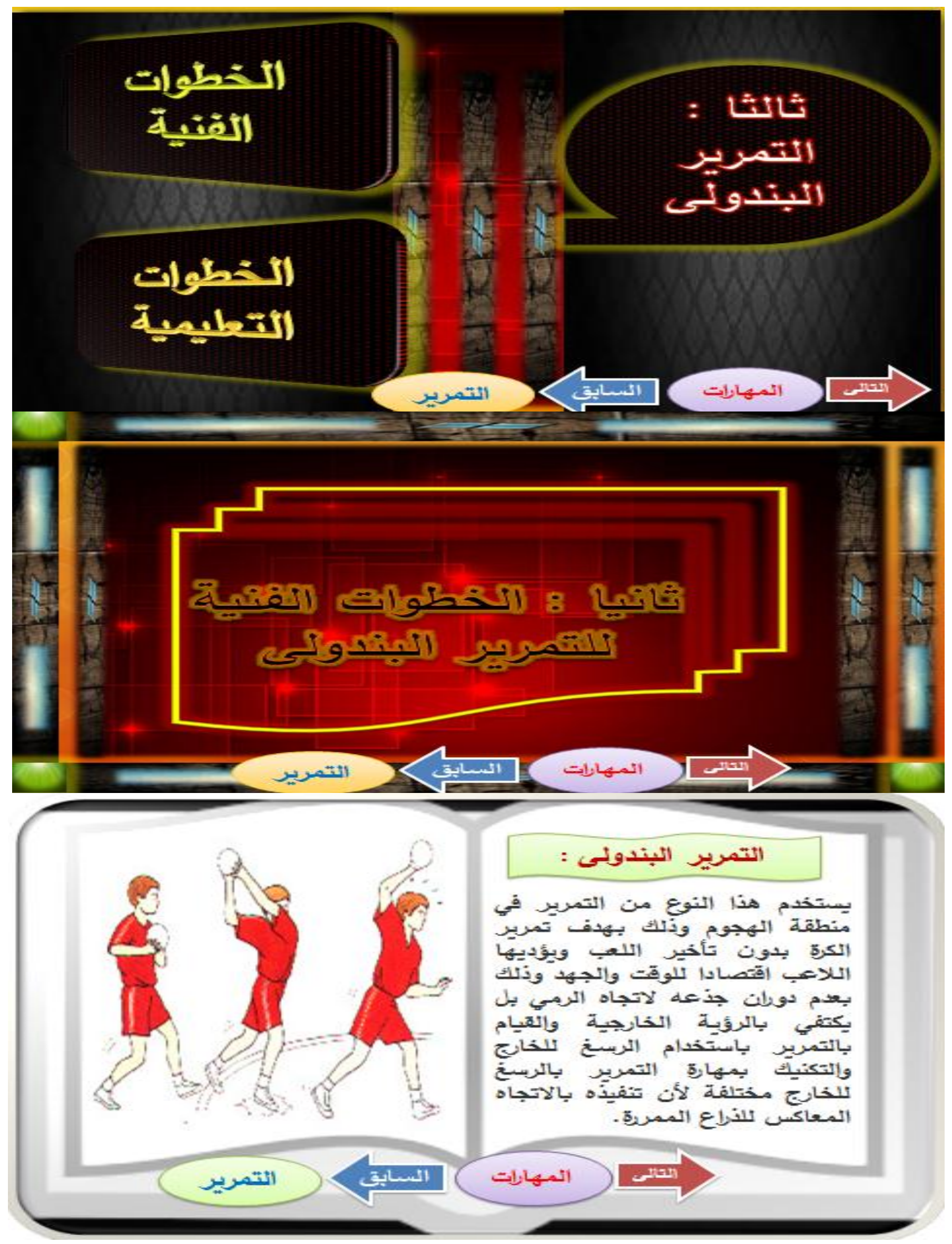




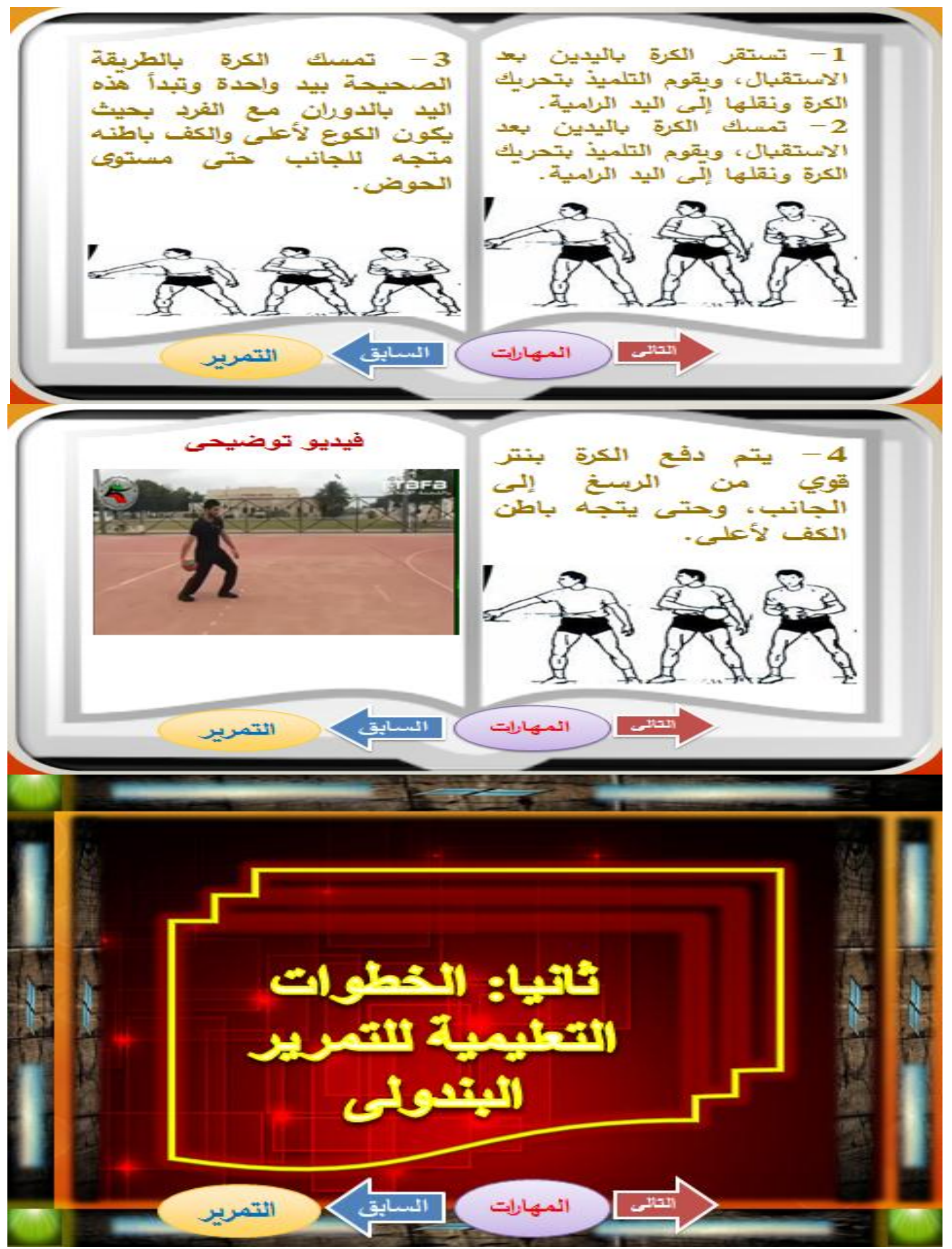



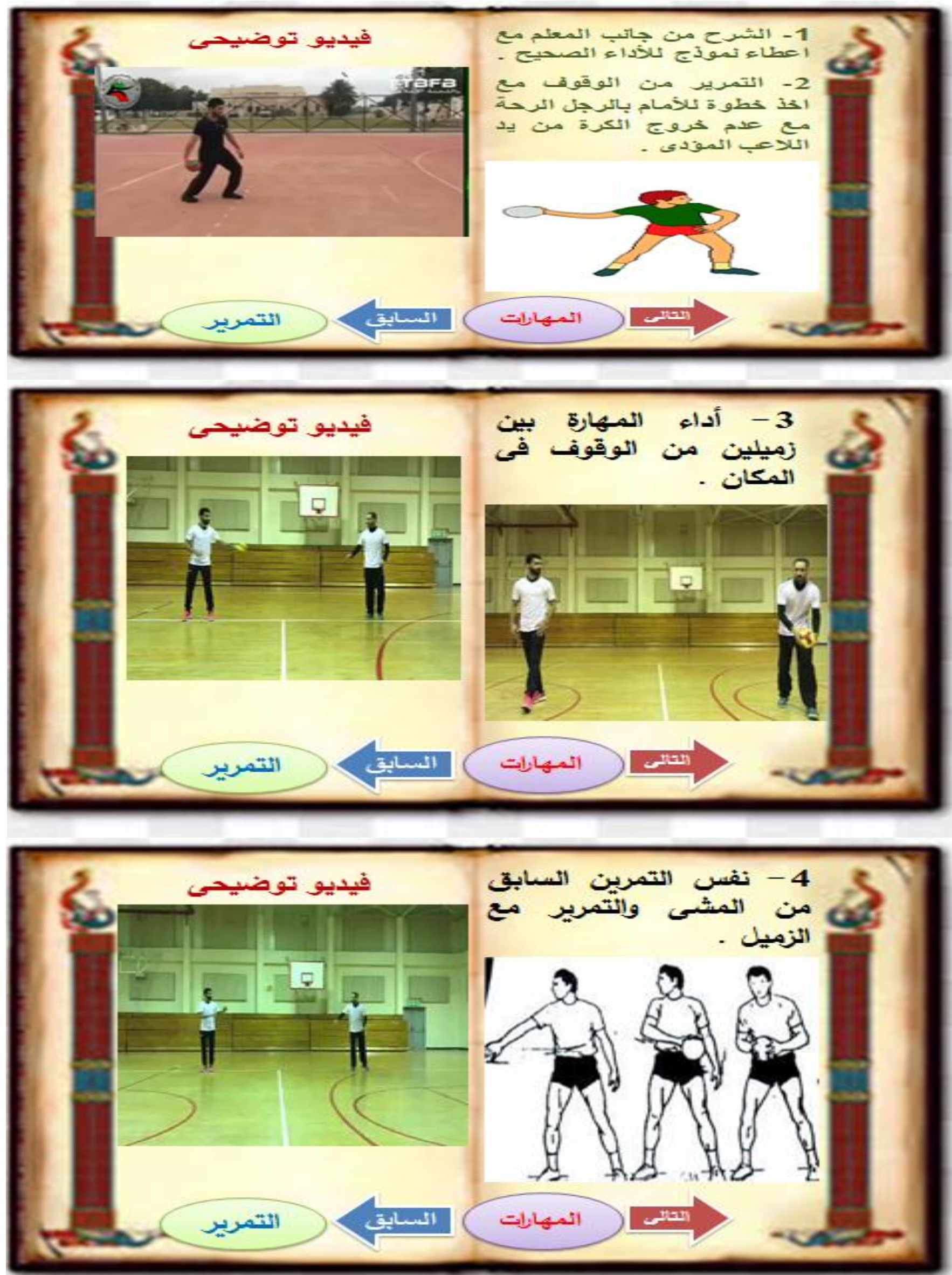


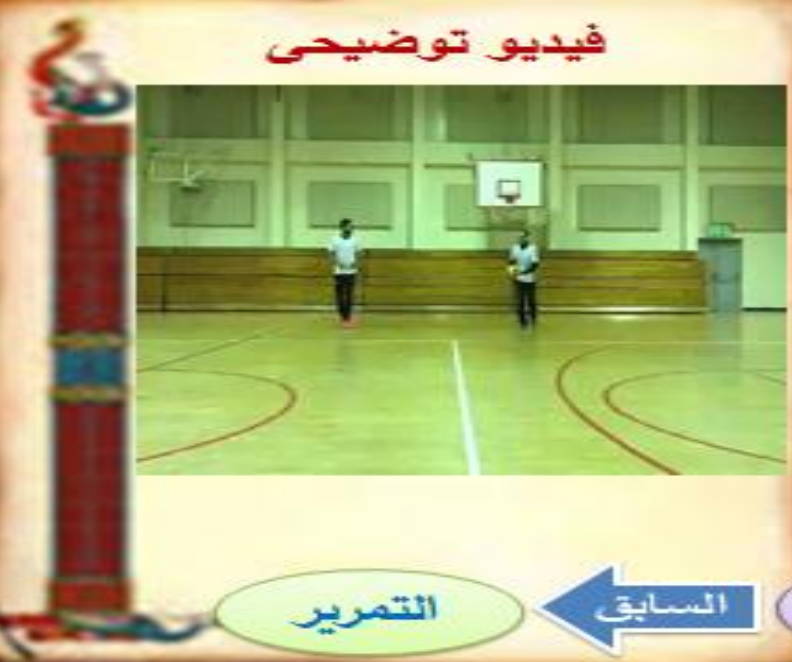

$$
\begin{aligned}
& \text { 5- نفس التمرين السابق }
\end{aligned}
$$

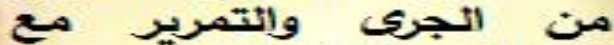

$$
\begin{aligned}
& \text { الزميل بطول الملعب. }
\end{aligned}
$$
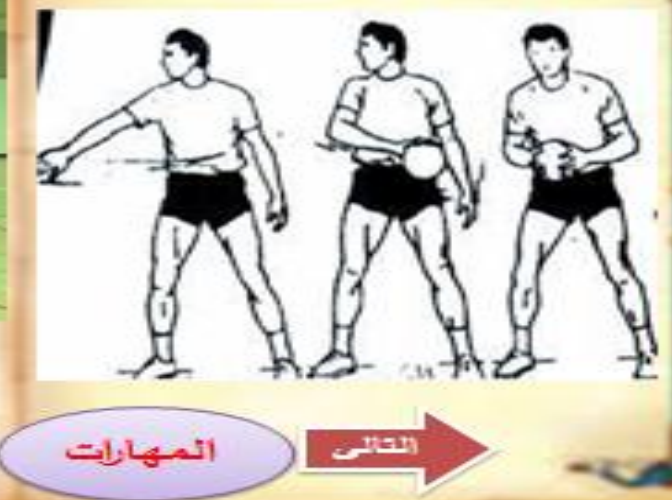

$-4000$

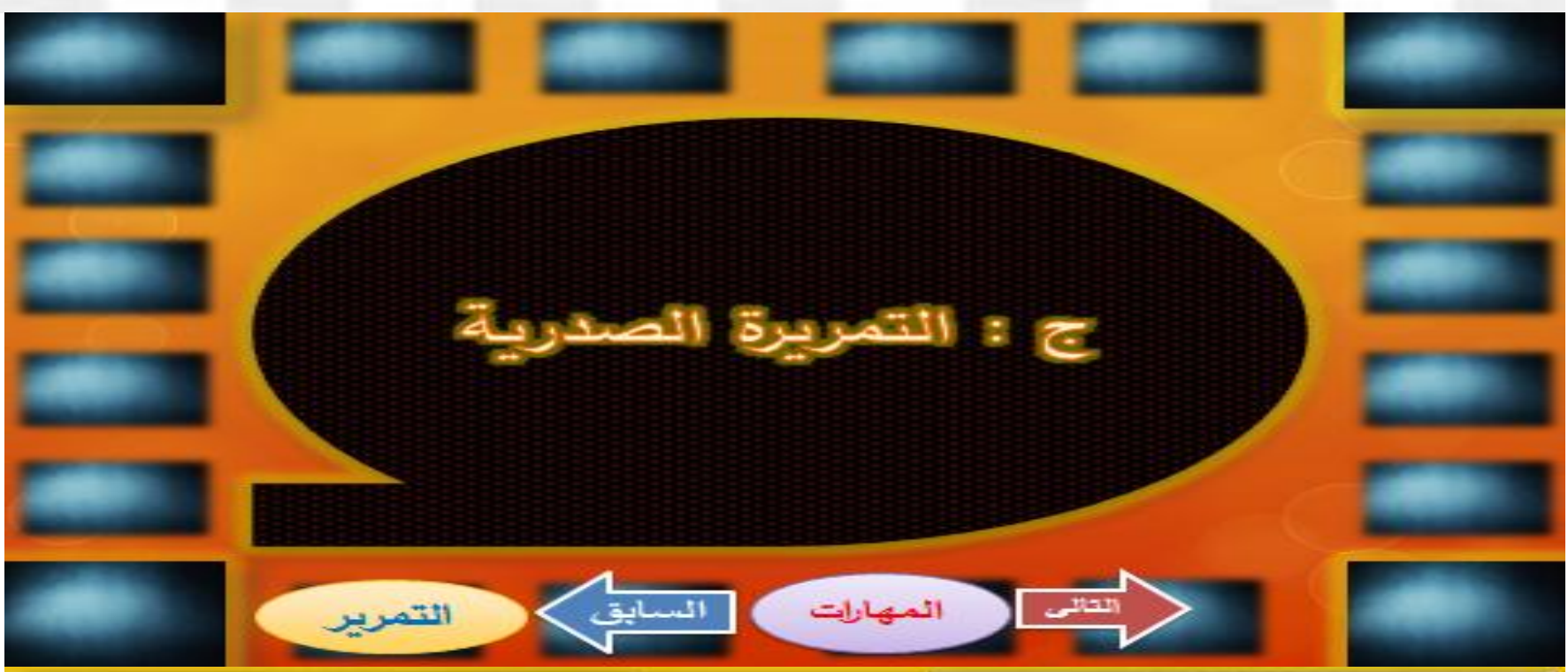

الخطوات الكن:_الة

الآنطولت آلتطيمية

$$
\begin{aligned}
& \text { : ᄂ2.1 } \\
& \text { التمبريزة } \\
& \text { 这, }
\end{aligned}
$$




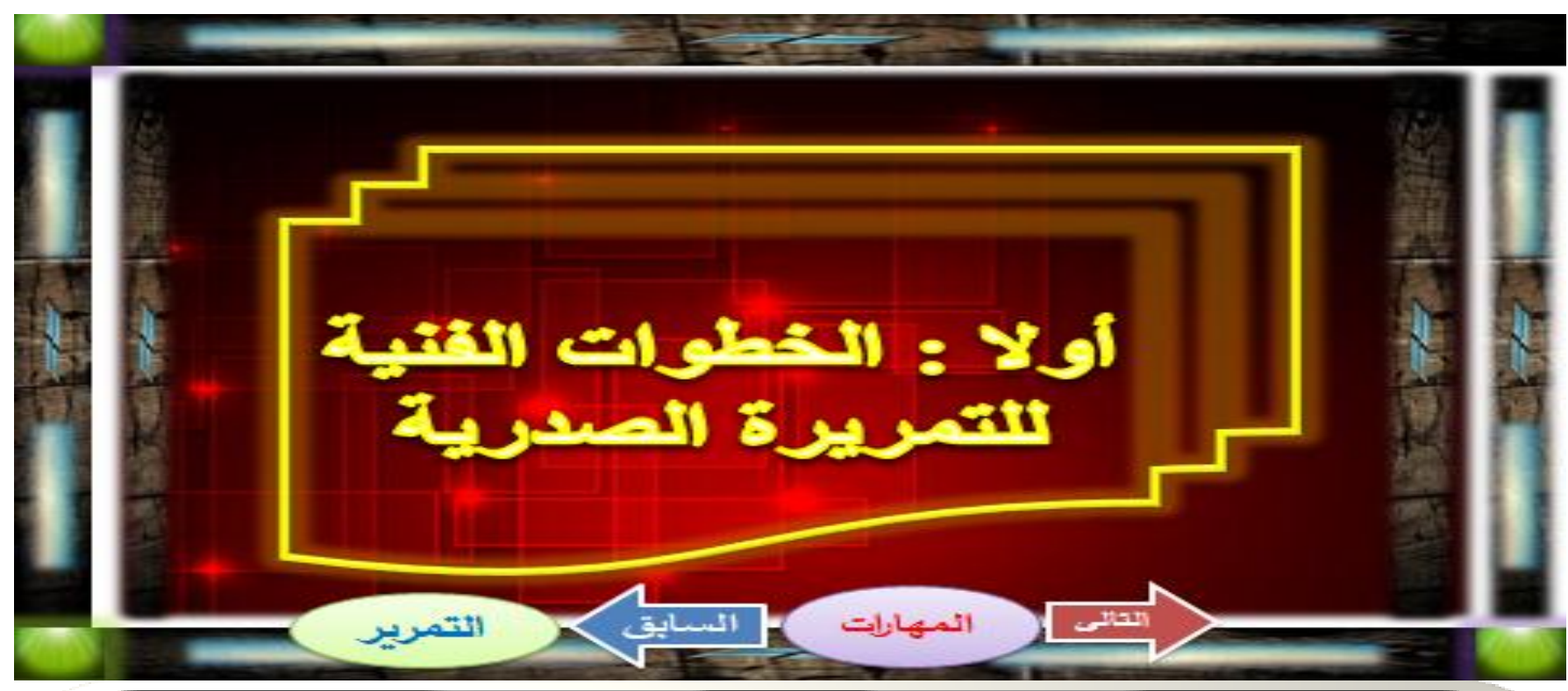

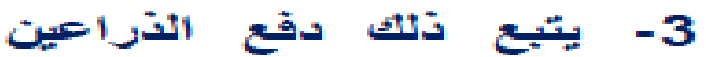

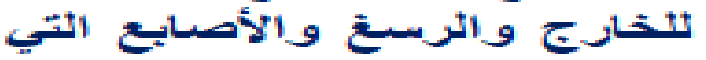

توجه الكرة بالاتخجاه المطلوبي. 4- ونت الجسم ينتقل تدريجيا

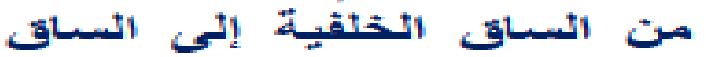

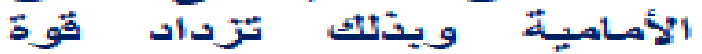
الرمبية. $\Rightarrow 2$ स $\Rightarrow$ a

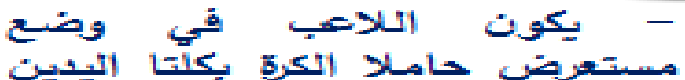

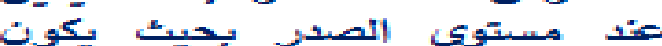
المرققيت مثتيست قرب الجسم.

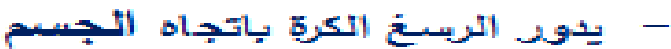

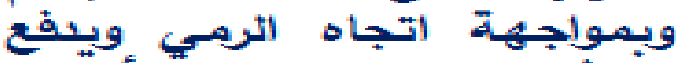

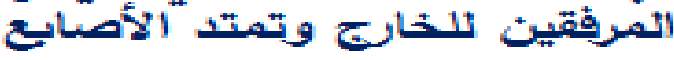

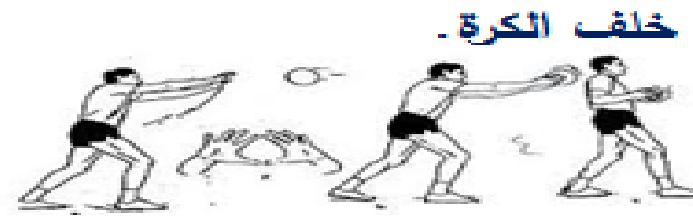
التبايقت | الميكانات

$$
\text { فيديو توضيحص }
$$

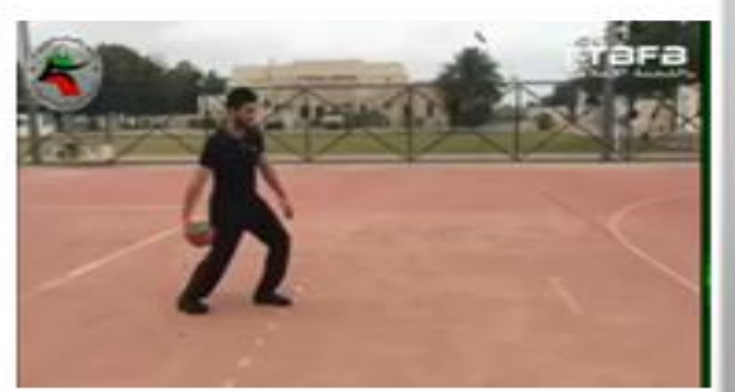

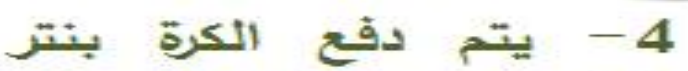
قوي من إلى إنى

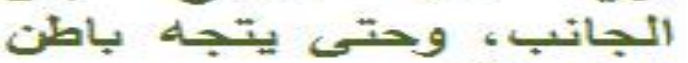

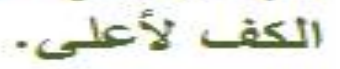

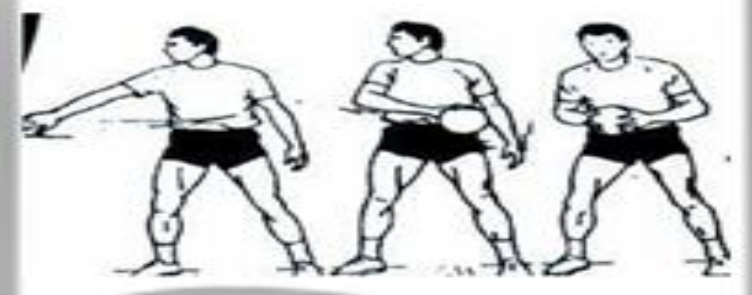

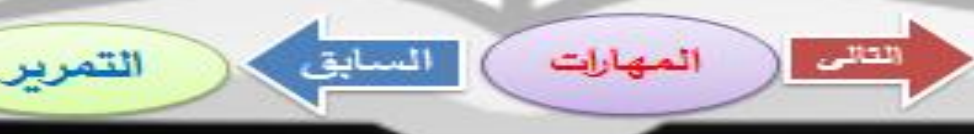




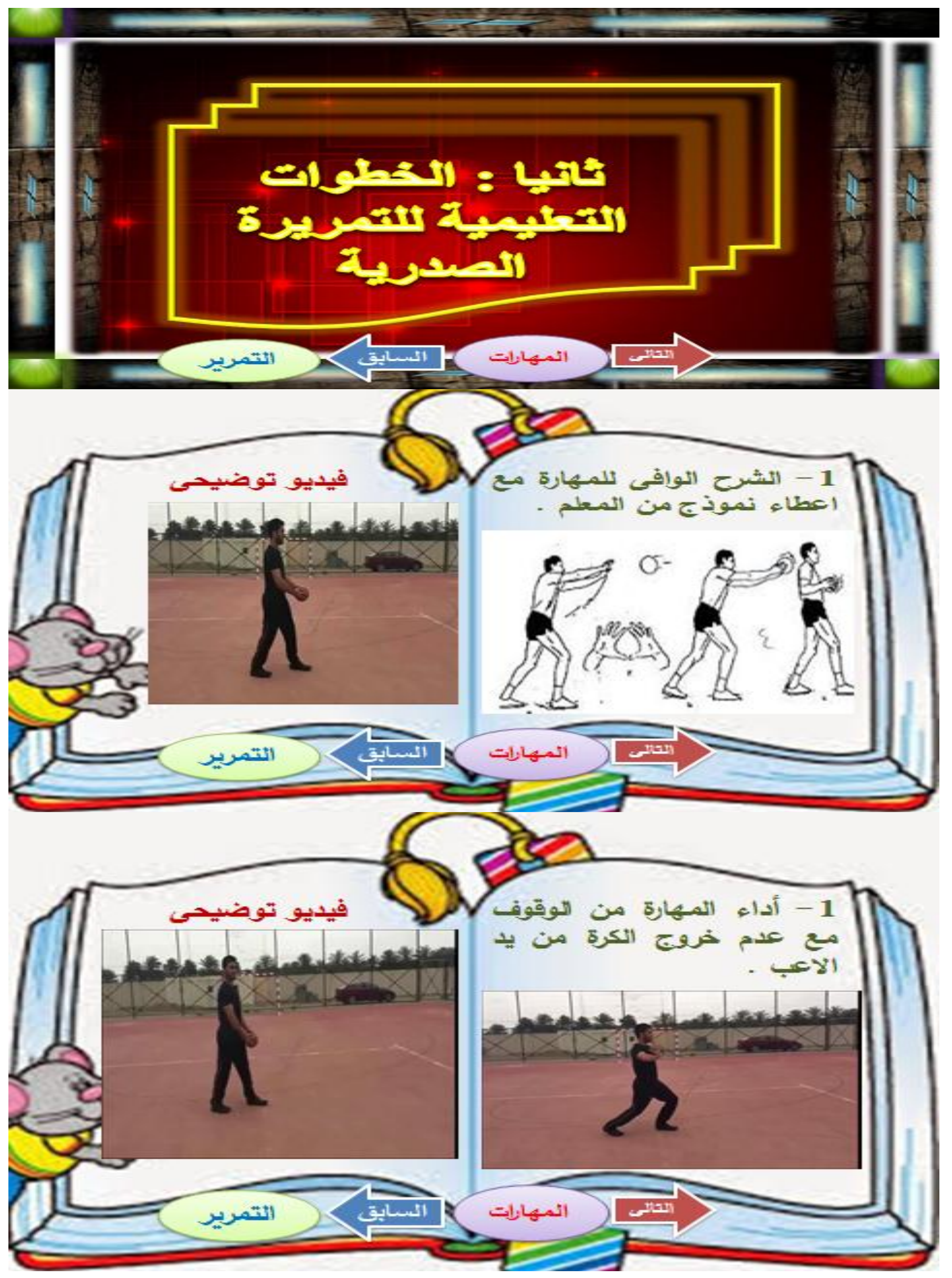




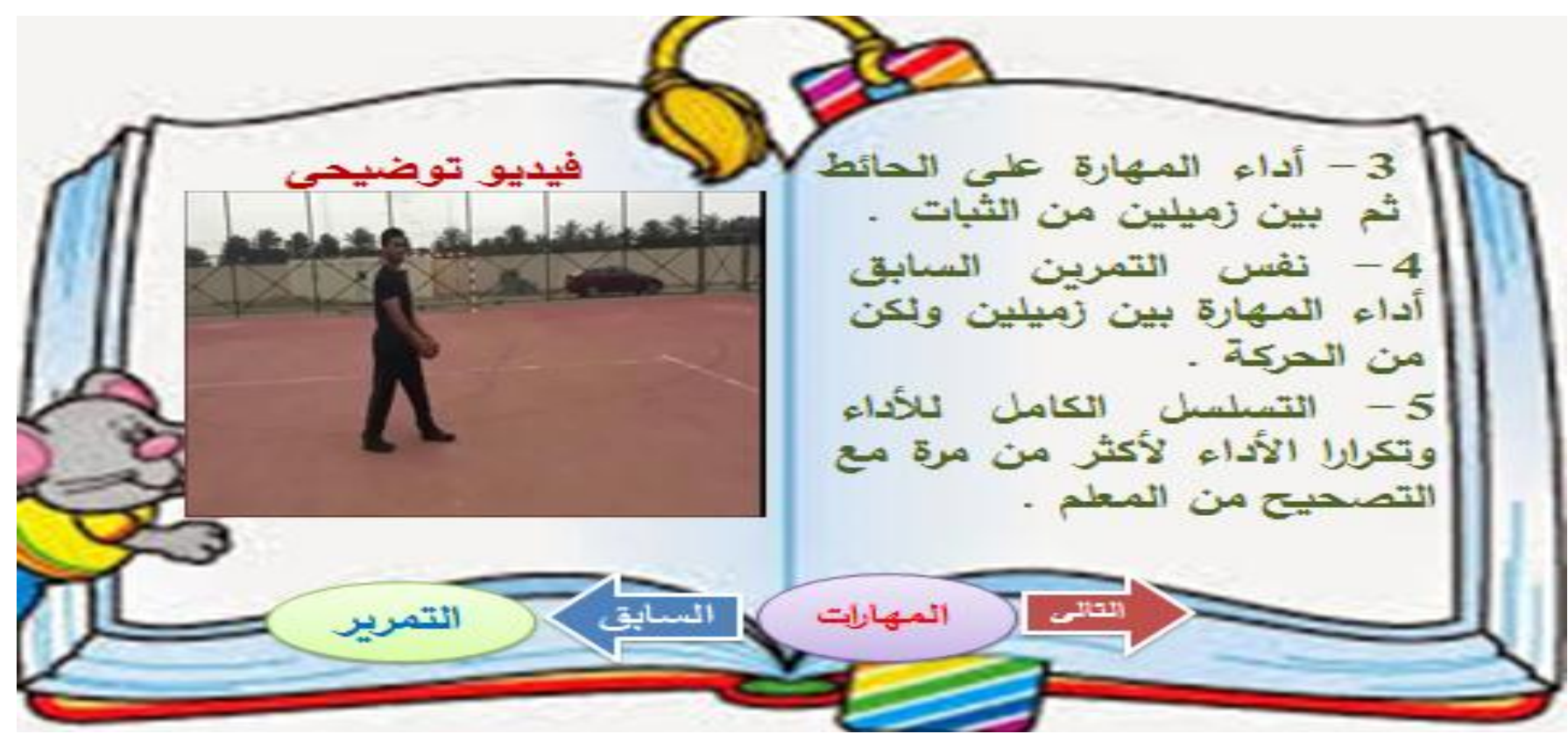




$$
\text { الاختبار المعرفى ( ؛ ) }
$$




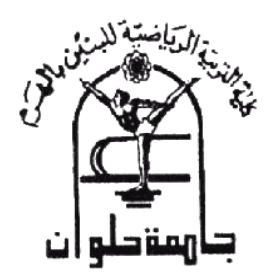

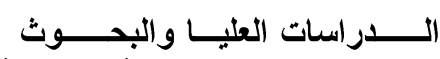

قسم مناهج وطرق تدريس التربية الرياضبة

\section{اختبار التحصيل المعرفي}

فى كرة اليد

إعـداد

عبد الله أحمد محمد محمد

مدرس تربية رياضية بمعهل مجمع بدر الأزهرى التباع لإدارة المراغة الأزهرية بمحافظة

$$
\text { سوهاج }
$$

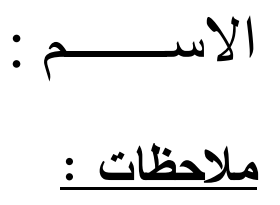

1- اقرأ الأسئلة جيداً قبل الإجابة عليها.

r- ب-زمن الاختبار (10 ) دقيقة.

r-فىى أسئلة الاختيار من متعدد يجب وضئع علامة واحدة وواضحة وفى حالة وجود

علامنتين تلغى درجة السؤال.

ع -فى أسئلة أكمل اختر الكلمة المناسبة الموجودة أعلى الأسئلة.

0-عدم الكثط أو الثطب حتى لا توثر على درجة السؤال.

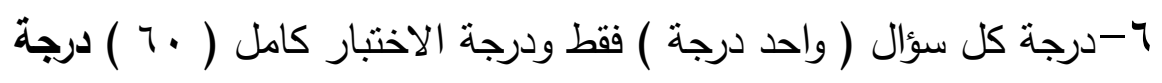


الاختبار المعرفى فى كرة اليا

$$
\text { السؤال }
$$

المستوى الأول : مستوى الحفظ والتزكر :

$$
\text { أولا : اختر الاجابة الصحيحة من بين كل من ( أ - ب- ج ج ) }
$$

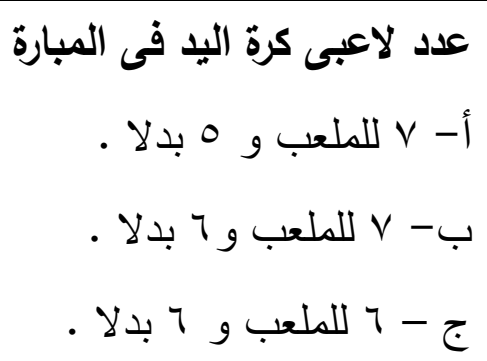

r | بستمر زمن المبارة للكبار لفريقى الرجال والسيدات

أ- شوطان زمن كل شوط ـ دقيقة .

ب- شوطان زمن كل شوط مب دقيقة .

ج- شوطان زمن كل شوط • ب دقيقة . ب- مساحة ملعب كرة اليل

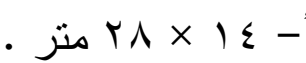

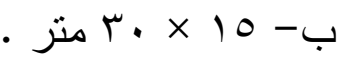

ج

فترة الراحة بين شوطى كرة اليد

أ- 0 دقائق .

ب- · · بقائق .

ج- 10 أقيقة .

وزن كرة اليد للرجال

- أ-

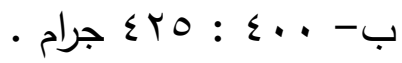

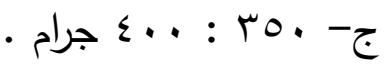




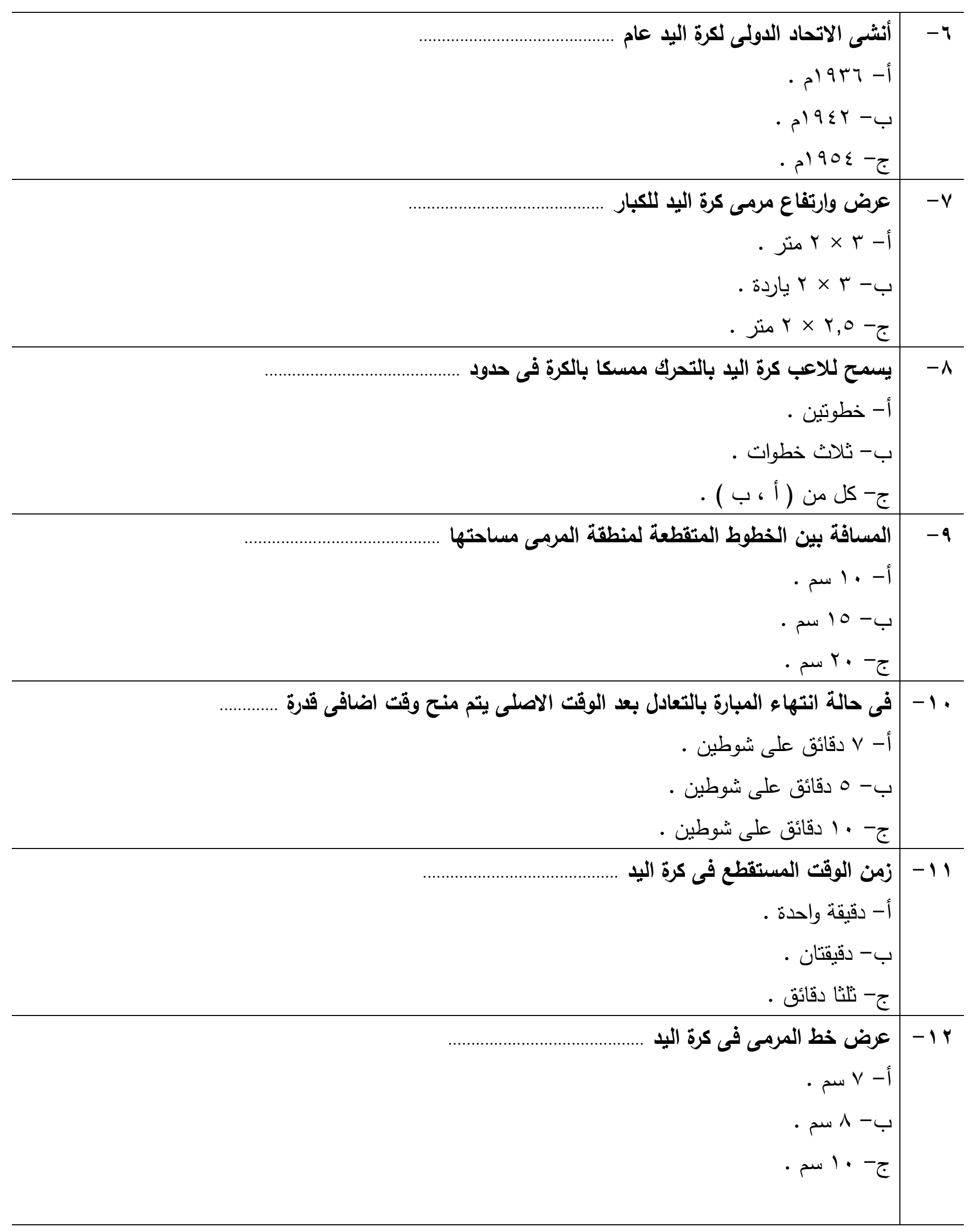


ثانيا : ضع علامة (ل ل ) أمام العبارة الصحيحة وعلامة ( × ج ) أمام العبارة الخاطئة

\begin{tabular}{|c|c|c|c|}
\hline & & اشترك المنتخب المصر لأول مرة فى الدورات الاولمبية لكرة اليد فى دورة برشلونة عام بو 9 ام & -14 \\
\hline( & ) & يسمى الخطان العزضيان فى كرة اليد بخطى المرمى . & $-1 \leqslant$ \\
\hline( & ) & يجب الا يقل عدد لاعبى كرة اليد قبل بداية المبارة عن اربعة لاعبين بالإضافة إلى حارس مرمى & -10 \\
\hline( & ) & فترة الراحة بين الوقت الاضافى فى كرة اليد ب دقائق . & -19 \\
\hline( & ) & محيط كرة اليد للرجال من به : ؛ه سم & $-1 \mathrm{~V}$ \\
\hline( & ) & يعتبر الاكتور محمد فضالى أول من ادخل كرة اليد فى مصر . & -11 \\
\hline( & ) & وزن كرة اليد موحد لكل من الرجال والسيدات & -19 \\
\hline( & ) & كرة اليد من اللعبات الفردية المحببة للجميع & $-r$. \\
\hline( & ) & تعتبر كرة اليد احلث لعبة جماعية فى مصر . & $-r_{1}$ \\
\hline( & 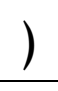 & بمكن لفريق كرة اليد اجراء تغييرات أثناء المبارة بدون الحصول على اذن من حكم المبارة & 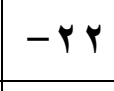 \\
\hline & ) & الاتحاد المصرى لكرة اليد هو أول اتحاد عربى تم انثائة فى اللعبة & $-r r$ \\
\hline
\end{tabular}


المستوى الثانى : الفهم والاستيعاب :

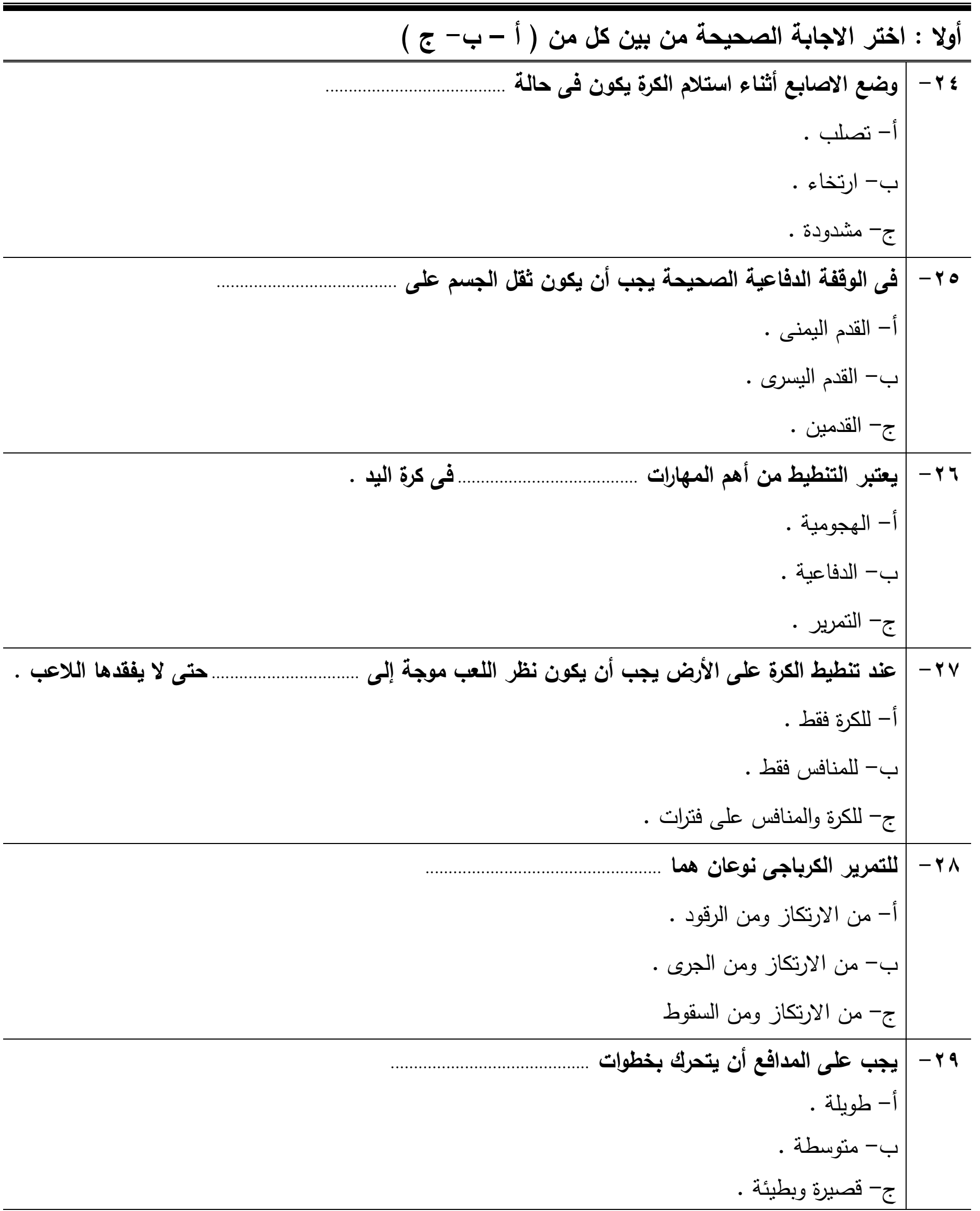




\begin{tabular}{|c|c|}
\hline 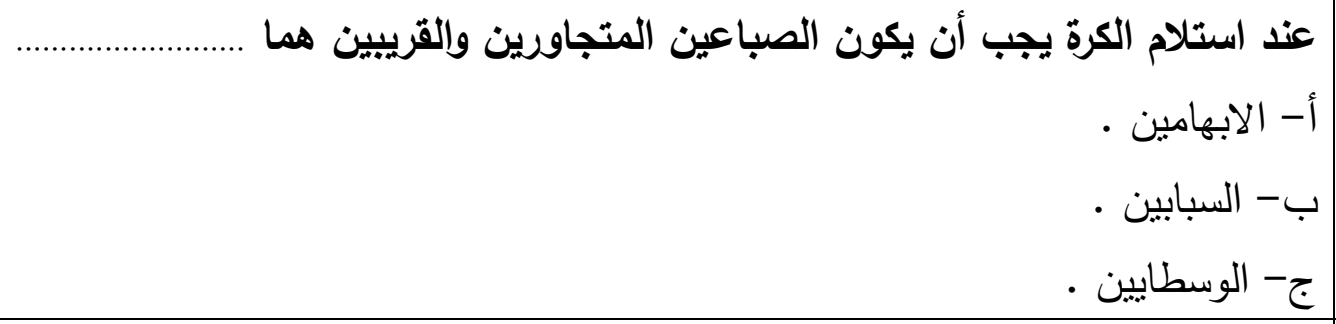 & . \\
\hline 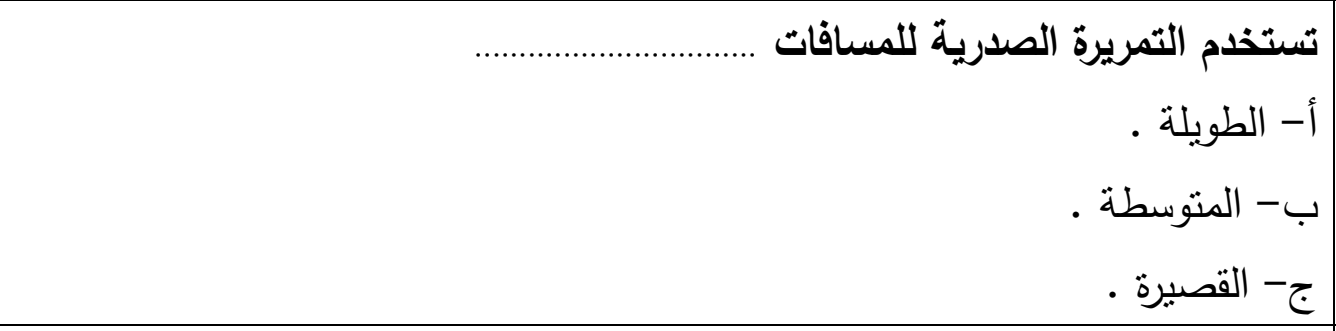 & I \\
\hline 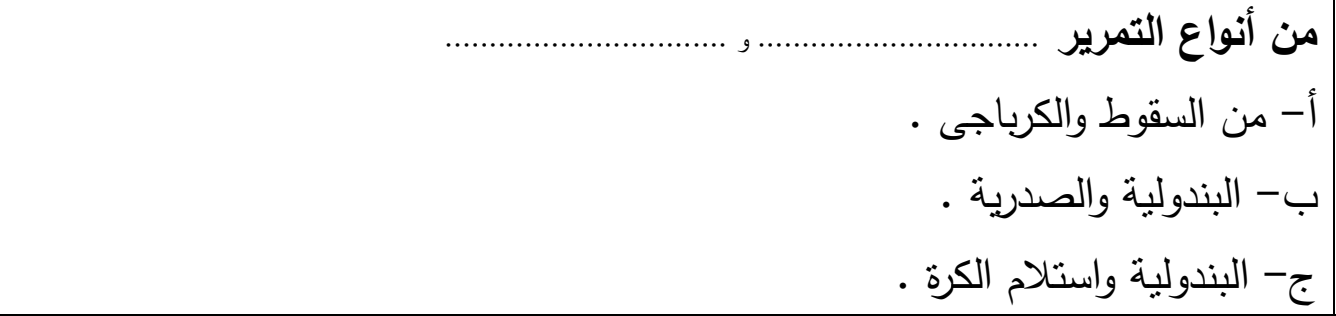 & $-r r$ \\
\hline 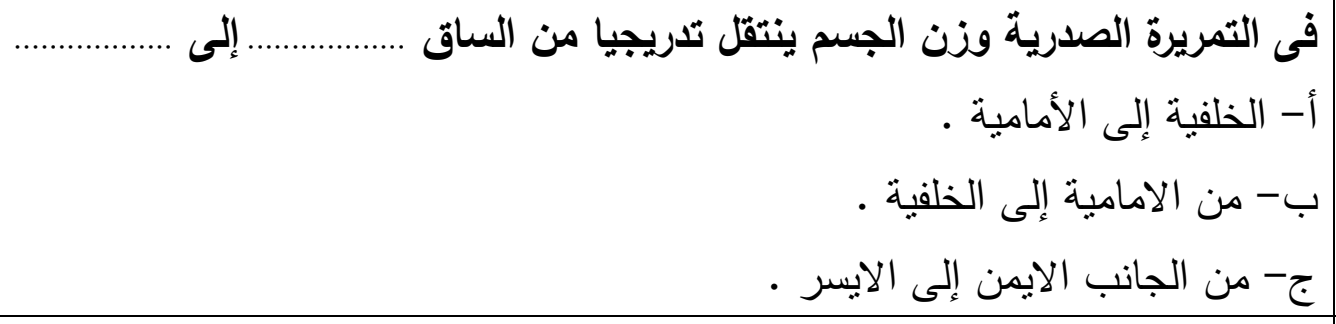 & r \\
\hline 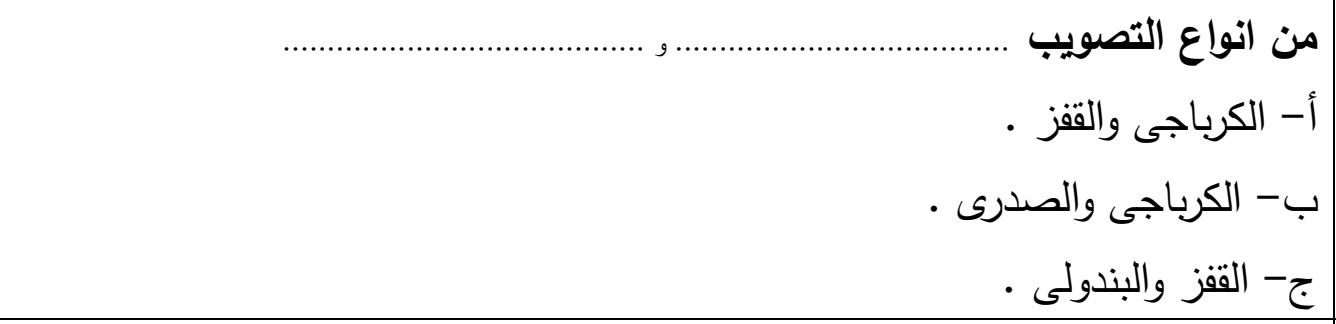 & - \\
\hline 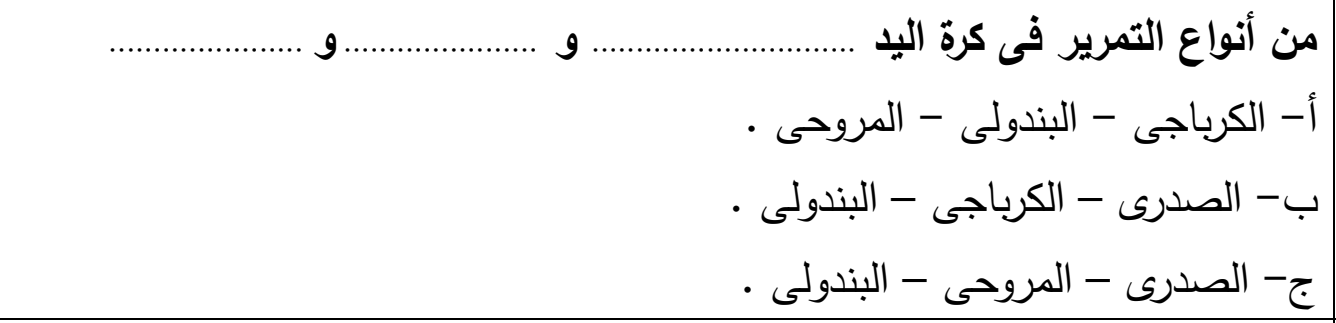 & o \\
\hline 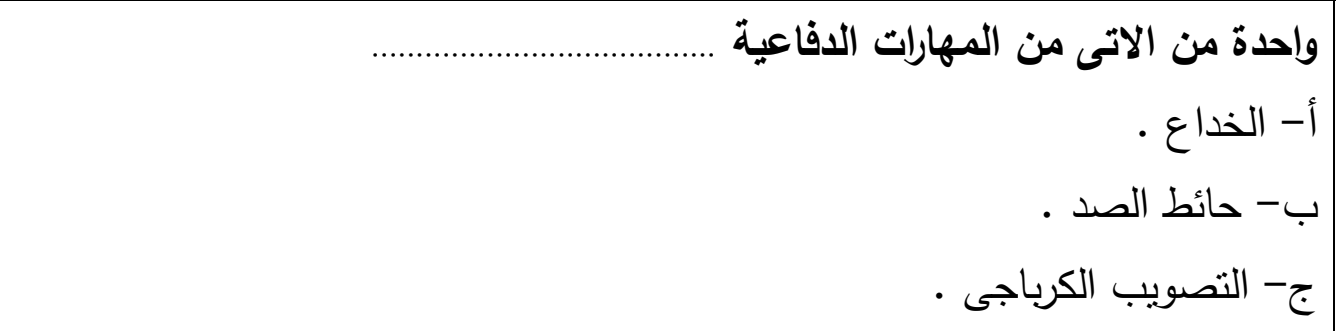 & q \\
\hline
\end{tabular}


ثانيا : ضع علامة ( ل ) أمام العبارة الصحيحة وعلامة ( × ) أمام العبارة الخاطئة

\begin{tabular}{|c|c|c|}
\hline$(\quad)$ & المؤدى التمرير الكرياجى من مستويات مختلفة من أعلى الرأس حتى مستوى الحوض للاعب & $-r v$ \\
\hline$(\quad)$ & يعتبر التصويب الكرياجى من الارتكاز أهم المهارات الدفاعية فى كرة اليد . & $-r \wedge$ \\
\hline( & تتم مهارة تنطيط الكرة أمام الجسم مباشرة . & $-r q$ \\
\hline( & عند استلام الكرة من الزميل تتاخذ اصابع اليا شكل الائرة & $-\varepsilon$. \\
\hline( & يمكن اداء التمرير البندولى فى اتجاهات عديدة . & $-£$ \\
\hline( & يمكن أداء التنطيط ثم التمرير للزميل المناسب . & $-\varepsilon r$ \\
\hline( & لا يوجد ارتباط واضح بين حركة الخداع والحركة التالية لة . & $-\varepsilon$ \\
\hline
\end{tabular}




$$
\text { أولا : اختر الاجابة الصحيحة من بين كل من ( أ - ب- ج ) }
$$

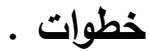

؟ ؛ - يسمح للاعب عند أداء التصويب ويعد استلام الكرة اخذ

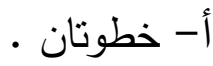

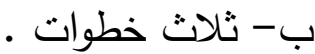

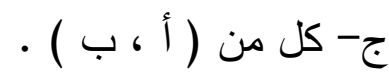

يستخام التصويب الكرياجى فى مستوى الرأس والكتف فى حالة

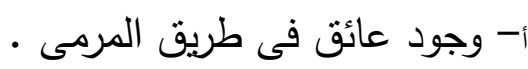

ب- عدم وجود عائق بين المرمى واللاعب .

ج- وجود اكثر من مدافع بين المرمى واللاعب .

؟

أ- محاولة المرور من الجهة اليمنى للمدافع فقط .

ب- محاولة المرور ن الجهة اليسرى للمدافع فقط .

ج- محاولة المرور من جهة والمرور من الجهة الاخرى .

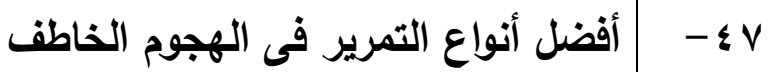

أ- التميرة الصدررية من الحركة .

ب- التمريرة الكرباجية من الحركة .

ج- التمريرة البندولية للامام •

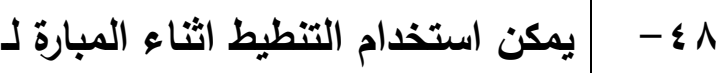

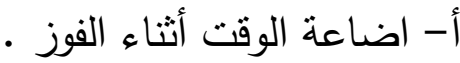

ب- ت تجديد الثناث خطوات .

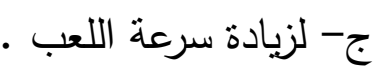

9 9

أ- هجومية دفاعية

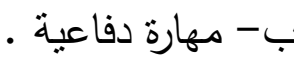

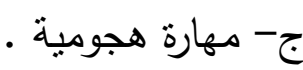




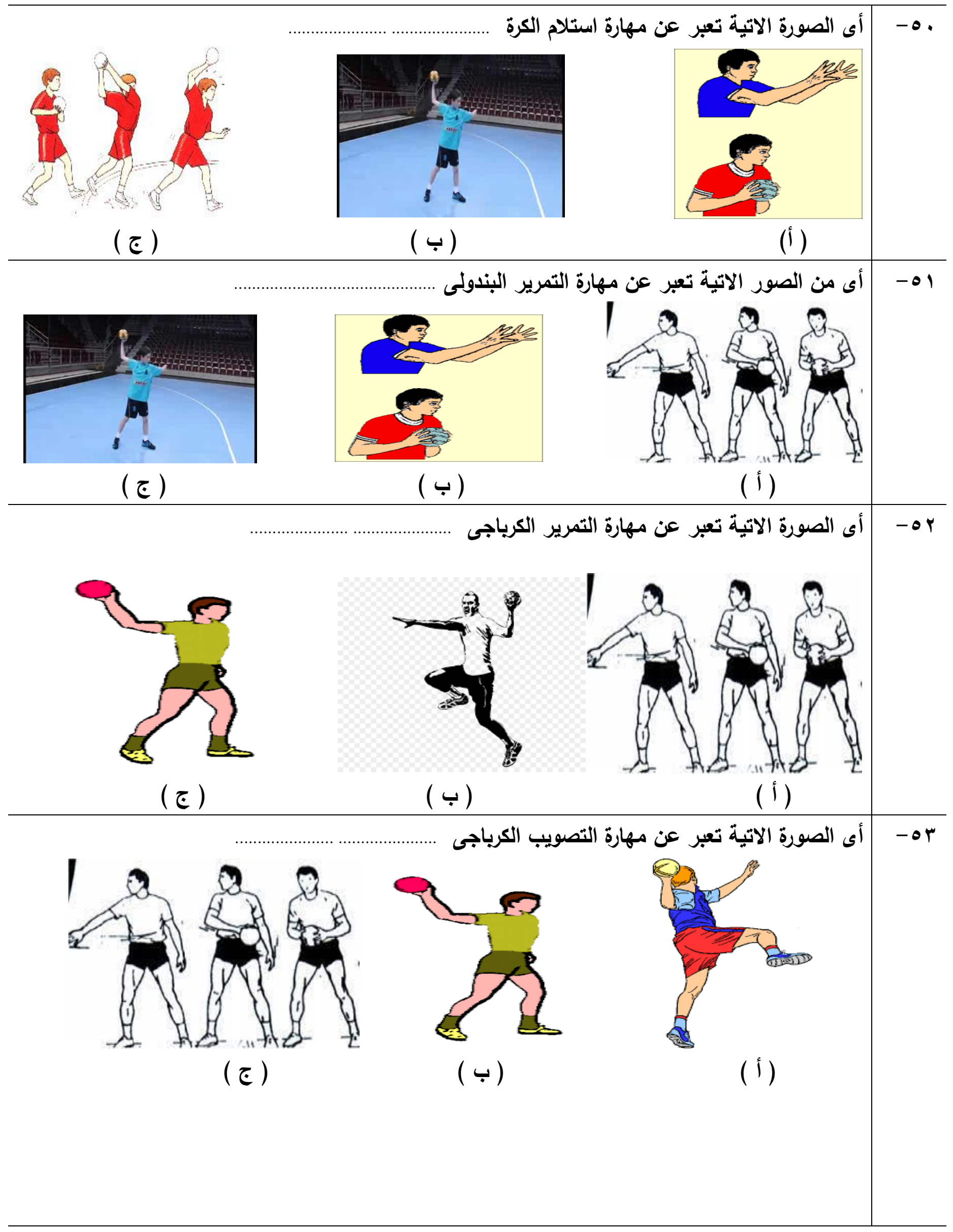




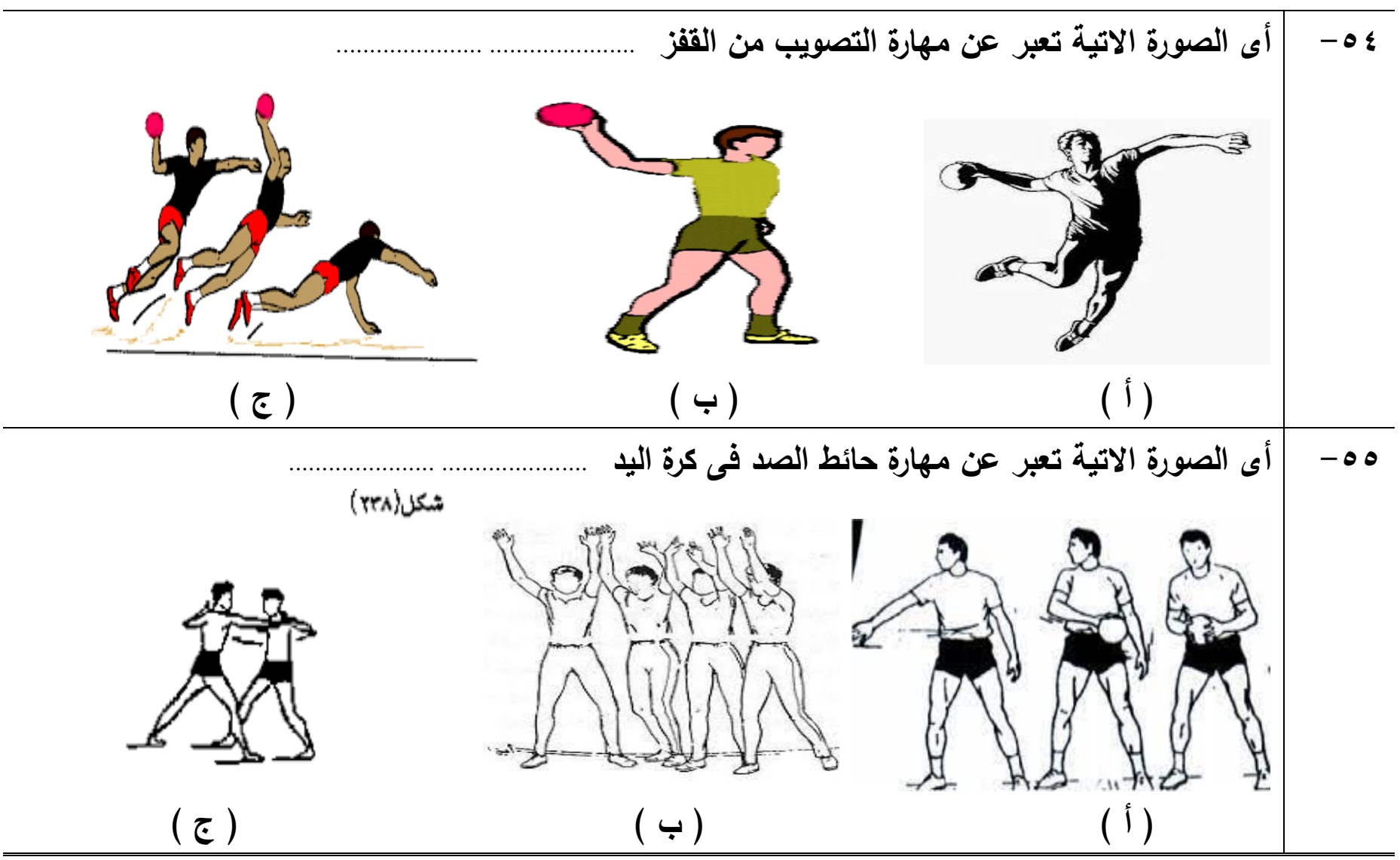

ثانيا : ضع علامة ( ل ل ) أمام العبارة الصحيحة وعلامة ( × ) أمام العبارة الخاطئة

\begin{tabular}{|c|c|c|}
\hline$(\quad)$ & أكثر انواع التمرير فى المبارة هو التمرير البندولى . & -04 \\
\hline ) & يقتصر استخذام التمرير البندولى على التمري لمسافات قصيرة أثناء اللعب . & $-o v$ \\
\hline ) & عقب التصويب الكرياجى باليد اليمنى يهبط اللعب على القدم اليسرى . & $-0 \wedge$ \\
\hline ) & من اكثر المهارات الهجومية استخداما أثناء المبارة مهارة التصويب . & -09 \\
\hline$(\quad)$ & تعتبر مهارة التمرير الكرياجى والتمرير الصدرى وحائط الصد من أكثر المهارات الهجومية & -7 \\
\hline
\end{tabular}


مفتاح تصحيح الاختبار المعرفى

\begin{tabular}{|c|c|c|c|c|c|c|c|}
\hline الاجابة & الرقم & الاجابة & الرقم & الاجابة & الرقم & الاجابة & الرقم \\
\hline ج & $\leq 7$ & ج & r & $x$ & 17 & \multicolumn{2}{|c|}{ الحفظ والتذكر } \\
\hline ب & $\leqslant V$ & ب & $r r$ & $x$ & iv & أ & 1 \\
\hline ب & $\leqslant 1$ & ب ب & $r r$ & $\sqrt{ }$ & 11 & أ & $r$ \\
\hline ج & $\leq 9$ & أ & $r \varepsilon$ & $x$ & 19 & ج & $r$ \\
\hline أ & o. & أ & ro & $x$ & $r \cdot$ & ب & $\varepsilon$ \\
\hline أ & 01 & ب & q & $\sqrt{ }$ & $M$ & أ & 0 \\
\hline ج & or & $\sqrt{ }$ & $r v$ & $\sqrt{ }$ & Yr & أ & 9 \\
\hline أ & or & $x$ & $\mu \wedge$ & $\sqrt{ }$ & $r r$ & أ & $v$ \\
\hline i & $0 \leqslant$ & $\sqrt{ }$ & rq & \multicolumn{2}{|c|}{ القهم والاستيعاب } & ج & $\wedge$ \\
\hline ب & 00 & $\sqrt{ }$ & $\varepsilon$. & ب & $r \varepsilon$ & ب & 9 \\
\hline$x$ & 07 & $\sqrt{ }$ & $\{1$ & ج & ro & ب & 1. \\
\hline$\sqrt{ }$ & ov & $\sqrt{ }$ & $\leqslant r$ & أ & rq & أ & 11 \\
\hline$\sqrt{ }$ & $0 \wedge$ & $x$ & $\varepsilon r$ & ج & $r v$ & ب & ir \\
\hline$\sqrt{ }$ & 09 & \multicolumn{2}{|c|}{ التطبيث } & أ & $r \wedge$ & $\sqrt{ }$ & Ir \\
\hline$x$ & 7. & ج & $\varepsilon \leqslant$ & ج & $r q$ & $\sqrt{ }$ & $1 \varepsilon$ \\
\hline-------- & ------- & ب & $\leq 0$ & أ & $r$. & $\sqrt{ }$ & 10 \\
\hline
\end{tabular}

